\title{
Dulcissimae Carmina Ecclesiae
}

\author{
Die Theologie und die Exegese
}

des Psalmenkommentars Melanchthons 


\title{
Dulcissimae Carmina Ecclesiae
}

Die Theologie und die Exegese

des Psalmenkommentars Melanchthons

\section{Dissertation}

zur Erlangung des Doktorgrades

an der Theologischen Universität

der Christlich-Reformierten Kirchen

in den Niederlanden

zu Apeldoorn

unter Aufsicht des Rektors,

Prof. Dr. Herman J. Selderhuis,

Professor für Kirchengeschichte und Kirchenrecht,

Öffentlich zu verteidigen

Am Dienstag, dem 27. Juni 2017

um 15.00 Uhr

in der Aula der Universität

Wilhelminapark 4, zu Apeldoorn

Durch

\author{
Seongmin Ryu, \\ geboren zu Chunnam \\ am 10. Dezember 1978
}




\section{Examenkommission:}

Promotor: Prof. Dr. Herman J. Selderhuis

Co-Promotor: 


\section{Inhaltverzeichnis}

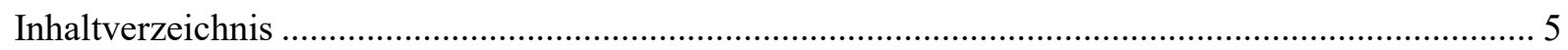

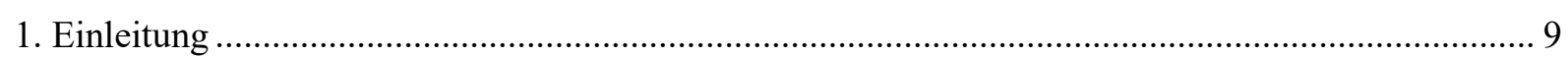

2. Geschichtliche Hintergrund und Überlieferung des PKs ............................................................ 14

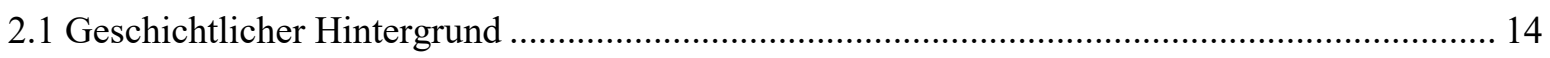

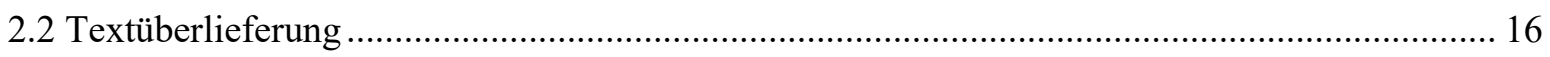

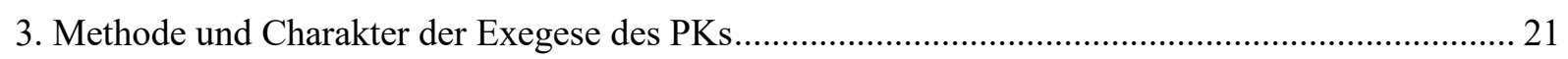

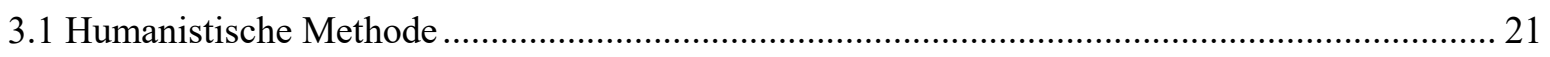

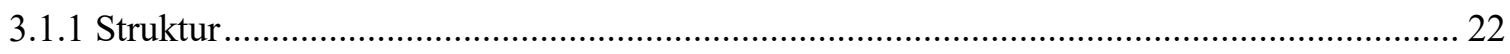

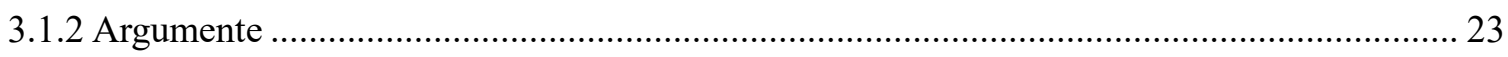

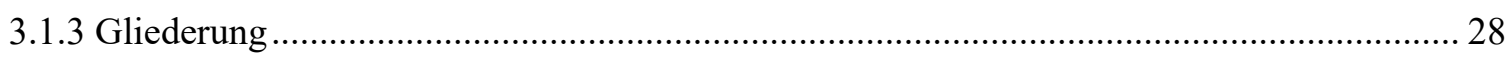

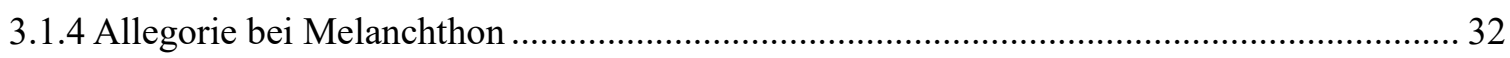

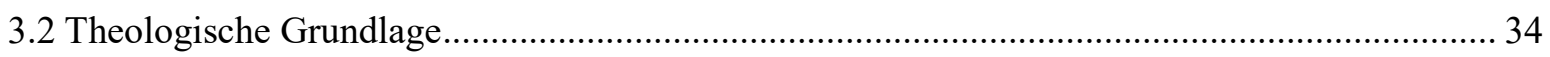

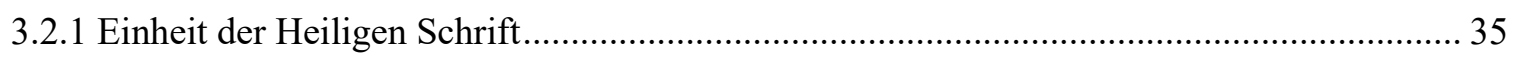

3.2.2 Unterscheidung zwischen dem Evangelium und dem Gesetz .......................................... 36

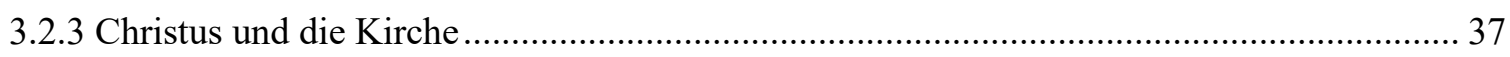

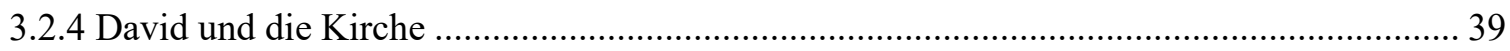

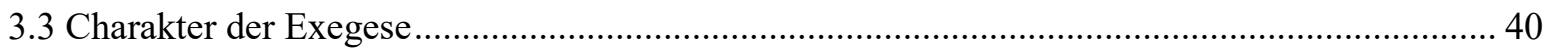

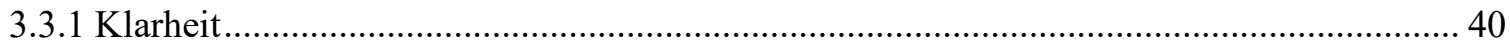

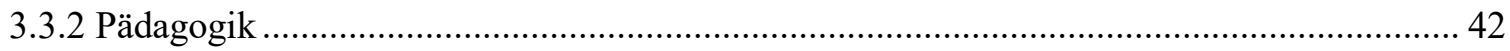

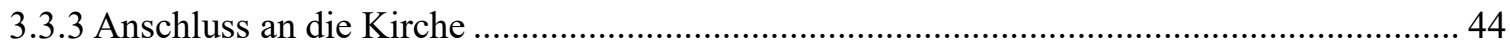

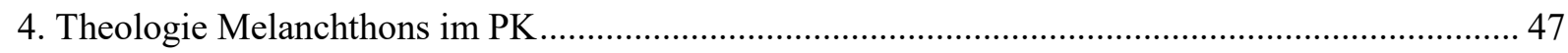

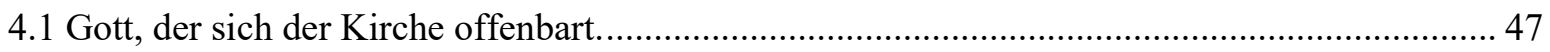

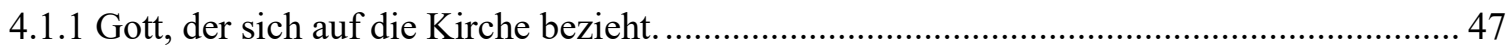

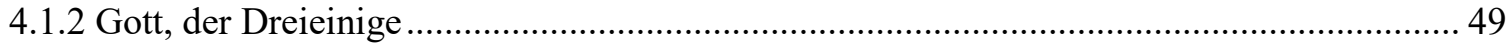

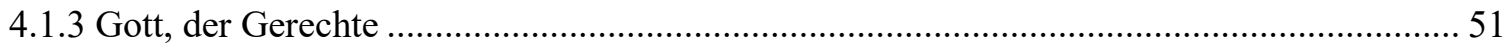

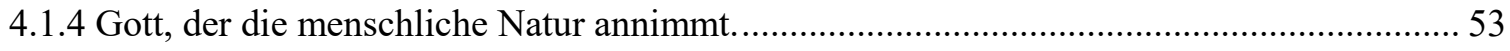

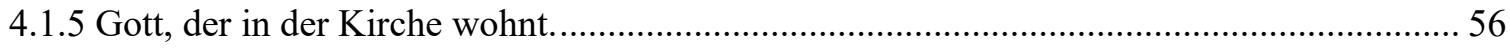

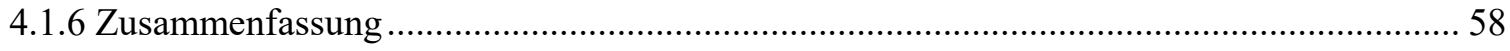

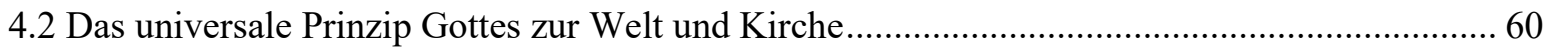

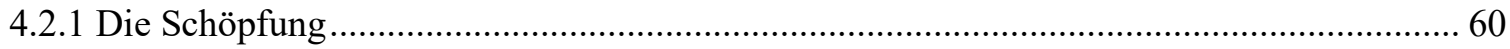

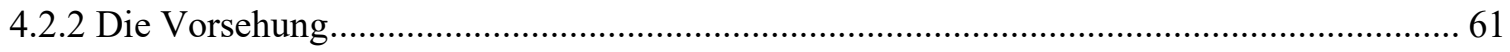

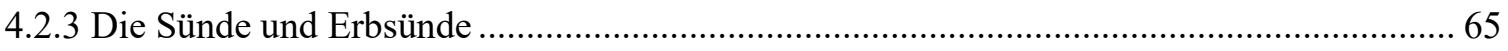

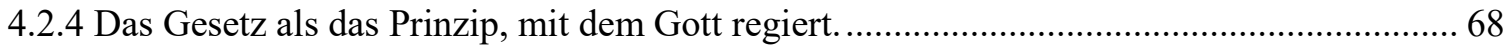

4.2.5 Die Gesetze, die besonders der Kirche gegeben werden ................................................... 70 
4.2.6 Das unrichtige Verständnis der Gottlosen über das Gesetz................................................. 72

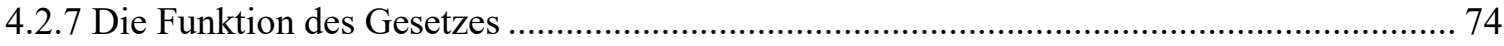

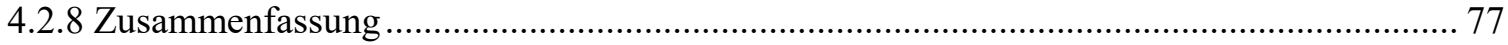

4.3 Das Evangelium als das Prinzip für die Erlösung ……........................................................ 78

4.3.1 Die Beziehung des Evangeliums zum Gesetz .................................................................... 78

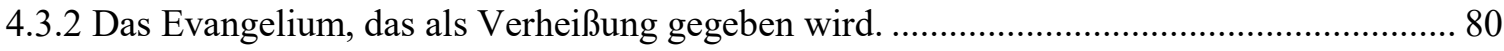

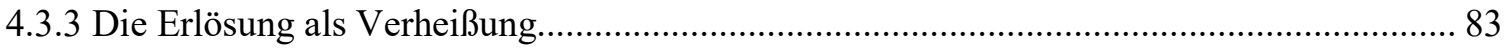

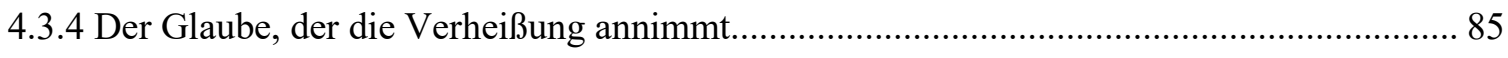

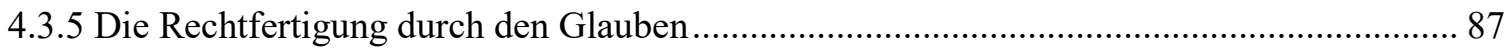

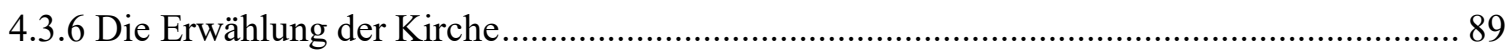

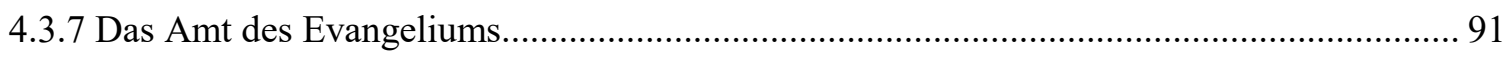

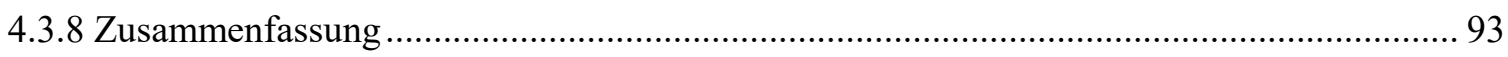

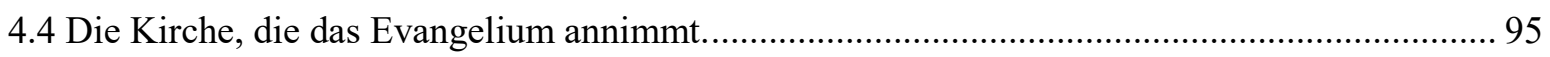

4.4.1 Der Unterschied zwischen dem Alten Testament und dem Neuen Testament...................... 95

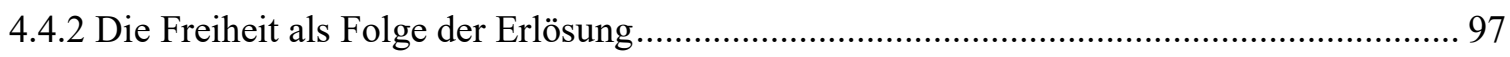

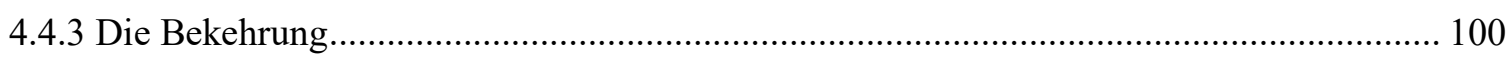

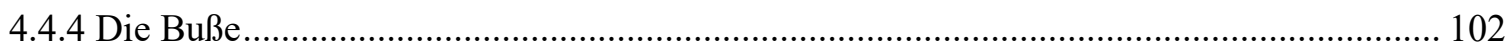

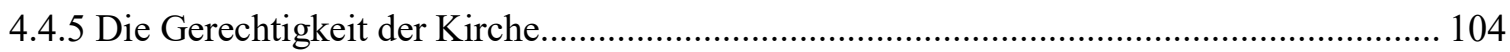

4.4.6 Der Zusammenhang zwischen der Kirche und dem politischen Reich ............................. 107

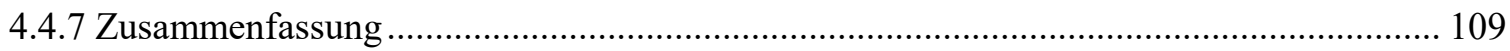

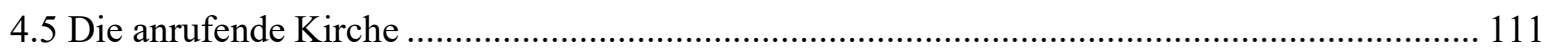

4.5.1 Die Passion des Messias und das Leiden der Kirche............................................................. 111

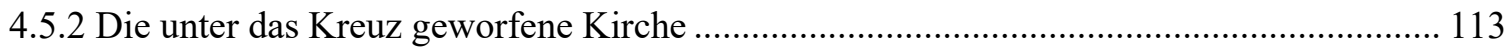

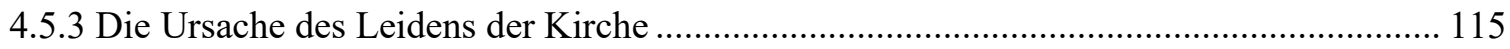

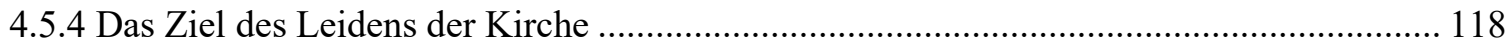

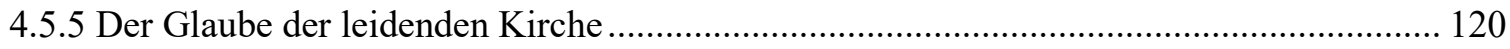

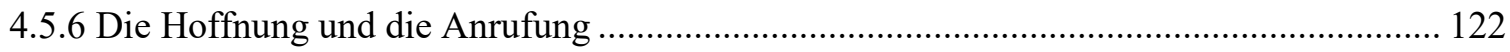

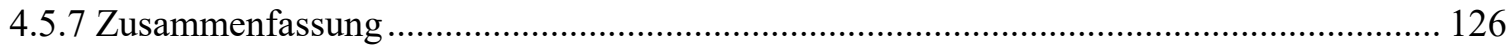

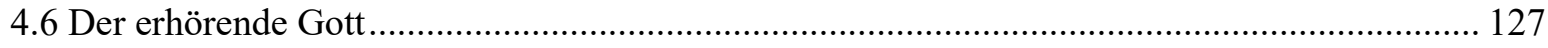

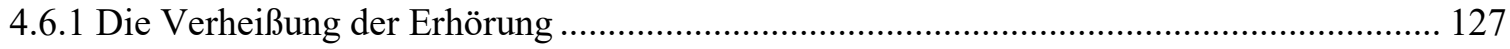

4.6.2 Das Verhältnis Gottes gegen die Gottlosen..................................................................... 131

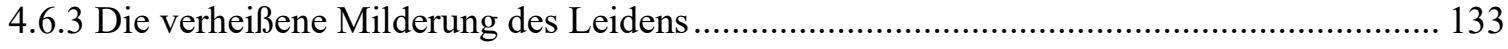

4.6.4 Der verheißene Trost für die anrufende Kirche................................................................ 136

4.6.5 Die verheißene Freiheit für die anrufende Kirche ............................................................ 138

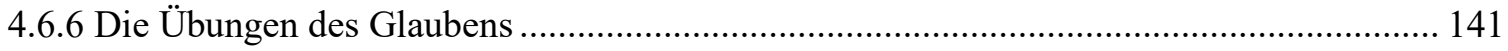




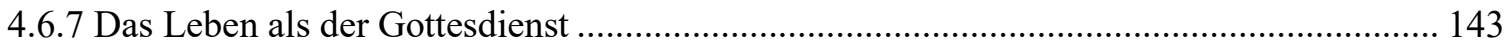

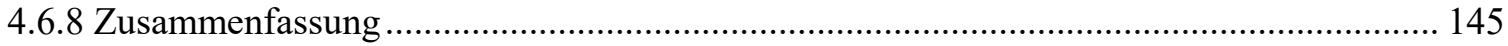

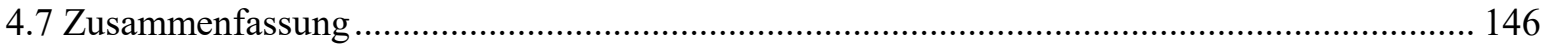

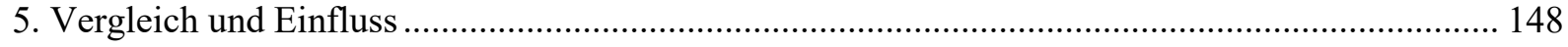

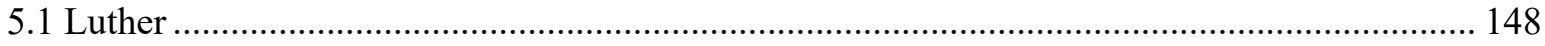

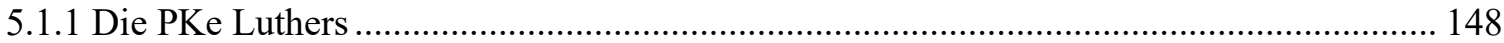

5.1.2 Exegese

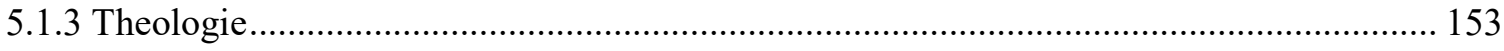

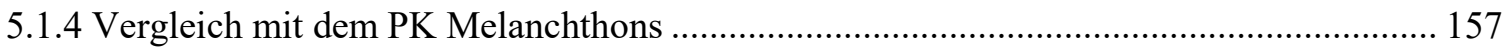

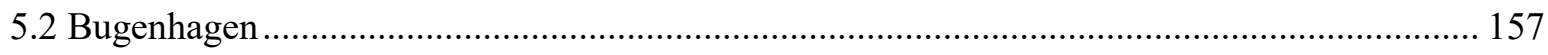

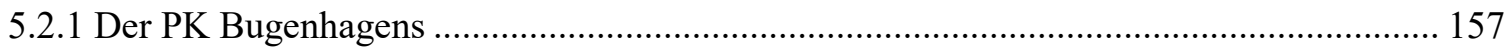

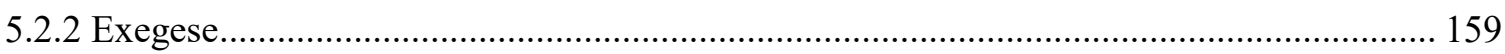

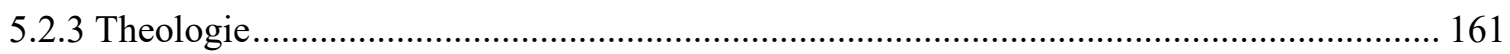

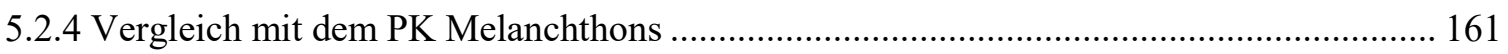

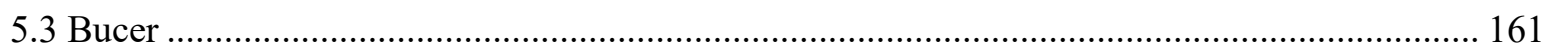

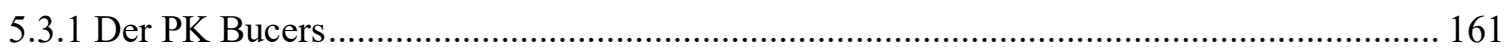

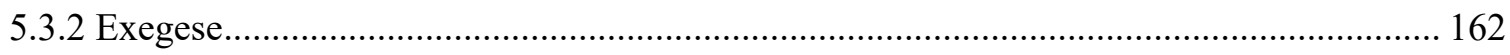

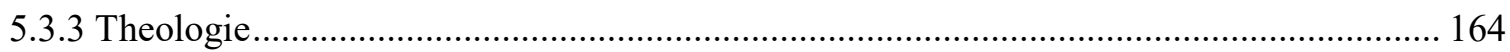

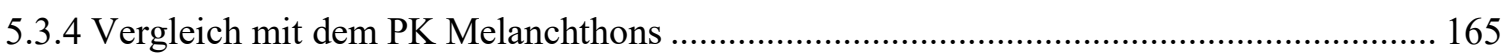

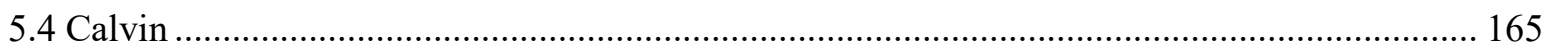

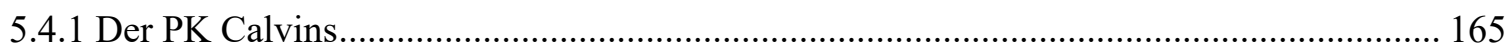

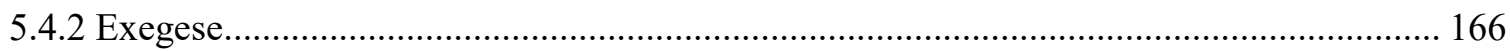

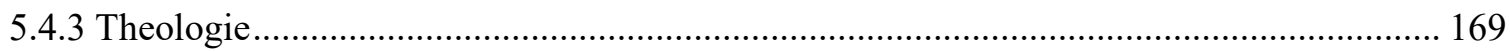

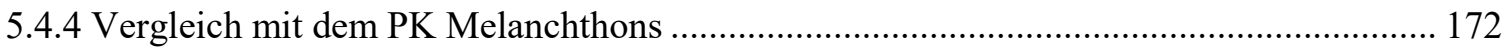

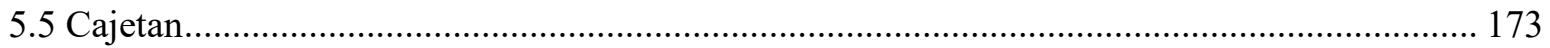

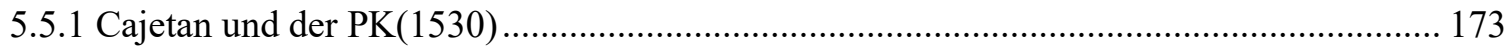

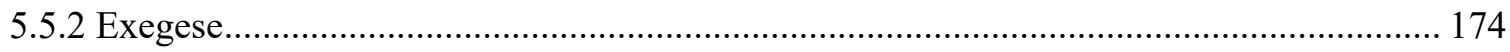

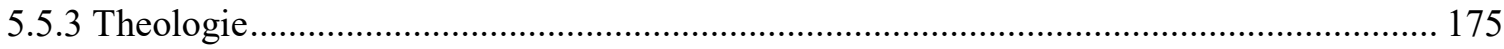

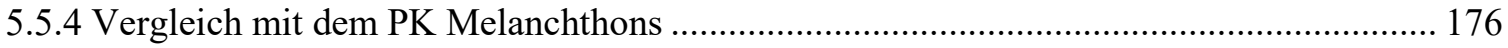

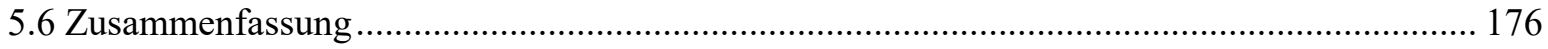

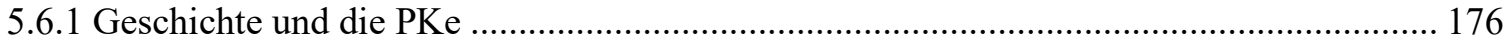

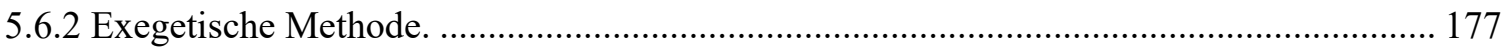

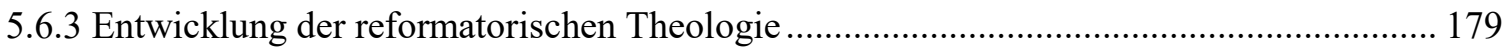

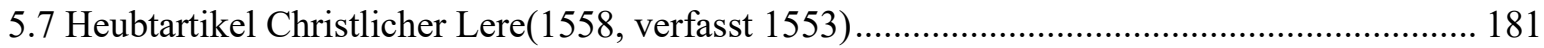

5.7.1 Geschichte und der Charakter der Heubtartikel ............................................................... 181 
5.7.2 Unterschiede von den Heubtartikel und dem PK 182

5.7.3 Gemeinsamkeiten und Einfluss von den Heubtartikel und dem PK... 186 Samenvatting 189

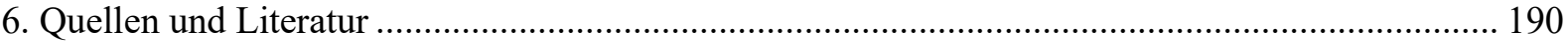

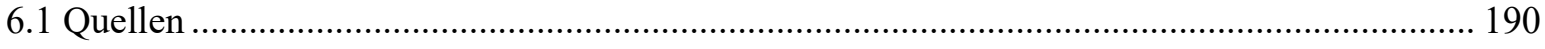

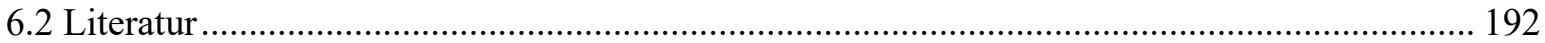




\section{Einleitung}

Die Psalmen sind die von den Reformatoren besonders geliebte biblische Schrift. ${ }^{1}$ Martin Luther (1483-1546) hielt seine Psalmenvorlesung als die erste Vorlesung 1513 nach seiner Berufung zum Professor der Theologie. Danach hielt er noch zwei weitere Psalmenvorlesungen in den Jahren 1518-1520 und 1532-1534. Johannes Bugenhagen (1485-1558) begann seine erste Vorlesung zu den Psalmen 1521 in Wittenberg. Martin Bucer hatte auch ein großes Interesse an den Psalmen. Aus diesem Grund übersetzte er den PK Bugenhagens 1526 ins Deutsche, hielt selbst eine Psalmenvorlesung in Straßburg und veröffentlichte seinen PK 1529. Der Genfer Reformator Johannes Calvin (1509-1564) veröffentlichte seinen großen PK 1557 nach dem Unterricht zu den Psalmen im Jahre 1554. Auch der altgläubige Theologe Thomas Cajetan (1469-1534) vergaß nicht die Psalmen in seinen biblischen Forschungen und legte seinen Psalmenkommentar im Jahre 1530 vor. Auch Melanchthon liebte die Psalmen. Er verwendete häufig die Psalmen in seinen Briefen und lehrte die Psalmen in der Vorlesung an der Wittenberger Universität. ${ }^{2}$ Diese Arbeit beschäftigt sich mit dem PK Melanchthons.

Der Grund dafür, dass die Psalmen von den Reformatoren so geliebt wurden, liegt vor allem in dem Reichtum der Psalmen für die wahre Lehre über Gott und Menschen, die persönliche Frömmigkeit und die Liturgie der Gemeinde. Außerdem sind die Psalmen sehr praktisch. Darin findet sich das konkrete Leben der Mitglieder der Kirche im Jetzt gespiegelt und sie zeigen das Leiden der Kirche, die Frage der Kirche danach und die Antwort Gottes darauf. Die Psalmen beanspruchen so Geltung nicht nur in der Zeit des ATs, sondern auch in der Zeit der gegenwärtigen Kirche. So wurden die Psalmen von den Theologen im 16. Jh. als Schrift für die Kirche verstanden, gelesen und verwendet. Dabei spielt David eine wichtige Rolle als der Vermittler, der in seinen Erfahrungen die Erfahrungen der Kirche vorwegnahm. So ist das Verständnis von David von Bedeutung bei der Betrachtung der PKe.

Trotz des Interesses der Reformatoren an den Psalmen sind die Forschungen über die PKe im 16. Jh. nicht reichhaltig. ${ }^{3}$ Die Forschungslage zum PK Melanchthons ist nicht anders.

\footnotetext{
${ }^{1}$ Über die Psalmen in der alten Kirche und dem Mittelalter siehe Sæbø 1996 und Sæbø 2000.

${ }^{2}$ Vgl. Wengert 2012, S.51f.

${ }^{3}$ Die Psalmenforschungen der Theologen im 16. Jh. werden im Kapitel 5. Vergleich weiter betrachtet. Neuerdings legte Selderhuis das nützliche Buch über Psalm 1-72 als die Reihe von „Reformation Commentary on Scripture“ vor.(Selderhuis 2015)
} 
Bisher gibt es allein zwei Arbeiten, die unmittelbar den PK Melanchthons behandeln. ${ }^{4}$ Seit der Mitte des 20. Jhs. wurde keine Monographie über seinen PK veröffentlicht.

Melanchthon ist eine sehr wichtige Gestalt der Reformation. Allerdings trifft es auch zu, dass im Vergleich mit der Bedeutung Melanchthons das Interesse an ihm und die Forschungen über ihn nicht genügend sind. ${ }^{5}$ Wahrscheinlich war die theologische Einstellung der Grund für die Vernachlässigung der Melanchthonforschung. Von den Lutheranern wird Melanchthon nämlich vorgeworfen, dass seine Theologie von der Theologie Luthers abgewichen sei. ${ }^{6}$ Die Ausschaltung des Philippismus in Kursachsen 1574 war das repräsentative Ereignis einer Verdächtigung des Kryptocalvinismus. ${ }^{7}$ Auch die Reformierten begegneten Melanchthon mit Misstrauen. Die Vermeidung einer Beschäftigung mit ihm entstand wahrscheinlich durch die Behauptung der Remonstranten in der Synode von Dordrecht (1618-1619), dass die Auffassung Melanchthons über die Prädestination mit ihrer Lehre übereinstimme. ${ }^{8}$ In der Tat betonte Melanchthon den menschlichen Willen bei der Erlösung und die Ethik mit der dritten Verwendung des Gesetzes(tertius usus legis). Somit könnten diese Verdächtigungen gegenüber der Theologie Melanchthons zur Vernachlässigung der Melanchthonforschung bei den Lutheranern und den Reformierten geführt haben. Negative Kritiken gegenüber Melanchthon gab es bereits während seiner Lebenszeit. Insofern ist die Arbeit Koblers über die protestantische Melanchthonkritik bis 1560 von Interesse. ${ }^{9}$

Die heutigen Forschungen lutherischer Theologen über Melanchthons urteilen, dass die Theologie Melanchthons nicht anders sei als die Theologie Luthers. ${ }^{10}$ Auch bei den reformier-

\footnotetext{
${ }^{4}$ Cornill 1897, „Melanchthons als Psalmenerklärer“ und Sick 1959, „Melanchthon als Ausleger des Alten Testaments“.

${ }^{5}$ Die Äußerung Stupperichs war richtig, dass Melanchthon „einer der am wenigsten bekannten Reformatoren ist“ und dass seine Lehre, sein Wirken und zahlreiche Ausprägungen „kaum beachtet oder gar nicht gesehen worden sind.“(Stupperich 1961, S.5) Die heutige Situation ist auch nicht so anders.(Vgl. Junghans 2000, S.100) Einige Ringvorlesungen im Jubiläumsjahr 1997 zum Geburtstag Melanchthons stellen allgemeinen Melanchthon vor.("Man weiss so wenig über ihn" 1997 und Schilling 1998, „Melanchthons bleibende Bedeutung“)

${ }^{6}$ Vgl. Kobler 2014, S.3 und vor allem siehe Anm. 11.

${ }^{7}$ Vgl. Mahlmann 2005, „Melanchthon als Vorläufer des Wittenberger Kryptocalvinismus“ und Kolb 2013, „Dynamics of Party Conflict in the Saxon Late Reformation Gensio-Lutherans vs. Philippists“.

${ }^{8}$ Selderhuis 2002, S.315.

${ }^{9}$ Kobler 2014, „Die Entstehung des negativen Melanchthonbildes“.

${ }^{10}$ Kuropka 2010, S.127, Wengert 1999, S.84-88 und Scheible 2016, S.9. Die Äußerung von Junghans ist wichtig, „Manche der heute angenommenen Differenzen verdanken sich mehr einer unzureichenden Kenntnis der im umfangreichen Nachlaß der beiden Reformatoren verstreuten Vorstellungen als
} 
ten Theologen ist die Einschätzung zu finden, dass die Theologie Melanchthons im Kern mit der reformierten Theologie übereinstimme ${ }^{11}$ und dass Melanchthon ein reformierter Theologe gewesen sei. ${ }^{12}$ So verändert sich das Urteil über Melanchthon.

Solche unterschiedlichen Urteile zu Melanchthon zeigen sich auch in den Forschungen während des Jubiläumsjahres zum 500. Geburtstag Melanchthons im Jahre 1997. Zum Gedächtnis fanden verschiedene Veranstaltungen, Tagungen und Forschungen statt. Junghans stellt die Forschungen in seinen Berichten vor. ${ }^{13}$ Aus diesen Forschungen werden unterschiedliche Strömungen in der Melancthonforschung entdeckt. Erstens, das Urteil über Melanchthon wird durchaus positiv. Die Zusammengehörigkeit von Luther und Melanchthon wird allgemein betont. ${ }^{14}$ Zweitens, das Interesse an Melanchthon beruht vor allem auf seinem weltlichen Wirken. ${ }^{15}$ Drittens, es wird auf die humanistische Bildung und den humanistischen Charakter Melanchthons aufmerksam gemacht. ${ }^{16}$ Melanchthon wird als humanistischer Philosoph, Pädagoge und Politiker gezeichnet. ${ }^{17}$

Trotz dieser Änderungstendenzen in der Melanchthonforschung stehen die heutigen Forschungen noch unter dem Einfluss der früheren Vernachlässigung dieses Theologen. Denn die

daß sie tatsächlich vorhanden waren oder von ihrem Schülern empfunden wurden."(Junghans 2000, Anm. 62, S.136-137)

${ }^{11}$ Mahlmann erklärt die Übereinstimmungen über die Prädestination und die Christologie zwischen Melanchthon und Calvin.(Mahlmann 2005) Lee erweist die Übereinstimmung zwischen Melanchthon und den Heidelberger Theologen.(Lee 2009, S.32-38)

${ }^{12}$ Die Remonstranten beruften sich auf Melanchthon, um zu beweisen, dass sie die Reformierten sind.(Selderhuis 2002, S.312-316)

${ }^{13}$ Über den Überblick der Jubiläumsveranstaltungen zum 500. Geburtstag Melanchthons siehe Junghans 2000, S.95-162, „Das Melanchthonjubiläum 1997“ und Junghans 2003, S.175-214, „Das Melanchthonjubiläum 1997 II“.

${ }^{14}$ Junghans berichtet häufig die Bemühung zum Beweis der Forscher für die Zusammengehörigkeit von Luther und Melanchthon.(Junghans 2000, S.101, 144, 147 und 148, Junghans 2003, S.198)

${ }^{15}$ Vgl. Frank und Treu 2001, „Melanchthon und Europa. 1. Teilband“ und Frank und Meerhof 2002, „Melanchthon und Europa. 2. Teilband“; Sträter 1999, „Melanchthonbild und Melanchthonrezeption in der Lutherischen Orthodoxie und im Pietismus“; Hendrix und Wengert 1999, „Philip Melanchthon: then and now(1497-1997)“. Die Ausstellung für die internationalen Briefwechsele(Briefe für Europa) Melanchthons fand als Wanderausstellung statt.(Junghans 2000, Anm. 40, S.124) Außer Deutschland fand das internationale Symposion »The life and work of Philipp Melanchthon: 1597-1997« vom 26. bis 28. September 1997 in Houston, Texas statt.(LQ 12, 1998, Heft 4) Dazu gibt es auch Stolt 1998 „Philipp Melanchthon und seine Rezeption in Skandinavien“ in Stockholm vom 9.-10. Oktober 1997. ${ }^{16}$ Vgl. Binder 1998, „Philipp Melanchthon: exemplarische Aspekte seines Humanismus“; Junghans et al. 1996, „Humanismus und Wittenberger Reformation“.

${ }^{17}$ Kuropka erklärt die Tendenz der Melanchthonforschung ähnlich, und sie stellt die Literatur für die Überblick vor.(Kuropka 2002, S.1-2 und Anm. 2, 3, 4, 5, 6, und 7) 
Melanchthonforschung beschäftigt sich vielfach mit außertheologischen Bereichen. Bezogen auf die Vielfältigkeit der Wirkung Melanchthons, könnte es durchaus sinnvoll sein, verschiedene Seiten der Tätigkeiten Melanchthons zu betrachten. Die theologische Bedeutung Melanchthons wird jedoch häufig übersehen.

Die Theologie war aber für Melanchthon sehr wichtig. Um seine vielfältigen Tätigkeiten richtig zu beurteilen, muss man seine Theologie die Grundlage der anderen Wissenschaften bildet. ${ }^{18}$ Aus diesem Grund ist es für die Melanchthonsforschung von Bedeutung, die Sichtweise Melanchthons zum Unterschied zwischen Theologie und Philosophie zu verstehen. Für Melanchthon ist die Theologie die Grundlage für alle Wissenschaften, während die Philosophie die Prinzipien auch für die nicht zur Kirche Angehörenden erklärt.

In der Melanchthonforschung gibt es eine weitere wichtige Strömung, die die Theologie des jungen Melanchthon von der Theologie des alten Melanchthon unterscheidet. Unter dieser Voraussetzung urteilten die Forscher, dass die Theologie des jungen Melanchthon mit der Theologie Luthers übereinstimme und normativ sei und dass die Theologie des alten Melanchthon von der Theologie Luthers abweiche. ${ }^{19}$ Wahrscheinlich aus diesem Grund gibt es wenig Interesse an der Theologie des späten Melanchthon.

Frank aber weist richtig darauf hin, dass diese Perspektive ,grundsätzlich zu einer problematischen Optik“ führt. ${ }^{20}$ Wie die oben erwähnten heutigen Forschungen zeigen, bietet die Theologie des alten Melanchthon keine Abweichung von der frühen normativen Theologie, sondern zeigt deren Einheit und zugleich seinen gedanklichen Reichtum und seine Reife.

Außerdem gibt es wenig Interesse an den biblischen Auslegungen Melanchthons. Ein Sammelwerk über den Kommentar Melanchthons liegt allerdings vor. ${ }^{21}$ Auch wird die Rhetorik Melanchthons behandelt, die in den biblischen Auslegungen angewendet wird. ${ }^{22}$ Neuerdings behandelte Kuropka in ihrer Arbeit den Kolosserbriefkommentar (1527) und den Psal-

\footnotetext{
${ }^{18}$ Nach der Auffassung Franks hatte Melanchthon von Anfang seiner Wittenberger Zeit an den Gedanken, dass die Philosophie selbst von theologischer Seite aus begrenzt wird.(Frank 1995, S.60) Die Äußerung Scheibles, die den Gedanke Franks zusammenfasst, ist einprägsam, „Melanchthon trieb als Theologe Philosophie, nicht etwa als Philosoph Theologie.“" (Scheible 1998, S.81)

${ }^{19}$ Vgl. Scheible, TRE 22, S.389.

${ }^{20}$ Frank 1995, S.51. Frank zeichnet den Gedanke als die These vom Bruch zwischen Reformation und Humanismus, der „,zur einer falschen Gewichtung des Philosophieverständnisses Melanchthons“ führt. (Frank 1995, S.64)

${ }^{21}$ Wengert und Graham 1997, „Philip Melanchthon(1497-1560) and the Commentary“.

${ }^{22}$ Vgl. Schneider 1997, „The Hermeneutics of Commentary“; Hoffmann 1997, „Rhetoric and Dialectic in Erasmus's and Melanchthon's Interpretation of John's Gospel“.
} 
menkommentar (1529) mit dem geschichtlichen Hintergrund. ${ }^{23}$ Scheible legt eine Forschung über den Kommentar zu Daniel. ${ }^{24}$ Besonders zeigt Wengert ein großes Interesse an den biblischen Auslegungen Melanchthons. ${ }^{25}$ Sonst gibt es keine weiteren Forschungen, die unmittelbar die biblischen Auslegungen Melanchthon behandeln.

In der vorliegenden Arbeit wird die späte Theologie Melanchthons Ende der 1540er Jahre und Anfang der 1550er Jahre in seinem PK betrachtet. So versucht die Arbeit sowohl in zeitlicher wie auch thematischer und methodischer Hinsicht eine Lücke in der Melanchthonforschung auszufüllen.

Die Zeitsituation und der Hintergrund während der Verfassung des PKs sollen in der vorliegenden Arbeit thematisiert werden. Der PK Melanchthons wurde nämlich in einer unruhigen, schwierigen Zeit der evangelischen Kirche verfasst und dies wird auch in der theologischen Einstellung Melanchthons deutlich. Die Arbeit zielt somit darauf ab, die Theologie Melanchthons in seiner reifen Zeit in seinem geliebten PK zu betrachten.

Nach dem einleitenden Kapitel behandelt das zweite Kapitel den geschichtlichen Hintergrund und die Textüberlieferung des PKs Melanchthons. Es enthält das grundlegende Material der Arbeit. Das dritte Kapitel befasst sich mit der Auslegungsmethode Melanchthons zu den Psalmen mit den exegetischen und theologischen Anlässen.

Auf diesen Grundlagen wird im vierten Kapitel die Theologie Melanchthons in seinem PK unter sechs Themen betrachtet. Unter den Aspekten: Gott, die Wirkung Gottes, die Erlösung der Menschen, das Leben der Mitglieder der Kirche, die Anrufung in der Kirche und die Erhörung Gottes wird die Theologie Melanchthons mit seinem PK systematisch geordnet.

Im letzten Kapitel werden die PKe von Luther, Bugenhagen, Calvin und Cajetan aufgrund der bestehenden Forschungen unter den exegetischen und theologischen Themen herangezogen und mit dem PK Melanchthon verglichen, um die Strömungen der PKe im 16. Jh. und ihre Gemeinsamkeiten zu betrachten. Abschließend werden die Loci Melanchthons mit seinem PK verglichen, um durch die Unterschiede und die Gemeinsamkeiten die Absicht des PKs zu verdeutlichen.

\footnotetext{
${ }^{23}$ Kuropka 2002.

${ }^{24}$ Scheible 2007, „Melanchthons Verständnis des Danielbuchs“.

${ }^{25}$ Wengert 1987, „Philipp Melanchthon's Annotationes in Johannem in Relation to its Predecessors and Contemporaries“; Wengert 2012, „The Biblical Commentaries of Philip Melanchthon“.
} 


\section{Geschichtliche Hintergrund und Überlieferung des PKs}

\subsection{Geschichtlicher Hintergrund}

Die genaue Kenntnis des geschichtlichen Hintergrunds ist von grundlegender Bedeutung für das Verständnis des PKs. In der Reformationszeit waren Kirche und Politik eng miteinander verbunden, und die Zeit der Verfassung des PKs war für beide Seiten sehr dynamisch.

Die zehn Jahre zwischen 1546 bis 1555 waren eine dynamische und wichtige Zeit für die evangelische Kirche in Deutschland. Zunächst hatte sie ihre angesehenste Führungsgestalt Luther am 18. Februar 1546 verloren.

Kurz darauf beschloss der altgläubige Kaiser Karl V. (1500-1558), das religiöse Problem im Deutschen Reich militärisch zu lösen, und erklärte am 20. Juli 1546 dem Schmalkaldischen Bund den Krieg. Anfangs waren die Hauptgestalten des Kriegs der Kaiser und der Kurfürst von Sachsen, Johann Friedrich I., der Großmütige (1503-1554). Als sie aber an der Donau gegeneinander kämpften, griff für den Kaiser der Herzog Moritz von Sachsen (15211553), obwohl er den evangelischen Glaube hatte, in den Krieg ein, weil der Kaiser ihm die Kurwürde und Gebietserweiterungen versprochen hatte. Darauf besiegte der Kaiser am 24. April 1547 den Kurfürst von Sachsen in der Schlacht auf der Lochauer Heide bei Mühlberg an der Elbe. Nach der Niederlage war Friedrich gezwungen, auf die Kurwürde und große Teil seines Territoriums zu verzichten. Am 6. Juni 1547 wurde dann Wittenberg, das Zentrum der Reformation, an Moritz von Sachsen übergeben. ${ }^{26}$ Die politische Macht der evangelischen Seite wurde dadurch stark eingeschränkt.

Der Krieg hatte Auswirkungen auf die Wittenberger Universität. Zum einen entstand das Problem der weiteren Existenz der Wittenberger Universität, da Moritz, der neue Herr Wittenbergs, bereits die Leipziger Universität besaß. Aber Moritz gewährte der Wittenberger Universität finanzielle Unterstützung und die Unabhängigkeit von päpstlicher Befehlsgewalt. ${ }^{27}$ So hatte Moritz zwei Universitäten. Zu anderem betrieb Johann Friedrich I. von Sachsen, der aufgrund der Niederlage Kriegsgefangener war, ,aus der Gefangenschaft die Gründung einer Hochschule in Jena, um den Verlust Wittenbergs auszugleichen. ${ }^{“ 28}$ Die neue Universität wollte Melanchthon als Professor einladen, aber er blieb an der Wittenberger Universität. Trotzdem half Melanchthon gerne bei der Gründung einer neuen Universität in Jena.

\footnotetext{
${ }^{26}$ Um den Prozess des Krieges kurz zu betrachten, siehe Kirchner und Haendler 1987, S. 89-93; Scheible 2016, S.208-211.

${ }^{27}$ Vgl. Scheible 2016, S.222.

${ }^{28}$ Scheible 2016,S.218.
} 
Nach dem Sieg im Schmalkaldischen Krieg berief Karl V. den Reichstag zu Augsburg ein, der von 1. September 1547 bis 30. Juni 1548 stattfand. Der Kaiser wollte ein allgemeines Religionsgesetz erlassen, das für das ganze Reich gültig sein sollte und „,den Protestanten einige Zugeständnisse machte, aber insgesamt blieb es bei der alten Lehre (Priesterehe; Laienkelch; Messopfer als Gedenk- und Dankopfer, nicht als Sühnopfer). “29 Aber die altgläubigen Reichsstände wehrten sich dagegen, das Gesetz für ihre Territorien durchzuführen, weshalb der Kaiser das Gesetz nur für die protestantischen Territorien erlassen konnte. Das Gesetz wurde das „Augsburger Interim“ genannt, weil es nur interimistisch bis zu einer endgültigen Entscheidung über den religiösen Streit durch ein Konzil gelten sollte. Durch das Interim erfuhr die evangelische Kirche eine große Gefahr. Besonders in Süddeutschland wurde „das Interim“ konsequent befolgt, und teilweise wurde sogar die volle katholische Ordnung wiederhergestellt. In Norddeutschland wurde die Annahme des Interims jedoch aufgeschoben, und in Magdeburg und Straßburg verweigerten sie „das Interim“. Melanchthon lehnte das Augsburger Interim ebenfalls ab. ${ }^{30}$

Obwohl Moritz von Sachsen beim Schmalkaldischen Krieg ein Bundesgenosse des Kaisers gewesen war, wollte er auf seine evangelische Konfession nicht verzichten. Er versuchte eine andere theologische Lösung im Umgang mit dem Interim mit seinen sächsischen Theologen zu finden, unter denen Melanchthon die Hauptrolle gespielt hatte. Ende 1548 wurde ein alternativer Kompromiss ausgearbeitet, das sogenannte Leipziger Interim, was (das) jedoch nicht rechtskräftig verabschiedet wurde. Das Leipziger Interim war entgegen der ursprünglichen Absicht Anlass unter evangelischen Theologen für den Streit um die so genannten Adiaphora.

Inzwischen tagte wieder das Trienter Konzil (die zweite Session, 1551-1552), das aufgrund des Kriegs suspendiert worden war. Melanchthon legte für die Teilnahme von Kursachsen am Konzil 1551 ein Bekenntnis vor, die sogenannte Confessio Saxonica. Aber seine Bemühungen blieben erfolglos, weil der neue Kurfürst, Moritz von Sachsen, das Interesse an einer theologischen Lösung verloren hatte und eine militärische anstrebte. So wurde das Trienter Konzil eine Versammlung nur aus den Altgläubigen, und in der Folge fasste das Konzil den die evangelischen Lehre verneinenden Beschluss.

\footnotetext{
${ }^{29}$ Jung 2010, S. 107-8.

${ }^{30} \mathrm{Vgl}$. Melanchthon an Markgraf Johann von Brandenburg, Wittenberg, 31. Juli 1548.(Melanchthon deutsch, Bd. 2, S. 246-49; vgl. CR 7, 84-87 (Nr. 4308); MBW 5, 324 Nr.5238)
} 
Moritz war über diese Vorgänge unzufrieden. Außerdem hatte der Kaiser einige Versprechungen für Moritz noch nicht eingehalten. Denn sein Schwiegervater Philipp von Hessen war noch gefangen und die vom Kaiser als Lohn für die Teilnahme an dem Krieg versprochenen Gebiete wurden Moritz noch vorenthalten. Aus diesen Gründen wandte sich Moritz gegen den Kaiser. Er griff an und besiegte den Kaiser im Mai 1552 bei Innsbruck mit militärischer Macht. Anders als beim Schmalkaldischen Krieg unterstützten weder Bayern noch Österreich den Kaiser, weil der Kaiser versuchte, die Kaiserwürde seinem Sohn zu übergeben. Am 2. Aug. 1552 wurde der Passauer Frieden geschlossen. „Die Reformation war damit gerettet.“31 Anschließend wurde 1555 der Reichstag von Karl V. einberufen, und ein Religionsfrieden wurde geschaffen. Es ist der Augsburger Religionsfrieden. Die Augsburger Konfession wurde im ganzen Reich rechtlich anerkannt. Die Landesherren bekamen das Reformationsrecht und die Freiheit, sich für ein Bekenntnis zu entscheiden.

Die oben betrachtete politische Geschichte ist von grundlegender Bedeutung für den PK. Denn Melanchthon hielt seine Vorlesungen über die Psalmen direkt nach der Wiedereröffnung der Wittenberger Universität, 1547-48 und Anfang der 1550er Jahre. Die evangelische Kirche war in der Zeit der Verfassung des PKs in einer großen politischen und religiösen Gefahr. Dieser geschichtliche Hintergrund ist untrennbar mit dem PK verbunden.

\subsection{Textuiberlieferung}

Der PK Melanchthons besteht aus drei Teilen. Der erste beinhaltet die Vorlesungen zu Ps 1-60, der zweite die Vorlesungen zu Ps 110-133. Der erste und der zweite Teil gehören eigentlich nicht zu einer gleichen Vorlesung, sondern beide Vorlesungen sind voneinander getrennt. ${ }^{32}$ Der dritte umfasst die weiteren Vorlesungen zu Ps 51, 31 und 34. Es ist nicht sicher bekannt, wie die Psalmenvorlesungen zusammengestellt wurden. Caspar Peucer (1525-1602), der Schwiegersohn Melanchthons, der die Opera Melanchthons herausgab, ${ }^{33}$ hatte keine genaue Information zum Datum der Psalmenvorlesungen. ${ }^{34}$ Zunächst soll die Geschichte der Psalmenvorlesungen und die Zusammenstellung der Psalmenvorlesungen nach den äußeren und inneren Zeugnissen betrachtet werden.

\footnotetext{
${ }^{31}$ Jung 2010, S. 119.

${ }^{32}$ Scheible vermutet, dass Melanchthon die Vorlesung zu Ps 61-109 halten könnte. (Scheible 1986, S.144)

${ }^{33}$ Melanchthon, Hg. von Peucer, „Omnium operum reverendi viri Philippi Melanthonis“(Opera), Bde. 1-4, Wittenberg 1562-1564.

${ }^{34}$ Peucer schreibt, dass der PK in 1555, 1553 und 1554 verfasst wurde.(Vgl. Opera 2, S.548.; CR 13, 1017.)
} 
Zuerst werden die inneren Zeugnisse zur Textüberlieferung betrachtet. Das strukturelle Element, das Melanchthon am Anfang der Psalmenvorlesung verwendet, ist das Vorwort. Das Vorwort enthält thematisch, was die Psalmen sind und wie die Psalmen ausgelegt werden sollen. Das Vorwort enthält vor allem methodische Äußerungen zu den Psalmen. Melanchthon beginnt eine neue Psalmenvorlesung immer mit einem solchen Vorwort.

Im ersten Teil des PKs zu Ps 1-60 hat das Vorwort einen eigenen griechischen Namen, PROLEgOMEnA. ${ }^{35}$ Im zweiten Teil des PKs zu Ps 110-133 hat das Vorwort keinen eigenen Titel, sondern im ersten Psalm (Ps 110) innen inkludiert. Auch die Auslegungen zu Ps 51, 31 und 34 im dritten Teil des PKs haben auch solches Vorwort im eigenen Psalm innen inkludiert. Somit ist das Vorwort ein bewusster methodischer Schritt Melanchthons und jeder Teil der Psalmenvorlesung ist an seinem Vorwort zu erkennen.

Außerdem unterscheidet sich der erste Teil des PKs von dem zweiten Teil in der Psalmenzählung. Der erste Teil (Ps 1-60) zählt die Psalmen nach der Abfolge im hebräischen Text, aber der zweite Teil (Ps 110-133) zählt die Psalmen nach der Abfolge in der Vg. Die Auslegungen zu Ps 114/115 und Ps 117/118 zeigen den Unterschied deutlich. Der Herausgeber, der die Psalmenvorlesungen zusammengestellt hat, wollte die Psalmenzählung vereinheitlichen. Aber Melanchthon legte die Ps 114/115 und Ps 117/118 nach der Zählung in der Vg aus.

Die Unterschiede in der Psalmenzählung zeigen sich auch in der Zitierung der Psalmen in jeder Auslegung. Im ersten Teil folgen die Zitate der Psalmen der Abfolge der Zählung des hebräischen Textes. Im zweiten Teil folgen die Zitate der Zählung der Vg. Dies bedeutet, dass der erste Teil des PKs und der zweite Teil des PKs einen anderen Grundtext haben. Melanchthon verwendet die einheitliche Zählung in je einer Psalmenvorlesung, aber er wählt den Grundtext der jeweiligen Psalmenvorlesung frei nach seinem Willen.

Nach den inneren Zeugnissen bilden der erste Teil und der zweite Teil des PKs keine einheitliche Vorlesung, sondern beide Teile sind zwei voneinander getrennte Vorlesungen.

Nun werden die äußeren Zeugnisse zur Textüberlieferung betrachtet. Für den ersten Teil des PKs existieren ein Manuskript (Ps 1-56) von Melanchthon selbst, ${ }^{36}$ eine Abschrift (Ps 1$51)^{37}$ und noch eine andere Abschrift (Ps 1-44). ${ }^{38}$ In der Hinsicht auf die Zeugnisse dieser Abschriften hat Melanchthon "mit seiner Psalmenvorlesung wahrscheinlich am 24. oder 25.

\footnotetext{
${ }^{35}$ Der Titel „PROLEGOMENA“ steht nicht im Manuskript Melanchthons.(Cod.Pal.Lat. 1829, S.2r.)

${ }^{36}$ Cod.Pal.Lat. 1829.

${ }^{37}$ Cod.Pal.Lat. 1830.

${ }^{38}$ Ms.LXXXVII, B1. 1-59 in der Ratsschulbibliothek Zwickau.
} 
Oktober 1547 “ angefangen. ${ }^{39}$ So wurde die Psalmenvorlesung des ersten Teiles des PKs direkt nach der Wiedereröffnung der Wittenberger Universität Oktober 1547 bis ungefähr Anfang 1548 gehalten.

Danach wurde der erste Teil des PKs(Ps 1-60) 1550 von Matthias Flacius(1520-1575) in Frankfurt am Main unter dem Titel „Argvmenta Psalmorvm Sexaginta Distributis ordine Versuum Sententijs“" veröffentlicht. ${ }^{40}$ Flacius fügte den Index des PKs zwischen dem Vorwort und dem Inhalt der Auslegung hinzu. ${ }^{41}$ Eine weitere Hinzufügung von Flacius ist die Überschrift zwischen der Psalmenzählung und den Inhalten der Auslegung zu jedem Psalm. Diese Überschriften finden sich nicht in dem Manuskript Melanchthons. ${ }^{42}$

Der zweite Teil des PKs (Ps 110-133) beginnt mit dem berühmten messianischen Ps 110 und behandelt bis die Stufenpsalmen. Eine Abschrift des Ps 110 trägt das Datum des 8. November $1550 .{ }^{43}$ Somit wurde die Vorlesung zum zweiten Teil des PKs im Wintersemester 1550 gehalten.

Als Datum der weiteren Psalmenvorlesung zu Ps 51 gibt Paul Krell (1531-1579) den 13. August 1552 als Datum und Torgau als Ort an. Damals war die Wittenberger Universität wegen der Pest nach Torgau verlegt worden. ${ }^{44}$ Peucer folgt der Meinung Krells. ${ }^{45}$ Die Herausgeber von CR folgten auch der Auffassung von Peucer. ${ }^{46}$ Die weiteren Psalmenvorlesungen zu Ps 31 und 34 haben keine Datumsinformationen.

Um zu wissen, wie die drei Teile des PKs Melanchthons zusammengestellt wurden, ist vor allem die Veröffentlichung Krells zu beachten. ${ }^{47}$ Krell sammelte erstmals die drei Teile

\footnotetext{
${ }^{39}$ Scheible erklärt mit den Zeugnissen der Abschriften recht die Daten der Psalmenvorlesung. (Scheible 1986, S.143-144.)

${ }^{40}$ Melanchthon, hg. von Flacius, „Argvmenta Psalmorvm Sexaginta Distributis ordine Versuum Sententijs“, Frankfurt am Main 1550.; VD 16 F 1273.

${ }^{41}$ Eigentlich ist es sehr auffällig, dass Flacius 1550 den PK Melanchthons veröffentlichte, weil schon damals die Auseinandersetzung über die Adiaphora wegen des sogenannten Leipziger Interim zwischen Melanchthon und Flacius heftig war. Über die adiaphorische Auseinandersetzung zwischen Melanchthon und Flacius siehe Scheible 2016, S.240-245.

${ }^{42}$ Die Manuskripte Melanchthons enthält die Überschrift in den Auslegung zu Ps 12, 19, 20, 36, 39, 40, 41, 43, 44, 46, 47, 48, 49, 50, 51, 52, 53, 54, 55 und 56.

${ }^{43}$ Melanchthon, ,Enarratio aliquot psalmorum, in psalm CX“، Wittenberg 08.11.1550, AFSt/H A 25: 5 in Franckesche Stiftungen zu Halle.

${ }^{44}$ Vgl. Scheible 2016, S.342.; MBW 6525.

${ }^{45}$ Opera 2, S.697.

${ }^{46} \mathrm{CR} 13,1224$.

${ }^{47}$ Krell spielte bei der Sammlung der Psalmenvorlesungen Melanchthons die wichtigste Rolle. Er begann mit seinem Studium 1548 in Wittenberg und nach seiner Aufnahme in das Kollegium der philo-
} 
des PKs Melanchthons und veröffentlichte sie 1561 auf seine eigene Weise. ${ }^{48}$ Er verfasste eine Widmung als Vorwort und dann folgten die Psalmenauslegungen Melanchthons. Vor jeder Psalmenauslegung gab er die lateinische Übersetzung des Psalms. Es ist auffällig, dass zu den Ps 61-109 und 134-150 allein die Übersetzungen der Psalmen vorliegen, weil er keine Auslegungen Melanchthons für diese Psalmen hatte. Dann fügte er die weiteren Psalmenauslegungen zu Ps 51, 31 und 34 hinzu. Wahrscheinlich nahm Krell die Auslegungen zu Ps 1-60 von den Argvmenta Psalmorvm Sexaginta von Flacius an und sammelte andere Psalmenauslegungen, nämlich die zweiten und dritten Teile des PKs selbst.

Betrachtet man die Überschriften zwischen der Psalmenzählung und dem Inhalt der Auslegung der Psalmen, unterscheiden sich einige Überschriften von den Zitaten Melanchthons in der Auslegung. Dies führt Cornill darauf zurück, dass Melanchthon frei den Text frei gewählt hat. ${ }^{49}$ Aber sein Urteil übersieht die Möglichkeit, dass die Überschriften von Melanchthon selbst nicht verfasst werden konnten. Denn - wie erwähnt - haben alle Psalmenauslegungen im Manuskript Melanchthons keine Überschriften.

Die Überschriften haben keine wesentliche inhaltliche Bedeutung in der Psalmenauslegung Melanchthons, sondern spielen eine Rolle als Signal des Anfangs der Psalmenauslegung. Denn Peucer nimmt Psalmorium Davidis Krells als den Grundtext seiner Opera und editiert den Text, indem er die Übersetzung Krells gegen den ersten Vers der Übersetzung tauscht, der als Überschrift angemerkt wird. So legte Peucer sie als Opera Melanchthons 1562-1564 vor. Und die Herausgeber von CR übernehmen das Vorgehen Peucers.

Zusammenfassend lässt sich festhalten: Melanchthon hielt seine Psalmenvorlesung zu Ps 1-60 von Oktober 1547 bis Anfang 1548. Die Zeugnisse für diese Vorlesung bestehen aus den Manuskripten Melanchthons selbst und den damaligen Abschriften. Flacius veröffentlichte diese Psalmenvorlesung 1550 mit einem eigenen Index. Dann begann Melanchthon eine weitere Psalmenvorlesung zu Ps 110-133 am 8. November 1550. Krell sammelte die erste Psalmenvorlesung zu Ps 1-60 aus den Jahren 1547-1548 aufgrund der Veröffentlichung von Fla-

sophischen Fakultät(1555) studierte er die Theologie, vor allem bei Melanchthon und Bugenhagen. 1556 wurde er zum Prediger an der Wittenberger Schlosskirche berufen. 1559 wurde er zum Doktor der Theologie promoviert. 1560 wurde ihm eine theologische Professur übertragen. Krell sorgte für die Verbreitung der Theologie Menalchthons und vertrat in den Auseinandersetzungen der Wittenberger Theologen mit Gnesiolutheranern die Position des Wittenberger Philippismus.(Vgl. Hasse 1997) ${ }^{48}$ Melanchthon, Hg. von Krell, „Psalterium Davidis integrum, in quo psalmi octoginta tres illustrati sunt argumentis \& enarratione viri Reverendi \& clarissimi D. Philippi Melanthonis“, Wittenberg 1561.; VD 16 B 3208.

${ }^{49}$ Cornill 1897, S.8. 
cius, die zweite Psalmenvorlesung zu Ps 110-133 aus dem Jahr 1550 und die weiteren Psalmenvorlesungen zu Ps 51, 31 und 34 von sich selbst. Dann veröffentlichte er die Sammlung der Psalmenvorlesungen Melanchthons 1561 mit der lateinischen Übersetzung der Psalmen nach der Abfolge der Psalmen. Peucer gab den PK Melanchthon 1562 aufgrund der Veröffentlichung Krells mit der Verkürzung der lateinischen Übersetzung als Opera Melanchthons heraus. Die Herausgeber von CR übernahmen die Opera von Peucer. 


\section{Methode und Charakter der Exegese des PKs}

Der Titel des PKs ist „Argumente und Gliederung“ (argumentn ac dispositio). ${ }^{50}$ Dieser Titel verweist auf den Zweck und die Struktur des PKs. Melanchthon will im PK nicht jeden Vers ausführlich auslegen, sondern wichtige Argumente und die Gliederung jedes Psalms kurz darstellen. Damit ist impliziert, dass die Psalmen für eine solche Auslegung als geeignet erfasst werden. Aus diesem Grund wendet Melanchthon die humanistische Methode für die Auslegung der Psalmen an, wie für antike Literaturen. Aber Melanchthon behandelt die Psalmen nicht wie antike Literaturen, weil die Psalmen das Wort Gottes sind, das die menschliche Vernunft nicht ganz verstehen kann. Deshalb ist auch die theologische Methode für die Auslegung der Psalmen von Bedeutung. Zuerst wird der PK aufgrund der humanistischen Methode, anschließend hinsichtlich der theologischen Grundlagen betrachtet. Dann wird in der Zusammenschau die Besonderheit des PKs deutlich werden.

\subsection{Humanistische Methode}

Melanchthon legt die Psalmen nach den Prinzipien der humanistischen Methoden aus, weil er glaubt, dass der Sinn der Psalmen durch diese Methoden wahrhaft verstanden werden kann. Er versucht, die Psalmen in die geeigneten rhetorischen Arten einzuordnen, um die Inhalte der Psalmen besser zu verstehen und auf die Kirche anzuwenden. Er ist davon überzeugt, dass diese Methode hilfreich ist, um die Lehre der Kirche in den Psalmen zu erkennen und $\mathrm{zu}$ entscheiden. ${ }^{51}$

Zuerst ist die Grammatik eine grundlegende Methode für die Auslegung, weil ein Text zuerst durch die Grammatik richtig gelesen werden muss. Im PK sind die hebräischen Wortsinne sehr wichtig für die rechte Deutung der Psalmen. ${ }^{52}$ Dazu benutzt Melanchthon mindes-

\footnotetext{
${ }^{50}$ Es ist umstritten, ob der Titel (,Argumente ac Dispositio“) von Melanchthon selbst genannt wird. Allerdings ist es sicher, dass Melanchthon die Struktur für die Auslegung der Psalmen gemeint hat. (Vgl. PK. Prol, CR 13, 1018. „Haec distinctio in genere multum lucis adfert Psalmis, ut prudens lector facile intelliget.")

${ }^{51}$ Vgl. PK Ps 110, CR 13, 1151. „Saepe dictum est, discernenda esse genera Psalmorum, ut in quolibet magis intelligi possit quid ibi agatur, et singuli ad usum recte accommodari possint, et in hac consideratione sciat mens quae sit propria Ecclesiae doctrina, et prudenter discernat praecipua capita."

${ }^{52}$ Z.B. PK Ps 15, CR 13, 1039. ,et sis immaculatus, quod Hebraeis ymiT' incorruptus, non morbidus. Nec significat perfectum, ut latine dicimus cumulatum seu consummatum, quod habet omnes partes, et omnium partium summos gradus. Nec significat immaculatum, ut multi intelligunt, in cuius moribus prorsus nihil sit victii:“; PK Ps 43, CR 13, 1089. „Primus versus est propositio Psalmi: Iudica me Deus. Hic phrasis Hebraica cognoscenda est. Nam Latini aliter loquuntur, sed David hoc vult.“
} 
tens im PK von PK Ps 1 bis PK Ps 60 den hebräischen Text als Grundlage. ${ }^{53}$ Bei Melanchthon ist die Auslegung zu den Psalmen ohne Zuhilfenahme der Grammatik unmöglich. Es ist unumstritten, dass Melanchthon auf die Grammatik im PK Gewicht legt.

Nach der Auffassung Melanchthons können die Dialektik und die Rhetorik nicht getrennt werden. Allein in der Funktion bezieht sich die Dialektik auf die logische Arbeit und die Rhetorik auf die stilistische. ${ }^{54}$ Die Dialektik spielt eine Rolle als die Grundlage der Rhetorik. ${ }^{55}$ Ohne die Dialektik kann die Rhetorik nicht bestehen. Diese untrennbare Beziehung zwischen der Dialektik und der Rhetorik zeigt die praktische Herangehensweise Melanchthons. Er hat kein Interesse an einer spitzfindig-abstrakten Dialektik. Besonders im PK ist der praktische Charakter in der Struktur des PKs deutlich zu sehen. Wie sein praktischer Charakter in der Methode, wird auch die exegetische Methode im PK in diesem Kapitel nicht theoretisch betrachtet, sondern praktisch nach der Anordnung des PKs.

\subsubsection{Struktur}

Die Psalmen sind für Melanchthon rhetorisch verfasste Texte. ${ }^{56}$ Auf dieser Voraussetzung organisiert Melanchthon den PK, um die Texte der Psalmen effizient auszulegen. Die Struktur des PKs besteht aus zwei Teilen, nämlich Argumente und Gliederung, wie der Titel des PKs lautet. Unter dem Aspekt der Argumente wird ein Überblick zu einem Psalm gegeben, so dass die Argumente des Psalms entdeckt und mit den rhetorischen Grundlagen verbunden werden können. Unter dem Aspekt der Gliederung werden die Verse jedes Psalms mit den rhetorischen Methoden betrachtet. Allerdings erklärt Melanchthon alle Verse nicht in gleicher Weise ausführlich, sondern gewichtet die Verse und betrachtet sie manchmal ausführlich und manchmal kurz oder auch nicht. Deshalb ist der PK keine akademisch abgeschlossene Auslegung. 57

Diese unabgeschlossene Form des PK war sicherlich von Melanchthon beabsichtigt. Denn der PK war zunächst keine allgemeine Veröffentlichung, sondern beruhte auf Vorlesungsakten. Melanchthon verfasste den PK nämlich nicht am Schreibtisch, sondern entwickel-

\footnotetext{
${ }^{53}$ Vgl. 2.1 Überlieferungsgeschichte.

${ }^{54}$ Vgl. Rhetorices, S.27.

${ }^{55}$ Wels 2001, S.449.

${ }^{56}$ Das Vorwort des PKs besteht aus zwei Teilen. Bei dem ersten Teil wird das Thema behandelt, dass die Psalmen das Wort Gottes ist, und bei dem zweiten Teil, dass die Psalmen durch die rhetorische Methode behandelt werden sollen. Besonders weist der vorstellende Teil von Ps $51 \mathrm{z}$ auf die rhetorische Eigenschaft der Psalmen deutlich hin. PK Ps 51z, CR 13, 1224. „Cogitemus Psalmos sapientiam, et vocem Dei esse, et Deum fontem eloquentiae, sapienter, recte et ordine loqui.“

${ }^{57}$ Vgl. Cornill 1897, S.17.
} 
te ihn vor den Zuhörern an der Wittenberger Universität. Die Hörer der Vorlesungen zu den Psalmen waren Studierende, die die Auslegung der heiligen Schriften an der Wittenberger Universität lernen wollten. Mit den Vorlesungen Melanchthons war nicht beabsichtigt, den Studierenden ein absolutes Resultat der Auslegung zu geben, sondern ihnen einen rechten Weg der Auslegung aufzuzeigen und Orientierung zu bieten. So ist in der Struktur des PKs die pädagogische Absicht Melanchthons zu beachten.

Zudem spielt die theologische Absicht Melanchthons, die sich auf den geschichtlichen Kontext bezieht, eine wichtige Rolle. Bedenkt man die Verfassungszeit des PKs (1547$1553)^{58}$, so ist es selbstverständlich, dass Melanchthon absichtlich diese Form der Psalmenvorlesung gewählt hat, höchstwahrscheinlich eine der ersten biblischen Vorlesungen nach der Wiedereröffnung der Wittenberger Universität im Oktober 1547. ${ }^{59}$ Seine Absicht zeigt sich im PK selbst deutlich. Im Vorwort des PKs erwähnt Melanchthon die Sukzession der Kirche Gottes, ${ }^{60}$ die ein bedeutendes Hauptthema im PK ist, indem Melanchthon sich damit beschäftigt, ob, wie und warum die wahre Kirche bewahrt wird. Nach der Auffassung Melanchthons stimmen viele Argumente der Psalmen mit dem Thema der Sukzession der Kirche zusammen. Die Argumente der Sukzession der Kirche werden von Melanchthon auf die Kirche seiner Zeit bezogen und daran angeschlossen. Melanchthon konzentriert sich mehr auf diese theologische und pädagogische Absicht bei dem PK als auf eine wissenschaftliche Arbeit.

Darüber hinaus entdeckt Melanchthon inhaltlich ähnliche Argumente in den Psalmen. Viele Wiederholungen von Argumenten sind in den Psalmen zu finden. Damit könnte auch der formale Charakter des PKs erklärt werden. Stellt Melanchthon eine Wiederholung der Argumente fest, dann überspringt er die Erklärung, die schon dargeboten wurde. Allerdings bedeuten die Auslassungen keine Lücke in der Auslegung und verweisen nicht auf eine vermeintliche Unwichtigkeit der Verse. Vielmehr lenken sie den Blick auf einen engen Zusammenhang der Psalmen zueinander. Deshalb war es für Melanchthon entbehrlich, alle Verse in den Psalmen ausführlich zu erklären.

\subsubsection{Argumente}

Die Auslegung zu einem Psalm im PK besteht aus zwei Teilen, nämlich aus dem Teil der Argumente und dem der Gliederung.

\footnotetext{
${ }^{58}$ Vgl. Kapitel 2. Überlieferungsgeschichte

${ }^{59}$ Siehe Kapitel 1. Einleitung, der geschichtliche Hintergrund.

${ }^{60}$ PK. Prol, CR 13, 1017. „Ac series temporum Ecclesiae Dei, inde usque a primis parentibus ostendit exempla huius ingentis beneficii Dei.“
} 
Der Teil der Argumente im PK spielt eine Rolle als Vorwort oder als Überblick zum Psalm. In diesem Teil erklärt Melanchthon die Sätze der Psalmen, ordnet die Sätze nach ihrer inhaltlichen Art in die entsprechende literarische Kategorie ein und bezieht sie auf die rhetorischen Gattungen.

Allerdings wird jeder Psalm im PK nicht in der gleichen Weise behandelt, weil sie sich bei den rhetorischen Elementen und der Länge voneinander unterscheiden. So behandelt Melanchthon z.B. in einigen Psalmen allein den Teil der Argumente. ${ }^{61}$

Methodisch sollen die Titel der Psalmen zuerst betrachtet werden. Die Titel der Psalmen geben nämlich einen Überblick oder einen Hintergrund zum jeweiligen Psalm. Melanchthon selbst hält die Titel der Psalmen für ein untrennbares Element der Psalmen. ${ }^{62}$ Deshalb soll ein Titel eines Psalms im PK berücksichtigt und im Zusammenhang mit dem ganzen Psalm betrachtet werden.

Die Titel geben vor allem die geschichtlichen Kontexte, die inhaltlichen Informationen und die Argumente der Psalmen wieder. Mit dem Hinweis im Titel werden die geschichtlichen Kontexte geklärt. (PK Ps 7, 32, 52, 54, 56, 59 und 60) Dadurch kann man den Inhalt des Psalms besser verstehen. Einige Titel zeigen direkt die Argumente der Psalmen. (PK Ps 5 und 52) und erwähnen die Verfasser, den Gegenstand und die literarische Art der Psalmen. (PK Ps 32 und 52) Außerdem spielen die Titel im PK eine Rolle als die Voraussetzung des dialektischen Schlusses in den Psalmen. (PK Ps 7) ${ }^{63}$ Deshalb kann man sagen, dass die Titel im PK einen Rahmen der Auslegung stellen, um recht und besser die Psalmen zu verstehen und um damit die richtige gegenwärtige Anwendung möglich zu machen. ${ }^{64}$ Ohne das richtige Ver-

${ }^{61}$ PK Ps 10, 12, 18, 24, 29, 37, 44, 113, 114/115, 116, 121, 123, 124 und 129.

${ }^{62}$ Vgl. PK Ps 7, CR 13, 1119. „Titulus est ignorantia David, quam cecinit Domino de verbis Cus, filii Iemini. Etsi autem variae sunt interpretationes, tamen simplicissimam hanc esse iudico.";PK Ps 52, CR 13, „Titulus indicat argumentum, quia narrat Davidem hanc consolationem scripsisse ${ }^{62}$ adversus delatorem, et parricidam Doëg, ...“; PK Ps 56, CR 13, 1131. „Notae sunt historiae, quarum in titulo fit mentio, ac recitantur primo libro Regum capite vigesimo tertio et vigesimo sexto."; PK Ps 59, CR 13, 1141. „Accommodat autem titulus hunc Psalmum ad liberationem Davidis, quae recitatur in libris 1. Sam. 19.“

${ }^{63}$ Z.B. PK Ps 7, CR 13, 1028. „Titulus est ignorantia David, quam cecinit Domino de verbis Cus, filii Iemini. ... Nos disceremus, inficiatio David, seu innocentia David. Ipse verecundius, gravius et significantius inquit, Ignorantia, quasi dicat, non agnosco obiecta crimina, nec multum interest, utrum Sauli et Semei criminanti oppositum dicas hunc Psalmum: ... Hunc vocat Cus, id est, Aethiopem, id est, atrum et hostem Israëlitarum, id est, verae Ecclesiae. ... et huic ratio gravissima additur, videlicet ne opprimatur vera doctrina, ne impii potiantur ministerio.“

${ }^{64}$ Durch das rechte Verständnis des Titels kann man eine richtige Anwendung erwarten. Vgl. PK Ps 7 , CR 13, 1028. „Titulus est ignorantia David, quam cecinit Domino de verbis Cus, filii Iemini. Etsi 
ständnis des Titels ist das wahre Verständnis des Psalms unmöglich.

In dem Teil der Argumente ordnet Melanchthon die Argumente der Psalmen in einen literarischen Katalog ein. Er erwähnt folgende Arten im Teil der Argumente des PKs: Darstellung (descriptio, narratio, praecepta), ${ }^{65}$ Vorhersage (prophetio), Gebet (praecatio, petitio), Danksagung (actio gratiarum), Verheißung (promissio), Trost (consolatio), Klage (querela) und Ermahnung (admonitio).

In der Darstellung behandelt Melanchthon folgende Themen: die wahre Kirche Gottes (PK Ps 1, 44 und 119), das Evangelium (PK Ps 19), das Lob Gottes (PK Ps 29), die Lehre über die Sündenvergebung (PK Ps 32), das Unheil (PK Ps 56), die Verfolgung der Kirche (PK Ps 129), die Vorschriften (PK Ps 133) und die Vorwürfe der Gegner gegen das Evangelium (PK Ps 58). Durch die Darstellungen wird die Lehre Gottes für die Kirche erklärt.

Melanchthon entdeckt in den Psalmen noch die Vorhersagen, die sich auf den Messias beziehen, die Ankunft des Messias (PK Ps 2 und 18), sein Evangelium (PK Ps 19), seine Auferstehung (PK Ps 16), sein Reich (PK Ps 47) und seine Kirche (PK Ps 8 und 116). Der Messias ist ein Hauptthema im PK, und die Wirkung des Messias bezieht sich immer auf die Kirche.

Im PK finden sich dazu die Verheißungen Gottes für die Kirche. Gott, das Subjekt der Verheißungen, gibt der Kirche die Verheißungen über die Hilfe (PK Ps 9 und 41), die Bewahrung der Kirche (PK Ps 11), die Geschenke (PK Ps 34), die Freiheit (PK Ps 53 und 125) und den Messias (PK Ps 45, 110 und 117/118).

Der Trost ist im PK das Geschenk Gottes für die Kirche (PK Ps 112). Die Kirche wird getröstet durch die Bewahrung der Frommen (PK Ps 11, 46 und 49), das Entgegenstellen der Verführung des Kreuzes und der Gottlosen (PK Ps 37 und 39), die Vorsehung (PK Ps 128), die Sündenvergebung (PK Ps 130) und die Milderung des Schmerzes der Kirche (PK Ps 126).

Im PK werden viele Psalmen als Gebete eingeordnet. Dabei ist das Subjekt der Gebete die Kirche. Die Kirche betet in dem Leiden (PK Ps 4, 22 und 38) und der Angst vor dem Zorn Gottes (PK Ps 28), gegen die Gegner (PK Ps 7, 36, 55 und 120), für die Sündenvergebung (PK Ps 25), die Freiheit (PK Ps 3 und 31), die Hilfe (PK Ps 13), die Milderung des Leidens (PK Ps 6 und 38), das politische Reich (PK Ps 20 und 21), die Bewahrung der wahre Lehre

autem variae sunt interpretationes, tamen simplicissimam hanc esse iudico. Ignorantiam vocat professionem innocentiae, seu non agnoscentis conscientiae obiecta crimina, quod invaserit regnum, et privata cupiditate grassatus sit adversus Saulem.“

${ }^{65}$ Mit der Darstellung ist hier eine objektive Erklärung einer Sache gemeint. 
und der Kirche (PK Ps 10, 17, 26, 43, 121 und 123) und die Übungen des Glaubens (PK Ps 42 und 54). So bezieht sich das Gebet auf die Lebensakte der Kirche in diesem Leben.

Die Danksagungen finden sich im PK auch häufig. Das Subjekt der Danksagung ist die Kirche. Sie dankt Gott für die Freiheit (PK Ps 8, 30 und 115), den Untergang der Gegner (PK Ps 9), die Geschenke (PK Ps 21, 48 und 111), die Vorsehung (PK Ps 33 und 113), die Verteidigung der Kirche (PK Ps 46), den Sieg (PK Ps 47 und 60) und die Stellung der Kirche (PK Ps 122).

Dazu werden die Arten der Klage (PK Ps 12) und der Ermahnung (PK Ps 15) erwähnt.

Die Argumente im PK gehören den Handlungen der Kirche. So entdeckt Melanchthon in den Psalmen die Beziehungen der Kirche zu Gott, dem Evangelium, den Gegnern, dem Leiden und dem Leben.

Bevor Melanchthon die Arten der Argumente in den Psalmen mit den rhetorischen Gattungen verbindet, unterscheidet er zuerst zwischen Gesetz und Evangelium. Dann ordnet Melanchthon diese Arten in die Unterscheidung von Gesetz und Evangelium ein. ${ }^{66}$ Dabei sind die Psalmen als die Lieder der Kirche, die von Gott die Geschenke des Evangeliums bekommen hat, zu verstehen. Die Psalmen gehören in der Folge zur Art des Evangeliums. Manche Psalmen behandeln die gesetzlichen Vorschriften, die für alle gefordert werden, ${ }^{67}$ aber trotzdem beziehen sie sich eng auf das Evangelium, weil sie allein für die Kirche gelten. ${ }^{68}$ Deshalb sind die Psalmen - sozusagen - die Stimme des Evangeliums.

Melanchthon ordnet die Psalmen jeweils bestimmten Gattungen zu. ${ }^{69} \mathrm{Im}$ PK werden drei Gattungen erwähnt: genus demonstrativum (die hinzeigende Gattung), genus didaskalikon (die belehrende Gattung) und genus suasorium (die anratende Gattung). ${ }^{70}$ Melanchthon verbindet die Arten der Darstellung, der Danksagung, der Vorhersage und der Verheißung mit

\footnotetext{
${ }^{66}$ PK Prol, CR 13, 1018. „Deinde materias discernito. Ut universa doctrina Ecclesiae in duas partes distribuitur, videlicet legem et Evangelium, ita discernantur et Psalmi: alii magis continent doctrinam legis, id est, praecepta et adhortationes: alii magis interpretantur promissionem de Christo propriam Evangelii: alii prorsus pertinent ad genus didaskaliko. n seu demonstrativum, ... alii sunt generis suasorii, ut qui concionantur de bonis operibus, aut consolantur pios in afflictionibus, aut continent petitiones, ..."

${ }^{67}$ PK. Prol, 6 CR 13, 1018 ,alii magis continent doctrinam legis, id est, praecepta et adhortationes“

${ }^{68}$ Z.B. siehe PK Ps 133, CR 13, 1221. „Ita consideretur quid praecipiat lex, et quomodo ad eam reducamur per Filium Dei, et in illa parte quae vere est Ecclesia Dei restituatur dilectio et concordia, et rursus adglutinentur ad unum caput, ad Filium Dei, et per Filium ad aeternum patrem.“

${ }^{69}$ Bei der Ordnung der Gattungen folgt Melanchthon der aristotelischen Tradition.(Alexiou 2014, S.761-772)

${ }^{70}$ Genus suasorium stimmt mit genus deliberativum (die beratende Gattung) überein.
} 
genus demonstrativum und genus didaskalikon, und die Arten des Gebetes, des Trostes und der Danksagung ${ }^{71}$ mit dem genus suasorium. ${ }^{72}$

Genus demonstrativum umfasst Lob und Tadel und wird für die Definition angewendet. ${ }^{73}$ Genus didaskalikon stellt eine Aufgabe, enthält die Dialektik und ist ,jene Methode des Unterrichtens" und verwandt mit genus demonstrativum. ${ }^{74}$ Im PK werden PK Ps 1, 2, 6, 9, 24, 29, 45, 47 und 110 namentlich als genus demonstrativum genannt, und PK Ps 1, 14, 16, 24, 50 und 110 als genus didaskalikon genannt. ${ }^{75}$ Der Zweck der beiden Gattungen ist die Erkenntnis des Sachverhaltes. ${ }^{76}$ Im PK bleibt der Zweck nicht in der reinen Erkenntnis, sondern er richtet sich auch auf die Anwendung. ${ }^{77}$ Obwohl Melanchthon einige Psalmen in genus demonstrativum und andere in genus didaskalikon einordnet, werden im PK die beiden Gattungen fast für gleich erachtet, weil die Erklärungen im PK immer einen pädagogischen Zweck haben. ${ }^{78}$

Genus suasorium umfasst Raten und Abraten. ${ }^{79}$ Im PK werden PK Ps 3, 4, 6, 9, 10, 11, 13, 45, 51, 52, 54, und 58 namentlich als genus suasorium genannt. ${ }^{80}$ Damit deutet Melan-

\footnotetext{
${ }^{71}$ Die Danksagung kann als eine Erklärung der Wirkung Gottes für die Kirche oder als die dankende Stimme der Kirche für die Wirkung Gottes gesprochen werden. Vgl. PK Ps 110, CR 13, 1151. „Saepe miscentur precationes, consolationes et gratiarum actiones. Horum multi non de solo Messia loquuntur, sed sunt communis vox omnium membrorum Ecclesiae, et exempla haec proposita sunt tanquam promissiones, ut nos quoque eodem modo, eadem fide, auxilium petamus et expectemus.“

${ }^{72}$ Vgl. PK. Prol, CR 13, 1018.; PK Ps 110, CR 13, 1151.; PK Ps 51z, CR 13, 1225.; PK Ps 34z, CR 13, 1240.

${ }^{73}$ Rhetorices, S.33.

${ }^{74}$ Rhetorices, S.33.

${ }^{75}$ Unter den Psalmen, zu denen Melanchthon keine Angabe über die Gattungen im PK gegeben hat, stehen die Psalmen, die für genus didaskalikon oder genus demonstrativum gehalten werden können. (PK Ps 8, 18, 19, 23, 30, 32, 33, 34, 40, 41, 44, 45, 46, 48, 53, 58, 60, 111, 113, 114/115, 115, 116, $117 / 118,119,122,124,125,127,129,131,133,31 \mathrm{z}$ und $34 \mathrm{z})$

${ }^{76}$ Rhetorices, S.39.

${ }^{77}$ Vgl. PK Ps 110, CR 13, 1151. „Ut autem promissio postulat fidem, ita sciamus finem esse horum Psalmorum, ut eorum testimoniis accendantur in nobis, et confirmentur agnitio Filii Dei, fiducia acquiescens in Filio Dei, vera invocatio, gratiarum actio, laeticia in Deo, et incoatio vitae aeternae, ... Possunt autem referri ad genus demonstrativum vel didaskalik. on et ad statum finitivum,..."

${ }^{78}$ Vgl. PK Ps 1, CR 13, 1019. „Primus Psalmus tanquam praefatio est totius operis, et est generis demonstrativi seu didascalici: Est enim descriptio, docens quae sit vera Ecclesia Dei, quae videlicet amplectitur verbum Dei.“; PK. Prol, CR 13, 1018. ,alii prorsus pertinent ad genus didaskaliko.n seu demonstrativum, ...“; PK Ps 110, CR 13, 1151. „Possunt autem referri ad genus demonstrativum vel didaskalik. on et ad statum finitivum, ..."

${ }^{79}$ Rhetorices, S.33.

${ }^{80}$ Unter den Psalmen, zu denen Melanchthon keine Angabe über die Gattungen im PK gegeben hat, stehen die Psalmen, die für genus suasorium gehalten werden können.(PK Ps 5, 6, 7, 12, 15, 17, 20, 21,
} 
chthon die Absicht dieser Psalmen hin, dass wir mit dem Glauben bitten und auf Hilfe warten. ${ }^{81}$

\subsubsection{Gliederung}

Nach dem Aspekt der Argumente wird nun der Aspekt der Gliederung(dispositio) betrachtet. Dabei erklärt Melanchthon die Verse des Psalms in der Reihe gemäß dem Überblick. Die Inhalte und die Deutungen des jeweiligen Psalms werden dargestellt. Melanchthon wendet verschiedene rhetorische Begriffe in der Gliederung an, dadurch sind die rhetorischen Funktionen in den Psalmen deutlich zu ersehen.

Rhetorisch bestehen die Redeteile aus Einleigung (exordium), Erzählung (narratio), Behauptung (propositio), Bestätigung (confirmatio), Widerlegung (confutatio) und Schluss (peroratio) ${ }^{82}$ Allerdings folgt Melanchthon im PK dieser Abfolge der Redeteile nicht immer. Die Psalmen sind keine Prosa und zeigen nicht durchgängig alle Elemente der Redeteile. Melanchthon passt die Psalmen nicht den rhetorischen Interpretationsprinzipien an, sondern nach dem jeweiligen Charakter der Psalmen wendet er die Prinzipien für die Auslegung der Psalmen an.

Die Einleitung (exordium) bereitet die Zuhörer vor. ${ }^{83}$ Durch die Einleitung eines jeden Psalms können die Zuhörer die Richtung und das Thema des Psalms ersehen und vorbereiten. Deshalb ist es hilfreich für das rechte Verständnis, die Einleitung jedes Psalms zu berücksichtigen.

Zunächst spielt die Einleitung eine Rolle für die Vorstellung der Entfaltung des Psalms. Durch die Einleitung zu PK Ps 2 über den Tadel der Gegner des Evangeliums wird der Trost der Schwachen erwartet. Die große Klage als die Einleitung zu PK Ps 13 stellt die Kirche im Leiden dar. Außerdem drückt die Einleitung direkt das Thema des Psalms aus. Die Einleitung zu PK Ps 11 fordert nicht nur das Hören der Verheißung, sondern auch das Annehmen durch den Glauben. Die Einleitung zu PK Ps 33 zeigt durch die Freude der Gerechten das Lob und den Dank für die Güte Gottes. Die Einleitung über Trauer und Schmerz zu PK Ps 40 verbindet

$22,25,26,27,28,31,35,36,37,38,39,42,43,49,51,52,55,56,57,59,112,120,121,123,126$, $128,130,132$ und $51 \mathrm{z})$

${ }^{81}$ Vgl. PK Ps 110,3 CR 13, 1152. „Haec discrimina nota sint, ut haec dulcissima carmina ad usum accommodari possint, et ut sciamus qui affectus lectionem sequi debeant, Timor Dei, fides, invocatio, tolerantia in afflictionibus, spes auxilii, gratiarum actio, gaudium in Deo. Tales autem Psalmi fere pertinent ad genus suasorium, et tamen passim admixta est doctrina.“

${ }^{82}$ Rhetorices, S.66.

${ }^{83}$ Rhetorices, S.69. 
sich mit der Vorhersage über die Hilfe und die Freiheit Gottes.

„Die Erzählung (narratio) ist die Darstellung dessen, was geschehen ist. “84 Im PK beinhaltet die Erzählung die Handlungen Gottes und der Kirche. Die Erzählung wird im PK angewendet, um zu erklären, welchen geschichtlichen Kontext der Psalm hat (PK Ps 44), was die Kirche ist und tun soll (PK Ps 15), wer der Messias ist und tun wird (PK Ps 16, 40 und 110), was Gott für die Kirche tut und ihr gibt (PK Ps 22, 26 und 111), warum und wie die Kirche leidet und wie sie befreit wird (PK Ps 30, 38, 49, 54, 56, 59, 60, 117/118, 119 und 126) und wie Gott die Welt, besonders die Gottlosen, richtet und straft (PK Ps 49 und 50).

Auf die Erzählung (narratio) folgt die Behauptung (propositio), „die den Kern des Sachverhaltes enthält.“ ${ }^{\circ 5}$ Die Behauptung ,,ist der wichtigste Bestandteil der ganzen Auseinandersetzung.“ ${ }^{66}$ „Man kann auch keine theoretische Erörterung beurteilen, wenn man nicht auf diese Ordnung der Behauptungen achtet. ${ }^{\text {(87 }}$ Bei den Behauptungen im PK werden die Sachen behandelt, die sich auf die Kirche beziehen.

Bei der Behauptung im PK werden folgende Themen behandelt: die Bitte um die Gnade und die Hilfe Gottes (PK Ps 42), die Bewahrung der Gerechtigkeit (PK Ps 43), die Bewahrung der Kirche gegen die Gegner (PK Ps 5) und die Freiheit, den Trost und die Verheißung für die Kirche (PK Ps 30, 35, 46 und 49), die Danksagung für die Gnade und die Hilfe Gottes (PK Ps 8), die Erklärung über die Gnade, die Sündenvergebung und den Dienst (PK Ps 32 und 50) und das Bekennen Gottes als das Refugium und die Kraft (PK Ps 46).

Die Bestätigung (confirmatio) vermittelt dem Zuhörer die Überzeugung, dass die Behauptung (propositio) zutrifft: „Weil die Behauptung nichts anderes ist als der Schluss (conclusio) der Bestätigung (confirmatio), wird eine Behauptung (propositio) keinen Glauben finden, wenn sie nicht durch eine Bestätigung (confirmatio) erkämpft worden ist. “88 Darauf bezieht sich der Syllogismus, nämlich die Dialektik. Die Behauptung ist der Schluss von der Dialektik der Bestätigung.

Die Kausalität wird im PK als die Methode der Bestätigung angewendet. Im PK werden unterschieden die Finalursache (causa finalis) und die Antriebsursache (causa impulsiva). Die

\footnotetext{
${ }^{84}$ Rhetorices, S.71.

${ }^{85}$ Rhetorices, S.71.

${ }^{86}$ Rhetorices, S.73.

${ }^{87}$ Rhetorices, S.73.

${ }^{88}$ Rhetorices, S.73.
} 
Finalursache verweist auf den Zweck eines Geschehens. ${ }^{89} \mathrm{Im}$ PK bestimmt Melanchthon die Antriebsursache ähnlich wie die Finalursache, aber als die relativ nähere Ursache zum Geschehen.

Z.B. fordert David im PK Ps 23 die Erlösung, dabei spielt der Name Gottes eine Rolle als die Antriebsursache. Er fordert die Bewahrung, um dem Haus Gottes zu dienen, um die himmlische Lehre zu lernen und um die Lehre der Erlösung zu verkündigen. Das ist die Finalursache. ${ }^{90}$ Wegen des Namens Gottes wird David erlöst und bewahrt und zur Folge dient er dem Haus Gottes, lernt und verkündigt die Lehre Gottes. Im PK wird das Thema von der Hilfe und der Freiheit Gottes für die Kirche häufig erwähnt. Dabei erklärt Melanchthon als die Finalursache das Lob Gottes (PK Ps 33 und 52), das Hindernis gegen die Feinde der Kirche (PK Ps 38 und 42), die Bewahrung der Kirche (PK Ps 58) und die Erkennung der Gegenwart Gottes (PK Ps 60). Melanchthon erklärt das Gebet der Kirche (PK Ps 33), die Anrufung (PK Ps 38), die verheißene Gnade Gottes (PK Ps 42) und die Verkündigung der Wahrheit (PK Ps 60) als die relativ nähere Ursachen, nämlich die Antriebsursachen für die Hilfe und die Freiheit Gottes für die Kirche. Daneben erklärt Melanchthon die Finalursache des Leidens des Messias, dass der Messias der Grund der Kirche wird (PK Ps 117/118), und die Finalursache der Wiederholung der Lehre des Kreuzes, dass die Mitglieder der Kirche nicht getötet werden, sondern sich zur Buße bekehren (PK Ps 119).

Bei der Anwendung der Kausalität im PK gibt es fast keinen Unterschied zwischen der Finalursache und der Antriebsursache. Wo die Antriebsursache erwähnt wird, findet sich die Finalursache immer dabei. Der Unterschied könnte eine relative Distanz der Ursache zum Geschehen sein.

Die Begründung (aitiologia, ratio) wendet Melanchthon im PK als eine dialektische Methode der Bestätigung an. Die Begründung bezieht sich auf die Handlungen der Kirche. Eine wichtige Prämisse dafür sind die Eigenschaften Gottes. Gott ist gut, treu und gerecht, deshalb

\footnotetext{
${ }^{89}$ Die Kausalität Melanchthons folgt der Kausalität Aristoteles, wobei die Finalursache am wichtigsten ist, weil die Finalursache das Ziel der Handlung zeigt. Melanchthon konzentriert sich bei der Finalursache auf Gott im Gegenteil zu Aritoteles, der Gott nicht erkennt, der die Welt aus nichts schuf. In der Neuzeit wurde man auf die Effektursache(causa efficiens) aufmerksamer, als auf die Finalursache.(Klowski, S.81-82) Insofern ist Melanchthon keine neuzeitliche Gestalt bei der Kausalität.

${ }^{90}$ PK Ps 23, CR 13, 1051 „Addit autem causam impulsivam, qua moveri Deum orat, ut haec tanta bona largiatur, videlicet hanc quae recensetur in versiculo tertio, Propter nomen tuum serva et rege nos Deus. ... Additur et causa finalis, quae vicina est impulsivae: Ad quem finem petenda est defensio? Num ut ociosi voluptatibus fruamur, sicut impii hunc solum esse fructum et finem laborum arbitrantur. ..."
} 
kann die Kirche, die von Gott eine Verheißung erhält, um die Bewahrung bitten (PK Ps 5). Gott ist barmherzig, aus diesem Grund kann die Kirche um die Milderung des Leidens bitten (PK Ps 6). So betet der Verfasser des Psalms „Mach uns frei für deine Ehre.“ (PK Ps 13). Gott bewahrt die Kirche um seiner Barmherzigkeit willen (PK Ps 52). Gott gedenkt der Armen, so dass die Kirche nicht vollständig aufgerissen wird (PK Ps 125).

Eine andere Prämisse ist die Lehre Gottes. Die Kirche bittet um die Freiheit, damit die wahre Lehre Gottes nicht unterdrückt wird (PK Ps 7), und um Bestrafung der Feinde, damit alle die überlieferte Lehre als die wahre bekennen können (PK Ps 10). Zugleich sind die Gebete und die Hoffnung die Ursache der Anrufung Gottes (PK Ps 52).

So findet Melanchthon die Begründungen vor allem in den Gebeten der Kirche um die Bewahrung, um die Milderung und die Freiheit im Leiden der Kirche. Die Eigenschaften Gottes und seine wahre Lehre begründen die Gebete der Kirche.

„Die Widerlegung (confutatio) ist die Widerlegung der gegnerischen Argumente. “91 Im PK findet sich die Widerlegung vor allem in der Antithese. Durch die Antithese zeigt sich die Absicht des Satzes deutlich, ${ }^{92}$ so dass ein Psalm leicht verstanden werden kann. ${ }^{93}$

Im PK finden sich die Gegensätze zwischen den Frommen und den Gottlosen (PK Ps 1, 2, 4, 5, 15, 16, 17, 49, 50, 51, 53, 112, 119 und 127), zwischen Gott und den Menschen (PK Ps $60,110,114 / 115,117 / 118$ und 51z) und zwischen dem gegenwärtigen Leiden und der Verheißung (PK Ps 3 und 52).

Die Frommen stehen im Gegensatz zu den Gottlosen. Die Frommen gehören der Kirche an, halten das Wort Gottes fest, sind durch das Leiden in diesem Leben nicht enttäuscht und erwarten die Hilfe Gottes. Aber die Gottlosen verweigern sich der Vorsehung Gottes, vertrauen auf sich selbst und werden von Gott gerichtet.

Gott steht im Gegensatz zu den Menschen. Gott ist der Schöpfer und der Regierende der Welt. Aber die Menschen sind Geschöpfe Gottes und sollen Gott dienen.

Die Kirche ist in diesem Leben unter dem Kreuz, aber sie hat die sichere Verheißung Gottes für die Erlösung und das ewige Leben.

Dazu findet Melanchthon die Folge von Frage und Antwort in den Psalmen als die Methode der Widerlegung. Die Methode von Frage und Antwort wendet er an, wenn ein Argu-

\footnotetext{
${ }^{91}$ Rhetorices, S.79.

${ }^{92}$ PK Ps 15, CR 13, 1040. „Faciens iusticiam, quod antithesi addita erit illustius“

${ }^{93}$ PK Ps 50, CR 13, 1111. ,illuserat Psalmum, ut plane quid velit intelligi possit.“
} 
ment von einer normalen Erwartung abweicht. ${ }^{94}$ Melanchthon findet die Methode von Frage und Antwort in Psalmen bei den Themen von der Art der Gerechtigkeit (PK Ps 7 und 59), dem Fluch gegen die Feinde (PK Ps 55 und 59), der noch in den Mitgliedern der Kirche bleibenden Sünde (PK Ps 19) und dem Leiden der Kirche (PK Ps 4, 7, 16, 30, 37, 46, 49, 51, 52, 112 und 34z), das sich auch auf die Vorsehung Gottes bezieht.

Diese Themen beziehen sich auf die gegenwärtigen Situationen der Kirche. Der Kirche wird die ewige Verheißung der Erlösung gegeben, aber die Kirche ist noch unter dem Kreuz. Melanchthon findet in den Psalmen die Frage und die Antwort danach, warum solches Geschehen der Kirche bestimmt. Damit erklärt er den Grund des Leidens der Kirche und stellt die Antwort auf die Bedeutung dieses Leidens für die Kirche dar. Dazu versucht er den Schluss auf die Kirche seiner Zeit zu beziehen.

„Der Schluß (peroratio) ist die Konklusion (conclusio) der Rede, in der die zentrale Behauptung (propositio) wiederholt wird.“95 Als eine Methode des Schlusses findet sich häufig

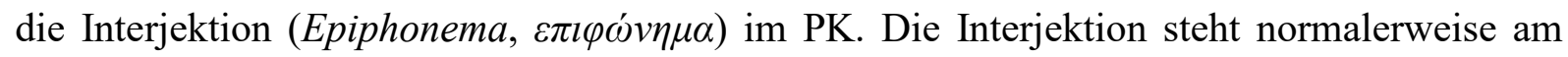
Ende des Psalms (PK Ps 20, 52, 111 und 31z). Sie drückt eine emotionelle und voluntative Feststellung der Kirche über die Handlungen Gottes für die Kirche aus (PK Ps 20, 30, 52 und 127) und leitet die Kirche zu dem Dank (PK Ps 52) und dem Vertrauen (PK Ps 46 und 117/118).

Mit dem Hauptpunkt (Summa) zeigt Melanchthon einen Hauptgedanken des Psalms auf. In PK Ps 23 erbittet die Kirche das Leben, um der Kirche zu dienen. In PK Ps 37 ist der Hauptpunkt, dass für die Mitglieder der Kirche die Erlösung vorgesehen ist, aber für die Blasphemisten der ewige Tod. In PK Ps 45, dass der Messias den Sieg und das ewige Reich erhalten, und dass der König seinem Volk die Gerechtigkeit und das ewige Leben gibt. In PK Ps 49, dass nach diesem Leben das Gericht stattfindet. In PK Ps 52, dass man Gott, der die Kirche befreit, die Hilfe erbitten soll. In PK Ps 53, dass der Messias die Kirche frei macht. Das ist ein Trost für die Kirche. In PK Ps 110, dass die Werke des Messias im PK dargestellt sind. In PK Ps 111, dass die Verheißungen über die Freiheit und die Geschenke in diesem Leben gegeben werden.

\subsubsection{Allegorie bei Melanchthon}

Außer der humanistischen Methode wendet Melanchthon auch die traditionelle Methode

\footnotetext{
${ }^{94} \mathrm{Vgl}$. Rhetorices, S.55.

${ }^{95}$ Rhetorices, S.83.
} 
zur Auslegung der Heiligen Schrift an, z.B. die Allegorie. Es ist eine bedeutende Frage, auf welche Weise er dies tut, weil die allegorische Methode bei der vierfachen Auslegung der Heiligen Schrift im Mittelalter angewendet wurde. Aus Melanchthons Auslegung sieht man dass er sich der vierfachen Auslegung der Heiligen Schrift verweigert. Nach seiner Auffassung ist die Allegorie eine besondere Redeform, ${ }^{96}$ durch die sich die wahrhafte Bedeutung der Heiligen Schrift zeigt. Diese Redeform hat keine verschiedenen Gedanken wie in der vierfachen Auslegung, sondern einen. Melanchthon glaubt, dass einige Texte der Heiligen Schriften durch diese Redeform, die Allegorie, verstanden werden sollen.

Besonders in den Auslegungen der Metaphern im PK ist die allegorische Methode zu ersehen. (PK Ps 23, 51, 57, 58, 51z und 34z) Sick weist darauf hin, dass bei Melanchthon die Typologie vor allem auf die Christologie und die Eschatologie angewendet werde. ${ }^{97}$ Er legt seinen Schwerpunkt allerdings auf das theoretische Interesse an der Theologie Melanchthons. Aber im PK konzentriert sich Melanchthon sehr praktisch auf die Gegenwart und den Trost seiner Kirche. ${ }^{98}$ Melanchthon glaubt, dass die Psalmen für die Kirche seiner Zeit das praktische Wort Gottes sind.

Bei den allegorischen Auslegungen im PK ist die Tendenz zu sehen, dass Melanchthon die Metapher überhaupt auf Christus bezieht. Aber Er bezieht alle Metaphern ohne Berücksichtigung auf den Messias nicht. ${ }^{99}$ Der Kontext für die Auslegung spielt eine wichtige Rolle. In dem messianischen Kontext legt Melanchthon die Metapher in der Beziehung zum Messias aus.

Bei den allegorischen Auslegungen achtet Melanchthon die traditionelle Auslegung hoch. ${ }^{100}$ Aber den Aberglauben vermeidet er. ${ }^{101}$ Und er folgt keiner Auslegung von anderen,

\footnotetext{
${ }^{96}$ Sick 1959, S.44.

${ }^{97}$ Sick 1959, S.72.

${ }^{98} \mathrm{Vgl}$. Bayer sagt, dass das humanistische Interesse Melanchthons sich ,in besonderer Weise in der Exegese biblischer Schriften“ bewährt. Dabei handelt sein Interesse „niemals um abstrakte Begriffe, sondern immer um die Bezeichnung geschichtlicher Entscheidungen." (Bayer 1994, S.142.)

${ }^{99}$ Z.B. PK Ps $58,51 z$ und $34 z$.

${ }^{100}$ Z.B. PK Ps 110, CR 13, 1156. „Est autem communis sententia vetustatis, Melchizedech fuisse filium Nohae Sem, ...“; PK Ps 117/118, CR 13, 1183. „Etiam vetus synagoga intellexit hunc Psalmum esse vocem Messiae, ..."

101 Z.B. PK Ps 58, CR 13, 1140. „Veterum superstitio finxit prodesse rhamni virgas contra fascinationes, et incubos seu ephialtas, qui dormientibus faciunt compressiones pectoris, ... Apud Ovidium et stryges depellere dicitur, quod eo recenseo, non ut superstitionem confirmem, sed ut hac grammatica enarratione vocabulum fiat notius."
} 
sondern er legt die Schrift nach seiner Überzeugung aus. ${ }^{102}$

Zusammenfassend verwendet Melanchthon die allegorische Methode im PK zumeist nicht, weil nach der Auffassung Melanchthons der Text keine verschiedenen Gedanken hat, sondern einen. Wenn der Text solche allegorische Auslegung erfordert, erklärt Melanchthon den Text allegorisch, aber logisch aus dem Kontext. Dabei schätzt er die traditionellen Auslegungen.

Zuletzt soll ein Gedanke Sicks erörtert werden. Sick bezieht die allegorische Methode auf die Verbindung der biblischen Geschichte mit der Gegenwart. ${ }^{103}$ Seine Frage ist, welche Beziehung es zwischen der biblischen Geschichte und dem damaligen Zeitraum gibt. Sick glaubt, dass Melanchthon die Allegorie anwendet, um die biblischen Geschichte in die Gegenwart anzuschließen. Diese Verbindungen seien ein willkürlicher Anschluss des Auslegers. Aber die allegorische Methode soll sich von der Verbindung der biblischen Geschichte mit der Gegenwart unterscheiden. Wie Sick schon erwähnt hat, wendeten aber die antiken Ausleger diese Verbindung an. ${ }^{104}$ Melanchthon glaubt, dass Gott, der sich in der Heiligen Schrift offenbarte, in diesem Leben noch mit der gleichen Weise für die Kirche wirkt. ${ }^{105}$ Dann ist es selbstverständlich für Melanchthon, die Weise der Wirkung Gottes zu betrachten und diese Weise an die gegenwärtige Kirche anzuschließen. Diese Verbindung entsteht aufgrund der Wirkung Gottes. Die allegorische Methode ist allein eine Redeform, um die Wahrheit Gottes der Kirche zu offenbaren. Aus diesem Grund ist es besser für das klare Verständnis der exegetischen Methode Melanchthons im PK, dass sich die allegorische Deutung von dem Anschluss der biblischen Geschichte in die gegenwärtige Kirche im PK unterscheidet. Dieser Anschluss bezieht sich sachgemäß besser auf seine Theologie.

\subsection{Theologische Grundlage}

Für Melanchthon sind die Psalmen nicht bloß menschlichen, sondern vornehmlich göttlichen Ursprungs. Die Psalmen wurden zwar aufgrund der rhetorischen Methode der Menschen

\footnotetext{
${ }^{102}$ Vgl. PK Ps 8, CR 13, 1032. „Et quanquam Psalmum in genere de tota Ecclesia intelligo, tamen non displicet mihi interpretatio eorum, qui ad caput Christum accommodant eum. Nam et Christus paulisper caret gloria, factus pro nobis maledictum. Postea vero rursus ornatur gloria, et propter eum redduntur Ecclesiae iusticia et vita aeterna.“

${ }^{103}$ Sick 1959, S.68.

104 Sick 1959, S.67.

${ }^{105}$ Vgl. PK Ps 33, CR 13, 1068. „At econtra Ezechias scit adesse Deum Ecclesiae suae, petit et expectat defensionem: nec fallit haec fides ipsius expectationem, sed vere impetrat defensionem.“
} 
verfasst, aber zugleich sind die Psalmen die Lehre Gottes. ${ }^{106}$ Sie erscheinen allerdings dunkel für die Gottlosen wie für die Philosophen. ${ }^{107}$ Für die wahrhafte Auslegung der Psalmen ist die wahre Theologie nötig. Dabei ist die theologische Einheit der Heiligen Schrift im PK impliziert. Und bei der Dialektik spielt die theologische Grundlage eine Rolle als die obere Voraussetzung des Schlusses. ${ }^{108}$ Im folgenden Kapitel werden die Themen: Einheit der Heiligen Schrift, Unterscheidung zwischen Gesetz und Evangelium, Christologie, David und die Kirche betrachtet.

\subsubsection{Einheit der Heiligen Schrift}

Aufgrund der humanistischen Methoden sind die Strukturen der Psalmen zu erkennen. Aber bei deren Auslegung stellt die Theologie eine wichtige Voraussetzung und einen Rahmen dar, um die Psalmen recht zu verstehen. Die einheitliche Auslegung der Psalmen durch Melanchthon hat in dessen theologischem Rahmen die Grundlage. Der theologische Rahmen Melanchthons ist in den Loci theologici zu finden. ${ }^{109}$ Die Loci kommen aber zuerst aus der Auslegung der Heiligen Schrift. Dabei ist die theologische Einheit der Heiligen Schrift impliziert, weil ohne die Einheit die Systematisierung nicht möglich ist. Im PK zeigt sich diese Einheit vor allem im Umgang Melanchthons mit biblischen Belegstellen.

Die Themen, die sich in den Psalmen finden, finden sich zugleich in den verschiedenen biblischen Schriften und stimmen damit überein. Aus diesem Grund zitiert Melanchthon in seinen Auslegungen zu den Psalmen sehr häufig andere biblische Schriften als bedeutende Belege, um seine Deutungen zu stützen. Melanchthon ist überzeugt, dass die Aussagen der Psalmen sowohl untereinander übereinstimmen als auch mit den anderen biblischen Schriften. Dieser Gedanke unterstützt die Richtigkeit und die Selbstverständlichkeit seiner Auslegungen.

Im PK ist dieser Charakter immer wieder zu sehen. Aber in diesem Kapitel sollen allein die Zeugnisse im Vorwort des PKs betrachtet werden. Die Auffassung Melanchthons über die theologische Einheit der biblischen Schriften zeigt sich schon in dem ersten Satz des Vorwortes. Er erwähnt das Thema der Bewahrung Gottes für die wahre Lehre und die Kirche zu

${ }^{106}$ PK. Prol, CR 13, 1018. „Sit ergo hoc fundamentum enarrationis, quod Psalmi vere sint doctrinae Dei, ...“

${ }^{107}$ Vgl. PK Ps 32, CR 13, 1066. „Haec tota doctrina, ut supra dixi, philosophis ignota est, ideo videtur obscurior. Philosophi iubent tantisper humana praesidia quaerere, ...“

${ }^{108}$ Sick 1959, S.64.

${ }^{109}$ Vgl. Kapitel 5.6. Aber die Äußerung Bayers ist recht für Melanchthon, Bayer sagt, „Die Dogmatik dient der Schriftauslegung; sie beherrscht sie nicht. Dogmatik ist Hilfswissenschaft.“ (Bayer 1994, S.135.) 
Ephesus 4., behauptet, dass das Thema der Psalmen damit gleich sei, und versucht, dies in den Psalmen zu betrachten. ${ }^{110}$ Dazu führt er 2 Pet 1. als Beleg an, womit er das Fundament der Auslegung erklärt, dass die Psalmen die Lehre Gottes seien. ${ }^{111}$ Damit ist der Gedanke impliziert, dass Gott, der in den Psalmen spricht, gleiches spricht wie in 2 Pet 1., und dass die theologischen Behauptungen in beiden biblischen Schriften nicht in Widerspruch, sondern miteinander gut übereinstimmen. Darüber hinaus zeigt sich hierin das starke Vertrauen Melanchthons auf die Deutungen und die Autorität der Apostel. ${ }^{112}$

Es ist auch interessant, dass Melanchthon frei das NT im PK zitiert. Durch die oben betrachteten Beispiele ist das Verständnis Melanchthons über den Zusammenhang zwischen dem AT und dem NT zu ersehen. ${ }^{113}$ Bei Melanchthon sind das NT und das AT das Wort Gottes, das eine einheitliche Behauptung hat. Beide Testamente erklären einander und zeigen die Beziehungen zueinander auf. Auf dieser Grundlage legt Melanchthon die Psalmen aus.

\subsubsection{Unterscheidung zwischen dem Evangelium und dem Gesetz}

Das theologische Thema, in dem sich das Verständnis der Heiligen Schrift konkret zeigt, ist die Unterscheidung zwischen dem Gesetz und dem Evangelium, die Melanchthon von Augustin und Luther gelernt hat. ${ }^{114}$

Das Prinzip, Gesetz und Evangelium, funktioniert im PK formal, aber nicht wirklich. Denn Melanchthon ordnet fast alle Psalmen in die Kategorie des Evangeliums ein. Das Gesetz wird noch im PK behandelt. ${ }^{115}$ Aber wenn Melanchthon das Gesetz im PK erklärt, legt er sein Anliegen auf die Kirche. Das Gesetz im PK ist nicht negativ konnotiert. Z.B., die bürgerliche Funktion des Gesetzes ist für die weltliche Regierung, und die Psalmen lehren auch diese Funktion, ${ }^{116}$ aber Melanchthon konzentriert sich allein auf die Beziehung zwischen der Kir-

\footnotetext{
${ }^{110}$ PK. Prol, CR 13, 1016. „Ad Ephesios quarto scribitur, divinitus servari ministerium doctrinae coelestis, et subinde excitari Prophetas, Pastores et Doctores, ne lux doctrinae coelestis, vera invocatio Dei, et veri cultus extinguantur, et totum genus humanum ruat in tenebras, errores et aeternum exitium.“

${ }^{111}$ PK. Prol, CR 13, 1017. „Sit ergo hoc fundamentum enarrationis, quod Psalmi vere sint doctrinae Dei, ut secundae Petri primo de Prophetis dicitur.“

${ }^{112}$ PK. Prol, CR 13, 1017. „sicut Apostoli ex Psalmo 16. confirmant resurrectionem Christi.“

${ }^{113}$ Siehe Kapital 4.4.1.

${ }^{114} \mathrm{Vgl}$. MelStA II/1, S.140. „Solet hic de litera et spritu disputari, de quibus malo vel Augustinum vel Lutherum quam me consuli, quamquam supra etiam in legis ratione attigerim. "Vgl. Peters 1981, S.59. ${ }^{115} \mathrm{Vgl}$. Siehe Kapitel 4.1.3

${ }^{116}$ PK Ps 60, CR 13, 1146. „In aliis regnis ubi erat ignota vera doctrina de Deo, summa ornamenta erant leges, iudicia, mediocris disciplina, praesidia exercituum, opes.“
} 
che und dem Gesetz Gottes. Denn die Psalmen beziehen sich allein auf die Kirche, die die Psalmen liest und hört. ${ }^{117}$ Im PK stellt Melanchthon die Kirche in die Mitte.

Im PK sind Gesetz und Evangelium die bedeutendsten theologischen Kategorien, die auch für die evangelische Theologie bedeutsam sind. Melanchthon erwähnt auch die Wichtigkeit der Unterscheidung zwischen dem Gesetz und dem Evangelium, allerdings spielt die Unterscheidung keine Rolle im PK, weil Melanchthon die Psalmen in der Kategorie des Evangeliums behandelt. Er legt den Hauptpunkt im PK nicht auf die universale Erkenntnis über Gott, sondern auf die besondere Erkenntnis der Kirche, die der Gegenstand der Psalmen ist.

Bei der Funktion des Gesetzes werden usus elenchticus und tertius usus legis behandelt, nicht usus politicus. Wenn Melanchthon das Moralgesetz behandelt, legt er den Hauptpunkt grundsätzlich auf die Funktion, zum Evangelium zu führen, und das Bürgergesetz und das Zeremoniengesetz werden allein auf das Volk Israel angewendet, beide werden durch Christus vollendet und danach abgeschafft. ${ }^{118}$ Dadurch zeigt sich das Anliegen Melanchthons im PK für die konkrete praktische Lehre der Kirche und das Leben der Glieder der Kirche, und diese Tendenz richtet sich selbstverständlich auf tertius usus legis.

Es ist wichtig, dass das Evangelium verheißen ist. Das Subjekt der Verheißung ist Gott und das Objekt ist die Kirche. Das Subjekt wirkt aktiv und das Objekt erhält die Verheißung mit dem Glauben. Der Glaube ist die Methode der Kirche, um die Verheißung zu erhalten. Dieses Prinzip des Evangeliums wirkt nicht nur bei dem Geschehen der Rechtfertigung, sondern auch in) diesem Leben und dem ewigen Leben. Für Melanchthon ist der Glaube das ewige Prinzip für das Leben des Volkes Gottes, in diesem Leben und auch in dem ewigen Leben. ${ }^{119}$ Das Volk Gottes lehnt sich nicht an sich, sondern an Gott an nach dem Prinzip des Evangeliums. Aus diesem Grund ist der Glaube das ewige Prinzip des Lebens der Gläubigen.

\subsubsection{Christus und die Kirche}

Im Mittelpunkt der theologischen Einheit der Heiligen Schrift steht Christus. ${ }^{120}$ Melan-

\footnotetext{
${ }^{117}$ Die Gottlosen lesen das Wort Gottes nicht. Vgl. PK Ps 59, CR 13, 1144. „Haec consolatio cum necessaria sit Ecclesiae, saepe repetitae sunt maledictiones, quae quidem scriptae sunt magis ad consolandos et confirmandos pios, quam ad sanandos impios, qui eas non legunt."

${ }^{118}$ Siehe Kapitel 4.2.5.

${ }^{119}$ Siehe Kapitel 4.6.6.

${ }^{120}$ Vgl. Durch das Priesteramt Melchizedecks ist die Auffassung Melanchthons über die Beziehung Israels zum Messias zu ersehen, dass die ganze Geschichte Israels sich auf den Messias bezieht. Vgl. PK Ps 110, CR 13, 1155. „Sacerdotium Leviticum erat typicum, et desiturum cum politia Moysi, postquam Messias in hac politia exhibitus esset, et sacrificium proprium obtulisset. Ideo enim tota
} 
chthon findet in den Psalmen viele Kontexte, die sich auf den Messias beziehen. Besonders hebt er hervor, dass einige Psalmen sich direkt auf den Messias beziehen. ${ }^{121}$

Außerdem zitiert Melanchthon Textstellen aus dem NT als das Wort Christi. ${ }^{122}$ Und das Wort der Psalmen stimmt mit dem Wort Christi überein. ${ }^{123}$ So beziehen sich die Psalmen für Melanchthon sehr eng auf den Messias. ${ }^{124}$

Bei Luther ist die christozentrische Auslegung ein wichtiges Prinzip. ${ }^{125}$ Und die theologische Beziehung zwischen Melanchthon und Luther ist sehr eng. ${ }^{126}$ Allerdings heißt es bei der Frage, ob Melanchthon in der methodischen Seite der Auslegung Luthers folgt, vorsichtig zu sein.

Wie erwähnt, verbindet Melanchthon im PK viele Psalmen mit Christus. ${ }^{127}$ Betrachtet man die Auffassung Melanchthons über die theologische Einheit zwischen dem NT und dem AT, so ist es berechtigt, die Psalmen mit dem Messias zu verbinden.

Sehr interessant ist es zu sehen, worauf Melanchthon das Gewicht seiner Betrachtungen legt. Melanchthon konzentriert sich im PK nicht auf den Messias selbst, sondern auf die Kirche, die sich auf den Messias bezieht. Der Messias ist der Kopf ${ }^{128}$ und der Eckstein der Kirche. ${ }^{129}$ Die Kirche erhält die Sündenvergebung durch den Messias und erfreut Gott. ${ }^{130}$ Melan-

haec politia constituta fuit, ut esset certa natio, et locus certus, ubi Messias conspiceretur et doceret, et testimonia de doctrina ederet. Ac sacerdotium Messiae perpetuum est, ut postea dicetur: prius enim exponendum est,“

${ }^{121}$ Melanchthon bezieht folgende Psalmen direkt auf den Messias. PK Ps 2, 16, 22, 40, 45, 47, 110 und $117 / 118$.

${ }^{122}$ Z.B. PK Ps 16, CR 13, 1042. „Conveniunt autem illa verba Christi, quae nunc ex Ioanne recitavi, prorsus ad hunc locum huius Psalmi.“

${ }^{123}$ Das AT, das als Propheten bezeichnet wird, hat die wahre Lehre über den Glauben, gleich wie das NT, das als Christus und Apostel bezeichnet wird. Vgl. PK Ps 2, CR 13, 1021. „Sed Prophetae inculcarunt veram de fide doctrinam, et postea Christus et Apostoli.“

${ }^{124}$ Z.B. PK Ps 3, CR 13, 1022. „Redditur nobis vita aeterna, quia Christo redditur, ut infra Psal. 15. diserte inquit, Non relinques animam meam in inferno. Adfirmat Christo reddendam esse vitam, sed simul complectitur se et omnia membra Ecclesiae. Nobis omnibus propter Christum redditur vita."

${ }^{125}$ Beutel sagt, „Die Einheit, dass alles, was die Schrift sagt, auf Christus als deren sachliche Mitte zu beziehen ist, gab Luther zugleich das Kriterium an die Hand, von dem aus biblische Sachkritik nicht nur möglich, sondern auch nötig erscheint.“(Beutel 2005, S.446.)

${ }^{126}$ Vgl. Kapitel 5.1.3.

${ }^{127}$ Vgl. Kapitel 3.1.4.

${ }^{128}$ PK Ps 24, CR 13, 1053. „Orditur autem Ecclesiae descriptionem a capite, scilicet ab ipso Domino Christo,“; PK Ps 117/118, CR 13, 1185. „propter hunc ipsum Messiam, qui hic profitetur se constitutum esse, ut sit caput anguli, id est, ut habeat Ecclesiam, quam non sinat interire.“

${ }^{129}$ PK Ps 117/118, CR 13, 1186. „Considerent autem iuniores figuram, Caput anguli seu lapidem angularem, nominat fundamentum, cui imponuntur anguli, id est diversi parietes, sicut Christo 
chthon schildert ausführlich die Geschenke, die die Kirche durch den Messias bekommt, und die Taten, die die Kirche im Leiden mit dem Vertrauen auf den Messias tut. ${ }^{131}$ Durch die Übereinstimmung von Messias und Kirche zeigt sich kernhaft der Zusammenhang zwischen dem Messias und der Kirche.

In diesem Sinne liegt der Hauptpunkt im PK nicht auf Christus, sondern auf der Kirche. Demnach ist das Objekt der Psalmen die Kirche, und die Psalmen handeln stets von dem Messias in der Beziehung zur Kirche. Die Kirche steht in der Mitte der Psalmen. Deshalb kann man sagen, dass Melanchthon die Psalmen ecclesiozentrisch auslegt.

\subsubsection{David und die Kirche}

Im Mittelpunkt des PKs steht die Kirche. Die Psalmen sind die Lieder der Kirche. Die Kirche zur Zeit Melanchthons stimmt mit dem Volk Israel in der Zeit des ATs und der Kirche der Apostel in der Zeit des NT überein. ${ }^{132}$ Aus diesem Grund sind die Psalmen die lebendigen Lieder der gegenwärtigen Kirche.

Dieser Sachverhalt zeigt sich an der Bedeutung von König David im PK. Melanchthon hält David für den Verfasser der meisten Psalmen. ${ }^{133}$ David erklärt durch die Psalmen, wer Gott ist, was seine Kirche ist, wie er Gott dient und ihn anruft, wie er in diesem Leben leidet, wie er Gott bittet, ihm dankt und ihn lobt. Die Lieder Davids gehören nicht nur zu David selbst, sondern auch zur Kirche. Denn David ist der Repräsentant der Kirche. ${ }^{134}$ Seine Stimme stimmt mit der Stimme der Kirche überein. Seine Lieder sind die der Kirche, seine Erfahrungen sind die der Kirche, und seine Gebete sind die der Kirche. Die Wirkungen Gottes für David sind die für die Kirche, und der Dank und der Lob Davids sind gleich denen der Kirche.

imponitur Ecclesia collecta ex Israël et ex gentibus. Intelligatur autem fundamentum non solum de doctrina, sed etiam de redemtione et de efficacia."

${ }^{130}$ PK Ps 130, CR 13, 1215. „tamen deinceps quoque retinenda est haec consolatio, quod fide propter Filium Dei propiciatorem Deum et hominem habeas remissionem peccatorum, et Deo placeas.“

${ }^{131}$ Vgl. PK Ps 50, CR 13, 1109. „Hoc audias, me qui illustribus testimoniis tibi legem et promissiones tradidi, videlicet Deum esse, et me velle sic coli, audita legis voce me timeas, et auditis promissionibus vera fiducia ad me accedas, me invoces, a me petas et expectes bona propter Mediatorem promissum, et hac fide praelucente, eo ordine praestes opera, ut ego praecepi.“

${ }^{132}$ Die Bewahrung der Kirche ist die Verheißung Gottes. Melanchthon ist davon überzeugt, dass die Kirche seiner Zeit die Kirche ist, die von Gott die Verheißung der Bewahrung erhält. Vgl. PK Ps 60, CR 13, 1148. „Usus igitur hic est Psalmi, ut primum promissione nos sustentemus, quae affirmat Ecclesiam mansuram esse, et vitricem fore, et hac spe perferamus labores docendi.“

${ }^{133}$ Cornil sagt, dass im PK Ps 42 die Ausnahme der von David abweichenden Verfasser hat. (Cornill 1897, S.8.)

${ }^{134}$ Z.B. PK Ps 8, 16, 23, 34, 118 und 131. Vgl. Cornill 1897, S.12f. 
David kommt in den Psalmen der Kirche gleich. Und, wie erwähnt, stimmt die Kirche Davids mit der Kirche der Zeit Melanchthons überein und auch mit der Kirche aller Zeiten. Das ist der Glaube Melanchthons über den Zusammenhang zwischen David und der Kirche in den Psalmen.

Außerdem ist David ein Bild des Messias. In einigen Psalmen spricht David, aber er spricht nicht mit seiner Stimme, sondern mit der Stimme des Messias. Die messianischen Psalmen geben Zeugnis davon. In diesen Psalmen wird erklärt, wer der Messias ist und was der Messias macht. Dadurch können die Hörer der Psalmen die Erlösung für die Kirche richtig verstehen.

Melanchthon sieht also die Übereinstimmung von dem Messias und der Kirche in den Psalmen. Der Messias kommt durch das Medium Davids der Kirche gleich. ${ }^{135}$ Der Messias ist der Eckstein und der Kopf der Kirche, und beide sind eins. Deshalb sind die Gegner der Kirche die Gegner Christi. Wie der Messias in diesem Leben gelitten hat, leidet die Kirche auch. Wie der Messias im Leiden Gott gebeten hat, bittet die Kirche Gott. Wie Gott den Messias bewahrt hat, bewahrt Gott die Kirche. Wie der Messias gesiegt hat, siegt die Kirche. Wie der Messias ewig herrscht, herrscht die Kirche mit ihm ewig.

Im PK ist also die Übereinstimmung zwischen dem Messias und der Kirche ein wichtiger theologischer Grund.

\subsection{Charakter der Exegese}

\subsubsection{Klarheit}

Melanchthon hält die Klarheit für einen wichtigen Charakter der Psalmen. Klarheit meint zunächst, dass ein Psalm einen einfachen Satz besitzt. ${ }^{136}$ So stimmt Melanchthon erstens nicht der Auffassung zu, dass verschiedene Deutungen in einem Psalm bestünden. ${ }^{137}$ Er findet stets einen einfachen Satz mit dem Sinn des Psalms.

Zweitens, nach der Auffassung Melanchthons sind die Psalmen nicht kompliziert und unverständlich. Im PK erwähnt er häufig die Einfachheit von deren Auslegung. ${ }^{138}$ In seinen Erwägungen zeigt sich die Klarheit der Sätze der Psalmen. Die Psalmen können leicht ver-

\footnotetext{
${ }^{135}$ PK Ps 3, CR 13, 1022. „Haec regula in Psalmis observetur, ut sciamus saepe vocem Davidis, simul esse vocem Christi, et econtra vocem esse Davidis seu nostram vocem.“

${ }^{136}$ Vgl. PK Ps 110, CR 13, 1151. „Nec ludendum est variis interpretationibus, sed una simplex nativa sententia, quam efficit grammatica, ..."

${ }^{137}$ Nach Sick zeigt in diesem Punkt Melanchthon einen Unterschied zu Erasmus.(Sick 1959, S.25.)

${ }^{138}$ Vgl. PK Ps 15, CR 13, 1040.; PK Ps 16, CR 13, 1041.; PK Ps 23, CR 13, 1052.; PK Ps 111, CR 13, 1167.; PK Ps 117/118, CR 13, 1184.; PK Ps 131, CR 13, 1216.
} 
standen werden, und die Sätze der Psalmen können einfach gewonnen werden. Man könnte die Kürze der Psalmen als eine Schwierigkeit der klaren Auslegung verstehen. In der Tat sind viele Psalmen kurz, in denen differenzierte Affekte und eine komplizierte Geschichte zu finden sind. Allerdings meint die Kürze der Psalmen keine Dunkelheit in der Deutung der Psalmen, sondern eine Klarheit und Knappheit der Sätze der Psalmen. ${ }^{139}$ Allein für die Philosophen und die Gottlosen sind die Psalmen dunkel. ${ }^{140}$ Die Psalmen sollen also einfach verstanden werden. ${ }^{141}$ Aus diesem Grund zieht Melanchthon lieber die einfache Deutung unter den verschiedenen Deutungsmöglichkeiten vor. ${ }^{142}$

Bei der Auslegung der Psalmen spielt selbstverständlich die Grammatik eine wichtige Rolle. Melanchthon zieht die grammatische Auslegung vor, ${ }^{143}$ kritisiert im PK die Auslegung ohne Berücksichtigung der Grammatik ${ }^{144}$ und fordert die Jugend auf, die Grammatik zu lernen. ${ }^{145}$ So wird im PK die Klarheit der Psalmen betont.

Drittens, durch die Klarheit der Psalmen können das Lesen und das Hören der Psalmen sehr nützlich für die Kirche sein. Dadurch kann die Kirche, der Gegenstand der Psalmen, deren Inhalt leicht verstehen und auf sich anwenden. Deshalb behauptet Melanchthon, dass die Psalmen gelesen werden sollen. ${ }^{146}$ Die Kirche kann durch das Lesen und das Hören der Psal-

\footnotetext{
${ }^{139}$ Vgl. Ahn weist darauf hin, dass das hermeneutische Prinzip, Brevitas et Facilitas sich nicht bei Luther, Melanchthon und Bucer findet, sondern allein bei Calvin.(Ahn 1999, S.271) Aber bei Melanchthon findet sich ein ähnliches hermeneutisches Prinzip. Vgl. PK Ps 50, CR 13, 1110. „Sequitur in eodem particula, quae propter brevitatem obscurior est, sed hae sunt simplicissimae interpretationes.“ ${ }^{140}$ PK Ps 31, CR 13, 1066. „Haec tota doctrina, ut supra dixi, philosophis ignota est, ideo videtur obscurior.“; PK Ps 51, CR 13, 1114. „Haec particula videtur obscura imperitis, qui non existimant iudicari Deum.“"

${ }^{141}$ Vgl. PK Ps 16, CR 13, 1041. „Hanc simplicem enarrationem recensendam esse duxi, quae nec absurda est, nec reddit Palmum obscuriorem.“

${ }^{142}$ Z.B. PK Ps 7, CR 13, 1028. „Etsi autem variae sunt interpretationes, tamen simplicissimam hanc esse iudico."

${ }^{143}$ PK Ps 58, CR 13, 1140. „sed ut hac grammatica enarratione vocabulum fiat notius.“

${ }^{144}$ PK Ps 110 , CR 13, 1152. „Nec ludendum est variis interpretationibus, sed una simplex nativa sententia, quam efficit grammatica,“

${ }^{145}$ PK Ps 110, CR 13, 1161. „hic primum iuniores de Grammatica admonendi sunt.“

146 Vgl. PK Ps 122, CR 13, 1205. „Saepe autem totum hunc Psalmum recitemus, ut his verbis et gratias agamus de conservatione Ecclesiae, et petamus ut conservetur.“; PK Ps 12, CR 13, 1036. „estque saepe recitandus, cum petimus, ut Deus impios doctores compescat, et verae doctrinae lucem accendat ac servet.“
} 
men belehrt werden und reichlichen Trost erhalten. ${ }^{147}$ Die Psalmen sind nicht nur für die Gelehrten, die wissenschaftlich die Psalmen erforschen, sondern für alle Glieder der Kirche von Bedeutung. Insofern sollen die Psalmen nicht spekulativ betrachtet werden, sondern praktisch. Wie die Psalmen von Nutzen für die Kirche sind, so richtet auch Melanchthon den PK auf den Nutzen der Kirche aus.

\subsubsection{Pådagogik}

Wie betrachtet, ${ }^{148}$ wurden die Psalmenvorlesungen von Melanchthon an der Wittenberger Universität gehalten, deshalb ist das pädagogische Element im PK zu beachten. Die Zuhörer der Vorlesungen waren die Studierenden an der Wittenberger Universität, die der zentrale Ort der Reformation war. Der Unterricht erfolgte in der lateinischen Sprache. Der Zeitraum der Vorlesungen zu den Psalmen war bedeutsam für die evangelische Kirche wegen der Niederlage im Krieg. Die Zuhörer der Vorlesungen zu den Psalmen waren keine normale Studierenden, sondern besonders tapfere und im Glauben zuverlässige Personen. Der Professor wollte sie wahrscheinlich ermuntern mit der Stimme der Psalmen.

Die Struktur der Vorlesungen zeigt die pädagogische Absicht Melanchthons. Indem die Argumente und die Gliederungen der Psalmen zusammenfassend betrachtet wurden, konnten die Zuhörer leicht den Plan Gottes und den Trost für die Kirche in den Psalmen finden. Dafür brauchte man keine lange und ausführliche Darstellung, sondern eine klare und deutliche.

Im PK finden sich noch die pädagogischen Elemente. So in der Beachtung der Grammatik bei der Auslegung der Psalmen. Um den Text der Psalmen richtig zu verstehen, ist es notwendig, die Grammatik zu lernen. ${ }^{149}$ Manche lateinische Übersetzungen verhindern die wahre Deutung des Textes, deshalb soll die Sprache der Psalmen gelernt werden. ${ }^{150}$ Und um die Deutungen der Psalmen an das Leben anzuschließen, ist das richtige Verständnis des Textes

\footnotetext{
${ }^{147}$ Vgl. PK Ps 20, CR 13, 1047f. „Erit autem hic Psalmus nobis et magis perspicuus et magis dulcis, si saepe recitabimus, precantes pro politia, et cogitantes de magnis periculis omnium piorum gubernatorum."

${ }^{148}$ Siehe Kapitel 3.1.1

${ }^{149}$ PK Ps 110, CR 13, 1162. „hic primum iuniores de Grammatica admonendi sunt. Lectio in textu hoc narrat, ..."

${ }^{150}$ Z.B. PK Ps 51z, CR 13, 1228. „Phrasin etiam observent iuniores, interpretes usi sunt verbo Asperges, sed in textu est, Fac me peccatorem hyssopo, ut si diceret Latine, Fac me piaculum vel expia me, quod recte interpretamur munda me, tolle reatum peccati, et ita tolle, sanguine scilicet Filii. Hebraicis illa verba sunt mesa ., in bonam et malam partem usurpata iuxta circumstantias."
} 
notwendig. ${ }^{151}$

Zum Zweiten findet sich Melanchthons pädagogisches Anliegen in der Anwendung der Dialektik. Die theologische Grundlage für die Auslegung der Heiligen Schrift soll gelernt werden. Die Deutung kann ohne Begründung nicht bestehen. Deshalb ist der theologische Grundlage von Bedeutung. So findet sich in PK Ps 119 der Satz, „Wer im Gesetz des Herren lebt, ist rein.“ Der Satz soll nicht „,gesetzlich“ verstanden werden, sondern er zeigt das Bekenntnis der reinen Lehre, die durch das guten Gewissen und den Glauben entsteht. ${ }^{152}$ Für die rechte Auslegung soll eine solche Grundlage erreicht werden.

Im PK lehrt Melanchthon diese Gründe, die sich auf Gott und die Beziehung Gottes zur Kirche richten. Diese Gründe spielen im PK in der Dialektik eine Rolle als Prämisse. Daraus leitet Melanchthon in Schlussfolgerungen den Nutzen für die Kirche ab.

Gott wirkt durch die Lehrer und hilft so der Kirche, der von Gott die Segnung gegeben wird. In der Folge ruft die Kirche leidenschaftlich Gott an, und der Glaube und die Hoffnung der Kirche werden fest. ${ }^{153}$

Das pädagogische Interesse Melanchthons zeigt sich drittens im Anschließen der Psalmen an die Situation der Kirche. Melanchthon betrachtet die Handlungen der Kirche in den Psalmen und wendet sie auf die Kirche seiner Zeit an. Die Anwendung der Psalmen auf die Kirche ist dabei kein einmaliges Geschehen, sondern sie soll ständig von der Kirche bedacht und geübt werden. Im PK wendet Melanchthon häufig die Worte, „Übung“, „Erinnerung“ und „Überlegung“. So soll man z. B. die Vorhersage und die Verheißung über den Messias durch

${ }^{151}$ Vgl. PK Ps 110, CR 13, 1151. „Nec ludendum est variis interpretationibus, sed una simplex nativa sententia, quam efficit grammatica, adhibita iudicii dexteritate, retinenda est, quod cum fit magnam dulcedinem et eloquentiam in his carminibus esse intelligemus."

${ }^{152}$ PK Ps 119, CR 13, 1188. „Hic primum monendi sunt iuniores haec verba in toto Psalmo sparsa, Immaculati, ambulantes in lege Domini, custodientes mandata Domini, iustificationes, testimonia, non intelligi nomikw/j de impletione legis, de qua dicitur in Deuteronomio, Maledictus qui non permanet in omnibus his, quae scripta sunt in lege: sed hoc loco et saepe alias loquitur vox divina evangelice de professione incorruptae doctrinae, quae tamen fit fide et bona conscientia, ut Ioan. 14.“

${ }^{153}$ PK Ps 133, CR 13, 1223. „Postrema particula est ratio propositionis, quare concordia bona sit, Quia ibi mandavit Deus benedictionem, et vitam in perpetuum. Iuniores discant phrasin, Deus dicendo efficit, iuxta illud, Dixit et facta sunt, ideo benedictio significat aliquando ubertatem divinitus donatam, hic felices successus quos Deus ipse adiuvat. Ita et verbo mandandi utitur, Deus mandat, id est, suo decreto efficit, ut ibi sint, bonus successus et vita, id est, suavis vita et laeticia in qua invocari Deus et celebrari potest, et promtis animis conferuntur labores: ut cum in exercitu Davidis concordia est, Primum invocatio Dei est ardentior, et minus impediuntur fides et spes, et omnes milites simul libenter perferunt communes labores, et suo quisque loco suam confert operam, et libenter alii aliis opem ferunt, et adest ipse Deus, accendit animos, adiuvat laborantes et addit felices eventus.“ 
den Glauben annehmen. Durch den Glauben nähert man sich der Anrufung. Dies muss man immer in diesem Leben üben. ${ }^{154}$ Dazu sollen die Jungen sich daran erinnern, dass die glücklich sind, die Gott recht anrufen und der Bewahrung der Kirche helfen. ${ }^{155}$ Über den Eckstein der Kirche sollen die Jungen überlegen. ${ }^{156}$

Viertens, die Wiederholung ist eine gute Methode in der Erziehung. Durch die Wiederholung kann man den Hauptpunkt des Textes leicht finden und sich merken. In den Psalmen findet sich die Wiederholung häufig, weil die Psalmen ähnliche Argumente haben. ${ }^{157}$ Melanchthon hält die Psalmen deshalb für eine Lernmethode.

\subsubsection{Anschluss an die Kirche}

Melanchthon legt den Hauptpunkt seiner Auslegung der Psalmen auf die praktische Bedeutung, wie es dem Charakter des Humanismus gemäß ist. ${ }^{158}$ Aber diese praktische Ausrichtung ergibt sich nach Melanchthon aus den Psalmen selbst. Melanchthon glaubt nämlich, dass die Psalmen selbst die Lehre an die Kirche anschließen. ${ }^{159}$ Die Beispiele der Anwendungen der Verheißungen zeigen sich in den Psalmen, dadurch erwartet Melanchthon von seiner Kir-

${ }^{154}$ Vgl. PK Ps 110, CR 13, 1151. „Haec promissio fide accipiatur, ..., ut propter hunc Messiam recipi nos a Deo credamus, et donari his bonis, quae in hoc Psalmo et alibi commemorantur. Hac fide ad Deum accedamus, invocemus eum, et hanc consolationem teneamus, ... Item, Ego vitam aeternam do eis. Tales consolationes intueamur quotidie in invocatione, in nostris et communibus periculis, et sciamus vere nos servari ab hoc Domino, ..., et hac fide accendatur invocatio, et acquiescamus in Deo, ita sentiemus nos vere vivificari et iuvari. Haec exercitia magis illustrant conciones propheticas, quam longi commentarii.“

${ }^{155}$ PK Ps 112, CR 13, 1175. „Itaque in hoc Psalmo inter magna bona recitatur felix posteritas, et in primis in Ecclesia dulce est habere tales posteros, qui recte Deum invocent, et adiuvent conservationem Ecclesiae, sicut Abrahae successit Isaac.“

${ }^{156}$ PK Ps 117/118, CR 13, 1185. „Considerent autem iuniores figuram, Caput anguli seu lapidem angularem, nominat fundamentum, cui imponuntur anguli, id est diversi parietes, sicut Christo imponitur Ecclesia collecta ex Israël et ex gentibus.“

${ }^{157}$ Z.B. PK Ps 115, CR 13, 1181. „Saepe repetita sunt eadem pavqh, ut fit, et invocatio similis in talibus aerumnis affert lucem Psalmo.“; PK Ps 115, CR 13, 1181. „In his verbis mente repetamus totam doctrinam promissionum de Mediatore et de gratia, et sciamus fidem oportere niti non nostra dignitate, sed sola misericordia propter Filium promissa, ...“;PK Ps 117/118, CR 13, 1184. „Saepe repetita est praecipua pars narrationis, in qua affirmat Christus se et passum et servatum esse, ..."; PK Ps 119, CR 13, 1199. „Et crebro repetita est haec precatio in hoc toto Psalmo.“

${ }^{158}$ Die Dialektik des Mittelalters konzentriert sich auf eine detaillierte Semantik und interessiert sich nicht dafür, wie die Sache im Alltag angewendet und betrachtet wird.( Wels 2001, S.445.)

${ }^{159}$ PK Ps 16, CR 13, 1041. „De applicatione incipit concionari in tertio versu, ..."; PK Ps 45, CR 13, 1093. „de applicatione concionatur, ...“; PK Ps 51, CR 13, 1115. „mors Christi praedicatur per Evangelium, et minister est hyssopus per Evangelium communicans cinerem, id est, mortis Christi efficaciam nobis applicans." 
che ähnliche Ergebnisse. Deshalb sind diese Beispiele für die Anwendung in der Kirche bestimmt. Wie Abraham, Joseph und David von Gott geholfen worden ist, so wird auch der Kirche der Zeit Melanchthons von Gott geholfen. ${ }^{160}$ Obwohl die Kirche im Leiden ist, hilft Gott der Kirche und das Leiden wird gemildert. Diese Beispiele stehen für die Anwendung in der Kirche und für den Trost der Kirche. ${ }^{161}$ Wie die Verfasser der Psalmen erhört und befreit worden sind, werden die Hörer auch erhört und befreit. Deshalb sollte die Verheißung der wahren Lehre nicht verachtet werden, ${ }^{162}$ sondern durch den Glauben getragen werden. ${ }^{163}$ Die Psalmen zeigen die Beispiele der Freiheit, und so kann die Kirche sich überzeugen. Die Lehre der Anwendung der Beispiele ist immer nötig in den ähnlichen Angelegenheiten der Kirche. ${ }^{164}$

David bekennt die Gerechtigkeit seines Gewissens, dann behauptet Melanchthon, dass wir auch mit dem gleichen Wort und Affekt darum bitten sollen. So schließt Melanchthon die Psalmen an die Gefahr seiner Kirche an. ${ }^{165}$ Dazu behauptet er, dass die Anwendung der Psalmen auf sich selbst größeres Licht in der Anrufung bringt als das Lesen der vielen Kommentare. Man soll durch die Lehre über die Verheißung den Glauben und die Hoffnung sehen und sich davon überzeugen, dass die Gnade für alle generaliter verheißen ist. ${ }^{166}$ Melanchthon behauptet, dass durch den Dienst des Evangeliums die Geschenke des Sohnes Gottes an die

\footnotetext{
${ }^{160}$ PK Ps 34, CR 13, 1069. „Etiamsi Abraham, Ioseph, David adiuti sunt, tamen non sequitur caeteris similia beneficia expectanda esse. Imo, inquit hic Psalmus, similia beneficia caeteri omnes expectent, qui Deum vere invocant, et ad eum confugiunt.“

${ }^{161}$ PK Ps 27, CR 13, 1059. „Ideo fidem suam ipse commemorat, ut exemplo suo nos admoneat de applicatione, et de expectanda consolatione:“"

162 PK Ps 31, CR 13, 1064. „non abiicite promissionem verae doctrinae, ...“

${ }^{163}$ PK Ps 34z, CR 13, 1242. „Doctrina est de applicatione promissionum, quasi dicat, antea proposui exemplum meae liberationis, et adiungo promissiones, quas affirmo ad vos quoque pertinere, sed oportet vos converti ad Deum, et fide amplecti promissionem, expresse igitur ponitur applicatio huius beneficii.“

${ }^{164}$ Vgl. PK Ps 56, CR 13, 1132. „sicut saepissime inquit, hanc ipsam ob causam se praedicare haec Dei beneficia, ut alii ad agnitionem Dei, timorem, fidem et spem invitentur, et expectent similes liberationes,"

${ }^{165}$ PK Ps 7, CR 13, 1029. „considerata hac argumenti expositione et applicatione ad nostra pericula. Ut David titulum fecit ignorantia, id est, inficiatio calumniae: ita nos inscribamus nobis hunc titulum, depulsio calumniae, videlicet per inficiationem, et per precationem, qua Deum oremus, ut ipse nos a sycophantis liberet, ne ministerium Evangelii deleatur."

${ }^{166}$ PK Ps 57, CR 13, 1135. „Haec doctrina de promissionibus, fide et spe semper luceat in mentibus, et quoties in Psalmis petimus, ut nostri misereatur Deus, intueamur promissiones, et statuamus misereri eum nostri propter Filium gratis, et misericordiam universaliter omnibus promissam esse.“
} 
Gläubigen angewendet werden. So wirkt der Sohn Gottes. ${ }^{167}$ Gott vergibt die Sünde, nimmt die Sünder an und freut sich darüber. Diese Lehre ist universal, deswegen soll diese auch auf andere angewendet werden. ${ }^{168}$ Aber besonders soll diese Lehre auf die Kirche angewendet werden, um die Menschen zu den Kindern Gottes und mit dem Glauben zur Anrufung einzuladen und um den Trost zu erhalten. ${ }^{169}$ Dieser Gedanke kommt aus der Überzeugung, dass die Verheißung der Psalmen zur Kirche gehört. ${ }^{170}$

${ }^{167}$ PK Ps 51z, CR 13, 1228. „Conspersio vero per hyssopum, significat ministerium Evangelii, per quod applicantur beneficia Filii Dei credentibus, et ipse Filius Dei est efficax, sicut mox in sequenti versu de ministerio loquitur.“

${ }^{168}$ PK Ps 31z, CR 13, 1036. „sed remissione peccatorum. Iam rursus applicat doctrinam ad caeteros, ..."

${ }^{169}$ PK Ps 34z, CR 13, 1241. „etiam exempli causa celebro beneficium Dei, ut alii invitentur ad agnitionem Dei, fidem, et invocationem et erigantur consolatione, et salvi fiant.““

${ }^{170}$ PK Ps 46, CR 13, 1095. „Psalmus et promissiones semper principaliter de Ecclesia loquuntur, id est, de coetu puram Evangelii vocem sonante, et recte Deum invocante.“ 


\section{Theologie Melanchthons im PK}

\subsection{Gott, der sich der Kirche offenbart.}

\subsubsection{Gott, der sich auf die Kirche bezieht.}

Bei der Betrachtung der Theologie Melanchthons im PK gehe ich von der Gotteslehre aus, wie seine Loci. Melanchthon sagt, dass die Psalmen die Lehre Gottes sind. ${ }^{171}$ In den Psalmen offenbart Gott sich selbst und seinen Willen für seine Geschöpfe. Dazu gibt es bei der Offenbarung Gottes einen bestimmen Adressaten. Die Offenbarung geschieht allein an diesen Adressaten, nämlich an die Kirche. Deswegen kann die Gotteslehre immer in dieser Offenbarung betrachtet werden, die an die Kirche ergeht. Aus diesem Grund deutet Melanchthon Gott im PK immer im Hinblick auf die Beziehung Gottes zur Kirche, sodass diese für seine Auslegung der Psalmen vorausgesetzt wird.

Melanchthon bemerkt die Außergewöhnlichkeit Gottes im PK. Gott ist der ewige und allmächtige Gott. Er schuf die Welt durch das Wort ${ }^{172}$ und unterscheidet sich von den Geschöpfen und anderen Göttern, die von Menschen gebildet werden. ${ }^{173}$ Gott ist als Schöpfer größer als seine Geschöpfe, die von sich aus Gott nicht erfassen können, sondern von Gott erfasst werden. Dieser Unterschied impliziert also die Möglichkeit einer Gotteslehre allein durch die Offenbarung Gottes. Deshalb schneidet Melanchthon die Offenbarung Gottes insbesondere auf die Kirche zu. Gott offenbart sich besonders an Israel, ${ }^{174}$ das Melanchthon mit der Kirche identifiziert. ${ }^{175}$ So setzt sich Gott mit der Kirche durch seine Offenbarung in Beziehung.

Melanchthon erkennt eine andere Möglichkeit der Gotteserkenntnis an, nämlich einen solche durch die Schöpfung in der Welt induziert. Er sagt, dass die Ordnung der Welt ein Zeugnis für das Dasein Gottes ist und dass die Welt nicht zufällig existiert. ${ }^{176}$ Aber diese Gotteserkenntnis in der Welt ist nicht vollständig, und die Welt ist von der wahren Erkenntnis Gottes abgewichen, nachdem die Sünde in die Welt eingegangen ist. Sie bildete ein Wesen,

\footnotetext{
${ }^{171}$ PK. Prol, CR 13, 1018. „quod Psalmi vere sind doctrinae Dei, ...“

${ }^{172}$ Vgl. PK Ps 33,8, CR 13, 1068. „Verbo Domini coeli facti sunt.“

${ }^{173}$ PK Ps 121,2, CR 13, 1203. „discernebatur verus Deus ... a commentitiis numinibus ...“

${ }^{174}$ PK Ps 25, CR 13, 1055. „qui se patefecerat in Israël.“

${ }^{175}$ Bei Melanchthon ist das Volk Israel im AT gleich mit der Kirche. Vgl. PK Ps 7, CR 1028. „et hostem Israëlitarum, id est, verae Ecclesiae.“

${ }^{176}$ Vgl. PK Ps19, CR 13, 1045 „Deum agnosci ex creatione, ex motibus coelestibus, et ordinatis temporum vicibus, quae certe sunt testimonia de mente aeterna architectatrice, et ostendunt mundum non extitisse casu ..."
} 
das kein Gott ist, um diesem Wesen zu dienen. ${ }^{177}$ Dies ist kein wahres Anbeten, wie es von Gott gefordert wird, sondern die Welt begeht Frevel, die Gottes Zorn verursachen. Melanchthon bezieht die bleibende Gotteserkenntnis auf das Moralgesetz: „Gib, und es wird euch gegeben. “178 Dieses Prinzip fordert immer den vollkommenen Gehorsam. ${ }^{179}$ Wer dem Gesetz Gottes vollkommen gehorcht, werde das ewige Leben und die ewige Seligkeit als Lohn verdienen. Aber niemand kann das Gesetz in Gänze befolgen. ${ }^{180}$ Zur Folge gibt es eine Strafe für sie. Für die Sünder bleiben vor dem gerechten Gott nur das Gericht und die ewige Strafe. ${ }^{181}$ Melanchthon weist darauf hin, dass die menschliche Ratio und das Gesetz sagen, dass die elenden unterdrückten Menschen durch die Leiden von Gott abgewiesen werden. ${ }^{182}$ Deshalb wissen auch die Weisen der Welt um Gottes Zorn gegenüber den Sündern, die nicht nach dem Gesetz leben, und sie haben Angst davor. ${ }^{183}$ Die Erkenntnis Gottes ohne die Offenbarung Gottes ist unvollkommen und nicht ausreichend für die Erlösung. Bei Melanchthon gibt es keine Möglichkeit der wahren Gotteserkenntnis ohne die Offenbarung Gottes. ${ }^{184}$

Melanchthon findet in den Psalmen eine andere Lösung für die wahre Erkenntnis Gottes und die Erlösung der Menschen. Dabei werden die Werke Gottes betont. Gott sammelt eine Gruppe und verheißt eine besondere Beziehung zu ihr. Er überliefert der Gruppe sein Wort über die Erkenntnis Gottes und über die Sündenvergebung und bewahrt es durch diese Gruppe. Diese Erkenntnis wurde dieser Gruppe als eine Verheißung gegeben, schon nachdem Adam und Eva in Ungehorsam gefallen waren. ${ }^{185}$ Dadurch zeigt Gott ihr die Gnade der Sündenvergebung und lässt sie sich im Glauben nahekommen, ${ }^{186} \mathrm{um}$ ihn anzurufen und zu

\footnotetext{
${ }^{177}$ Vgl. PK Ps 117/118,13, CR 13, 1187 ,gentium numina sunt commentitia, ...“

178 PK Ps 130, CR 13, 1215 „Date et dabitur vobis.“

${ }^{179}$ PK Ps 25, CR 13, 1054 ,quia lex semper postulat conditionem perfectae obedientiae.“

${ }^{180}$ Vgl. PK Ps 14, CR 13, 1037 „cum legi nemo satisfaciat, ...“

${ }^{181}$ PK Ps 39, CR 13, 1079. ,impii vero deinde futuri sint in aeternis poenis.“

182 PK Ps 51z, CR 13, 1232. „Nam ratio et lex dicunt, homines miseros et oppressos doloribus reiectos esse a Deo.“

${ }^{183}$ Vgl. PK Ps 112, CR 13, 1174. „Etiamsi Aeacus aut Numa sunt honesti viri, et timent iram Dei, ...“ ${ }^{184}$ Vgl. Heubtartikel, S.68f. „Nach dem ich nu ernnert, das mann gottes erkenntnus in seinen offembarungen und seinen klaren, ausgetrukten reden suchen soll und die selbige mit festem glauben in demut annemen, und habe gesagt, das menschliche vernunfft one gottes wort in grosser blintheit und zweifel steket, sollen wir nu erstlich merken, was Gott ist und was man allein gottlich wesen nennen soll und mit warheit nennet.“

${ }^{185}$ Vgl. PK Ps 110, CR 13, 1151. ,promissio de hoc ipso redemtore statim initio cum recepti sunt Adam et Eva, tradita est, “

${ }^{186}$ PK Ps 112, CR 13,1178. „et primum accipit remissionem peccatorum, ... Fide accedimus ad Deum.“
} 
verehren. ${ }^{187}$ Melanchthon sagt, dass die Gruppe, die Gott besonders um sich sammelt, die Kirche ist.

Insofern ist für Melanchthon eine besondere Beziehung Gottes zur Kirche von Bedeutung. Diese Beziehung ist auch in den Bezeichnungen der Kirche im PK zu ersehen. Zur Bezeichnung der Kirche verwendet Melanchthon verschiedene Ausdrücke, z.B. die Gläubigen, die von Gott gesammelte Gruppe, das Volk Gottes, das Haus Gottes und das Reich Gottes. Die Kirche wird immer in der Beziehung zu Gott dargestellt. Die Kirche wird von Gott gestiftet und gesammelt. Und umgekehrt kann Gott allein durch die Kirche wahrhaft erkannt werden, weil Gott die wahre Erkenntnis Gottes nur in der Kirche bleiben lässt.

In diesem Punkt unterscheidet Melanchthon die Kirche von den Heiden. Die Heiden haben keine wahre Gotteserkenntnis. Wenn auch sie noch etwas wahre Erkenntnis haben, ist ihre Erkenntnis nicht rein und nicht hinreichend als die wahre Erkenntnis Gottes, um Gott zu dienen und vor Gott gerecht zu werden. Der Mensch allein kann Gott nicht wahrhaft erkennen, sondern Gott gibt und bewahrt die Erkenntnis über sich. Das ist die einzige Möglichkeit der wahren Erkenntnis Gottes, die allein in der Kirche bleibt.

So betrachtet Melanchthon Gott in der Beziehung zur Kirche. Für Melanchthon ist Gott kein Gegenstand eines spekulativen Gedankens der Welt. ${ }^{188}$ Gott redet zur Kirche, und die Kirche hört seine Rede. Gott überliefert der Kirche seine wahre Erkenntnis, und die Kirche erhält sie und bewahrt sie. Gott wird nur durch seine Offenbarung Gottes in der Kirche wahrhaft erkannt, besonders in der Beziehung zur Kirche.

\subsubsection{Gott, der Dreieinige}

Wie geschrieben betrachtet Melanchthon Gott nicht spekulativ, sondern er richtet seinen Blick immer auf die Wirkung Gottes in der Beziehung zur Kirche. Deshalb ist es zu sagen, dass Melanchthon im PK den Nutzen für die Kirche in den Mittelpunkt seiner Betrachtungen stellt. Er erläutert die Lehre über Gott in seiner Auslegung nicht theoretisch, sondern prak-

\footnotetext{
${ }^{187}$ Vgl. PK Ps 25, CR 13, 1055. „fide eius verbi ipsum invocat et eum colit.“

${ }^{188}$ Vgl. Brül sagt von der Gotteslehre Melanchthons, „ein „Gott an sich“ liegt außerhalb seines Interessenfeldes, sein Grundanliegen ist der „Gott für uns“, und Melanchthon geht stets von der Erfahrung und vom konkreten Menschen aus.“ Brüls 1975 Es ist klar, dass Melanchthon nicht von Gott an sich ausgeht, weil nach seinem Gedanken nur durch die Offenbarung die wahre Erkenntnis Gottes erreicht werden kann. Aber Brül übergeht, wem Gott sich offenbart. Nach Melanchthon offenbart Gott sich nicht einfach dem Menschen, sondern der Kirche, die von Gott selbst erwählt und gesammelt wird, um die wahre Gotteserkenntnis und die Rettung zu bewahren._Außerdem erwähnt Strohm den Begriff religio in der Beziehung zwischen Gott und Menschen als eine Gemeinsamkeit zwischen Melanchthon und Calvin. Strohm 2009
} 
tisch, indem er die Beziehung Gottes zur Kirche erklärt. Die Wirkung Gottes enthüllt die Eigenschaften Gottes und damit betet die Kirche Gott an. ${ }^{189}$ So lässt sich Melanchthons Gottesverständnis deutlich aus seinem Dankgebet zum Dreieinigen Gott ersehen, das in seiner Auslegung von Psalm 111 liegt. ${ }^{190}$

Melanchthon geht von der Dreieinigkeit Gottes aus. Die erste Peron ist der ewige und allmächtige Vater. Er ist der Schöpfer, der Erhalter von der Welt und der Kirche, der Richter und der Freilassende. Er schickte seinen Sohn, um sein Volk zu retten, und sendet seinen Geist aus ihm. Er sammelt die Kirche mit der Stimme des Evangeliums, vergibt die Sünden um seines Sohnes willen und bewahrt die Kirche. ${ }^{191}$ Die zweite Person ist der ewige und allmächtige Sohn, der vom ewigen Vater ausgeht. Er ist das Ebenbild des Vaters und das Wort. Er offenbart den Vater. Die Person des Sohnes unterscheidet sich von der Person des Vaters. Als Vermittler zwischen dem Vater und der Kirche nimmt der Sohn die menschliche Natur an. ${ }^{192}$ Die dritte Person ist der Heilige Geist. Er geht aus dem Vater und dem Sohn hervor. ${ }^{193}$ Er wird der Geist Gottes genannt. ${ }^{194}$ Durch ihn entzünden sich die Anrufung und die Freude ${ }^{195}$, und der Heilige Geist regiert die Kirche. ${ }^{196}$

Melanchthon stellt die erste Person als den Herrn der Kirche und das Subjekt der Erlösung in seiner Beziehung zur Kirche vor. Die zweite Person spielt eine Rolle als der Vermittler und der Ausführende des väterlichen Planes für die Erlösung der Kirche. Die dritte Person wird als der Anwender des Werkes Christi auf die Mitglieder der Kirche bezeichnet. Melanchthon versteht die Dreieinigkeit in den Wirkungen der drei göttlichen Personen in der Beziehung zur Kirche.

Außerdem betrachtet Melanchthon die Unterschiede der göttlichen Personen überhaupt in ihren Wirkungen in Bezug auf die Kirche. Der Vater ist der Herr der Kirche und der Welt.

\footnotetext{
${ }^{189}$ Jung erklärt in diesem Sinn „die Gleichrangigkeit von Gotteserkenntnis und Gottesanbetung und damit die Gleichrangigkeit von Lehre und Gebet, von Theologie und Frömmigkeitspraxis." Jung 1998 ${ }^{190}$ PK Ps 111, CR 13, 1168. Die durch drei Teile getrennte Form des Gebetes findet sich immer wieder bei den Schriften Melanchthons. Jung 1998

${ }^{191}$ PK Ps 111, CR 13, 1168.

192 PK Ps 111, CR 13, 1168.

${ }^{193}$ PK Ps 111, CR 13, 1169.

${ }^{194}$ PK Ps 51, CR 13, 1177.

195 PK Ps 130, CR 13, 1214. „et accendit hanc invocationem et laeticiam Spiritu suo sancto, ...“

${ }^{196}$ PK Ps 111, CR 13, 1169. , „regis nos, ...“
} 
Der Sohn ist der Sohn des ewigen Vaters, nimmt die menschliche Natur an ${ }^{197}$ und wurde der Fürbitter und Vermittler der Kirche als Gottmensch. ${ }^{198}$ Der Heilige Geist wird den Gläubigen geschenkt. ${ }^{199}$ So folgt die Trinitätslehre Melanchthons im PK der traditionellen Auffassung über den Dreieinigen Gott. ${ }^{200}$

Diese Gotteslehre ist für Melanchthon nur in der Kirche recht von Bedeutung, weil die wahre Gotteserkenntnis durch das Wort Gottes der Kirche überliefert wird. Deshalb kann nur die Kirche wahrhaft Gott erkennen, ehren, anrufen und ihm dienen. ${ }^{201}$ Die Anrufung in der wahren Kirche, die auf der wahren Gotteserkenntnis und auf dem Versprechen Gottes beruht, unterscheidet sich deutlich von der Anrufung in den Heiden, weil sie um keine Verheißung der Sündenvergebung wissen. ${ }^{202}$

\subsubsection{Gott, der Gerechte}

Die Gerechtigkeit Gottes ist im PK als ein wichtiges Thema zu erwähnen. Denn die Eigenschaft der Gerechtigkeit Gottes ist dabei vorausgesetzt, wenn Gott durch die Sündenvergebung zu sich die Kirche sammelt. Gott, der gerecht ist, schuf die Menschen als die Gerechten. Die Menschen sollen das Gesetz Gottes halten, nämlich die Liebe zu Gott und den Nächsten. Gott schuf das Menschengeschlecht so. ${ }^{203}$ Dazu bedeutet für Melanchthon die gerechte Handlung, die Dienste und Werke nicht durch sich selbst zu bilden, sondern die Dienste und Werke zu tun, die von Gott überliefert werden. ${ }^{204}$ Deshalb ist die gerechte Handlung im Gesetz und Dienst, die von Gott gegeben sind, zu bleiben. Diese Erkenntnis über das Gesetz und den Dienst wurde der Kirche von Gott durch sein Wort überliefert. Hier verbindet Melan-

\footnotetext{
${ }^{197}$ Vgl. PK Ps 110, CR 13, 1169. „,veniet ex utero Messias, videlicet ex virgine, ...“ und vgl. PK Ps 51z, CR 13, 1228. „ut Augustinus inquit ... ut sit homo, aliter ut sit cum homine.“

${ }^{198}$ Vgl. PK Ps 121, CR 13, 1203. „et nitatur precatio Mediatore et intercessore Filio.“

${ }^{199}$ PK Ps 45, CR 13, 1092-1093. „et donet illis etiam Spiritum sanctum, ...“

${ }^{200}$ Vgl. PK Ps 51z, CR 13, 1228. Da zeigt sich die Übereinstimmung Melanchthons mit Athanasius und Augustin.

${ }^{201}$ Vgl. PK Ps 110, CR 13, 1154. „Meminerimus igitur hic significari veros cultus Dei qui sunt in sola Ecclesia,..."

${ }^{202}$ Vgl. PK Ps 50, CR 13,1109. „,sed ut sint signa promissionum vere credenti: deinde ut sint signa professionis, quae discernant Ecclesiam ab ethnicis. Imo cum non accedunt, vera fides, et obedientia moralis, et existimantur mereri remissionem peccatorum, nihil differt talis cultus ab ethnico.

${ }^{203} \mathrm{Vgl}$. PK Ps 133, CR 13, 1220, „Notum est autem totam legem praecipere de dilectione Dei et proximi, quia Deus ita condidit genus humanum, ...“

${ }^{204}$ PK Ps 15, CR 13, 1040. „Est igitur faciens iusticiam, non fingens cultus aut opera per sese: non faciens cultus aut opera non tradita a Deo, sed faciens iusticiam, id est, cultus et opera a Deo tradita.“
} 
chthon die Gerechtigkeit mit der Kirche als dem Ort, an dem Gott bleibt. ${ }^{205}$ Gott ist in der gerechten Versammlung, nämlich in der Kirche. ${ }^{206}$

Dazu bezieht Melanchthon die Gerechtigkeit Gottes auf die Sünde, weil es Sünde ist, nicht im Gesetz Gottes zu bleiben. Gott erinnert sich an die Sünde und richtet und urteilt die Sünder. ${ }^{207}$ Sein Zorn gegen die Sünde ist gerecht. ${ }^{208} \mathrm{Um}$ sich vor Gott stellen zu können, muss man die Gerechtigkeit haben. Allerdings besitzt niemand die Gerechtigkeit vor Gott nach dem Sündenfall. Als Folge erwähnt Melanchthon das Gericht Gottes, das Gericht findet statt, sowohl in diesem Leben als auch nach diesem Leben, obwohl die Menschen das Gericht Gottes verleugnen. ${ }^{209}$ Für die Sünde bleibt nur die ewige Strafe. ${ }^{210}$ Hier ist die Auffassung Melanchthons über die allgemeine Situation der Menschen vor dem Zukommen der Gerechtigkeit Gottes zu ersehen, nämlich dass die Menschen Sünde haben und vor dem Gericht Gottes als Sünder dastehen. ${ }^{211}$ Darin findet Melanchthon den göttlichen Heilswillen. Gott wünscht nicht, dass alle Menschen mit dem ewigen Tod verurteilt werden. Stattdessen wählt er die Kirche für die Erlösung. ${ }^{212}$

Dann verbindet Melanchthon die Frage, wie die Erlösung mit der Gerechtigkeit Gottes übereinstimmen kann, mit der Wirkung der zweiten Person, Der ewige gerechte Vater offenbart sich und seinen Willen für die Erlösung der Kirche durch die Sendung von Jesus Christus. ${ }^{213}$ Hier gehört der Wille für die Erlösung zum Vater und deren Ausführung zum Sohn.

${ }^{205}$ Vgl. Nach der Auffassung Sicks ist die Kirche im Psalmenkommentar Melanchthon der Ort, wo das Wort Gottes ist und wo die wahre Anwendung des Wortes besteht. Sick 1959, S.83f.

${ }^{206}$ PK Ps 14, CR 13, 1038. „Deus est in generatione iusta, id est, in coetu iusto:“

${ }^{207}$ Vgl. PK Ps 52,7, CR 13, 1120. ,sed est commonefactio de iudicio Dei, qua Deus ostendit se non esse oblitum delicti, ut alii metuant futurum iudicium, ..."

${ }^{208}$ Vgl. PK Ps 28, CR 13, 1059. Deplorant suam immunditiem, agnoscunt iustam iram Dei, sentiunt poenas, fatentur poenas minores esse suis peccatis, ...“

${ }^{209}$ Vgl. PK Ps 49, CR 13, 1106. ,sed volunt praesenti vitae consulere, huic quaerunt praesidia, hanc muniunt, et eam anteferunt voluntati Dei, quasi doctrina de vita aeterna, et futuro iudicio sit inanis fabula, ...“

${ }^{210}$ PK Ps 39, CR 13, 1079. ,impii vero deinde futuri sint in aeternis poenis.“

${ }^{211}$ Der Gedanke Melanchthons über die Sünde folgt Augustin(Löhr 2007) und Luther.(Lohse 1995)

${ }^{212}$ PK Ps 25, CR 13, 1055. „Noluisti genus humanum totum perire, sed excerpsisti tibi Ecclesiam, ...“

${ }^{213}$ Vgl. PK Ps 111, CR 13, 1168. „quod revelasti te nobis, aeternum patrem Domini nostri Iesu Christi, et Iesum Christum Filium tuum, et Spiritum sanctum, et quod misisti Iesum Christum Filium tuum, et voluisti eum pro nobis esse victimam, colligis tibi aeternam Ecclesiam voce Evangelii inter nos, remittis nobis peccata, ...“; PK Ps 51z, CR 13, 1228. „Simul autem cum hac voce ipse Filius Dei dicit verbum in corde tuo, remittuntur tibi peccata, quo verbo te vivificat. Sic enim congruunt actiones Filii et Spiritus sancti in homine, Filius dicit verbum quo ostendit voluntatem patris, ..." 
Melanchthon bringt in anderen Worten zum Ausdruck, dass die Kirche die Stimme des Evangeliums aus dem Schoß des Vaters durch den Sohn hört. ${ }^{214}$

Bezüglich der Wirkung des Sohnes stellt Melanchthon die zwei Ämter des Sohnes auf. Der Vater ordiniert seinen Sohn zum Priester und König. ${ }^{215}$ Durch das Opfer des Messias für die Kirche wurde der Zorn Gottes versöhnt. ${ }^{216}$ Der Vater begnügt sich mit dem Werk des Sohnes, des Vermittlers, und die Kirche erhält darauf die Sündenvergebung und die Liebe des Vaters wieder. ${ }^{217}$ Und als der König regiert der Sohn.

In dieser Weise sammelt der Vater die Kirche um sich und schenkt ihr die Sündenvergebung und den Heiligen Geist. ${ }^{218}$ So mischt Melanchthon die Wirkung des Heiligen Geistes mit den Wirkungen des Vaters und des Sohnes in der Erlösung der Kirche. Im Herzen des Heiligen Geistes atmen der Vater und der Sohn. So wohnt Gott in der Kirche. ${ }^{219}$ Melanchthon denkt, dass in dieser Weise die Kirche Gott anrufen kann und dass Gott ihr Gebet erhört. Bei Melanchthon spielt die Gerechtigkeit eine Schlüsselrolle für die Erlösung und die Wirksamkeit des Dreieinigen. Ohne die Gerechtigkeit kann die Erlösung nicht erklärt werden.

\subsubsection{Gott, der die menschliche Natur annimmt.}

Nach der Auffassung Melanchthons wirkt der Dreieinige für die Erlösung zusammen, aber in einer bestimmten Phase kommt eine Person deutlich vor. Insbesondere bei der Ausführung der Erlösungstat ist die Wirkung des Sohnes deutlich. Der Sohn ist ewiger und allmächtiger Gott und das Ebenbild des Vaters. Melanchthon konzentriert sich auf das Erlösungswerk des Sohnes in der Welt. Der Sohn wurde von dem Vater zur Welt geschickt und offenbart den Vater. Indem der Sohn die menschliche Natur annimmt, wird er nach der Voraussage Gottes als ein Nachkomme von David geboren. Trotzdem existiert er vor der Geburt Abrahams. ${ }^{220}$ Auch nach der Annahme der menschlichen Natur hat er noch die göttliche Natur, er ist Gott. ${ }^{221}$ So wirkt der Sohn selbst als Gottmensch für die Erlösung. Und der Sohn

\footnotetext{
${ }^{214}$ PK Ps 133, CR 13, 1222. „Filium Dei, per quem vox Evangelii ex sinu aeterni patris prolata est, ..."

${ }^{215}$ PK Ps 45, CR 13, 1092. „,ideo aeternus pater Filium misit, et ordinavit ad hoc sacerdotium et regnum, ..."

${ }^{216}$ PK Ps 110 CR 13, 1166. „sacrificio ipsius placatam esse iram aeterni patris, ...“

${ }^{217}$ PK Ps 119, CR 13, 1189. „Pater remittet peccata, diliget nos, ...“

${ }^{218}$ PK Ps 111, CR 13, 1168. „remittis nobis peccata, donas nobis Spiritum sanctum, ...“

${ }^{219}$ PK Ps 119, CR 13, 1189. ,et efficiemur domicilium divinitatis.“

${ }^{220}$ PK Ps 110, CR 13, 1156. „Antequam Abraham natus est, ego sum.“

${ }^{221}$ PK Ps 16, CR 13, 1041. „quia divina natura non discessit a corpore Christi.“
} 
herrscht als Gottmensch nach der Himmelfahrt mit der gleichen Vollmacht wie der Vater. ${ }^{22}$ Im PK betrachtet Melanchthon den Sohn mit seinen Wirkungen in der Beziehung zur Kirche generell als Gottmensch.

Im PK ist die Wirkung des Sohnes als Gottmensch bei der Sündenvergebung deutlich. Melanchthon sagt von den messianischen Verheißungen der Psalmen, wer der Messias ist und welche seine Wohltaten sind. ${ }^{223}$ Deshalb ist diese Vorstellung des Messias nicht neu, als der Sohn die menschliche Natur annimmt, nämlich nach der Geburt Jesu Christi, sondern er existiert schon als der Bewahrer der Kirche. ${ }^{224}$ Dieser Messias wirkt aktiv bei der Sündenvergebung. Nach der Auffassung Melanchthons kann man die Sündenvergebung allein durch den Glauben an die Verheißung Gottes erlangen, die auf den Vermittler, den Sohn Gottes bezogen wird. Der Trost der Sündenvergebung durch die Verheißung entsteht um des Sohnes Gottes willen. ${ }^{225}$ Durch den Glauben an den Sohn, den Versöhner, der Gottmensch ist, ist die Sündenvergebung möglich. ${ }^{226}$ Melanchthon erklärt, dass dieses Prinzip auf alle Menschen nach dem Fall Adams angewendet wird, ${ }^{227}$ indem er doch auf die Unfähigkeit der menschlichen Vernunft hinweist, die die Offenbarung über den Gottmenschen und die Sündenvergebung nicht verstehen kann. Aus diesem Grund kreuzigten die Juden den Messias. ${ }^{228}$

Außerdem betont Melanchthon die Wirkung des Sohnes als des Vermittlers. Der Sohn Gottes wird Mensch, um der Vermittler zwischen Gott und der Kirche zu werden. Er wirkt als Vermittler von Anfang an. Nach dem Fall von Adam und Eva wurde zugleich die Verheißung über den Samen der Frau gegeben. ${ }^{229}$ Der Samen der Frau, nämlich Christus, lädt auf sich die Strafe gegenüber der Sünde der Kirche, damit der Zorn Gottes versöhnt wird. Melanchthon erwähnt neben der Sündenvergebung das ewige Leben und die Gerechtigkeit, die der Sohn

\footnotetext{
${ }^{222}$ Vgl. PK Ps 110, CR 13, 1165. „regnans eadem potentia cum patre, ...“

${ }^{223}$ PK Ps 51z, CR 13, 1225. „Sunt igitur alii Psalmi prophetici, ..., docent quis sit Messias, et quae sint eius beneficia, ..."

${ }^{224}$ Vgl. PK Ps 110, CR 13, 1153. ,sed scit David eum esse Filium Dei aeternum, et iam esse custodem Ecclesiae, ..."

${ }^{225}$ Vgl. PK Ps 130, CR 13, 1214. „quia tantum recipis propter propiciatorem.“

${ }^{226}$ Vgl. PK Ps 130, CR 13, 1215. „qui me sustentat suo Filio Mediatore, et liberat me ex morte, et ex portis inferorum, ...“

${ }^{227}$ Vgl PK Ps 53, CR 13, 1123. „ut Paulus inquit, Causati sumus omnes sub peccato esse, ut omne os obstruatur, et totus mundus reus fiat Deo.“

${ }^{228}$ Vgl. PK Ps 47, CR 13, 1099. „Iudaei non psallunt Messiae sapienter, cum fingunt regnum politicum et interiturum, imo cum fascinati hac persuasione crucifigunt Messiam.“

${ }^{229}$ Vgl. PK Ps 110, CR 13, 1156. „qui primus sacerdos tunc statim fuit, quando post lapsum Adae et Evae intercessit pro toto genere humano, ...“ und vgl. PK Ps 125, CR 13, 1207. „Ponam inimicicias inter serpentem et semen mulieris, et semen mulieris conculcabit caput serpentis."
} 
der Kirche gibt. ${ }^{230}$ Er richtet dabei seinen Blick auf den Nutzen für die Kirche. Der Nutzen der Menschwerdung des Sohnes ist nicht allein für ihn selbst, sondern für die Kirche. Deshalb bittet der Sohn beständig für die Kirche um diesen Nutzen, nämlich um die Freiheit und die Erlösung der Kirche. ${ }^{231}$

Melanchthon erklärt, dass die Reinheit der menschlichen Natur des Sohnes die Außergewöhnlichkeit des Sohnes als Mensch unter allen Menschen zeigt. Die menschliche Natur, die der Sohn Gottes annahm, ist nicht sündhaft. Alle Nachkommen von Adam dagegen sind Sünder von der Geburt an. ${ }^{232}$ Aber der Sohn Gottes hat keine Sünde. ${ }^{233}$ Nach Melanchthon ist diese Reinheit der Grund für die Sündenvergebung. Deswegen konnte der Sohn die ganze Sünde der Kirche auf sich laden. Die menschliche Sünde muss nur auf einem Menschen geladen werden. Der Sohn Gottes machte das möglich, indem er die nicht sündhafte menschliche Natur annahm.

Dazu weist Melanchthon bei der Sündenvergebung und der Verleihung der Gerechtigkeit auf die Rolle des Sohnes als Gott hin. Die Person des Sohnes ist mehr als die menschliche Person, weil er zugleich Gott ist. Deshalb konnte er die Strafe, die die Sünde fordert, auf sich laden, den Tod mit der Kraft der göttlichen Person besiegen und der Kirche die Gerechtigkeit und das ewige Leben geben. ${ }^{234}$ So gewinnt und bringt der Sohn die Sündenvergebung und die ewige Seligkeit für die Kirche. Die Kirche wird dadurch von der Sünde, dem Tod und den Teufeln befreit. ${ }^{235}$

Nach Melanchthon hat der Sohn als der Messias zwei Ämter, nämlich das Priesteramt und Königsamt. Gott ordiniert den Sohn als Hohepriester und König. ${ }^{236}$ Zuerst ist er Hohepriester, der sich auf die Opfer bezieht. Er ist kein Priester der Leviten, sondern er ist der ewige Priester nach der Weise von Melchisedek. ${ }^{237}$ Die Priester der Leviten haben Anteil an dem

\footnotetext{
${ }^{230}$ Vgl. PK Ps 110, CR 13, 1152. „Ecclesiam, ... et donabit aeterna vita, et aeterna iusticia.“

${ }^{231}$ PK Ps 117/118, CR 13, 1186. „,nam et ipse Messias petit pro se et pro tota Ecclesia liberationem et salvationem ..."

${ }^{232}$ Vgl. PK Ps 14, CR 13, 1037. „docet reos esse omnes secundum hanc naturae pravitatem.“

${ }^{233}$ PK Ps 40, CR 13, 1083. „Filius Dei, qui non fecit peccatum, ...“

${ }^{234}$ Vgl. PK Ps 110, CR 13, 1153, ,solus hic Messias qui est Filius Dei, aboliturus peccatum et mortem, et redditurus nobis iusticiam et vitam aeternam. Hic est Davidis Dominus, etiamsi ex eius posteritate nascetur, sed scit David eum esse Filium Dei aeternum, ..."

${ }^{235}$ PK Ps 2, CR 13, 1021. "Adfirmat beatos fore homines, id est, liberos a peccato, morte, tyrannide diaboli, ..."

${ }^{236}$ PK Ps 45, CR 13, 1092. „et ordinavit ad hoc sacerdotium et regnum ...“

${ }^{237}$ PK Ps 110, CR 13, 1160. „Secundum ordinem Melchizedech: Haec differentia discernit Messiae sacerdotium a Levitico, quasi dicat, Messias erit sacerdos non Leviticus, non typicus, non mactans
} 
Amt des Hohepriesters. ${ }^{238}$ Der Hohepriester lässt den Zorn Gottes durch das Opfer versöhnen und vergibt die Sünde, indem er sich ein für alle Mal darbrachte. ${ }^{239}$ Die Macht der Sündenvergebung gibt er dann der Kirche, damit die Kirche gerecht durch den Glauben wird und den Frieden hat. ${ }^{240}$ Das Priesteramt bezieht sich auf die Sündenvergebung bei Melanchthon.

Zweitens, der Sohn als Gottmensch ist auch der König. Er ist der Grund, auf den die Kirche baut, denn nur auf dem Sohn Gottes kann die Kirche gebildet werden. ${ }^{241}$ Er ist das Haupt der Kirche, die Kirche muss an ihm als dem Haupt der Kirche festhalten und an ihm anlehnen. Und der Sohn regiert die Kirche ${ }^{242}$ und wirkt mit dem Wort und dem Heiligen Geist. ${ }^{243}$ Seine Regierung ist für Melanchthon wichtig, weil die Kirche in diesem Leben viele Schwierigkeiten erleiden kann. ${ }^{244}$ In jedem Fall ruft sie den regierenden König an und fordert ihn um Hilfe, und dann erhört Gott durch den Vermittler. ${ }^{245}$ Das ist sein Reich, und das Reich vollendet sich in der universalen Auferstehung ${ }^{246}$ und bleibt ewig. ${ }^{247}$ So steht der Sohn als der König der Kirche immer bei.

\subsubsection{Gott, der in der Kirche wohnt.}

Im PK bezieht Melanchthon den Heiligen Geist auf die Zuteilung der Wirkung des Sohnes, nämlich Sündenvergebung und Heiligung, an die Kirche. Der Heilige Geist wird zusammen mit der Sündenvergebung verheißen. ${ }^{248}$ So wohnt der Heilige Geist in der Kirche. Von dem Heiligen Geist wird die Kirche mit dem Evangelium gesammelt. ${ }^{249}$ Dadurch werden die

pecudes, non ceremonias legis et condemnationem sonans, non inefficax, sicut Levitici et typici Sacerdotes, sed erit sacerdos sonans benedictionem, sicut Melchizedech benedicit Abrahae.“

${ }^{238}$ PK Ps 110, CR 13, 1157. „Postea alii qui vero ministerio funguntur, participatione sacerdotes sunt, quia aliquam partem sacerdotii Christi administrant, ...“

${ }^{239}$ PK Ps 110, CR 13, 1157. „Qua voluntate sanctificati sumus per oblationem corporis Iesu Christi semel."

${ }^{240}$ PK Ps 110, CR 13, 1166. „Iustificati fide pacem habemus.“

${ }^{241}$ Vgl. PK Ps 117/118, CR 13, 1183. „hic Messias ... factus est fundamentum Ecclesiae, ...“

${ }^{242}$ Vgl. PK Ps $117 / 118$, CR 13, 1185. „coetus Deo placens in quo regnat Filius Dei ostendens patrem ..."

${ }^{243}$ PK Ps 45, CR 13, 1092. „et id faciat verbo et Spiritu sancto, ...“

${ }^{244}$ Vgl. PK Ps 6, CR 13, 1027. „sciamus eam precationem esse communem, quam omnes pii in magnis periculis et aerumnis corde et ore recitent ..."

${ }^{245}$ PK Ps 111, CR 13, 1169. ,sed vere iuvans et exaudiens nos propter mediatorem, ...“

${ }^{246}$ Vgl. PK Ps 14, CR 13, 1039. „quod coepit Christus facere in resurrectione sua, et perficiet in universali resurrectione.“

${ }^{247}$ PK Ps 45, CR 13, 1093. „quidem eius regnum aeternum fore.“

${ }^{248}$ PK Ps 29, CR 13, 1161. „quae promisit, scilicet remissionem peccatorum et Spiritum sanctum.“

${ }^{249}$ Vgl. PK Ps 110, CR 13, 1161. ,semper colligit Ecclesiam Evangelio et Spiritu sancto, ...“ 
Gläubigen befreit und den Geist erhalten, durch den das neue Licht, die Gerechtigkeit und das ewige Leben bewirkt werden. ${ }^{250}$ So besitzt die Kirche den Heiligen Geist und wird durch den Heiligen Geist geheiligt, ${ }^{251}$ der im ganzen Leben der Mitglieder der Kirche wirkt.

Melanchthon sieht die Lehre und die Wirkung des Heiligen Geistes auch in den Psalmen. ${ }^{252}$ Besonders lehrt der Heilige Geist, dass die weltlichen Regierungen weder zufällig noch durch die menschliche Weisheit konstituiert werden. ${ }^{253}$ Das meint, dass die Welt nicht zufällig oder durch die Menschen regiert wird, sondern von Gott nach dem Plan Gottes. Das lehrt der Heilige Geist, und das ist für die Kirche immer noch gültig. Der Heilige Geist lehrt die Frommen, d.h. die Kirche, durch die Propheten, dass Gott der Kirche die Wohltaten und die Verheißung Gottes geben wird. ${ }^{254}$ So lernt man nach Melanchthon vom Heiligen Geist den Zusammenhang zwischen der Welt und Gott und die ausgewöhnliche Beziehung Gottes zur Kirche.

Melanchthon betont, dass der Heilige Geist die Gläubigen zum ewigen Leben heiligt. ${ }^{255}$ Die Gläubigen besitzen schon die Sündenvergebung und den Heiligen Geist, aber sie können das Gesetz noch nicht erfüllen. Für die Gläubigen bleibt noch die Sünde in diesem Leben. ${ }^{256}$ Aber sie sollen wegen ihrer noch verbleibenden Sünde nicht entmutigt werden, weil sich durch den Heiligen Geist die Anrufung und die Freude entzünden. ${ }^{257}$ Außerdem sänftigt er unser Herz ${ }^{258}$ und belebt die Kirche durch die Gerechtigkeit und das ewige Leben. ${ }^{259}$ Er ist der Verursacher, denn durch den Heiligen Geist, der in das Herz der Gläubigen gegossen ist, ${ }^{260}$ wird die Erkenntnis des Sohnes Gottes in den Herzen der Gläubigen gezündet. ${ }^{261}$ So

${ }^{250}$ PK Ps 45, CR 13, 1093. „Spiritum sanctum, quo in eis novam lucem, iusticiam et vitam aeternam efficiat.“

${ }^{251}$ PK Ps 117/118,10 CR 13, 1186. „,sanctificat eos Spiritu suo sancto, ...“

${ }^{252}$ Vgl. PK. Prolegomena, CR 13, 1018. ,ut sciat lector, quid velit docere vel efficere Spiritus sanctus in singulis Psalmis,"“

${ }^{253}$ PK Ps 21, CR 13,1048. „Docet igitur Spiritus sanctus in his Psalmis, sicut in multis aliis locis, non casu, non tantum humana sapientia, ut philosophi putant, constitutas esse politias, ...“

${ }^{254}$ Vgl. PK Ps 23, CR 13,1051. „Spiritus sanctus per Prophetam docet omnes pios, haec esse beneficia Dei, et promissa esse Ecclesiae.“

${ }^{255}$ PK Ps 117/118, CR 13, 1185. ,per eum Spiritu sancto sanctificati ad vitam aeternam.“

${ }^{256}$ PK Ps 15, CR 13, 1039. ,et quae peccata maneant in renatis in hac vita, ...“

${ }^{257}$ Vgl. PK Ps 130, CR 13, 1214. „et accendit hanc invocationem et laeticiam Spiritu suo sancto, ...“

${ }^{258}$ PK Ps 51z, CR 13, 1230. ,ideo quia Spiritus sanctus flectit cor, ...“

${ }^{259}$ PK Ps 111, CR 13, 1169. „vivificas iusticia et vita aeterna ...“

${ }^{260}$ PK Ps 51z, CR 13, 1230. „Notum est autem Spiritum sanctum esse agilatorem, et ideo effundi in corda credentium, ..."

${ }^{261}$ PK Ps 133, CR 13, 1221. „et accendatur agnitione Filii Dei per Spiritum sanctum, ...“ 
überwinden die Gläubigen den Zweifel mit der Hilfe des Heiligen Geistes und werden im Glauben standfest. ${ }^{262}$ So heiligt der Heilige Geist die Mitglieder der Kirche. Durch den Heiligen Geist werden sie gerecht und geheiligt, und dazu erben sie das ewige Leben. ${ }^{263}$ Damit erhalten sie das Zeugnis als die Kinder Gottes. ${ }^{264}$ Deshalb soll die Kirche Gott anrufen, um den Heiligen Geist und den Glauben nicht zu verlieren, ${ }^{265}$ wie David durch die Hilfe des Heiligen Geist dem unrechten Angriff Einhalt gebieten konnte. ${ }^{266}$ Darüber hinaus regiert der Heilige Geist die Kirche mit dem Sohn. ${ }^{267}$ Die Herrschaft des Heiligen Geistes meint nämlich die Herrschaft Gottes. Die Herrschaft zeigt sich konkret darin, die wahre Lehre Gottes zu erkennen und zu halten.

\subsubsection{Zusammenfassung}

Im Denken Melanchthons bezieht sich die Gotteserkenntnis immer auf die Kirche. Deshalb muss man Gott in seiner Beziehung zur Kirche betrachten. Menschen aber können die wahre Gotteserkenntnis nicht erhalten, weil sie Sünder sind. Allerdings offenbart sich Gott der Kirche. Deshalb kann die Kirche wahrlich Gott erkennen, anrufen und ehren. Die Kirche hält und bewahrt die wahre Gotteserkenntnis durch die Bewahrung Gottes. So ist die Kirche eine besondere Gruppe, die zu Gott gesammelt wird. Diese Beziehung zwischen Gott und Kirche ist der Hintergrund des PKs.

Gott, der im PK gezeigt wird, ist der Dreieinige. Die Lehre über Gott im PK entspricht der traditionellen Lehre über den Dreieinigen. Die Personen Gottes sind drei, der Vater, der Sohn und der Heilige Geist. Es ist im PK zu erkennen, dass die Lehre über Gott stets in der Beziehung Gottes zur Kirche betrachtet wird. Der Vater ist der Vater von Jesus Christus, dem Schöpfer und Erhalter der Kirche. Er ist gerecht und zornig auf den sündhaften Menschen. Aber er offenbart der Kirche seinen Willen und schickt den Sohn, um die Kirche zu erlösen. Die Kirche wird durch den Sohn erlöst und ehrt Gott. Der Sohn ist Gott, der die menschliche Natur angenommen hat. Er wird als der Nachkomme Davids nach den Vorhersagen der Propheten geboren. Der Sohn wird als ein sündloser Mensch geboren, um die Kirche zu sammeln.

\footnotetext{
${ }^{262}$ PK Ps 51z, CR 13, 1229. „et vincentem dubitationes, ...“

${ }^{263}$ PK Ps 130, CR 13, 1215. ,et efficimur haeredes vitae aeternae ...“

${ }^{264}$ PK Ps 111, CR 13, 1172. „Accepistis spiritum quo clamamus Abba pater, ipse spiritus dat testimonium spiritui nostro, quod simus Filii Dei.“

${ }^{265}$ PK Ps 119, CR 13, 1199. ,sed hic orat ne dominentur, ne Spiritus sanctus et fides excutiantur, ...“

${ }^{266}$ Vgl. PK Ps 54, CR 13, 1126. „sed vicit dolorem suum scandali et exempli detestatione, et fiducia auxilii divini, frenante vehementes impetus Spiritu sancto."

${ }^{267}$ Vgl. PK Ps 58, CR 13, 1138. ,suo Spiritu sancto regat, ...“
} 
Er lädt die Strafe der Sünden der Kirche auf sich. Als der Hohepriester bringt er sich Gott als das Opfer dar. Dadurch wird der Zorn Gottes versöhnt. Und der Sohn bezieht die Kirche auf sich, am Ende vollendet er sein Reich als der König. Der Heilige Geist ist Gott, der in den Gläubigen wohnt. Er sammelt die Kirche, lehrt das Wort und heiligt sie bis zum ewigen Leben. Dazu regiert der Heilige Geist mit dem Sohn die Kirche.

Melanchthon betrachtet im PK Gott immer in der Beziehung zur Kirche. Nach Melanchthon handeln die Psalmen davon, welche Beziehung Gott zur Kirche hat, und wie die Kirche von Gott behandelt wird. Im PK hat Melanchthon kein Interesse an eine Spekulation über Gott, sondern an einen aktuellen Zusammenhang zwischen Gott und der Kirche. 


\subsection{Das universale Prinzip Gottes zur Welt und Kirche}

\subsubsection{Die Schöpfung}

Gott schuf die ganze Welt. Die Gotteserkenntnis in der Schöpfung ist allgemein und universal, deshalb zeigt Melanchthon, dass Gott durch die Bewegungen der Himmel und die Ordnungen im Wechsel der Zeiten bekannt wird, ${ }^{268}$ und er bezeichnet diese Erkenntnis als die philosophische. ${ }^{269}$ Durch diese allgemeine Gotteserkenntnis wird bezeugt, dass die Welt nicht zufällig existiert, sondern durch ein vernünftiges Wesen geschaffen wurde. ${ }^{270}$ Dabei findet Melanchthon den Willen Gottes. Gott wünscht, dass durch das Zeugnis die vernünftigen Geschöpfe sich mit Gott verbinden ${ }^{271}$ und dass wiederum die Menschen Gott erkennen und loben. ${ }^{272}$ Allerdings dienen nicht alle, die das Zeugnis finden, Gott wahrlich. Wie angedeutet(Vgl. Kapitel 4.1.1), ist die allgemeine Gotteserkenntnis durch die Sünde verderbt. Deshalb ist diese allgemeine Erkenntnis schwach und nicht ausreichend für die Erlösung. Melanchthon kennt im PK keine Möglichkeit der Gotteserkenntnis ohne die Offenbarung. Eigentlich hat er im PK auch kein Interesse daran, weil Gott immer in der Beziehung zur Kirche dargestellt wird. Melanchthon richtet sich im PK nicht auf einen allgemeinen Gegenstand, sondern allein auf die Kirche.

Für Melanchthon hat die Schöpfung Gottes eine besondere Bedeutung für die Kirche. Nur bei den Frommen, nämlich in der Kirche können Gott und seine Werke wahrlich verstanden werden. Deswegen bezieht Melanchthon die Schöpfung und Bewahrung der Welt auf die Kirche. Die Schöpfung und Bewahrung der Welt stellen sicher, dass Gott die Kirche bewahrt. ${ }^{273}$ Hiermit zieht Melanchthon aus der Schöpfung und der Bewahrung einen Nutzen für die Kirche. Gott, der die Welt regiert, regiert die Kirche, und Gott, der die Welt besitzt, besitzt besonders die Kirche. Deshalb ist Gott der Schöpfer der Welt und Kirche. ${ }^{274}$ Die Kirche kann sicher wissen, dass sie somit von Gott regiert und geschützt wird, wenn sie die von Gott re-

\footnotetext{
${ }^{268}$ PK Ps 19, CR 13, 1045. „Deum agnosci ex creatione, ex motibus coelestibus, et ordinatis temporum vicibus, ..."

${ }^{269}$ Vgl. PK Ps 19, CR 13, 1045. „Nam noticia illa philosophica etiam gentibus nota est, ...“

${ }^{270}$ PK Ps 19, CR 13, 1045. „quae certe sunt testimonia de mente aeterna architectatrice, et ostendunt mundum non extitisse casu:"

${ }^{271}$ PK Ps 133, CR 13, 1224. „Quia vult omnes rationales creaturas ad creatorem copulatas esse, ...“

${ }^{272}$ Vgl. PK Ps 133, CR 13, 1224. „et (ut) vicissim nos ipsum agnoscamus et celebremus“"

273 Vgl. PK Ps 33,3, CR 13, 1067. „Tradit doctrinam quod Deus vere et condiderit universum opificium mundi, et adsit suis operibus, eaque servet, et praecipue tueatur Ecclesiam.“

${ }^{274}$ Vgl. PK Ps 54, CR 13, 1127. ,a Deo aeterno patre Domini nostri Iesu Christi conditore generis humani et Ecclesiae discamus,“
} 
gierte und geschützte Welt sieht. Deswegen kann die von Gott geschaffene Welt als das Zeugnis Gottes für die Kirche bezeichnet werden.

Fernerhin lehrt Melanchthon, dass die Welt um der Kirche willen bewahrt wird, besonders um die Kirche aus dem Menschengeschlecht zu sammeln. ${ }^{275}$ Die Kirche ist die wichtigste Versammlung in der Welt und steht im Mittelpunkt der Schöpfung. Deshalb muss man die Welt, die unter der Regierung und Herrschaft Gottes ist, in Hinsicht auf die Kirche betrachten, weil die Welt ohne die Kirche belanglos ist. Die Welt wird von Gott regiert und bewahrt, der besonders die Kirche regiert und bewahrt. Insofern würde nach Melanchthon sich die Welt von der Kirche verschulden, wenn die Welt die Kirche für unwichtig halten würde.

Melanchthon weist darauf hin, dass die Kirche die wahre Gotteserkenntnis hat. ${ }^{276}$ Die Welt, die sich durch Sünde verdunkelt, kann Gott nicht wahrlich erkennen, obwohl sie die Schöpfung Gottes sieht. ${ }^{277}$ Vielmehr hasst die Welt die Kirche und versucht, die Kirche zu zerstören. ${ }^{278}$ Nur die Kirche hat die wahre Erkenntnis über Gott und kann sie der Welt zeigen, und die wahre Bedeutung der Schöpfung Gottes kann nur durch die Kirche gewusst und gezeigt werden, weil sich Gott besonders der Kirche offenbart. Deshalb kann nur die Kirche den wahren Gottesdienst abhalten und Gott wahrlich loben. Dabei sieht Melanchthon die Außergewöhnlichkeit der Kirche, die darin besteht, dass es ohne die Kirche keine wahre Gotteserkenntnis in der Welt gibt.

\subsubsection{Die Vorsehung}

Bei Melanchthon ist Gott nicht nur der Schöpfer, sondern auch der die Schöpfung Regierende. Die Schöpfung Gottes impliziert die Vorsehung. Die Schöpfung bedeutet nicht nur die Sache, dass Gott die Welt schuf, sondern auch die Vorsehung, dass Gott auch die Welt regiert. Obwohl die Welt die Vorsehung Gottes nicht zugibt, legt Gott doch die Geschöpfe unter seine Herrschaft. Nach der Schöpfung der Welt sorgt Gott für die Welt. Melanchthon betont, dass Gott kein arbeitsscheuer Betrachter ist, ${ }^{279}$ sondern der aktive Regierende der Welt, an den die

\footnotetext{
${ }^{275}$ Vgl. PK Ps 36, CR 13, 1074. „Deus servat totam rerum universitatem, coelum, terram, pecudes, et universum genus humanum, sed propter Ecclesiam, scilicet ut Ecclesiam sibi colligat ex humano genere."

${ }^{276}$ PK Ps 113, CR 13, 1178-1179. „Ecclesia monstrat verum Deum.“

277 Vgl. PK Ps 33, CR 13, 1069. „,non intelligatur malarum cogitationum autor esse, ...“

${ }^{278}$ PK Ps 53, CR 13, 1124. „et impia multitudo ardet odio alterius coetus, et eum delere conatur.“

${ }^{279}$ PK Ps 54, CR 13, 1127. „Nam respicere non significat ociosum spectatorem.“
} 
Kirche glaubt und auf den sich die Kirche stützt. Das ist ein Trost für die Kirche. ${ }^{280}$ Melanchthon erklärt die Regierung der Welt durch Gott als die Vorsehung. Die Regierung Gottes, nämlich die Vorsehung, ist allgemein. Gott regiert die ganze Welt. Er macht seinen Plan und erfüllt ihn. Er bindet sich nicht durch eine andere Ursache, sondern er wirkt von sich selbst aus. ${ }^{281}$ Über den Bereich der Vorsehung erklärt Melanchthon, dass die Vorsehung Gottes in der ganzen Welt wirkt, und seine Regierung beharrlich, wachsam, eifrig und ewig ist. ${ }^{282}$ Gott bewahrt die Geschöpfe, die er selbst schuf, und er hält sie. Bei Melanchthon ist die Vorsehung Gottes folglich allgemein und umfangreich.

Melanchthon bezieht die Vorsehung Gottes besonders auf die Kirche, weil die Kirche im Mittelpunkt der Vorsehung steht, wie auch in der Schöpfung. Gott sorgt für die Kirche und verteidigt die Kirche gegen die Tyrannei der Welt. ${ }^{283}$ Er bewahrt die Kirche und regiert die Kirche und die ganze Welt. Gott hat einen besonderen Plan für die Kirche und erfüllt den Plan gemäß seiner Vorsehung. Man darf an der Vorsehung Gottes nicht zweifeln, wenn auch die Gottlosen prosperieren. ${ }^{284}$ Dabei denkt Melanchthon an die Schwierigkeit des Glaubens der Kirche an die Vorsehung Gottes. Deswegen ermuntert Melanchthon die Kirche. Die Kirche soll gegen diesen Zweifel streiten und um die Hilfe des Heiligen Geistes bitten. ${ }^{285}$

Melanchthon bemerkt deutlich den Gegensatz der Gottlosen zur Vorsehung Gottes. Die Gottlosen kennen zwar den Begriff der Vorsehung, ${ }^{286}$ aber sie glauben nicht an die Vorsehung Gottes und denken, dass die wahre Lehre über die Vorsehung Gottes nicht vorhanden sei. Deshalb behaupten sie, dass die besondere Vorsehung für die Kirche nicht existiere und dass es bei der Vorsehung zwischen dem Verständnis der Vorsehung in der Kirche und dem der Gottlosen keinen Unterschied gebe. ${ }^{287}$ So zweifeln sie an die Vorsehung Gottes, ehren

\footnotetext{
${ }^{280}$ Vgl. PK Ps 37, CR 13, 1075. „Deinde addit consolationem, in qua est asseveratio de providentia. Adfirmat certe Deum curare Ecclesiam, et punire impios.“

${ }^{281}$ Vgl. PK Ps 9, CR 13, 1033. „quod Deus vere sit efficax, non sit inane vocabulum, non sit ociosus, non sit alligatus causis secundis, ..."

${ }^{282}$ Vgl. PK Ps 122, CR 13, 1204. ,gubernatio est assidua, vigilans, intenta, et erit perpetua.“

${ }^{283}$ Vgl. PK Ps 33, CR 13, 1068. „Hic iam recitat doctrinam de providentia, quod curet et defendat Ecclesiam, reprimat impetus tyrannorum, ..."“

${ }^{284}$ PK Ps 39, CR 13, 1079. „ne dubites de providentia etiamsi florent impii, ...“

${ }^{285}$ Vgl. PK Ps 110, CR 13, 1155. ,repugnemus dubitationi, et petamus nos iuvari Spiritu sancto, ...“

${ }^{286}$ Vgl. PK Ps 113, CR 13, 1078.

${ }^{287}$ Vgl. PK Ps 35, CR 13, 1071. „,ne impii vociferentur me deserto, nihil esse veram providentiam, non esse doctrinam Ecclesiae Dei, non esse discrimen Ecclesiae Dei et impiorum, ..."
} 
nicht Gott und wollen die Welt mit der eigenen Weisheit regieren. ${ }^{288}$ Sie denken, als ob Gott nicht existieren würde, sie behaupten, dass alle Religionen vergeblich seien. ${ }^{289}$ Sie negieren nicht nur die Kirche, sondern auch die Ehre Gottes. Darüber hinaus denken die Gottlosen, dass wenn die Vorsehung Gottes existiere, es nicht möglich sei, dass die Guten im Menschengeschlecht elend werden. ${ }^{290}$ Sie meinen, dass es sowohl für die Guten als auch für die Bösen Elend im Allgemeinen gibt und dass es ab und zu größeres Elend bei den Guten gibt als bei den Bösen. Somit räumt die Vernunft der Menschen die Vorsehung und die Regierung Gottes weg. ${ }^{291}$

Allerdings weist Melanchthon darauf hin, dass die Gottlosen dadurch den Zorn Gottes erhöhen. ${ }^{292}$ Denn die Vernunft der Menschen versteht nicht, warum die Kirche unter das Kreuz und das Leiden gestellt ist. Und Ihr Zweifel an der Vorsehung entsteht wegen der allgemeinen Bosheit im Menschengeschlecht. ${ }^{293}$ Bei Melanchthon ist die Verachtung der Gottlosen über die Vorsehung Gottes eine selbstverständliche Folge, weil die menschliche Vernunft verderbt ist. Um die Vorsehung Gottes wahrlich zu verstehen, braucht man die Offenbarung Gottes.

Im Gegensatz zu den Gottlosen glauben die Frommen an die Vorsehung Gottes. Melanchthon bezeichnet den Glauben an die Vorsehung Gottes als einen wichtigen Unterschied zwischen der Kirche und den Gottlosen. ${ }^{294}$ Die Frommen sollen keinen Zweifel an der Vorsehung haben, wenn auch die Gottlosen prosperieren und die Kirche durch die Welt bedrängt

\footnotetext{
${ }^{288}$ PK Ps 53, CR 13, 1124. „dubitatio de Deo et de providentia, esse sine timore Dei, et confidenter regi propria sapientia, ..."

${ }^{289}$ PK Ps 10, CR 13, 1034. „Triumphant impii quasi nihil sit Deus, aut nulla sit providentia, et omnes religiones sint commentitiae."

${ }^{290}$ PK Ps 49, CR 13, 1104. „Si est providentia, impossibile est bonos in genere humano tantum ad miserias conditos esse."

${ }^{291}$ Vgl. PK Ps 37, CR 13, 1075. „Cum igitur nec praemia dari iustis, nec poenae tantum iniustos opprimere videantur, sed pariter vagari poenas per malos et bonos adpareat, caeca ratio hominum tollit providentiam, et removet Deum a gubernatione, imaginatur casu omnia ferri, pingit fortunam caecam, denique horrendos furores cumulat, ut multorum Epicureorum sermones quotidie ostendunt.“

${ }^{292}$ PK Ps 37, CR 13, 1075. „Remota vero providentia deinde ratiocinantur impii:““

${ }^{293}$ Vgl. PK Ps 53, CR 13, 1124. „sed etiam interiora magna mala communia hominum, dubitatio de Deo et de providentia, ...“

${ }^{294}$ Vgl. PK Ps 35, CR 13, 1071. „tuam causam defende, ne impii vociferentur me deserto, nihil esse vera providentiam, non esse doctrinam Ecclesiae Dei, non esse discrimen Ecclesiae Dei et impiorum, ideo tu ostendas discrimen, ..."
} 
wird. ${ }^{295}$ Um die Vorsehung Gottes festzuhalten, braucht man keine menschliche Vernunft, sondern den Glauben. Hier ist die Auffassung Melanchthons über den Zusammenhang zwischen der Vorsehung Gottes und dem Glauben zu sehen. Wie erwähnt, haben die Gottlosen auch einen Begriff über die Vorsehung, allerdings ist ihr Begriff über die Vorsehung anders als der über die Vorsehung Gottes, weil sie nicht an die Vorsehung Gottes glauben.

Melanchthon weist in der Auslegung zu Ps 113 auf zwei Unterschiede zwischen der Vorsehung der Kirche und der der Gottlosen hin. Erstens, die Kirche zeigt den wahren Gott, der der Schöpfer der Welt ist und sich mit seiner Stimme und durch Zeugnisse offenbart. Das Subjekt der Vorsehung ist Gott selbst. Zweitens, die Kirche erklärt die Verheißung der Gnade Gottes, durch die die Kirche trotz ihrer Wertlosigkeit von Gott angenommen wird und Gott anrufen kann, um Gutes zu fordern und zu erwarten. ${ }^{296}$ Der Inhalt der Vorsehung ist das Gnadenhandeln Gottes für die Kirche. Melanchthon erklärt so die Unterschiede in zwei Punkten, nämlich mit dem Subjekt und mit dem Inhalt der Vorsehung. Die Gottlosen wissen nicht um das Gnadenhandeln Gottes für die Kirche in der Vorsehung. Infolge dessen meiden die Gottlosen Gott im Leiden, weil sie ihre Wertlosigkeit wegen ihrer Sünde erkennen und deswegen Angst vor Gott haben. Die Kirche erkennt auch, dass sie sich wie die Gottlosen in einer Situation des Leidens befindet, doch beruft sie sich auf die Verheißung des Vermittlers, weil Gott die Sünder durch den Vermittler annehmen will. ${ }^{297}$ Somit überliefert Gott der Kirche die Verheißung für die Kirche und bestätigt die Vorsehung Gottes.

Bei Melanchthon ist die Vorsehung als ein Bestanteil der Regierung Gottes über die Kirche und die Welt zu sehen. Die Kirche erkennt von der Vorsehung Gottes, dass Gott für die Kirche sorgt und die Gottlosen richtet. In diesem Leben und nach dem Leben ist die Regel allgemein, dass die Bösen bestraft werden. ${ }^{298}$ Obwohl die Regel in diesem Leben nicht immer

\footnotetext{
${ }^{295}$ PK Ps 39, CR 13, 1079. „ne dubites de providentia etiamsi florent impii, et Ecclesia magnis aerumnis premitur."

${ }^{296}$ Vgl. PK Ps 113, CR 13, 1178. „tamen Ecclesiae doctrina in hoc ipso loco dupliciter ab ethnica differt. Ecclesia monstrat verum Deum, qui se patefecit non solum opificio naturae, sed etiam sua voce et certis testimoniis, ut misso filio, resuscitatione mortuorum, eductione populi ex Aegypto. Secundo non tantum recitat Ecclesia legalem doctrinam de Deo, sed etiam promissionem gratiae, ut sciamus nos recipi quanquam sumus indigni, et invocare eum possimus, et petere et expectare bona."

${ }^{297}$ Vgl. PK Ps 113, CR 13, 1179. „Etsi enim Ethnici norunt dicta de providentia, tamen in aerumnis fugiunt Deum, quia agnoscunt se reos et indignos esse, sed Ecclesia opponit promissionem de Mediatore, imo etiamsi es reus, tamen Deus edidit promissionem, et vult te recipere propter Mediatorem, ..."

${ }^{298}$ PK Ps 49, CR 13, 1105. „Certum est atrocia delicta atrocibus poenis in hac vita puniri, ...“
} 
Geltung habe, muss man die Regel fürchten. ${ }^{299}$ Und es ist klar, dass nach dem Leben die in der Gottlosigkeit Beharrenden von Gott bestraft werden. So werden die die Vorsehung Gottes Verweigernden in Strafe genommen. Melanchthon erkennt, dass die Anwendung des Prinzips Gottes in diesem Leben nicht immer richtig wäre, aber die Gläubigen können sich durch den Glauben an die Vorsehung Gottes trösten. Dafür muss die Vernunft der Gläubigen durch die Vorsehung Gottes gestärkt werden, um die Sorge Gottes zu erkennen und recht zu handeln. ${ }^{300}$

In diesem Leben wird die Kirche gemäß der Vorsehung Gottes noch nicht vom Leiden befreit. Melanchthon weiß gut, dass es gar nicht leicht ist, dass in dieser Situation des Leidens die Kirche immer an Gott glaubt und sich an ihn anlehnt. Die Frage nach den Gründen dafür kann allein durch die göttliche Lehre in der Kirche geklärt werden. ${ }^{301}$ Gerade dies ist für Melanchthon auch wichtig und schwer, weil er während seiner Vorlesungen der Psalmen die schmerzhaften Folgen des Schmalkaldischen Krieges erfahren hat. Aber man muss vor allem erwägen, dass das Leiden der Kirche sich auch auf die Sünde bezieht.

\subsubsection{Die Süinde und Erbsünde}

Im PK behandelt Melanchthon die Sünde ernst, weil die Sünde sich eng auf die Vergangenheit, Gegenwart und Zukunft der Kirche bezieht. Warum Gott die Kirche zu sich sammelt, warum der Sohn als Gottmensch auf die Erde gekommen ist und die Kirche erlöst, warum der Heilige Geist in der Kirche wohnt und wie Gott die Kirche am letzten Tag vollendet, alle diese Fragen haben eine enge Beziehung zum Problem der Sünde. Wenn Melanchthon die Schöpfung und Vorsehung im PK erklärt, ist ein wichtiges Argument, dass die Gottlosen die Vorsehung Gottes verweigern. Dazu weist er darauf hin, dass der Grund für diese Verweigerung der Gottlosen gegenüber der Vorsehung Gottes auf der Sünde liegt. ${ }^{302}$ Nämlich ist für Melanchthon die Sünde eine Barriere gegen die wahre Erkenntnis Gottes. Ohne Absolvierung des Problem über die Sünde gibt es keine Möglichkeit für die wahre Gotteserkenntnis.

\footnotetext{
${ }^{299}$ PK Ps 37, CR 13, 1075. „Haec regula vera et formidanda est, etiamsi aliquid interdum praeter regulam fit:“"

${ }^{300}$ Vgl. PK Ps 37, CR 13, 1075. „Cum igitur certissimum sit, Deum punire perseverantes in impietate, execrandi sunt Epicurei, qui tollunt providentiam, et nostrae mentes confirmandae sunt, ut sciant Deum vere curare humana, et ut recte faciamus.“

${ }^{301}$ Vgl. PK Ps 49, CR 13, 1104. „Haec confusio bonorum et malorum valde multos movet, ut de providentia dubitent. Nec explicari haec quaestio potest nisi ex doctrina divinitus revelata certissimis testimoniis in Ecclesia."

${ }^{302}$ Vgl. Pk. 53, CR 13, 1124. „sed etiam interiora magna mala communia hominum, dubitatio de Deo et de providentia,“
} 
Melanchthon betrachtet die Sünde immer im Zusammenhang mit Gott. Die Sünde hat einen bestimmten Bezug, nämlich Gott. Bei Melanchthon ist die Sünde die Abweichung von Gott. Die Sünde ist die Konfusion ohne die Regierung Gottes. Die Sünde widersetzt sich Gott und hasst Gott. ${ }^{303}$ Alle Geschöpfe werden von Gott geschaffen und regiert, deswegen ist es nicht recht, von Gott abzuweichen. Gott zu gehorchen, ist nach dem Prinzip der Schöpfung allgemeingültig und selbstverständlich. Konkret zeigt sich die Sünde darin, das Gesetz Gottes nicht zu halten. Gott bestimmt die Ordnung der Welt und macht die Welt darin bleiben, und so nennt man Gerechtigkeit, das Gesetz Gottes in Gänze zu halten. Sünde dagegen ist, von der Ordnung und dem Gesetz Gottes abzuweichen und so die Gerechtigkeit zu verfehlen. ${ }^{304}$ So verbindet Melanchthon die Sünde mit dem Gesetz Gottes.

Bei den Betrachtungen Melanchthons über die Gerechtigkeit des Gesetzes ist nicht nur die äußere Seite des Gesetzes als Gehorsam, sondern auch die innere Seite des Gesetzes zu bedenken. Melanchthon lehrt im PK deutlich, dass der Bereich der Sünde eine äußere Seite und auch eine innere beinhaltet. ${ }^{305}$ Das Gesetz Gottes fordert den vollkommenen Gehorsam von beiden Seiten, der äußeren und inneren.

Die innere Bosheit wird zur Wurzel der äußeren Bosheit und ist für alle Menschen allgemein. Die Menschen bezweifeln durch die innere Bosheit die Vorsehung Gottes, ehren Gott nicht und wollen mit der eigenen Weisheit die Welt regieren. ${ }^{306}$ So handeln die Menschen von Geburt an unrecht gegen das Gesetz Gottes. Alle Menschen haben so die angeborene Ungerechtigkeit, nämlich die Sünde. ${ }^{307}$ Das nennt man Erbsünde.

Die Erbsündenlehre ist für Melanchthon eine grundlegende Lehre seiner Theologie. Nach dem Sündenfall Adams sind alle Menschen Sünder von Geburt an. Die Erbsünde ist mit der Geburt gegeben, und es ist nicht möglich, die Schwachheit der Vernunft, den Zweifel, den

\footnotetext{
${ }^{303}$ Vgl. PK Ps 25, CR 13, 1056. „Propicius esto peccato, qui magnum est, seu multiplex, id est, magna caligo et aversio seu aberratio a Deo, et magna confusio omnium motuum carentium gubernatione Dei, ruens contra Deum, et ei displicens."

${ }^{304}$ Vgl. PK Ps 25, CR 13, 1055. „scio me non esse iustum legis impletione.“

${ }^{305}$ Vgl. PK Ps 14, CR 13, 1037. „Ut omne os obturetur, et reus fiat totus mundus Deo. Et alii manifestis sceleribus polluti sunt, quae iudicare ratio potest, alii vero, etiamsi non habent manifesta scelera, tamen secum circumferunt in mente dubitationes, in voluntate et corde securitatem et contentum iudicii divini, amorem sui, tyrannicas cupiditates, ambitionem, studium premendi imbecilliores, fiduciam suae potentiae, odium verae doctrinae, et alios vitiosos adfectus."

${ }^{306}$ Vgl. PK Ps 53, CR 13, 1124. „sed etiam interiora magna mala communia hominum, dubitatio de Deo et de providentia, esse sine timore Dei, et confidenter regi propria sapientia, ..." ${ }^{307}$ Vgl. PK Ps 51z, CR 13, 1227. „cum formaretur foetus, illa massa erat immunda, ...“
} 
ungerechten Willen und die Bosheit des Herzen abzulegen. ${ }^{308}$ Melanchthon erklärt dies deutlich in der Auslegung zu Psalm 51. David bekennt, dass er in der Ungerechtigkeit konzipiert wurde, indem er äußerliches Vergehen und Unreinigkeit der Natur beklagt. Dass er von Anfang an ohne Licht und Aufrichtigkeit geboren sei, beklagt er, und dass das dunkle Herz und die elende Natur von Gott abgeworfen werden sollen, verlangt er. Das ist das rechte Bekenntnis der Erbsünde. ${ }^{309}$ Somit steht die Erbsünde dem Gesetz Gottes entgegen, aus dieser Wurzel entsteht die Verderbnis des Menschengeschlechtes. ${ }^{310}$ Aus diesem Grund zeigt Melanchthon, dass die Ursache des Leidens der Menschen gerade die in ihrer Natur bestehende Sünde ist, nämlich die Erbsünde. ${ }^{311}$

Für Melanchthon steht Gott nach seiner gerechten Eigenschaft der Sünde entgegen, wie auch die Sünde Gott entgegensteht. Gott ist wahrhaft zornig gegen die Sünde ${ }^{312}$ und richtet die Sünder. Melanchthon sagt, dass die Strafe Gottes über die sündhaften Menschen der ewige Tod ist. ${ }^{313}$ In diesem Leben folgen die äußere Strafe und das Elend den Sündern nach der Ordnung Gottes, und in letztem Gericht folgt die Strafe des ewigen Todes für sie. So sind die Strafe und das Elend die Gitter für die Gottlosen. ${ }^{314}$ Dabei bemerkt Melanchthon den Willen Gottes für die Kirche. Gott erinnert alle Menschen daran, dass sie den Zorn Gottes erkennen sollen und einige sich zu Gott bekehren. ${ }^{315}$

Nach Melanchthons Auffassung darf man nicht sagen, dass Gott die Ursache der Sünde ist oder Gott die Sünde wünscht, obwohl Gott die ganze Welt geschaffen hat und noch regiert. Melanchthon erklärt, dass Gott nach seiner Eigenschaft treu, gut und gerecht ist, dass er die guten und gerechten Dinge wünscht und die Lüge und die bösen Dinge nicht wünscht, die gegen seinen Willen und sein Wort gerichtet sind. Deshalb ist Gott nicht die Ursache der

\footnotetext{
${ }^{308}$ Vgl. PK Ps 25, CR 13, 1054. „etiamsi sentimus manere in nobis magnam imbecillitatem, caliginem, dubitationes, pravos affectus, et varias flammas peccatorum. Ac nominatim fit mentio peccati nobiscum nascentis, quod vocamus peccatum seu morbum originis."

${ }^{309}$ Vgl. PK Ps 51z, CR 13, 1226. „Haec mala nobiscum nascentia dicit se agnoscere, et recte citavit hoc dictum de peccato originis."

${ }^{310}$ Vgl. PK Ps 51, CR 13, 1115. „In hac ipsa inquit pravae inclinationes sunt contra legem Dei, ex quibus oriuntur multi tristes et horrendi lapsus omnium hominum.“

${ }^{311}$ Vgl. PK Ps 32, CR 13, 1066. „Principalis causa calamitatum humanarum est, non, ut philosophi putant, materia, sed peccatum in natura hominum.“

${ }^{312}$ Vgl. PK Ps 51, CR 13, 1116. „quod vere irascatur peccato, ...“

${ }^{313}$ Vgl. PK Ps 37, CR 13, 1076. „Propter peccatum corpus nostrum morti destinatum est.“

${ }^{314}$ PK Ps 32, CR 13, 1066. „Mors et aliae miseriae humanae sunt carcer impiorum, ...“

${ }^{315}$ Vgl. PK Ps 32, CR 13, 1066. ,et commonefacit omnes homines, ut agnoscant Deum vere irasci peccatis, et aliqui ad Deum convertantur.“
} 
Sünde, er wünscht keine Sünde und erlaubt sie auch nicht. ${ }^{316}$ So beruht die Auffassung Melanchthons auf der Gerechtigkeit Gottes.

Schließlich ist noch der jüngste Tag zu erwähnen. Wenn der letzte Tag kommt, will Gott alle Menschen richten. ${ }^{317}$ Insofern werden sowohl die Frommen als auch die Gottlosen durch den Tod gedrückt. ${ }^{318}$ Dann werden die Gottlosen am jüngsten Tag zum ewigen Tod verdammt, weil sie die Sündenvergebung nicht annehmen. Im Gegenteil fordern die Frommen wahrlich die Sündenvergebung, obwohl sie anerkennen, dass sie selbst wegen der Sünde in den ewigen Tod und das Elend geworfen werden sollten. ${ }^{319}$ Ihnen wird die Sündenvergebung geschenkt. Dabei ist es auffällig, dass das letzte Gericht bei Melanchthon auf dem Gesetz Gottes als Prinzip beruht. Das Gesetz bleibt bis zum Ende.

\subsubsection{Das Gesetz als das Prinzip, mit dem Gott regiert.}

Das Gesetz wird im PK als sehr wichtig behandelt. Melanchthon erklärt so, dass die Themen der Heiligen Schrift zwei sind, nämlich das Gesetz und Evangelium. ${ }^{320}$ Bei Melanchthon beziehen sich beide Themen zueinander einerseits negativ, andererseits positiv. Den Zusammenhang hat Melanchthon nicht neu entdeckt, sondern er findet den Zusammenhang in der Wirkung der Propheten. Propheten wirken als Zeugen der wahren Interpretation des Gesetzes und der göttlichen Verheißung über den Vermittler, Christus. ${ }^{321}$ In diesem Zusammenhang soll nun betrachtet werden, was Melanchthon im PK über das Gesetz lehrt. Dabei muss man berücksichtigen, dass Melanchthon die bekannten Arten des Gesetzes unterscheidet, obwohl er bei der Auslegung der Psalmen keine begriffliche Bezeichnung zu den Arten des Gesetzes erwähnt. Es ist davon auszugehen, dass er die Psalmen mit dem vorausgesetzten Unter-

\footnotetext{
${ }^{316}$ Vgl. PK Ps 5, CR 13, 1025. „quia Deus vere sit verax, bonus, iustus, volens tantum vera, bona, iusta, et vere nolens mendacia, et omnia dicta et facta pugnantia cum sua voluntate et verbo. Ac sumitur ex hoc loco vera et necessaria doctrina, quae adfirmat Deum non esse causam peccati, nec velle nec adprobare peccatum."

${ }^{317}$ Vgl. PK Ps 58, CR 13, 1141. „In his autem exemplis iusticiae Dei cum hostes tolluntur, signa proponuntur futuri iudicii:“"

${ }^{318}$ PK Ps 32, CR 13, 1074. „Utrique pii et impii morte onerati sunt, et horrendis calamitatibus excruciantur."

319 PK Ps 32, CR 13, 1074. „Econtra vero petentes remissionem peccatorum, sciunt se propter peccatum subiectos esse morti et aliis miseriis,“"

${ }^{320}$ Der Gedanke Melanchthons folgt Luther.(WA 39,I,S.361. ,nempe ut dividamus doctrinam christianam in duas partes, scilicet in legem et evangelium.“) Vgl. PK. Prol, CR 13, 1018. „Ut universa doctrina Ecclesiae in duas partes distribuitur, videlicet legem et Evangelium,“"

${ }^{321}$ PK. Prolegomena, CR 13, 1018. „et Prophetam esse ... et testem verae interpretationis legis et promissionum divinarum de mediatore Christo.“
} 
schied der Arten des Gesetzes auslegt. Üblicherweise wird das Gesetz in drei Arten geteilt, Zeremoniengesetz, Bürgergesetz und Moralgesetz. Melanchthon folgt dieser traditionellen Einteilung. ${ }^{322}$

Melanchthon erklärt, dass der Inhalt des Gesetzes die Vorschrift und der Zuspruch ist. ${ }^{323}$ So lehrt das Gesetz das Prinzip, wie Menschen leben sollen. Das Prinzip wird auch in der Welt allgemein angewendet. Das grausamere Verbrechen soll durch die grausamere Strafe bestraft werden. ${ }^{324}$ Das Prinzip ist bestimmt und klar, obwohl es manchmal nicht richtig angewendet wird. ${ }^{325}$ Und der Maßstab des Gesetzes ist der vollkommene Gehorsam dem Gesetz gegenüber. ${ }^{326}$ Bei dem Bereich der Urteilung des Gesetzes unterscheiden sich die Welt und Gott. Die Welt urteilt nur über die äußere Handlung, aber Gott urteilt sowohl über die äußere als auch die innere. Deswegen ist das Gesetz Gottes höher als das der Welt.

Nach der Auffassung Melanchthons ist das Gesetz das Prinzip für die Regierung Gottes. Mit dem Gesetz regiert Gott die Welt. Das Gesetz ist der Maßstab der Gerechtigkeit Gottes und lehrt, wer gerecht ist. Wenn man die Gerechtigkeit nicht erreicht, ist Gott zornig, und die gerechte Strafe wird von Gott gegeben. In diesem Grund ist Gott sehr furchtbar für die Sünder. Die, die sich als Sünder erkennen, wollen Gott vermeiden. ${ }^{327}$ Allerdings ist das Gesetz als das regierende Prinzip Gottes, nämlich als das Prinzip des Gerichtes, ewig und unveränderbar. Dieses Gesetz wird nach der traditionellen Teilung als das Moralgesetz bezeichnet. Und das Gesetz verurteilt alle Menschen zum Tode.

Nach Melanchthon haben die Gläubigen dabei eine besondere Stellung inne. Sie erkennen, dass sie sündhaft sind und die Gerechtigkeit des Gesetzes nicht erreichen können und dass Gott deswegen zornig gegen sie ist. Trotzdem nähern sich sie Gott um der Lehre über die Gnade willen. ${ }^{328}$ Das verbindet sich mit dem Evangelium. Gott hat der Kirche für die Erlösung durch sein Wort die anderen Gesetze gegeben, die sich mit dem Evangelium verbinden,

\footnotetext{
${ }^{322}$ Vgl. Heubtartikel, S.228-234.

${ }^{323}$ PK. Prolegomena, CR 13, 1018. „alii magis continent doctrinam legis, id est, praecepta et adhortationes:"“

${ }^{324}$ PK Ps 49, CR 13, 1105. „Certum est atrocia delicta atrocibus poenis in hac vita puniri, ...“

${ }^{325}$ Vgl. PK Ps 49, CR 13, 1105. „Quantumvis igitur impii glorientur se regnare et florere, tamen certissimum est ruere in poenas in hac mortali vita regulariter omnes qui violant externam disciplinam.“

${ }^{326}$ Vgl. PK Ps 25, CR 13, 1054. „quia lex semper postulat conditionem perfectae obedientiae.“

${ }^{327}$ Vgl. PK Ps 113, CR 13, 1179. ,tamen in aerumnis fugiunt Deum, quia agnoscunt se reos et indignos esse, ..."

${ }^{328}$ Vgl. PK Ps 25, CR 13, 1055. „Agnosco meum peccatum, et scio me non esse iustum legis impletione. Quare confugio ad misericordiam tuam, quam patefecisti ab initio.“
} 
nämlich das Zeremoniengesetz und Bürgergesetz. Deshalb wirken diese Gesetze immer in der Verbindung mit dem Evangelium. Derartige Gesetze haben bestimmte Ziele, aber auch Grenzen, nämlich durch Christus, das Evangelium und die Kirche.

\subsubsection{Die Gesetze, die besonders der Kirche gegeben werden.}

Die Gesetze, die außer dem Moralgesetz besonders der Kirche gegeben werden, sind das Bürgergesetz und das Zeremoniengesetz. Melanchthon erklärt im PK, dass beide Gesetze eine enge Beziehung zum Messias, dem Evangelium und der Kirche haben. Diese Gesetze haben anders als das Moralgesetz - zeitliche Grenzen, und nach der Erfüllung des Ziels gelten sie nicht mehr. Aber die Gesetze vollenden sich im Evangelium mit der wahren reichen Bedeutung. So haben diese Gesetze einen positiven Zusammenhang mit dem Evangelium. Deshalb spielt das Evangelium eine Rolle für das wahre Verständnis des Gesetzes. So bezieht Melanchthon das Gesetz eng auf das Evangelium, besonders soll man das Bürgergesetz und das Zeremoniengesetz direkt in Bezug auf das Evangelium betrachten.

Das Zeremoniengesetz wird als das Gesetz über die Priester und Opfer bezeichnet. Priester predigen das Gesetz und befolgen die Zeremonien. ${ }^{329}$ Aber Melanchthon stellt fest, dass durch die Opfer, die durch das Gesetz gestiftet werden, die Sünde und der Tod nicht weggeräumt werden. ${ }^{330}$ Nach Melanchthon sind die Priester ein Vorgänger des besseren Priesters, nämlich des Messias. ${ }^{331}$ Deshalb vollendet sich das Zeremoniengesetz selbst nicht, sondern das ist eine Erklärung und Voraussage über das Werk des Messias. ${ }^{332}$ Das Ziel des Gesetzes über die Priester und Opfer vollendet sich so durch den Gehorsam des Messias, dass er mit seinem Opfer die Sünde und den Tod wegräumt und den Zorn Gottes versöhnt. Nach dem Werk des Messias wird das Zeremoniengesetz abgeschafft. ${ }^{333}$ Mit anderen Worten, das Zeremoniengesetz zeigt das wahre Opfer des Messias und vollendet sich, als der Messias in die

\footnotetext{
${ }^{329}$ Vgl. PK Ps 110, CR 13, 1159. „Sacerdos typicus est certus minister ordinatus ad docendam legem, et ad sacrificia ceremonialia, ...“

${ }^{330}$ PK Ps 40, CR 13, 1082. „Et clare adfirmat his sacrificiis non tolli peccatum et mortem.“

${ }^{331}$ Vgl. PK Ps 110, CR 13, 1159. „et ostenderet signa esse venturi Messiae, quod qui faciebant non tantum typici, ...“

${ }^{332}$ Vgl. PK Ps 40, CR 13, 1081. „Filius Dei ipse offert se, ut fiat victima. Tunc dixi, Ecce venio. Et ait de se scriptum esse in lege, promissiones de ipso editae et promulgatae sunt. Lex lata est, et omnes illi cultus instituti, ut significarent venturum Messiam, ..."

${ }^{333}$ Vgl. PK Ps 40, CR 13, 1082. „Concionatur ergo haec pars de abrogatione legis, et testatur mactationibus pecudum non potuisse tolli peccatum et mortem, sed Messiae obedientia placatam esse iram Dei.“
} 
Erde kommt. ${ }^{334}$ Allerdings bedeutet die Abschaffung des Zeremoniengesetzes nicht seine Wertlosigkeit. Bei Melanchthons ist es klar, dass das Zeremoniengesetz von Gott überliefert wird und deutlich auf das wichtigste Opfer des Messias hinweist. Damit kritisiert Melanchthon den Unverstand derer, die das Zeremoniengesetz noch halten wollen, obwohl der Messias schon das Opfer fertig dargebracht hat, auf das vollends das Zeremoniengesetz hinweist. Nun ist das Zeremoniengesetz wert allein als ein Zeichen auf das Opfer des Messias.

Nun geht es um das Bürgergesetz. Bei der Erklärung des Mosaischen Gesetzes im PK erwähnt Melanchthon das Bürgergesetz, das mit dem bestimmten Ort und der Bewahrung der politischen Einrichtung verbunden ist. Und nach der Zerstörung Jerusalems liegt die Kirche im Ort, wo die wahre Lehre verkündigt wird. ${ }^{335}$ Melanchthon bezieht so das Bürgergesetz auf die Kirche, wenn er die Besonderheit des Volkes Gottes als die Offenbarung der Verheißung, die Erlassung des Gesetzes und die Bewahrung Gottes erklärt. ${ }^{336}$ Immerhin mündet der Inhalt des Gesetzes, das von Mose gelehrt wurde, in die Kirche ein. Die Zeit des Gesetzes Mose bereitet das Volk und die Erde auf das Kommen des Messias vor, und das Gesetz lehrt das Werk, das Leiden und die Auferstehung des Messias, bewahrt die wahre Lehre Gottes und erhält seine Versammlung, der Gott seine Verheißung gibt und erklärt. Nach der Meinung Melanchthons erwählt dafür Gott Abraham und seine Nachkommen. Aber das Bürgergesetz gilt nicht mehr, als Jesus Christus ankommt, das Erlösungswerk erfüllt und die Apostel beruft, um in allen Völkern das Evangelium zu verkündigen und die Kirche zur ganzen Welt zu erweitern. ${ }^{337}$ Deshalb nun lässt sich das Privileg des Volkes Gottes, das Israel genossen hat, auf die Kirche anwenden. So ist die Auffassung Melanchthons über das Volk Israel klar, dass das Volk Israel außergewöhnlich war, aber nun nicht mehr ist. Damit erweist sich der Unterschied zwischen dem vergangenen Gesetz und dem ewigen Gesetz bei Melanchthon. Allerdings

\footnotetext{
${ }^{334}$ Vgl. PK Ps 110, CR 13, 1160. „et ostenderet signa esse venturi Messiae, quod qui faciebant non tantum typici, sed etiam vere sacerdotes erant, sed quatenus legem et ceremonias proponebant, tantum erant typici sacerdotes, id est, significabant aliud melius sacrificium, quo homines sanctificarentur.“

${ }^{335}$ Vgl. PK Ps 46, CR 13, 1096. „Tempore legis Mosaicae nominatus fuit certus locus, nunc non nominatus est certus locus, et tamen dat Deus aliqua domicilia, sicut enim in populo Israël promissionem potius de Ecclesia quam de loco intelligi voluit. Ideo dispersit decem tribus, et postea abduxit tribum Iuda in Babylonem, deleta Hierosolyma, ut scirent Ecclesiae sedem ibi fore, ubicunque vera doctrina sonaret, nec superstitiose ad locum alligandam esse promissionem."

${ }^{336}$ Vgl. PK Ps 111, CR 13, 1170. „tamen hic principaliter loquitur de vocatione huius populi, et segregatione a caeteris gentibus, de revelatione promissionum, et de promulgatione legis, ...“

${ }^{337}$ Vgl. PK Ps 45, CR 13, 1093. „Et clare significatur hic Ecelesiam colligendam esse ex semine Abrahae, et ex gentibus. Imo et hoc tecte significat, politiam Mosi delendam esse, quia iubet Ecclesiam collectam ex semine Abrahae oblivisci populi sui.“
} 
meint diese Änderung keine Wertlosigkeit des Bürgergesetzes, das Gott Moses gegeben hat, sondern das Bürgergesetz Moses vollendet sich in der Kirche und erscheint als die wahre reiche Bedeutung, wie das Zeremoniengesetz im Evangelium.

Das Zeremoniengesetz und Bürgergesetz selbst gelten nicht mehr, als der Messias auf der Erde ankommt, das Werk des Evangeliums erfüllt, und das Evangelium der ganze Welt verkündigt wird. Allerdings vollzieht sich deren Abschaffung nicht, weil sich das Gesetz dem Evangelium widersetzt, sondern weil der Gegenstand von dem Zeremonien- und dem Bürgergesetz erscheint und das Ziel des Zeremonien- und Bürgergesetzes sich so vollendet. Darin zeigt sich die wahre Bedeutung des Gesetzes, das Gott der Kirche durch das Wort überliefert hat. Die beiden Gesetze verlieren zeitlich die Gültigkeit, zeigen aber ihre wahre Bedeutung im Evangelium und der Kirche. Deswegen weist Melanchthon darauf hin, dass das Gesetz über den Sohn Gottes, geschrieben wird. ${ }^{338}$ Das Gesetz und die Zeremonien sollen durch das Licht des Evangeliums recht interpretiert werden. ${ }^{339}$ Aber Melanchthon merkt, dass die Gottlosen, die das Evangelium nicht annehmen, kein richtiges Verständnis über das Gesetz haben.

\subsubsection{Das unrichtige Verständnis der Gottlosen über das Gesetz}

Wenn das Gesetz von Melanchthon im PK im negativen Sinne gedeutet wird, meint er damit, durch das eigene Verdienst des Gesetzes die Gerechtigkeit zu gewinnen. Ein solches Verständnis des Gesetzes stellt Melanchthon in einen Gegensatz zum Evangelium. ${ }^{340}$ Denn die Gottlosen verwechseln die Gerechtigkeit des Gesetzes mit dem Evangelium, wenn sie die Gerechtigkeit als Verdienst durch das Einhalten des Gesetzes statt sie als gnädige Sündenvergebung gewinnen wollen. ${ }^{341}$ Melanchthon weist darauf hin, dass mit dieser Ursache die Juden in der Vergangenheit töricht Christus kreuzigten und dass in seiner Zeit die Mönche das Gesetz lehren und befehlen, das Gesetz zu halten. ${ }^{342}$ Aber Melanchthon lehrt deutlich, dass die

\footnotetext{
${ }^{338}$ Vgl. PK Ps 40, CR 13, 1081. „Filius Dei ipse offert se, ut fiat victima. Tunc dixi, Ecce venio. Et ait de se scriptum esse in lege, promissiones de ipso editae et promulgatae sunt.“

339 PK Ps 50, CR 13, 1108. „quia homines sine luce Evangelii, non recte intelligunt legem et ceremonias."

${ }^{340}$ Vgl. PK Ps 55, CR 13, 1130. „sciendum esse quid sit fides et quomodo iusti reputemur, ne hae consolationes excutiantur animis falsa persuasione de iusticia legis:“

${ }^{341}$ Vgl. PK Ps 32, CR 13, 1065. „et multi ineruditi confundunt genera doctrinarum, Legem et Evangelium.“

${ }^{342}$ Vgl. PK Ps 47, CR 13, 1099. „Iudaei non psallunt Messiae sapienter, cum fingunt regnum politicum et interiturum, imo cum fascinati hac persuasione crucifigunt Messiam. Id nequaquam erat iubilare et sapienter psallere. Sic de caeteris impiis doctoribus omnium temporum iudicemus. Non
} 
Sündenvergebung um des Vermittlers, des Sohnes Gottes willen frei gegeben wird, nicht um des Gesetzes willen. ${ }^{343}$

Melanchthon erklärt im Psalm 50, dass die Auffassung der Gottlosen über das Gesetz auf einer Verkennung des Zeremoniengesetzes beruht. Melanchthon teilt die Menschen in drei Gruppen bei der Erklärung zu den Zeremonien und dem wahren Gottesdienst im Psalm 50. Erstens, absolute Atheisten. Sie verachten die Zeremonien und den wahren Gottesdienst, sie fürchten das Gericht Gottes nicht. Trotzdem ist es klar, dass sie verurteilt werden. Und sie sind nicht viele. Die zweite Gruppe ist die der Menschen, die wissen, dass Gott existiert. Wenn sie aber kein wahres Gesetz haben und dessen Bedeutung nicht erkennen, ist ihr Wissen über Gott vergeblich. Sie denken sich ihr Wissen über Gott aus und meinen, dass Gott in den Zeremonien und den moralischen Handlungen wirke. Sie glauben, dass ihre Sünde durch ihre Zeremonien kompensiert werde. Aus diesem Grund erfinden die Heiden vielfältige Zeremonien und schreckliche Dinge, z.B. Menschenopfer. Der Gedanke über die Zeremonien für die Versöhnung mit Gottes ist eine Spur der wahren Zeremonien Gottes, wie die Gotteserkenntnis in der Welt, aber die Spur ist nicht hinreichend und kann deswegen von Gott nicht angenommen werden. Allerdings halten die Gottlosen ihr Wissen und ihre Zeremonien für gerecht. Auf dem gleichen Verständnis beruhen die Opfergaben der Juden und auch die Zeremonien der Mönche und der Heiden. Auf diesem Verständnis der Zeremonien verharrt die Mehrzahl der Menschen. Sie glauben, durch die besonderen Zeremonien Gott erfreuen zu können und dadurch die Sündenvergebung zu erhalten. Sie denken, dass diese besonderen Tugenden, nämlich die Zeremonien, besser seien als eine moralische Handlung. Dann beginnen ihre Frevel, sie begehen Verbrechen nach ihrer Begierde, weil diese Verbrechen durch die Zeremonien kompensiert werden können. ${ }^{344}$ Diese Gottlosen haben kein Interesse an der Ehre Gottes, sondern nur an ihrer Kraft und ihrer Annehmlichkeit. ${ }^{345}$ Dazu erwähnt Melanchthon, dass einige noch weiter gehen, indem sie denken, dass die Zeremonien die Hauptlehre seien, deswegen sind sie zornig gegenüber denen, die verneinen, durch die Zeremonien die Sünden-

sapienter psallunt monachi, qui tantum docent legem et iubent dubitare, atque ita delent Evangelium et doctrinam de fide."

${ }^{343}$ PK Ps 40, CR 13, 1099. „Testatur enim remissionem peccatorum dari propter Filium Dei mediatorem, Gratis, non propter legem.“

${ }^{344}$ PK Ps 50, CR 13, 1107.

${ }^{345}$ Vgl. PK Ps 50, CR 13, 1108. „Nam multi cum vident ceremonias esse nervos potentiae suae, aut aucupia quaestus, sine modo eas laudari volunt, non propter gloriam Dei, sed ad stabiliendam potentiam, et augendum quaestum.“ 
vergebung zu gewinnen. Obwohl die Frommen die wahre Anwendung der Zeremonien lehren, versuchen diese Gottlosen die Frommen zu zerstören. ${ }^{346}$ Die Gottlosen beflecken die wahre Auffassung über das Gesetz, setzen sich mit dem Zorn den frommen Lehrern zuwider, ${ }^{347}$ betrügen die Kirche mit den unfrommen Lehren, setzen sich Gott zuwider und beleidigen Gott. ${ }^{348}$ Dagegen lehrt Melanchthon, dass Gott sich der Meinung der Gottlosen entgegensetzt und sie tadelt, die die Gegner der Wahrheit sind. Weil die Gottlosen ohne das Licht des Evangeliums das Gesetz und die Zeremonien verstehen wollen, entsteht die schreckliche Folge, denn Jerusalem wurde aus diesem Grund zerstört. ${ }^{349}$ Die meisten Menschen bleiben bei dieser Auffassung.

Drittens geht es um die, die das Gesetz wissen, hören und wahrlich erkennen. Diese erkennen die Verheißung der Sündenvergebung, die durch die Gnade vom Vermittler gegeben wird. Sie hören die unveränderlichen Befehle Gottes und glauben, dass sie durch die VerheiBung angenommen werden und dass ihre Gebete von Gott erhört werden. ${ }^{350}$ Gott überliefert mit dem deutlichen Zeugnis der Kirche das Gesetz und die Verheißung, dadurch wünscht Gott geehrt zu werden. Deshalb muss man zuerst durch das Stimme des Gesetzes Gott fürchten, dann die Verheißung hören, sich mit dem Vertrauen Gott nähern, Gott anrufen und die Wohltaten durch die Verheißung des Vermittlers erwarten. Somit verursacht das Gesetz die Furcht und es fordert den Vermittler zu sehen. Bei Melanchthon ist diese kirchliche Erkenntnis über das Gesetz einzig wahrhaft.

\subsubsection{Die Funktion des Gesetzes}

Im PK stellt Melanchthon als wichtige Funktion des Gesetzes vor, die Furcht vor Gott zu bewirken. Die Erlösung wird nicht durch Verdienst als Einhaltung des Gesetzes gewonnen. Niemand kann vollkommen gesetzestreu leben und mit der sündhaften Natur sündlos blei-

\footnotetext{
${ }^{346}$ Vgl. PK Ps 50, CR 13, 1108. „Alii qui videntur graviores, qui iudicant ceremonias esse disciplinae nervos, ut sunt aliquo modo, vehementius etiam irascuntur iis, qui negant hos cultus mereri remissionem."

${ }^{347}$ Vgl. PK Ps 36, CR 13, 1072. „Huic artificiosae imposturae proxima est calumnia, qua corrumpunt veras sententias, ..."

${ }^{348}$ Vgl. PK Ps 36, CR 13, 1073. „Hic aperte doctrina impia taxatur, quae est mendacium perniciosum Ecclesiae, et contumeliosum contra Deum.“

${ }^{349}$ PK Ps 50, CR 13, 1108. „Ideo funditus deleta est Hierosolyma, quia stante politia Iudaica, semper mansisset opinio, tam pulcros ritus, divinitus ordinatos, necessarios cultus Dei esse.“

${ }^{350}$ Vgl. Ps 50, CR 13, 1108. „Et scit mandatum Dei esse immotum, ut iuxta hanc promissionem credamus nos recipi et exaudiri:“"
} 
ben. ${ }^{351}$ Nach Melanchthon zeigt das Gesetz den Sündern nur die Strafe des ewigen Todes als das ewige Prinzip der Regierung Gottes. Durch das Gesetz kann der Sünder die Sache erkennen, dass er Sünder vor Gott ist und dass der ewige Tod folgt. Dabei spielt das Predigtamt eine Rolle, weil durch das Hören des Gesetzes die Furcht vor Gott entsteht. ${ }^{352}$ Alle Menschen haben Furcht vor Gott wegen der Sünde, aber nach der Erkenntnis der Furcht vor Gott entsteht ein großer Unterschied zwischen der Kirche und den Gottlosen. Obwohl die Gläubigen den Zorn Gottes gegen die Sünde erkennen und Furcht vor Gott haben, nähern sie sich Gott und bekennen, dass sie mit der Ungerechtigkeit geboren wurden und die äußeren Verbrechen und die Unreinigkeit ihrer Natur haben. ${ }^{353}$ Das Gesetz klagt die Bosheit und Schwäche der Menschen an, aber es sagt zugleich den Messias vorher, der die Bosheit und Schwäche heilt und die Gläubigen erlöst. Dies erkennen die Gläubigen. Dabei verbindet Melanchthon das Gesetz mit dem Evangelium. Der Messias folgt dem Gesetz für die Auserwählten, nämlich für die Kirche und lädt ihre Strafe auf sich. ${ }^{354}$ Deswegen bedeutet das Bekenntnis der Gläubigen, dass der Messias ihre Sünde von den Gläubigen abbringt und ihre Strafe auf sich lädt und dass sie sich Gott durch den Gehorsam des Messias und seine Gerechtigkeit nähern können. Für Melanchthon spielt die Furcht vor Gott eine positive Rolle für die Kirche, denn sie führt die Gläubigen zu Gott. Diese Funktion nennt man usus elenchticus oder theologicus legis, ${ }^{355}$

Außerdem erklärt Melanchthon das Gesetz als das unveränderliche Prinzip des Lebens der Menschen. Dies gilt vor allem in der Kirche. Gott wünscht, dass die Gläubigen sein Tempel seien, dass sie mit Gott übereinstimmen und dass in ihnen seine Weisheit und Gerechtigkeit leuchte. ${ }^{356}$ So fordert Gott die gerechten Taten im Leben der Gläubigen. Dabei ist selbstverständlich das Gesetz Gottes von Bedeutung. Melanchthon lehrt, dass das Gesetz für wichtig gehalten werden soll, damit Gott die Liebe und Übereinstimmung mit der Kirche wiederherstellt. ${ }^{357}$ Im Leben der Mitglieder der Kirche spielt das Gesetz eine Rolle als Maßstab des Lebens. Sie leben in diesem Leben als die Gerechten nach dem Gesetz, weil sie durch die

\footnotetext{
${ }^{351}$ Vgl. PK Ps 15, CR 13, 1039. „quae concionatur de lege, quomodo, cum legi nemo satisfaciat, ...“ ${ }^{352}$ Vgl. PK Ps 50, CR 13, 1110, ,audita legis voce me timeas ...“

${ }^{353}$ Vgl. PK Ps 51z, CR 13, 1226. „quod peccatum deploret, scilicet non tantum externa delicta, sed naturae immunditiem.“

${ }^{354}$ PK Ps 40, CR 13, 1081. „Ego vere et toto corde obediam, sustinebo poenas pro electis, ac redimam Ecclesiam meo sanguine, ..."

${ }^{355}$ Vgl. Scheible 2010

${ }^{356}$ Vgl. PK Ps 133, CR 13, 1220. „et secum congruere, imo vult nos sua templa esse, nobis sese communicare, et in nobis suam sapientiam et iusticiam lucere."

${ }^{357}$ Vgl. PK Ps 133, CR 13, 1220 , ,quae vere est Ecclesia Dei restituatur dilectio et concordia, ...“
} 
Wirkung des Sohnes gerecht werden. Sie sind nämlich wiedergeboren. Allerdings ist klar, dass die Gläubigen nicht wegen des Gesetzes oder ihres eigenen Wertes gerecht werden. Melanchthon sagt, dass nach ihrer Wiedergeburt der Gehorsam mit der Einhaltung des Gesetzes beginnt. ${ }^{358}$ Hiermit berücksichtigt Melanchthon die Funktion des Gesetzes im Leben der Gläubigen. Für die Mitglieder der Kirche bezieht sich das Einhalten des Gesetzes allerdings nicht auf die Erlösung. Diese Funktion nennt man usus tertius legis. ${ }^{359}$

Obwohl die Gläubigen an Gott glauben und durch das Wort und den Heiligen Geist wiedergeboren sind, können sie aber den Forderungen des Gesetzes nicht genügen. Zwar bleiben die Gläubigen in der Sünde. ${ }^{360}$ Wenn man sagt, dass die Gläubigen das Gesetz halten, bedeutet dies nicht, dass die Gläubigen das Gesetz vollständig halten und halten können. Solchen Gehorsam gibt es auch bei den Gläubigen in diesem Leben nicht. Nach der Auffassung Melanchthons ist es unmöglich, in diesem Leben nach der Bekehrung den vollständigen Gehorsam zu erfüllen. Für Melanchthon bedeutet der Gehorsam der Gläubigen, die wahre Lehre zu bewahren ${ }^{361}$ und sie unter dem Glauben und dem guten Gewissen zu tun. ${ }^{362}$ Das ist nur möglich, wenn Gott mit den Gläubigen ist.

In Bezug auf das Gesetz haben die Mitglieder der Kirche einen Charakter. Das Volk Gottes vergisst das Gesetz Gottes nicht. ${ }^{363}$ Melanchthon lehrt, das Gesetz und die Lehre der Verheißung über den Messias und die Gnade im Glauben fest zu halten. Seine Aussage ist die: wer mich liebt, mein Wort hält und sich über den Befehl freut, ist der, der im Gesetz unbefleckt lebt. Und das meint, durch den Glauben die von Gott überlieferte Lehre zu halten. Das erfreut Gott. Die Gläubigen rufen Gott im Vertrauen an den Vermittler an und gehorchen Gott mit gutem Gewissen. Das ist das Leben von dem, der im Gesetz lebt. ${ }^{364}$ Bei Melanchthon

\footnotetext{
${ }^{358}$ Vgl. PK Ps 53, CR 13, 1123. „et incipiunt Deo obedire, ...“

${ }^{359}$ Scheible 2010

${ }^{360}$ Vgl. PK Ps 15, CR 13, 1039. „et quae peccata maneant in renatis in hac vita, ...“

${ }^{361}$ Die Aufgabe der Bewahrung der wahren Lehre als das Einhalten des Gesetzes ist auffällig. Bei Melanchthon liegt diese Aufgabe auf der Kirche. Das Leben im Gesetz zeigt nicht nur das Einhalten des Gesetzes, sondern auch die Bewahrung der wahren Lehre. Die Aussage Melanchthons könnte sich auf die Wirklichkeit seiner Kirche beziehen, weil die Gefahren seiner Kirche sich auf die Bewahrung der wahren Lehre richten.

${ }^{362}$ Vgl. PK Ps 119, CR 13, 1189. „sed de custodia incorruptae doctrinae in fide et bona conscientia, ita intelligantur similia verba in hoc Psalmo, Ambulantes in lege tua.“

${ }^{363}$ Vgl. PK Ps 119, CR 13, 1200, „quia legem tuam non sum oblitus, etc.“

${ }^{364}$ Vgl. PK Ps 112, CR 13, 1174. „Ita hic intelligatur dictum, Qui delectatur mandatis, sicut et Psalmo, Beati immaculati qui ambulant in lege Domini, id est, qui vera fide amplectuntur doctrinam a Deo traditam, et iuxta eam invocant ipsum fiducia Mediatoris, et bona conscientia ei obtemperant.“
} 
funktioniert das Gesetz nicht als das Erlösungsmittel, sondern als ein Prinzip für das gerechte Leben der Gläubigen. Und die Gläubigen sollen im Gesetz mit dem Glauben und dem guten Gewissen leben und die wahre Lehre unbefleckt bewahren.

\subsubsection{Zusammenfassung}

Melanchthon legt immer die Kirche in den Mittelpunkt, wenn er im PK das universale allgemeine Prinzip, nämlich die Schöpfung und die Vorsehung erklärt, dass Gott sich auf die Welt bezieht. Gott wirkt allgemein und universal in der Schöpfung und der Vorsehung, aber er hat immer einen besonderen Plan für die Kirche. Die Gottlosen verstehen diesen Plan Gottes nicht, weil sie die Kirche nicht für besonders halten, die unter das Kreuz und das Leiden gelegt wird. Melanchthon weist darauf hin, dass diese Auffassung der Gottlosen und das Leiden der Kirche sich auf die Sünde beziehen.

Melanchthon lehrt die Sünde als von Gott abzuweichen. Dagegen ist Gerechtigkeit, nicht nur die menschliche äußere Regel, sondern die absolute Regel Gottes in innerer und äußerer Seite einzuhalten. Nach dem Sündenfall Adams sind alle Menschen mit der Erbsünde geboren, deswegen können sie dem Maßstab Gottes Genüge nicht tun, der als das Moralgesetz bezeichnet wird. Nur bleibt das Gericht Gottes zum Tod für die Sünder. Allerdings erklärt Melanchthon noch andere Gesetze Gottes für die Kirche, das Bürgergesetz und das Zeremoniengesetz, die sich auf den Messias beziehen und für die Erlösung der Kirche wirken. Die Gesetze vollenden sich und wurden abgeschafft, nach der Ankunft Messias. Die Gottlosen verkennen die Funktion dieser Gesetze.

Bei Melanchthon funktioniert das Moralgesetz als das ewige Prinzip Gottes immer noch, aber nicht um die Erlösung durch das Einhalten des Gesetzes zu gewinnen, sondern um die Furcht vor Gott zu bewirken und die rechte Lebensregel Gottes zu zeigen. Das Gesetz ist in der Kirche besonders wirksam. So im PK ist zu ersehen, dass das universale Prinzip Gottes immer gilt und in diesem Mittelpunkt die Kirche steht. Dazu erklärt Melanchthon das Leben im Gesetz als die Bewahrung der wahren Lehre. Die Aussage Melanchthons bezieht sich auf die Wirklichkeit seiner Kirche. 


\subsection{Das Evangelium als das Prinzip für die Erlösung}

\subsubsection{Die Beziehung des Evangeliums zum Gesetz}

Für Melanchthon ist das Evangelium ein weiteres wichtiges Thema der heiligen Schriften, wie das Gesetz. Nach Melanchthons Auffassung gibt Gott der Kirche das Evangelium als anderes Prinzip für die Erlösung statt des Gesetzes, damit Gott die Kirche aus dem Menschengeschlecht sammelt. Er erklärt das Evangelium im Zusammenhang mit dem Gesetz. Dabei verwendet er den Begriff des Gesetzes in einer breiten Bedeutung. Aussagen wie: die philosophische Erkenntnis, ${ }^{365}$ die weltliche Meinung, ${ }^{366}$ das Urteil der Vernunft und der Satz des Gesetzes, ${ }^{367}$ die Heiden, ${ }^{368}$ die Vernunft und das Gesetz ${ }^{369}$ und das Gesetz Mose ${ }^{370}$ werden als Gegensatz zum Evangelium angewendet. Dabei bezeichnet Melanchthon das Gesetz als das allgemeine und universale Prinzip Gottes, nämlich das Moralgesetz.

Bei Melanchthon liegt der größte Unterschied zwischen dem Evangelium und dem Gesetz vor allem in der Sündenvergebung. Die Erkenntnis über die weltlichen Ordnungen und die philosophische Erkenntnis, besonders über das Moralgesetz ist ein Teil des Wortes Gottes, aber diese beinhaltet kein Evangelium über die Sündenvergebung. ${ }^{371}$ Diese Erkenntnis gehört zum allgemeinen Prinzip Gottes. Durch diese Prinzipien enthüllen sich die Sünder und die Schwachheit der Menschen, und die Menschen werden durch das Gesetz angeklagt, weil das Gesetz immer den vollkommenen Gehorsam fordert. ${ }^{372}$ Melanchthon stellt die Situation so dar, dass das Gewissen unsere Unwürdigkeiten ausspricht und uns anklagt, aber die Lehre des Evangeliums über die gnädige Sündenvergebung der Anklage entgegenstellt. ${ }^{373}$ Ohne das Evangelium spricht das Gesetz über den Menschen allein die Verurteilung zum Tod.

Dann weist Melanchthon auf die Folgen des Evangeliums hin. Das Evangelium hat durch die Sündenvergebung andere Folgen als das Gesetz im Zusammenhang mit Gott. Gott nimmt einige vom Menschengeschlecht durch die Sündenvergebung an. Dabei bemerkt Melanchthon

\footnotetext{
${ }^{365}$ PK Ps 19, CR 13, 1045. „,noticia illa philosophica“

${ }^{366}$ PK Ps 29, CR 13, 1062. „mentes prophanae“

${ }^{367}$ PK Ps 34, CR 13, 1070. ,a iudicio rationis, et sententiis legis“

${ }^{368}$ PK Ps 28, CR 13, 1060. „Ethnici, ut Cato, Brutus et similes“

${ }^{369}$ PK Ps 51z, CR 13, 1032 ,ratio et lex“

${ }^{370}$ PK Ps 19, CR 13, 1046 ,lex Mosi““

${ }^{371}$ PK Ps 19, CR 13, 1045. „Nam noticia illa philosophica etiam gentibus nota est, et utcunque est particula legis Dei, sed non complectitur Evangelium de remissione peccatorum.“

${ }^{372}$ PK Ps 25, CR 13, 1054. „quia lex semper postulat conditionem perfectae obedientiae.“

${ }^{373}$ PK Ps 23, CR 13, 1051. „Obstrepit autem nobis indignitas nostra et accusat nos conscientia, ... sed opponatur huic accusationi doctrina Evangelii de gratuita remissione peccatorum.“
} 
das andere Urteil des Gesetzes. Die Vernunft und das Gesetz besagen, dass die Menschen elend, durch die Schmerzen unterdrückt und von Gott abgelehnt sind. Dagegen behauptet die Stimme des Evangeliums, dass diese Menschen die Tempel Gottes sind. ${ }^{374}$ Mit anderen Worten: alle, die Gott anrufen und durch das Vertrauen auf den Sohn Gottes an die Sündenvergebung glauben, werden um des Sohnes Gottes willen umsonst gleich angenommen. Diese Lehre der Annehmung ist anders als das Urteil der Vernunft und der Satz des Gesetzes. ${ }^{375}$ Somit zeigt sich der Wille Gottes für die Erlösung der Kirche im Evangelium wahrhaft und ehrlich.

Außerdem erwähnt Melanchthon noch eine Folge des Evangeliums. Das Evangelium führt die Menschen zur Bitte um die Sündenvergebung. Denn die Sündenvergebung wird durch die Gnade und die Barmherzigkeit Gottes gegeben, nicht durch das Einhalten des Gesetzes. ${ }^{376}$ Nach Melanchthon behaupten die Juden und Mönche, die das unrichtige Verständnis vom Gesetz haben, dass das Gesetz für die Erlösung eingehalten werden solle. So zerstören sie das Evangelium und die Lehre des Glaubens. ${ }^{377}$ Bei Melanchthon ist die Sündenvergebung nicht durch das Einhalten des Gesetzes zu erhalten, sondern von Gott gegeben, deshalb soll man Gott darum bitten.

Darüber hinaus zeigt Melanchthon den göttlichen Willen in Bezug auf die Erlösung der Kirche durch die Sündenvergebung im Evangelium. Die Lehre des Evangeliums ist über die Sündenvergebung außer und über die Philosophie und das Urteil der menschlichen Vernunft gestellt und ist unterschieden vom Gesetz. In der Stimme des Evangeliums enthüllt der geheime Wille über die gnädige Sündenvergebung und den wahren Trost im Kreuz. ${ }^{378}$ Daher kann die menschliche Vernunft den Willen Gottes in Bezug auf die Erlösung der Kirche nicht verstehen, bevor Gott ihr ein richtiges Verständnis für seinen Willen gibt.

Noch einen anderen wichtigen Unterschied zwischen dem Evangelium und dem Gesetz findet Melanchthon in Bezug auf unterschiedliche Gegenstände. Das Gesetz wird auf das

\footnotetext{
${ }^{374}$ PK Ps 51z, CR 13, 1032. „Nam ratio et lex dicunt, homines miseros et oppressos doloribus reiectos esse a Deo. Vox Evangelii affirmat hos esse templa Dei, ...“

${ }^{375}$ PK Ps 34, CR 13, 1070. „Postquam autem scimus recipi propter Filium Dei gratis aequaliter omnes qui Deum invocant, et fiducia Filii Dei credunt sibi remitti peccata, ... Haec doctrina aliena est a iudicio rationis, et sententiis legis, ...“

${ }^{376}$ Vgl. PK Ps 25, CR 13, 1054. „At hic petitur remissio peccati, Testatur ergo dari remissionem peccatorum, et est vox Evangelii docens totam Ecelesiam de hoc articulo, videlicet de remissione peccatorum certa et gratuita, donata per misericordiam, quae ex voce legis non potest esse certa, ..."

377 PK Ps 47, CR 13, 1099. ,atque ita delent Evangelium et doctrinam de fide.“

${ }^{378}$ PK Ps 32, CR 13, 1065. „Haec tota doctrina extra et supra philosophiam et rationis humanae iudicium posita est, et discernenda est a lege. Est enim vox Evangelii, in quo patefit arcana voluntas de gratuita remissione peccatorum, et de vera consolatione in cruce.“
} 
ganze Menschengeschlecht angewendet, aber das Evangelium nur auf die Kirche. Daher stellt Melanchthon dar, dass Gott die Kirche durch die Stimme des Evangeliums sammelt ${ }^{379}$ und dass die Kirche das Evangelium annimmt. ${ }^{380}$ Dann hat Gott eine besondere Beziehung zur Kirche. Gott bewahrt die Kirche in diesem Leben, bindet sie im ewigen Leben an sich und schmückt die Kirche mit den ewigen Guten. ${ }^{381}$ Und nach der Annahme des Evangeliums verkündigt die Kirche die reine Stimme des Evangeliums und ruft Gott wahrlich an. ${ }^{382}$

Melanchthon unterscheidet die Kirche durch das Evangelium von anderen Versammlungen, wie die Politik Israels sich von den antiken politischen Regierungen unterscheidet, weil Gott dem Volk Israel die Verheißung der Bewahrung gibt, damit ein Ort der Lehre existiert. ${ }^{383}$ Aber die, die das Evangelium nicht besitzen, verweigern das Evangelium, verachten Gott, versuchen, die Stimme des Evangeliums und die Kirche zu vernichten ${ }^{384}$ und streiten gegen die Stimme des Evangeliums, weil das Evangelium lehrt, dass die Erlösung außer der Kirche nicht besteht. ${ }^{385}$ Hierin zeigt sich die Auffassung Melanchthons über die Intoleranz des Evangeliums zum Thema der Erlösung. Bei Melanchthon ist das Evangelium die einzige Lösung der menschlichen Unerlöstheit.?

\subsubsection{Das Evangelium, das als Verheißung gegeben wird.}

Melanchthon erklärt das Evangelium als Form der Verheißung. Melanchthon erklärt, dass Gott die Verheißungen gibt und wünscht, dass die Kirche diese durch den Glauben annimmt. ${ }^{386}$ Gott ist das die Verheißungen gebende Subjekt. Die Kirche ist das Objekt, das die

\footnotetext{
${ }^{379}$ PK Ps 117/118, CR 13. 1183. „colligit eam voce Evangelii ...“ und vgl. PK Ps 111, CR 13, 1168. „colligis tibi aeternam Ecclesiam voce Evangelii inter nos ..."

${ }^{380}$ PK Ps 36, CR 13, 1074. „videlicet eam quae amplectitur Evangelium, ...“

${ }^{381}$ PK Ps 36, CR 13, 1074. „Hanc vero Ecclesiam non solum in hac vita servat, sed etiam adiunget sibi in vita aeterna, et ornabit aeternis bonis."

${ }^{382}$ Vgl. PK Ps 46, CR 13, 1096. „,de coetu puram Evangelii vocem sonante, et recte Deum invocante.“ und vgl. PK Ps 48, CR 13, 1101. „et hic vere esse Ecclesiam, ubi vox Evangelii sonat, acquiescamus in Deo monstrato per Evangelium, invocemus eum, petamus ab eo bona, ..." und vgl. PK Ps 40, CR 13, 1083. „necesse est igitur sonare vocem Evangelii in Ecclesia“ und vgl. PK Ps 52, CR 13, 1121. „ut semper aliqui sint superstites custodes Evangelii, vere invocantes Deum, ...“

${ }^{383}$ Vgl. PK Ps 60, CR 13, 1147. „tamen magnum discrimen est inter politiam Israël, et caeteras omnes. Expressa voce promisit Deus se servaturum esse politiam Israël, ut sedes esset doctrinae:““

${ }^{384}$ Vgl. PK Ps 53, CR 13, 1124. „et extinguere vocem Evangelii conantur“ und vgl. PK Ps 58, CR 13, 1137. „Generalis obiurgatio est hostium Evangelii, qui superbe, petulanter, pertinaciter et contra conscientiam defendunt errores, et conantur delere veritatem, et opprimere veram Christi Ecclesiam, ..."

${ }^{385}$ PK Ps 117/118, CR 13, 1187. „Non est salus extra Ecclesiam“

${ }^{386}$ PK Ps 34, CR 13, 1071. „Edit Deus promissiones et vult nos eas fide accipere,“
} 
Verheißung Gottes annimmt und deren Segnungen genießt. Dazu ist die Rolle des Messias als des Vermittler zwischen Gott und der Kirche nach Melanchthon zu erwähnen.

Melanchthon sagt, dass Gott von Anfang an mit der großen Barmherzigkeit die VerheiBung für die Bewahrung der Lehre des Evangeliums und der Wahrheit durch die Freiheit der Kirche gibt. ${ }^{387}$ Dazu verspricht Gott, im Evangelium der Kirche das Gute zu schenken, d.h. die Sündenvergebung und den Heiligen Geist. ${ }^{388}$ Für Melanchthon spielt Gott eine Rolle als Bürge für seine gegebene Verheißung. Er ist kein Lügner, sondern der Allmächtige und Treue nach seinen Eigenschaften. Daher ist seine Verheißung wirklich wirksam. Indem Gott sich in dieser Verheißung zeigt, stellt er fest, dass die Sünder um des Vermittlers willen von Gott angenommen werden. 389

Dabei bezeichnet Melanchthon den Vermittler, den Messias, als den Besitzer der VerheiBung Gottes, dass Gott ihn erhört. Der Vermittler hat den Auftrag, dass er selbst unmittelbar durch die Stimme des Evangeliums die ewige Kirche sammelt. ${ }^{390}$ Er wendet die Verheißung Gottes auf die Kirche an. Aus diesem Grund überliefert Gott Abraham und David die VerheiBung über den Messias ${ }^{391}$ und verspricht diese gleich für alle die, die sich zu Gott um des Vermittlers willen flüchten. ${ }^{392}$ Deshalb betont Melanchthon die Wirkung des Vermittlers für die Annahme der Kirche. Die Kirche wird um des Vermittlers willen von Gott angenommen.

\footnotetext{
${ }^{387}$ Vgl. PK Ps 60, CR 13, 1149. „quia sicut ab initio Deus immensa misericordia edidit promissionem: ... ita nec doctrina Evangelii conservari posset, nisi Deus eam et conservaret, ... liberari Ecclesiam ne veritas extinguatur.“

${ }^{388}$ Vgl. PK Ps 29, CR 13, 1061. ,et Deum vere hoc modo per fidem acquiescentem in Evangelio, dare haec ipsa bona, quae promisit, scilicet remissionem peccatorum et Spiritum sanctum.“"

${ }^{389}$ Vgl. PK Ps 113, CR 13, 1179. „sed Ecclesia opponit promissionem de Mediatore, imo etiamsi es reus, tamen Deus edidit promissionem, et vult te recipere propter Mediatorem, iuxta iusivrandum:“ und vgl. PK Ps 31z, CR 13, 1035. „et talibus vere remitti peccatum, credentibus scilicet in Mediatorem iuxta promissionem."

${ }^{390}$ PK Ps 110, CR 13, 1157. ,et habens promissionem, quod Deus eum exaudiat, ... Habens mandatum, ut immediate ipse per vocem Evangelii aeternam Ecclesiam colligat." und vgl. PK Ps 44, CR 13, 1091. „Semper autem sciamus in his petitionibus fidem accendi oportere: vere credamus nos quoque recipi et exaudiri propter promissam misericordiam.“

${ }^{391}$ Vgl. PK Ps 45, CR 13, 1091. „Adiungatur autem hic Psalmus promissionibus de Messia traditis Abrahae et Davidi.“ PK Ps 111, CR 13, 1170. „Deus qui te patefecisti Abrahae, et ei promissionem tradidisti,“

${ }^{392}$ Vgl. PK Ps 50, CR 13, 1112. „Imo ratae sunt propter Mediatorem omnibus ad eum confugientibus.“
} 
Nach Melanchthon finden sich die Beispiele in der heiligen Schrift, dass Gott wahrhaft die erhört, die in der Kirche Gott anrufen. ${ }^{393}$ Deswegen ist die Anrufung der Kirche nicht irrtümlich. ${ }^{394}$ Somit vertraut die Kirche darauf, angenommen zu werden, deswegen erbittet, hofft und erwartet die Kirche die Hilfe nach der Verheißung Gottes. ${ }^{395}$ So funktionieren die Beispiele der heiligen Schrift als Zeugnisse der Erfüllung der Verheißung Gottes.

Die Eigenschaften der Verheißung werden nach Melanchthon mit den Eigenschaften Gottes erklärt. Die Verheißung Gottes ist gnädig, ewig und wirksam nach der Gnade Gottes, der der Kirche die Verheißung gibt. Zuerst ist die Versprechung Gottes gnädig. Die Kirche wird gerecht, nicht durch die Werke und die Tugend selbst, sondern um Gottes willen, der die Kirche mit seiner Barmherzigkeit annimmt, die durch die Verheißung gegeben wird. ${ }^{396}$ Außerdem ist seine Verheißung ewig. Der Messias ist der Sieger und hat das ewige Reich, ${ }^{397}$ deshalb wird die Kirche als die ewige Kirche bezeichnet, ${ }^{398}$ und die Verheißung der Gnade ist universal, der Auftrag Gottes ist ewig. ${ }^{399}$ Darüber hinaus ist die Verheißung nicht vergeblich, sondern wirksam. Deshalb erfährt die Kirche den Trost der Erlösung im Leiden ${ }^{400}$ und wird bewahrt. ${ }^{401}$ Diese Verheißung ist für die Kirche fest und stabil, ${ }^{402}$ weil Gott sich in seiner Verheißung zeigt. ${ }^{403}$ Dabei zeigt sich bei Melanchthon ein Unterschied zwischen den Frommen und Gottlosen über die Verheißung. Die Verheißung bietet die Verteidigung für die Frommen und droht die Strafe für die Gottlosen an. ${ }^{404}$ Deshalb soll man im Bitten sich an die

\footnotetext{
${ }^{393}$ PK Ps 30, CR 13, 1062. „ut exempla proponantur, quae testentur Deum vere exaudire eos qui invocant in Ecclesia, ...")

${ }^{394}$ Vgl. PK Ps 50, CR 13, 1112. „et invocationem non esse irritam.“

${ }^{395}$ Vgl. PK Ps 56, CR 13, 1133, ,ideo confido me recipi, ideo peto, spero et expecto auxilium, quia ipse tradidit nobis promissiones suas, ..."

${ }^{396}$ PK Ps 32, CR 13, 1065. „Non propter merita nostra, non propter virtutes nostras, sed propter Deum recipientem nos sua misericordia, data promissione, sumus iusti.“

${ }^{397}$ Vgl. PK Ps 45, CR 13, 1091. „hunc Messiam victorem fore et habiturum regnum aeternum.“

${ }^{398}$ Vgl. PK Ps 45, CR 13, 1094. ,et colliget aeternam Ecclesiam, ...“

${ }^{399}$ Vgl. PK Ps 57, CR 13, 1134. ,promissionem gratiae universalem esse, et mandatum Dei aeternum esse, ut assentiamur promissioni, ...“

${ }^{400}$ Vgl. PK Ps 52, CR 13, 1120 „cum sint in aerumnis, experiuntur has consolationes salutares esse, quia nec promissiones irritae sunt, nec inanis et fallax est expectatio."

${ }^{401}$ Vgl. PK Ps 110, CR 13, 1164. ,et in hac mortali vita semper aliquas fore reliquias Ecclesiae Dei, ..." und vgl. PK Ps 111, CR 13, 1171. „,non sinit deleri Ecclesiam et promissiones irritas fieri.“

${ }^{402}$ PK Ps 119, CR 13, 1196. „et promissiones nobis ratas et firmas esse.“

${ }^{403}$ PK Ps 130, CR 13, 1214 ,videlicet ad verum Deum patefactum in hoc populo per promissionem suam,“

${ }^{404}$ PK Ps 11, CR 13, 1035. „Et opponuntur promissiones, quae defensionem piis pollicentur, et minitantur poenas impiis.“
} 
Befehle und die Verheißungen Gottes erinnern. ${ }^{405}$ So ahmen die Eigenschaften der Verheißung die Eigenschaften Gottes nach.

Melanchthon weist auch auf die Unfähigkeit der Menschen hin, die Verheißung Gottes zu erfassen. Für die Verheißung Gottes ist die menschliche Natur taub wegen des Zweifels. ${ }^{406}$ Die menschliche Vernunft ist ohne die Erkenntnis der Verheißungen und den Heiligen Geist voller Zweifel. ${ }^{407}$ Die Gottlosen zweifeln und wissen nicht, dass Gott die Menschen mit der Barmherzigkeit annimmt, ihre Sünde vergibt und ihr Bitten erhört. Dagegen bekennt Melanchthon für die Kirche, dass die Verheißung über die Verteidigung und die ewige Erlösung in der Kirche gemacht wird, die durch das Wort Gottes eingerichtet wird. ${ }^{408}$ Deshalb hat die Kirche keinen Zweifel an der Verheißung der Bewahrung, auch nicht in den Zeiten der Verfolgung der Kirche durch die Welt. ${ }^{409}$ Wie Gott Abraham die Segnungen versprochen hat, verspricht er der Kirche, dass Gott die Kirche liebt, umsorgt, schützt und segnet. ${ }^{410}$ Und die Kirche vertraut auf die Verheißungen Gottes, die durch das Wort Gottes überliefert werden. ${ }^{411}$ Allein durch die menschliche Vernunft kann man die Verheißung nicht annehmen.

\subsubsection{Die Erlösung als Verheißung}

Melanchthon handelt von der Erlösung als eine Verheißung durch das Evangelium, das Gott der Kirche als die Verheißung gibt. Gott wünscht nicht, dass das ganze Menschengeschlecht in der Sünde stirbt, sondern er selbst erwählt die Kirche für die Erlösung und plant, dass die Verheißung des Evangeliums verkündigt wird und dass die Kirche Gott anruft. ${ }^{412}$ Für Melanchthon ist das Evangelium vor allem die Botschaft der Erlösung, dass der Messias

\footnotetext{
${ }^{405}$ PK Ps 132, CR 13, 1219. „In hac autem precatione necesse est, intueri mandata Dei et promissiones, ..."

${ }^{406}$ Vgl. PK Ps 38, CR 13, 1078. „Sed humana natura, propter magnam confusionem dubitationum in corde, pene surda est ad has promissiones, ..."

${ }^{407}$ PK Ps 51, CR 13, 1116. „quia mens humana sine noticia promissionum et sine Spiritu sancto plena est harum dubitationum."

${ }^{408}$ PK Ps 36, CR 13, 1074. „in Ecclesia aedificata verbo tuo, facta est promissio defensionis, et aeternae salutis.“

${ }^{409}$ PK Ps 46, CR 13, 1096. „Hunc servari prorsus non dubium est, etiamsi membra aliqua trucidantur.“ ${ }^{410}$ Vgl. PK Ps 122, CR 13, 1204. „et addita est promissio. Deum benefacturum esse his qui diligunt, fovent, tuentur Ecclesiam, ..."

${ }^{411}$ Vgl. PK Ps 111, CR 13, 1167. ,et huic verbo credere quod nobis traditum est, nec irrita erit haec fides, ..."

${ }^{412}$ Vgl. PK Ps 25, CR 13, 1055. „Noluisti genus humanum totum perire, sed excerpsisti tibi Ecclesiam, dedisti promissiones, ...“ und vgl. PK Ps 45, CR 13, 1094. „Psalmus et promissiones semper principaliter de Ecclesia loquuntur, id est, de coetu puram Evangelii vocem sonante, et recte Deum invocante.“
} 
durch die Sündenvergebung die Gerechtigkeit und das Leben der Kirche wiederherstellt. ${ }^{413}$ Melanchthon schätzt die Verheißung über den Messias und die Sündenvergebung und die Verheißung über die Gerechtigkeit und das ewige Leben, nämlich die Erlösung als die beste Verheißung. ${ }^{414}$

Für Melanchthon ist die Verheißung der Erlösung nicht neu, sondern bereits bei Adam und Abraham bekannt. Die Verheißung der Erlösung wurde schon Adam als die Wiederherstellung der Gerechtigkeit und des ewigen Lebens ${ }^{415}$ und Abraham als gleiche Segnungen bekannt, dass er Gott erfreut und mit der wahren Weisheit, der Gerechtigkeit und dem Leben anzieht und dass die Sünde und der Tod vernichtet werden. ${ }^{416}$ Bei Melanchthon ist die Verheißung der Vorfahren dieselbe wie bei der Kirche. Die Einheit der Verheißung der Erlösung wird von Melanchthon für wichtig erachtet, weil aus diesem Grund die Psalmen sich auf die Kirche seiner Zeit anwenden lassen.

Außerdem bezieht Melanchthon diese Verheißung unmittelbar auf den Messias. Daher wird in Psalmen über den Messias erklärt, wer der Messias ist, wo sein Reich ist, welche Guten er dem Volk Gottes darbietet. ${ }^{417}$ Die Erlösung wird der Kirche allein um des versprochenen Messias willen gegeben. Dabei spielt seine Eigenschaft als Gottmensch eine wichtige Rolle. ${ }^{418}$ Durch seinen Gehorsam wird der Zorn Gottes versöhnt, und der Tod und die Sünde werden aufgehoben. ${ }^{419}$ Die Sündenvergebung entsteht allein durch das gnädige Werk dieses Vermittlers. ${ }^{420}$ So wird die Kirche um des Messias willen erlöst. Bei Melanchthon gibt es keinen anderen Weg zur Erlösung ohne den Messias. Allein dadurch nimmt Gott die Kirche

\footnotetext{
${ }^{413}$ Vgl. PK Ps 47, CR 13, 1099. „Noster Messias aeternum regnum constituet, abolito peccato, deleta morte, et restituta aeterna iusticia et vita.“

${ }^{414}$ Vgl. PK Ps 48, CR 13, 1102. „Et ad praecipuam maxime referenda est, id est, ad promissionem Mediatoris et remissionis peccatorum, iusticiae et vitae aeternae."

${ }^{415}$ Vgl. PK Ps 8, CR 13, 1031. „sed rursus erigitur propter promissum semen, et ornatur gloria, id est, abolito peccato et morte, restituuntur iusticia et vita aeterna.“ und vgl. PK Ps, 110, CR 13, 1145. ,et promissio de hoc ipso redemtore statim initio cum recepti sunt Adam et Eva, tradita est, et discrimen Ecclesiae deinceps et aliarum gentium fuit.“

${ }^{416}$ Vgl. PK Ps 45, CR 13, 1092. „Hac voce significat se enarrare promissionem traditam Abrahae. ... Deo placens, ornatus vera sapientia, iusticia et vita, deleturus peccatum et mortem, ..."

${ }^{417}$ PK Ps 45, CR 13, 1091. „Totus Psalmus prophetia est de Messia promisso, narrans quis sit, quale sit eius regnum, et quae bona populo Dei exhibeat.

${ }^{418}$ PK Ps 45, CR 13 1093. „quod docet hunc regem, promissum Messiam et Hominem esse et Deum.“ ${ }^{419}$ Vgl. PK Ps 40, CR 13, 1082. „ut mea obedientia fiat placata ira tua, et tollantur peccatum et mors.“ ${ }^{420}$ Vgl. PK Ps 50, CR 13, 1108. „scit datam esse promissionem remissionis peccatorum Gratis dandae propter Mediatorem.“
} 
mit seiner Barmherzigkeit an. ${ }^{421}$ Dabei gibt es keinen Unterschied zwischen den Vorfahren vor Christus und der Mitglieder der Kirche nach Christus.

\subsubsection{Der Glaube, der die Verheißung annimmt}

Der Glaube wird von Melanchthon als ein Mittel für die Annahme der Verheißung der Erlösung vorgestellt. Um von Gott angenommen zu werden, ist es notwendig, das Wort Gottes in den Verheißungen anzunehmen. ${ }^{422}$ Mit anderen Worten: Wer glaubt, wird erlöst. ${ }^{423} \mathrm{Im}$ Evangelium gibt Gott durch den Glauben der Kirche die Sündenvergebung und den Heiligen Geist. ${ }^{424}$ Melanchthon betont bei der Erlösung die Handlung des Glaubens. Aber diese Handlung spielt bei der Erlösung nur eine Rolle als eine Anlehnung an die Verheißungen Gottes, dass Gott mir beisteht, mich verteidigt und bewahrt. ${ }^{425}$ Der Glaube lehnt sich nämlich nicht an die eigenen Werte und die eigene Würde an, sondern an die um des Sohnes willen versprochene Barmherzigkeit. ${ }^{426}$

Bei Melanchthon funktioniert der Glaube als eine Handlung der Kirche, um die versprochene Sache Gottes festzuhalten. Melanchthon stellt den Glauben als das Vertrauen dar, das die Verheißung Gottes sieht. ${ }^{427}$ Im Glauben soll gefestigt werden, dass der König, nämlich der Messias, immer mit der Kirche ist und überall und zu jeder Zeit die Anrufenden erhört und fördert. ${ }^{428}$ So soll die Kirche die Verheißung Gottes mit dem Glauben annehmen.

Für Melanchthon ist charakteristisch, den Glauben als eine menschliche, aktive Handlung zu betonen. Gott legt die Verheißung vor, Menschen nehmen sie durch den Glauben an. ${ }^{429}$ Nach der Auffassung Melanchthons ist es nicht genug, nur die Verheißung zu hören, sondern es ist notwendig, durch den Glauben die Verheißung anzunehmen. ${ }^{430}$ Der Prozess der Erlö-

\footnotetext{
${ }^{421}$ Vgl. PK Ps 32, CR 13, 1065. „,sed propter Deum recipientem nos sua misericordia, ...“

${ }^{422}$ Vgl. PK Ps 25, CR 13, 1055. „,dedisti promissiones, in quibus testatus es te recipere amplectentes verbum illud.“

${ }^{423}$ PK Ps 119, CR 13, 1193. „Si credideris salutus eris.“

${ }^{424}$ Vgl. PK Ps 29, CR 13, 1061. ,et Deum vere hoc modo per fidem acquiescentem in Evangelio, dare haec ipsa bona, quae promisit, scilicet remissionem peccatorum et Spiritum sanctum.")

${ }^{425}$ PK Ps 27, CR 13, 1059. „tamen Deus mihi aderit, me defendet et servabit.“

${ }^{426}$ Vgl. PK Ps 111, CR 13, 1167. „et sciamus fidem oportere niti non nostra dignitate, sed sola misericordia propter Filium promissa, ...“

${ }^{427}$ PK Ps 57, CR 13, 1135 ,videlicet fide, quae est fiducia intuens promissionem Dei, ...“

${ }^{428}$ Vgl. PK Ps 45, CR 13, 1091. „Hic vero noster rex semper adest Ecclesiae, et ubique et omnibus temporibus exaudit et iuvat invocantes. Haec omnia firma fide statuenda sunt.“

${ }^{429}$ Vgl. PK Ps 34, CR 13. 1071. „Edit Deus promissiones et vult nos eas fide accipere, ...“

${ }^{430}$ Vgl. PK Ps 11, CR 13, 1036. „Sed exordium ipsum docet nos, ne satis esse putemus, quod promissiones audimus, sed oportet eas fide accipi.“
} 
sung der Mitglieder der Kirche entsteht nicht automatisch ohne eine menschliche Handlung, sondern dabei braucht man den Glauben als eine menschliche Handlung, um die Verheißung der Erlösung auf sich anzuwenden. So fungiert der Glauben als eine menschliche Handlung, die sich an die Verheißung Gottes anlehnt und die der Verheißung Gottes zustimmt. Hiermit ist kein Synergismus gemeint

Dabei unterscheidet sich die Handlung des Glaubens von der Handlung der menschlichen Vernunft ohne den Glauben - weil wie erwähnt - die menschliche Vernunft von sich aus die Verheißung nicht bemerken könnte. Der Glaube kommt nicht aus der menschlichen Vernunft, sondern aus Gott. Und der Glaube wirkt in der menschlichen Vernunft. Melanchthon erklärt, dass in den echten Gefahren die durch den Glauben aufgestellte Vernunft auf Gott beruhen soll. ${ }^{431}$ Die Lehre der Verheißung, des Glaubens und der Hoffnung erstrahlt immer in der Vernunft. ${ }^{432}$ Die Vernunft bezeichnet Melanchthon als die Vernunft, die das Evangelium versteht. ${ }^{433}$ So kann diese Vernunft durch den Glauben die Verheißung sehen. Daher ist bei Melanchthon der Glaube zwar eine menschliche Handlung, aber er kommt nicht aus der menschlichen Vernunft, sondern er wirkt an der Vernunft mit der Verheißung Gottes. Insofern hält Melanchthon den Glauben niemals für ein eigenes Verdienst für die Erlösung. Nur beruht der Glaube auf dem Gehorsam Christi, ${ }^{434}$ nicht auf der menschlichen Würde. ${ }^{435}$ Gerecht sind die zu Gott Bekehrten, die in der wahren Buße glauben, dass sie um des Sohnes Gottes willen umsonst angenommen werden. ${ }^{436}$ Daher ist es nicht richtig, bei Melanchthon eine Zusammenwirkung von Menschen an der Erlösung zu finden.

Dazu ist der Glaube keine einmalige Handlung der Kirche. Melanchthon erklärt die Übungen des Glaubens, trotz der Unsichtbarkeit um der Verheißung willen Gott um Hilfe zu bitten. ${ }^{437}$ Wenn auch die Kirche durch den Glauben gerecht wird und den Frieden mit Gott hat,

\footnotetext{
${ }^{431}$ PK Ps 60, CR 13, 1148. „sed in veris periculis fide erectae mentes nitantur Deo.“

${ }^{432}$ PK Ps 57, CR 13, 1135. „Haec doctrina de promissionibus, fide et spe semper luceat in mentibus, ..."

${ }^{433}$ PK Ps 32, CR 13, 1066. „Sed mens intelligens Evangelium, in qua fides accensa est, scit Deum adesse invocantibus etiam cum destituimur humanis auxiliis, ..."

${ }^{434}$ PK Ps 31z, CR 13, 1234. ,et haec fides nititur obedientia Christi ...“

${ }^{435}$ Vgl. PK Ps 115 , CR 13, 1181. „et sciamus fidem oportere niti non nostra dignitate, sed sola misericordia propter Filium promissa, ...“

${ }^{436}$ PK Ps 55, CR 13, 1130. „idem hic moneo, iustos dici omnes conversos ad Deum, qui in vera poenitentia credunt se propter filium Dei gratis recipi, ..."

${ }^{437}$ Vgl. PK Ps 46, CR 13, 1097. ,sed acquiescite in Deo, quem etsi non cernitis, tamen scitis tradidisse promissiones, et velle ut sic invocetur, petito auxilio iuxta promissionem, etiamsi ipse non cernitur.Haec doctrina de fidei exercitiis saepe repetita est, ..."
} 
sind die Gläubigen in diesem Leben noch sündhaft und voller Zweifel und haben Angst vor dem Zorn Gottes. Deswegen brauchen sie noch die Übungen des Glaubens. Die Kirche lernt, sich in den Übungen der Buße und der Anrufung Gottes durch den Glauben dem Vertrauen zu nähern. ${ }^{438}$

\subsubsection{Die Rechtfertigung durch den Glauben}

Bei Melanchthon ist die Rechtfertigungslehre ein Hauptpunkt seiner Theologie. ${ }^{439}$ Nach der Auffassung Melanchthons wird die Kirche durch den Glauben an den Vermittler erlöst und erhält seine Gerechtigkeit. So wird die Kirche gerecht. Dabei gibt es eine Rolle des Wortes Gottes. Durch die Predigt des Wortes Gottes fürchten die Gläubigen den Zorn Gottes und die ewige Strafe wegen ihrer Sünden, aber sie hoffen auf Gott und glauben an die Verheißung des Evangeliums und an die Annahme Gottes durch die Barmherzigkeit um des Vermittlers willen. So lehnt die Kirche sich an den Vermittler an und wird von Gott angenommen, nicht durch ihr Verdienst, sondern durch die Gerechtigkeit um des Vermittlers willen. ${ }^{440}$ Das ist die Rechtfertigungslehre Melanchthons, die Gerechtigkeit durch den Glauben zu gewinnen.

Melanchthon findet in den Psalmen solche Beispiele, z.B. Adam, Noah, Abraham, Mose, Aaron, ${ }^{441}$ David ${ }^{442}$ und Joseph. Davon wird Joseph als ein Beispiel betrachtet. Joseph wird als der Gerechte bezeichnet, aber er ist wie alle Anderen Sünder. Ebenso werden die Menschen auch gratis durch die Barmherzigkeit Gottes um des Sohnes willen angenommen. ${ }^{443}$ Dazu

\footnotetext{
${ }^{438}$ Vgl. PK Ps 110, CR 13, 1166. „Item per hunc habemus accessum in fiducia per fidem Iesu Christi. Haec in exercitiis poenitentiae et invocationis discuntur, ..."

${ }^{439}$ Richter sagt recht, „die eigentliche Mitte der Hl. Schrift sei die Rechtfertigung des Menschen allein durch den Glauben, weil Gott in ihm durch Jesus Christus dem Menschen ganz nahe komme und der Mensch nur im Glauben vor Gott recht fertig werde." Richter 1999

${ }^{440}$ Vgl. PK Ps 42, CR 13, 1087. ,crede per misericordiam propter Filium mediatorem te vere recipi a Deo, etiamsi nulla merita adfers. Sic accommodanda est haec sententia ad doctrinam de iusticia fidei, ..."

${ }^{441}$ PK Ps 25, CR 13, 1055. „Agnosco meum peccatum, et scio me non esse iustum legis impletione. Quare confugio ad misericordiam tuam, quam patefecisti ab initio. Noluisti genus humanum totum perire, sed excerpsisti tibi Ecclesiam, dedisti promissiones, in quibus testatus es te recipere amplectentes verbum illud. Recepisti Adam, Nohe, Abraham, Mosen, Aaron, qui horribiliter lapsus erat. Sic me quoque recipias immensa misericordia tua propter promissum Dominum.“

${ }^{442}$ In Ps 7 wird die Gerechtigkeit Davids erwähnt, aber Melanchthon erklärt den Vers mit der Unterscheidung der Art der Gerechtigkeit. Die Gerechtigkeit, durch die die Erlösung erhalten werden kann, wird allein durch die Zurechnung der Gerechtigkeit erhalten. Vgl. PK Ps 7, CR 13, 1029. „Alia est iusticia personae, qua persona tota coram Deo gratis reputatur iusta. Haec imputatio tantum fide accipitur, nec opponuntur nostrae virtutes aut beneficia.“

${ }^{443}$ Vgl. PK Ps 34, CR 13, 1071. „sed et Ioseph recipitur gratis per misericordiam, et nos gratis recipimur per misericordiam propter Filium Dei.“
} 
braucht man nur den wahren Glauben. Der Glaube hält die Verheißung des Evangeliums fest, dass wir allein durch die Gnade angenommen werden.

Die Rechtfertigungslehre Melanchthons widersetzt sich dem Versuch, die Gerechtigkeit für die Erlösung durch das Gesetz zu gewinnen. Nach Melanchthon verstehen Pharisäer und Heuchler diese Lehre nicht, sie werden durch die menschliche Fantasie und die Philosophie über die Erziehung zurückgehalten und rufen in ihren eigenen Zweifeln Gott an. ${ }^{444}$ Die Juden und die Mönche lehren das Einhalten des Gesetzes und befehlen den Zweifel, aber so zerstören sie das Evangelium und die Lehre über den Glauben. ${ }^{445}$ Allerdings erklärt Melanchthon im PK zu Psalm 31 die Lehre der Rechtfertigung gegen die Gerechtigkeit des Gesetzes.

Bei Melanchthon ist es klar, dass man gerecht vor Gott nicht durch seine eigenen Handlungen, Tugenden und Eigenschaften wird, sondern durch die Annahme der Sündenvergebung durch den Glauben. Durch den Glauben wird der Mensch geschützt, und die Sünde wird ihm nicht zugeschrieben. Wenn er seine Sünde bekennt, so nähert er sich Gott, damit er glaubt, dass er durch die Barmherzigkeit um des Vermittlers willen angenommen wird, nicht durch die eigene Würde oder das eigene Verdienst. ${ }^{446}$ Nur durch den Glauben an den Vermittler kann man sich Gott nähern, ${ }^{447}$ nur mit der Gerechtigkeit des Vermittlers kann man vor Gott stehen.

Melanchthon betont, dass für die Annahme der Gerechtigkeit durch die Gnade Gottes der Glaube genug ist. Aus diesem Grund kritisiert Melanchthon die Wiedertäufer und die Schwärmer, weil sie andere Illuminationen außer dem Wort Gottes suchen und nicht wünschen, mit dem Glauben zur Ruhe zu kommen. ${ }^{448}$ Die Gläubigen werden gerecht nicht durch das Einhalten des Gesetzes, sondern durch den Glauben. Deshalb unterscheidet der Glaube zwischen den Gerechten und den Heuchlern, ${ }^{449}$ denn die Heuchler haben keinen Glauben.

\footnotetext{
${ }^{444}$ PK Ps 2, CR 13, 1021. „Hanc doctrinam non intelligebant Pharisaei et alii hypocritae, oppressi imaginationibus humanis et philosophicis de disciplina, et qui Deum dubitatione invocabant.“

${ }^{445}$ Vgl. PK Ps 47, CR 13, 1099. „Non sapienter psallunt monachi, qui tantum docent legem et iubent dubitare, atque ita delent Evangelium et doctrinam de fide.“

${ }^{446}$ Vgl. PK Ps 31z, CR 13, 1234. „Est autem sententia, homines fiunt beati, id est, iusti coram Deo non propter propria opera, virtutes et qualitates, sed accipiendo fide remissionem peccatorum, qua teguntur, et non imputantur peccata, cum quidem et fatentur se reos esse, et sic accedunt ad Deum, ut credant se recipi gratis per misericordiam propter Mediatorem, non propter propriam dignitatem aut merita.“

${ }^{447}$ Vgl. PK Ps 51z, CR 13, 1232. „et fides agnoscens Mediatorem, qua habemus accessum ad Deum, ..."

${ }^{448}$ Vgl. PK Ps 119, CR 13, 1193. „quaerunt Anabaptistae et Enthusiastae alias illuminationes et raptus extra verbum Dei, et non volunt acquiescere fide.“

${ }^{449}$ Vgl. PK Ps 32, CR 13, 1066. „discernens hypocritas et iustos fide.“
} 
Aber die Kirche nimmt durch den Glauben ohne jeglichen Zweifel an, dass das Blut Christi sie von allen Sünden reinigt. ${ }^{450}$ Dabei lehnt die Kirche sich durch den Glauben nur an den Gehorsam Christi, nämlich an seine Gerechtigkeit an. So haben die Gerechten durch den Glauben den Frieden und nähern sich Gott. ${ }^{451}$

Nach Melanchthon nimmt die Kirche die gnädige, ewige und wirksame Verheißung der Erlösung durch den Glauben an. Dann ist die Rechtfertigung, die durch den Glauben der Kirche gegeben ist, auch gnädig, ewig und wirksam. Diese Rechtfertigung ist nach der Auffassung Melanchthons die einzige Hoffnung für die Erlösung, weil die Menschen in diesem Leben keinen anderen Weg zur Erlösung haben.

\subsubsection{Die Erwählung der Kirche}

Bei Melanchthon wird die Rechtfertigung durch den Glauben nur der Kirche gegeben, die Gott erwählt hat. Im PK ist der Kontrast zwischen der Kirche und den Heiden, den Frommen und den Gottlosen gemein. Melanchthon unterscheidet die Mitglieder der Kirche, die das von Gott überlieferte Wort annehmen, von denen, die die menschlichen Meinungen über Gott vertreten, wie die Heiden oder die Juden oder die Philosophen oder diejenigen, die etwas außerhalb des Wortes Gottes erdichten. ${ }^{452}$ Außerdem unterscheidet er zwischen den Gerechten durch den Glauben und denen, die den Glauben verweigern. Die Rechtfertigung durch den Glauben gehört nur zur Kirche, die Gott anruft. Nach der Auffassung Melanchthons wünscht Gott nicht alle zu erlösen, sondern dass nicht alle umkommen. ${ }^{453}$ So hat Melanchthon die Erwählung der Kirche im PK vorausgesetzt, mithin dass Gott eine Gruppe für die Erlösung und die andere Gruppe für die Verwerfung auserwählt. Es besteht also ein ewiger Unterschied zwischen den Frommen und den Gottlosen, da alle Frommen sich über das ewige Gute freuen, den Gottlosen aber die ewigen Strafen zuteilwerden. ${ }^{454}$ Dies geschieht nicht zufällig oder auBerhalb des Planes Gottes. ${ }^{455}$

\footnotetext{
${ }^{450}$ PK Ps 51z, CR 13, 1229. „Sanguis Christi purificat nos ab omnibus peccatis.“

${ }^{451}$ PK Ps 31z, CR 13, 1234. „Iustificati fide pacem habemus, et accessum ad Deum, ...“

${ }^{452}$ Vgl. PK Ps 1, CR 13, 1019. „qui hoc verbum a Deo traditum amplectitur, et non sequitur humanas opiniones de Deo, seu Ethnicas, seu Iudaicas, seu philosophicas, seu quascunque extra verbum Dei confictas."

${ }^{453}$ Vgl. PK Ps 25, CR 13, 1055. „Noluisti genus humanum totum perire, sed excerpsisti tibi Ecclesiam, ..."

${ }^{454}$ Vgl. PK Ps 52, CR 13, 1120. „sed tamen postea cum fiet aeternum discrimen piorum et impiorum, universaliter omnes pii fruentur aeternis bonis, et impii erunt in poenis aeternis.“

${ }^{455}$ Vgl. PK Ps 52, CR 13, 1120. „et tamen non fit casu, aut sine singulari consilio Dei,“
} 
Bei Melanchthon besteht die Erwählung der Kirche von Anfang an. Gott schuf das Menschengeschlecht als ein Paar nach seinem wunderbaren Plan. Melanchthon legt dieses Paar als die Kirche aus. ${ }^{456}$ Außerdem wird der Messias ordiniert, um die Kirche aus dem ganzen Menschengeschlecht zu sammeln, ${ }^{457}$ und er ist der Sohn Gottes, der die Sünde und den Tod vernichtet und der Kirche die Gerechtigkeit und das ewige Leben zurückgibt. ${ }^{458}$ Daraus kann man die Auffassung Melanchthons ersehen, dass die Erwählung der Kirche mit dem Plan der Schöpfung Gottes schon vor dem Sündenfall besteht, und dass der Sündenfall und die Erlösung durch die Sündenvergebung dem Plan Gottes folgen.

Die Ursache der Erwählung der Kirche ist der gnädige Wille Gottes. Melanchthon weist darauf hin, dass Gott den Tod des ganzen Menschengeschlechtes nicht wünscht, deswegen die Kirche aus dem Menschengeschlecht erwählt und der Kirche die Verheißung gibt. ${ }^{459}$ Eigentlich sollte das ganze Menschengeschlecht zum Tod wegen der Sünde verurteilt werden. ${ }^{460}$ Aber Gott erwählt einige aus dieser Welt. Der Messias gehorcht Gott, lädt die Strafe für die Erwählten auf sich und erlöst die Kirche mit seinem Blut. ${ }^{461}$ Die Erwählten erhalten die ewigen Guten in der Kirche. ${ }^{462}$ Der gnädige Wille Gottes für die Erlösung richtet sich allein auf die Kirche. Deshalb wird das Werk der Erlösung von dem Messias nur auf die Kirche bezogen, obwohl die Barmherzigkeit Gottes allgemein versprochen wird. ${ }^{463}$ Bei Melanchthon entsteht die Erwählung allein durch den gnädigen Willen Gottes.

Im PK ist es zu sehen, dass deutlich der Gegenstand der Erwählung Gottes die Kirche ist. Der Messias wurde um der Sünden der Erwählten willen getötet und gibt ihnen die Gerechtigkeit, die er für sie durch seinen Gehorsam gewonnen hat. Deshalb geschieht die Erwählung der Kirche für einen Teil des Menschengeschlechtes. Die Erlösung der Erwählten wird durch

\footnotetext{
${ }^{456}$ Vgl. PK Ps 128, CR 13, 1212. „Mirabili consilio Deus hoc modo condidit genus humanum, in quo colligit sibi aeternam Ecclesiam ordinata propagatione. Primum voluit esse duos, ut esset Ecclesia.“

${ }^{457}$ Vgl. PK Ps 45, CR 13, 1093. „ordinatus ad hoc ministerium, ... ad perficiendam hanc mirandam liberationem, Ecclesiae colligendae ex toto genere humano, et donandae iusticia et vita aeterna."

${ }^{458}$ Vgl. PK Ps 110, CR 13, 1153. „solus hic Messias qui est Filius Dei, aboliturus peccatum et mortem, et redditurus nobis iusticiam et vitam aeternam."

${ }^{459}$ PK Ps 25, CR13, 1055. „Noluisti genus humanum totum perire, sed excerpsisti tibi Ecclesiam, dedisti promissiones, ..."

${ }^{460} \mathrm{Vgl}$. PK Ps 32, CR 13, 1066. „Utrique pii et impii morte onerati sunt, et horrendis calamitatibus excruciantur."

${ }^{461}$ PK Ps 40, CR 13, 1081. „Ego vere et toto corde obediam, sustinebo poenas pro electis, ac redimam Ecclesiam meo sanguine, “

${ }^{462}$ PK Ps 132, CR 13, 1219. „electi, qui accipient aeterna bona in Ecclesia.“

${ }^{463}$ Vgl. PK Ps 57, CR 13, 1135. „et statuamus misereri eum nostri propter Filium gratis, et misericordiam universaliter omnibus promissam esse."
} 
die Sündenvergebung durch das Leiden des Messias und die Zuschreibung der Gerechtigkeit durch den Gehorsam des Messias stattgefunden. Melanchthon sagt, dass der Kirche die Verheißung der Bewahrung, die Segnung und die Liebe gegeben werden, die Gott seiner erwählten Kirche versprochen hat.

Dazu ist nach Melanchthon bei den Erwählten charakteristisch, an der Verheißung durch den Glauben festzuhalten. Bei Melanchthon ist der Glaube nicht die Ursache der Erwählung, sondern eine notwendige Folge der Erwählung Gottes. Diese Auffassung stimmt mit den Lehren vom Glauben und der Rechtfertigung überein. Aber man muss bei der Auffassung Melanchthons über die Erwählung berücksichtigen, dass Melanchthon bei der Erklärung der Erwählung von der aktuellen Erfahrung der Gläubigen ausgeht, nicht von einer Spekulation über den ewigen Willen Gottes. Die Psalmen sind solche Beispiele.

\subsubsection{Das Amt des Evangeliums}

Wenn Melanchthon im PK über das Evangelium schreibt, bezieht er sich meistens auf die Stimme des Evangeliums. Er weist damit nicht auf das geschriebene Wort hin, sondern auf das durch die Predigt verkündigte Evangelium. Insofern spielt das Amt der Kirche, das das Amt für die Predigt ist, eine wichtige Rolle für das Evangelium. Der Messias ist das Vorbild dafür. Er lehrt das Evangelium als der König. ${ }^{464}$ Mit anderen Worten, er sammelt die Kirche durch die Stimme des Evangeliums. ${ }^{465}$ Die Aufgabe des Amts ist die Bewahrung der Lehre und der wahren Anrufung, damit der wahre Gottesdienst erhalten bleibt. Damit hat das Amt die bedeutende Aufgabe, zu verhindern, dass das ganze Menschengeschlecht in Dunkelheit, Irrtümern und ewigem Untergang vernichtet wird. ${ }^{466}$ Das Amt wirkt nämlich die Erlösung der Kirche. Die andere Aufgabe des Amts ist es, das Evangelium zu verkündigen, nämlich die ewige Kirche zu sammeln. ${ }^{467}$

Für Melanchthon ist das Amt wichtig. Der Dienst des Amts muss wirksam sein, weil ohne das Evangelium Gott nicht gefunden wird. ${ }^{468}$ Das wahre Amt des Evangeliums besteht in

\footnotetext{
${ }^{464}$ Vgl. PK Ps 45, CR 13, 1092. „Est autem inter praecipua officia huius regis, docere Evangelium.“

${ }^{465}$ PK Ps 117/118, CR13, 1183. „colligit eam voce Evangelii““

${ }^{466}$ PK. Prolegomena, CR 13, 1017 „(ne) et totum genus humanum ruat in tenebras, errores et aeternum exitium.“

${ }^{467}$ PK Ps 45, CR 13, 1094. ,set colliget aeternam Ecclesiam, ...“

${ }^{468}$ Vgl. PK Ps 29, CR 13, 1061. „Diligenter autem doctrina de efficacia ministerii Evangelii discenda est, ne quaeramus Deum sine suo Evangelio:“
} 
allen Zeiten. ${ }^{469}$ Gott stellt für das Amt des Evangeliums die Väter, die Propheten und die Apostel. ${ }^{470}$ In verschiedenen Zeiten spielen die verschiedenen Diener die Rolle des Amts, ${ }^{471}$ so die Priester in der Zeit des Alten Testaments. Die Priester, die den ewigen Hohepriester zeigen, werden für das Amt ordiniert und bekommen die göttliche Kraft und den Heiligen Geist. Dafür sind die Einrichtung und die Bewahrung der Kirche und des Amts in der politischen Regierung Israels Beispiel. ${ }^{472}$ Dabei bedenkt Melanchthon wahrscheinlich die politischen Führer in seiner Zeit, die sich in einer schwierigen Situation befinden. ${ }^{473}$ Sie haben die Pflicht, die wahre Lehre zu bewahren und das Amt des Evangeliums zu fördern. ${ }^{474}$ Aber Melanchthon merkt den Unterschied zwischen dem Amt der Kirche und der weltlichen Regierung. Die ewige Bewahrung gilt allein der Kirche, und die weltliche Regierung hat eine Pflicht, die wahre Kirche zu fördern.

Im PK sind die schwierigen Situationen des Amts des Evangeliums leicht zu finden. Der Widerstand von denen, die nicht zur Kirche gehören, besteht immer. Die Welt kann das Amt des Evangeliums nicht verstehen, weil sie den Inhalt des Evangeliums verneint. ${ }^{475}$ Die Welt lacht über das Wort Gottes und das Amt, weil sie denkt, dass diese erfunden seien.

Aber nach Melanchthon wird das Amt von Gott bewahrt. Denn die Wahrheit Gottes ist allein wahr, der Glauben ist nicht falsch, sondern die Kirche erhält die ewigen Guten und die Bedürfnisse in diesem Leben. ${ }^{476} \mathrm{Ab}$ und zu wird das Amt durch die Tyrannei der bösen Führer schwer behindert. Wenn diese Situation länger anhalten würde, würden noch mehr entmu-

${ }^{469}$ PK Ps 122, CR 13, 1203. „et verum ministerium futurum et mansurum esse omnibus temporibus, ..."

${ }^{470}$ Vgl. PK Ps 117/118, CR 13, 1187. „Sunt et sequentia verba vox patrum, Prophetarum, et Apostolorum narrantium quid doceant, et iubentium conservari ministerium, sonamus inquiunt hanc benedictionem, ..."

${ }^{471}$ Vgl. PK Ps 110, CR 13, 1159 „Sacerdotes participatione qui sunt membra Christi, et tamen vere sacerdotes, sunt omnes accipientes unctionem a summo sacerdote Filio Dei, Evangelium et Spiritum sanctum, ordinati ad confessionem, ac pro tempore ad ministerium,“

${ }^{472}$ PK Ps 111, CR 13, 1171. „Psalmum loqui de constitutione ac defensione Ecclesiae ac ministerii in politia Israël, ...“

${ }^{473}$ Vgl. PK Ps 20, CR 13, 1047. „et cogitantes de magnis periculis omnium piorum gubernatorum.“

${ }^{474}$ Vgl. PK Ps 24, CR 13, 1053. „Et hic locus observandus est, ad docendos magistratus politicos, ut sciant ad se quoque pertinere curam iuvandi propagationem Evangelii, et tuendi veras Dei Ecclesias.“

${ }^{475}$ Vgl. PK Ps 29, CR 13, 1062. „Hanc doctrinam de efficacia ministerii evangelici non intelligunt mentes prophanae: ... et opponenda sunt testimonia de efficacia ministerii evangelici.“

${ }^{476}$ PK Ps 111, CR 13, 1166. „,nec irrita erit haec fides, sed vere accipiemus promissa beneficia aeterna et necessaria in hac vita.“ 
tigt. Melanchthon erwähnt Antiochus als ein Beispiel. ${ }^{477}$ Somit streiten die Gegner der Kirche mit der Stimme des Evangeliums. Trotzdem ist die Kirche eine exklusive Gruppe, weil außer der Kirche keine Erlösung besteht. ${ }^{478}$

Melanchthon betont, dass Gott den Ort des Amts gegen die Gegner bewahrt ${ }^{479}$ und die Verleumder behindert, die das Amt des Evangeliums vernichten wollen. ${ }^{480}$ Mit dieser VerheiBung bittet das Amt Gott darum, die Kirche zu bewahren und zu verteidigen. Und Melanchthon erwähnt die Rolle der Kirche, dass die Kirche sich dafür einsetzen soll, das Amt des Evangeliums zu bewahren, um für die Kirche die Reinheit der Lehre zu halten. ${ }^{481}$

\subsubsection{Zusammenfassung}

Das Kapitel behandelte das Evangelium in seiner Bedeutung für die Erlösung der Kirche. Melanchthon unterscheidet das Evangelium vom Gesetz, das das allgemeine Prinzip Gottes ist. Das Evangelium ist ein besonderes Prinzip für die Erlösung der Kirche. Denn beim Evangelium ist die Sündenvergebung von wesentlicher Bedeutung. Das Gesetz verurteilt die Sünder, aber das Evangelium erlöst die Kirche durch die Sündenvergebung. Dafür ist das Kommen des Messias versprochen worden. Er kommt in die Welt, gehorcht dem Gesetz Gottes vollkommen und lädt die Strafe der Sünde auf sich. So erhält er die Gerechtigkeit und die Sündenvergebung, und beides gibt er der Kirche.

Das Evangelium wird der Kirche als die Verheißung gegeben. Das Subjekt ist Gott, das Objekt ist die Kirche. Gott gibt die Verheißung, und die Kirche bekommt sie. Dazwischen vermittelt Christus. Die sündhafte Vernunft der Menschen hat daran Zweifel, aber die Kirche hält an der Verheißung fest, die nach den Eigenschaften Gottes gnädig, ewig und wirksam ist.

\footnotetext{
${ }^{477}$ Vgl. PK Ps 125, CR 13, 1208. „Ne languefacti etiam Sancti deficiant, impedita propagatione doctrinae, ut si Antiochus diutius grassatus esset, multo plures defecissent, multo pluribus locis fuisset deletum et impeditum ministerium, ...“

${ }^{478}$ Vgl. PK Ps 117/118, CR 13, 1187. „Significat igitur non esse Ecclesiam Dei ullas gentes aut congregationes, quae pugnant cum voce Evangelii, et quod usitate dicitur, Non est salus extra Ecclesiam, ...“

${ }^{479}$ Vgl. PK Ps 46, CR 13, 1097. „huic defensio promittitur ubicunque est. Et tamen aliquam sedem doctrinae et ministerii Deus etiam servat, et defendit tantisper, dum ibi gubernatores recte funguntur ministerio.“

${ }^{480}$ Vgl. PK Ps 7, CR 13, 1029. „Reprimat autem Deus sycophantas, ne deleatur ministerium Evangelii:"“

${ }^{481}$ Vgl. PK Ps 117/118, CR 13, 1187. „Ita praecipiunt reverenter adiuvari publicam ministerii Evangelii conservationem, non dissipari Ecclesiam, non fieri vastitatem, sed foveri vera doctrinae studia, communem Ecclesiae consociationem omnibus officiis.“
} 
Das Evangelium wirkt für die Kirche als die Erlösung, die schon seit Adam geplant wurde. Die Erlösung bezieht sich auf das Werk des Messias und wird durch den Glauben angewendet. So spielt der Glaube eine Rolle als die Methode, durch die die Kirche die Verheißung und die Geschenke Gottes annimmt. Melanchthon betont den Glauben als eine aktive Handlung der menschlichen Vernunft. Allerdings ist dies nicht die Ursache der Erlösung, sondern eine Folge, die von dem Heiligen Geist angeregt wird. So erhalten die Gläubigen die Rechtfertigung um der Barmherzigkeit Gottes willen. Und dazu braucht man nur den Glauben.

Bei Melanchthon gilt die Rechtfertigung nur für die Kirche, die von Gott erwählt wird, weil die Kirche den wahren Glauben besitzt. Die Erwählung ist eine Handlung Gottes, die schon mit der Schöpfung von Gott geplant worden ist. ${ }^{482}$ Dabei gibt es einen wichtigen Unterschied zwischen den Frommen und den Gottlosen. Für die Frommen, nämlich für die Erwählten, sind die ewigen guten Dinge, aber für die Gottlosen die ewige Strafe. Die Ursache der Erwählung ist keine menschliche Sache, sondern allein Ausdruck der Barmherzigkeit im Willen Gottes.

Das Evangelium wird durch das Amt verkündigt, verbreitet und bewahrt. In den Zeiten gab es verschiedene Minister des Evangeliums, z.B. Väter, Priester, Propheten, Apostel etc. Mit ihnen richtete Gott die Kirche ein und bewahrt sie.

Das Evangelium als Verheißung wurde von Gott der Kirche gegeben. Damit hat die Kirche ihren Grund für das Gebet und die Hoffnung. Bei Melanchthon besteht das Evangelium für die Kirche. Seine Darstellung des Evangeliums ist nicht theoretisch sondern praktisch. Er richtet sich immer auf den Nutzen für die Kirche hin. Das ist ein Charakter des PKs.

\footnotetext{
${ }^{482}$ Im PK erklärt Melanchthon die Erwählung nicht deutlich sondern impliziert. Aber Calvin drückt die Auffassung über die Erwählung in seinem Psalmenkommentar deutlich aus. (Selderhuis 2000, S.287-291)
} 


\subsection{Die Kirche, die das Evangelium annimmt.}

\subsubsection{Der Unterschied zwischen dem Alten Testament und dem Neuen Testament}

Bisher wurde im PK Melanchthons das Evangelium betrachtet, das der Kirche gegeben worden ist. Nun wird die Kirche betrachtet, die das Evangelium annimmt. Dieses Kapitel handelt nun von der Auffassung Melanchthons, wie die Kirche das Evangelium versteht und es auf sich anwendet. Zunächst ist das Verständnis Melanchthons im PK über den Unterschied zwischen dem Alten Testament und Neuen Testament zu betrachten, weil Melanchthon die Auslegungen der Psalmen auf die Kirche seiner Zeit anwendet. Welches Verständnis also über den Zusammenhang der im AT geschriebenen Psalmen mit der neutestamentlichen Kirche legt Melanchthon im PK vor, welche Segnungen hat die Kirche durch das Evangelium? Aufgrund der Antworten Melanchthons ist dann zu fragen, welche Brücken zwischen der gegenwärtigen und der damaligen Kirche zu sehen sind.

Melanchthon geht von einem deutlichen Unterschied zwischen dem AT und dem NT aus. Allerdings ist dieser Unterschied ein anderer als der Unterschied zwischen dem Gesetz und dem Evangelium. Das Gesetz unterscheidet sich vom Evangelium durch die Funktion des Wortes Gottes. Das Gesetz ist das allgemeine Prinzip Gottes, mit dem Gott die Welt regiert, und das Evangelium ist das außergewöhnliche Prinzip Gottes für die Erlösung der Kirche. Dagegen ist der Unterschied zwischen dem AT und dem NT ein zeitlicher bedingt durch die Ankunft des Messias. Insofern ist es für Melanchthon ein Irrtum zu denken, dass in der Zeit des ATs nur das Gesetz bestanden habe und das Evangelium nicht, und dass in der Zeit des NTs das Gesetz nicht mehr bestehe und nur noch das Evangelium. Im Gegenteil: Melanchthon entdeckt im PK sowohl das Gesetz als auch das Evangelium und legt beide zusammen aus. In der Zeit des NTs ist das Gesetz noch gültig nach Melanchthon. (Vgl. Kapitel 4.2.4) Allerdings findet sich die Vorhersage über den Messias im AT, und die Vorhersage erscheint konkret in den Arten des Gesetzes, nämlich dem Zeremoniengesetz und dem Bürgergesetz. (Vgl. Kapitel 4.2.5) Endlich vollendet sich das Evangelium, das im Gesetz impliziert wird, in der Zeit des NTs durch Jesus Christus. Deshalb ist zwischen dem Unterschied zwischen dem Gesetz und dem Evangelium und dem Unterschied zwischen dem AT und dem NT zu differenzieren. 
Melanchthon erklärt den Unterschied zwischen AT und NT im PK deutlich. Die Ehre des NTs ist größer als die ATs. ${ }^{483}$ Im AT wirkt Gott, sammelt die Kirche und kündigt an, die Sündenvergebung, das neue Licht und das ewige Leben zu geben. Das ist die Ehre des ATs. Aber im NT enthüllt Gott die Ehre, so stellt Gott das Evangelium für die Kirche im NT bestimmter heraus als im AT. Der konkrete Unterschied findet sich in der Betrachtung des Zeremoniengesetzes und des Bürgergesetzes. Das Zeremoniengesetz des ATs wird nicht für die Sündenvergebung eingesetzt, sondern es hilft der Verkündigung der Lehre als ein Zeichen des Bekenntnisses. Die Zeremonien werden für die damalige Zeit von Gott aufgetragen. Die Zeremonien gelten für den Dienst in der Zeit des ATs, in NT trägt Gott der Kirche andere auf. ${ }^{484}$ Im Hinblick auf das Bürgergesetz ist die politische Regierung des Volkes Israel in AT am besten, weil sie von Gott aufgestellt wird. ${ }^{485}$ Aber in der Zeit des NTs sammelt Gott die Kirche mit der großen Barmherzigkeit um seines Sohnes willen durch den Sohn. ${ }^{486}$ So stellte Gott in der Zeit des ATs die Verfassungen auf, die nur in der Zeit des ATs gelten, und nach der Ankunft des Messias verändern sich die Verfassungen. Allerdings meint die Änderung einfach keine einfache Ablegung der vorzeitlichen Verfassungen und Gesetze, sondern die Vollendung dieser Verfassungen mit der Ankunft des Messias nach dem Willen Gottes. (Vgl. Kapitel 4.2.4) Deshalb verurteilt Melanchthon als gottlos, die Verfassungen und Gesetze noch zu halten, die schon vollendet wurden.

Trotz des zeitlichen Abstandes zwischen dem AT und dem NT, zeigen beide eine innere Einheit. Melanchthon entdeckt das Verständnis über den Messias in den Psalmen. Das Verständnis ist übereinstimmend mit der Erkenntnis der alten Synagoge. ${ }^{487}$ Melanchthon behauptet, dass diese Auffassung der Einheit nicht neu bei ihm ist. Der Messias ist der Grund der Kirche, er sammelt die Kirche durch die Stimme des Evangeliums und kümmert sich um die

\footnotetext{
${ }^{483}$ Vgl. PK Ps 29, CR 13, 1061. „Cum fuerit ingens gloria veteris Testamenti, multo maior erit gloria novi Testamenti“"

${ }^{484}$ Vgl. PK Ps 51, CR 13, 1118. „quae pro tempore a Deo mandatae sunt. Tempore veteris Testamenti servabantur ceremoniae tunc mandatae, nunc nostrae servandae sunt.“

${ }^{485} \mathrm{Vgl}$. PK Ps 58, CR 13, 1138. „Sic Iudaei cum existimarent propter Evangelium suam politiam ruituram esse, quae fuerat expressa voce Dei et manifestis testimoniis divinis constituta, nec erat alia pulcrior politia in toto genere humano acerrime adversabantur doctrinae mutanti usitatos cultus."

${ }^{486}$ PK Ps 111, CR 13, 1167. „quod immensa bonitate propter Filium et per Filium colligit Ecclesiam“

${ }^{487}$ Vgl. PK Ps 117/118, CR 13, 1183. „Etiam vetus synagoga intellexit hunc Psalmum esse vocem Messiae.“
} 
Kirche. ${ }^{488}$ Außerdem implizieren die Psalmen, dass die Kirche auch aus den Heiden gesammelt wird. So entdeckt Melanchthon die feste und unveränderbare Verheißung über den Messias in den Psalmen. ${ }^{489}$ Darüber hinaus bezeichnet Melanchthon die Psalmen als die Lehre davon, was die wahre Kirche Gottes ist, wo die Kirche ist. Die Kirche bewahrt die Reinheit dieser Lehre, die von Gott überliefert wird. Nach Melanchthon sollen die wichtigen und ewigen Sätze der Psalmen ständig bewahrt, gelesen und erinnert werden. ${ }^{490}$ So ist die Auffassung Melanchthons über die Psalmen im PK zu bestätigen, dass die Psalmen auf die Kirche der Zeit Melanchthon angewendet werden können und sollen. Vor dem Hintergrund dieser Annahmen über den Zusammenhang zwischen dem AT und dem NT legt Melanchthon die Psalmen aus.

\subsubsection{Die Freiheit als Folge der Erlösung}

Wer das Evangelium durch den Glauben annimmt, wird in der Folge gerettet, und die Rettung zeigt sich konkret durch die Freiheit. Die Freiheit impliziert eine vorzeitlich unfreie Phase. Melanchthon erklärt die Freiheit so, dass obwohl Adam nach dem Sündenfall gottlos geworden ist, Gott ihn nicht wegwirft, sondern ihn aufrichtet, ihn mit der Kleidung der Ehre anzieht und ihm die Gerechtigkeit und das ewige Leben wiederherstellt. ${ }^{491}$ Außerdem erklärt Melanchthon so, wer daran glaube, durch den Sohn von Gott angenommen, geschützt und gerettet zu werden, werde von der Sünde, dem Tod und der Tyrannei des Teufels befreit. ${ }^{492}$ Deshalb meint die Freiheit, dass Gott die, die ohne Gott in der Sünde und dem Tod geblieben und unter der Tyrannei des Teufels gebunden sind, durch den Glauben befreit. Dies bedeutet zugleich, dass Gott diese annimmt, schützt und rettet. Für Melanchthon beinhaltet die Freiheit sowohl die Erlösung als auch die Annahme Gottes und den ständigen Schutz Gottes.

\footnotetext{
${ }^{488}$ Vgl. PK Ps 117/118, CR 13, 1183. „factus est fundamentum Ecclesiae, id est, propter eius obedientiam Ecclesia recepta est, et ipse dominatur in Ecclesia, id est, colligit eam voce Evangelii et est in ea efficax, sanctificat illam Spiritu suo sancto, protegit et salvat eam, ...“

${ }^{489}$ PK Ps 116, CR 13, 1183. ,promissio facta de Messia sine ulla dubitatione rata et immota est,“

${ }^{490}$ Vgl. PK Ps 119, CR 13, 1188. „est autem hic Psalmus principaliter doctrina, quae sit et ubi sit vera Dei Ecclesia, videlicet, quae retinet puritatem doctrinae a Deo traditae, Hanc principalem et perpetuam sententiam huius Psalmi esse sciamus, ideoque vetustas voluit eum familiarissime notum esse hominibus, ut quotidie lectores commonefierent, de retinenda puritate doctrinae."

${ }^{491}$ Vgl. PK Ps 8, CR 13, 1031. ,abolito peccato et morte, restituuntur iusticia et vita aeterna. Haec est illa liberatio, quae hic describitur.“

${ }^{492}$ Vgl. PK Ps 2, CR 13, 1021. „liberos a peccato, morte, tyrannide diaboli, si confidant se propter filium a Deo recipi, et per filium defendi et servari.“
} 
Das Subjekt der Freiheit ist Gott und das Objekt ist die Kirche. Dazu spielt der Messias die Rolle als Vermittler. Gott als der Schützende verteidigt und befreit die Kirche, ${ }^{493}$ und er will von der Kirche angerufen werden und sie befreien. ${ }^{494}$ Melanchthon bezeichnet die Freiheit als das Geschenk Gottes. ${ }^{495}$ So werden die Frommen trotz der großen Bedrängnisse vom Tod befreit ${ }^{496}$ und freuen sich in Gott durch die Freiheit. ${ }^{497}$ Die Freiheit wird durch den Messias gegeben, deswegen ist der Messias der Vermittler der Freiheit. Mit diesem Grund zeigt Melanchthon den Messias als den Sieger, der die Sünde und den Tod vernichtet und die Kirche aus der Tyrannei des Teufels befreit, ${ }^{498}$ und als den allmächtigen Befreier. ${ }^{499}$ Der Messias bittet für sich und für die ganze Kirche um die Freiheit und die Erlösung. ${ }^{500}$ Das Objekt der Freiheit, die Gott verheißt, ist die Kirche. ${ }^{501}$

Melanchthon sieht in den Psalmen die Freiheit des Messias durch die Freiheit Davids. ${ }^{502}$ Wie David befreit wurde, wird der Messias befreit. Diese Freiheit des Messias ist nicht nur für sich selbst sondern für die Kirche. Der Messias wird von Gott geschickt und als der Priester und der König ordiniert, um seine Kirche zu befreien. ${ }^{503}$ Der Messias schenkt seine Freiheit der Kirche, die Psalmen bringen sie mit dem Bild Davids zum Ausdruck. Als der Messias

\footnotetext{
${ }^{493}$ PK Ps 4, CR 13, 1024. „quod tu es protector noster, et defendes et liberabis nos.“

${ }^{494}$ PK Ps 13, CR 13, 1037. „scio te velle invocari, et velle liberare.“

${ }^{495}$ Vgl. PK Ps 18, CR 13, 1043. „Deinde recitat gloriosas liberationes, et fatetur eas Dei beneficia esse."“

${ }^{496}$ PK Ps 49, CR 13, 1105. „At econtra pii etsi nunc sunt in magnis aerumnis, tamen in ipsa morte liberabuntur"

${ }^{497}$ PK Ps 51z, CR 13, 1230. „Nomen laeticiae perspicuum est, et liberatio ex inferis et morte, est talis vita, quae sentit laeticiam in Deo.“

${ }^{498}$ PK Ps 47, CR 13, 1098. „Delevit peccatum et mortem, et liberavit nos a tyrannide diaboli.“

${ }^{499}$ Vgl. PK Ps 110, CR 13. 1154. ,et confugiamus ad hunc Filium liberatorem omnipotentem“

${ }^{500}$ PK Ps 117/118, CR 13, 1186. „nam et ipse Messias petit pro se et pro tota Ecclesia liberationem et salvationem"

${ }^{501}$ Vgl. PK Ps 25, CR 13, 1056. „quae toti Ecclesiae liberationem pollicetur.“

${ }^{502}$ Vgl. PK. 22, CR 13, 1049. „Nam etiam David de se quoque loquitur, et similia patitur, tamen scit suas afflictiones et liberationes imagines esse afflictionum et victoriarum Christi, quas secutura erat Evangelii propagatio et collectio Ecclesiae."

${ }^{503}$ Vgl. PK Ps 45, CR 13, 1092 ,ideo aeternus pater Filium misit, et ordinavit ad hoc sacerdotium et regnum, data ei potentia divina et Spiritu sancto, ut ipse consortes suos liberet, et donet illis etiam Spiritum sanctum, quo in eis novam lucem, iusticiam et vitam aeternam efficiat."
} 
ankommt, beginnt die Freiheit der Kirche und in der allgemeinen Auferstehung vollendet sich die Freiheit. ${ }^{504}$

Die Freiheit, die der Kirche durch den Messias gegeben wird, zeigt sich vor allem durch die Freiheit vom Bösen, der Sünde und dem ewigen Tod. ${ }^{505}$ Diese Freiheit ist nämlich die Rettung der Kirche. ${ }^{506}$ Durch die Passion und den Sieg Christi erhält die Kirche die Freiheit. Melanchthon erklärt dies so in der Auslegung zu Psalm 49: „obwohl die Frommen nun in den großen Bedrängnissen sind, werden sie aber im Tod selbst befreit und von Gott geschmückt mit der ewigen Güte, dem Leben, der Weisheit, der Gerechtigkeit und der Freude in jener ewigen Gewohnheit der Kirche. “507 Dadurch erhält die Kirche das aus der Hölle und dem Tod frei werdende Leben und freut sich in Gott. ${ }^{508}$ Dazu werden im PK als Beispiele Joseph, David und Jeremiah erwähnt. ${ }^{509}$

Die Freiheit, die durch den Messias der Kirche gegeben wird, ist so ehrenhaft, weil die Freiheit das Geschenk Gottes ist. ${ }^{510}$ Die Kirche, die dies Geschenk der Freiheit besitzt, gewinnt das ewige Leben durch den Heiligen Geist. ${ }^{511}$ Und im ewigen Leben ruht die Kirche frei von allem Bösen in Gott. ${ }^{512}$ So erscheint Gott in der Freiheit der Kirche. Außerdem soll

\footnotetext{
${ }^{504}$ Vgl. PK Ps 14, CR 13, 1039. „tamen liberabitur et regnabit gloriose, tunc cum ex Zion dabitur salvator, id est, cum veniet Messias, et suum regnum incoabit, et gloria ornabit, quod coepit Christus facere in resurrectione sua, et perficiet in universali resurrectione."

${ }^{505}$ Vgl. PK Ps 110 , CR 13, 1153. „sed divina potentia liberaturum esse Ecclesiam a summis malis, a peccato et a morte aeterna, quod nulla creatura facere potest." Und vgl. PK Ps 49, CR 13, 1198.; PK Ps 47, CR 13, 1098.; PK Ps 110, CR 13, 1153.

${ }^{506} \mathrm{Vgl}$. PK Ps $117 / 118$, CR 13, 1186. „nam et ipse Messias petit pro se et pro tota Ecclesia liberationem et salvationem, ..."Vgl. PK Ps 16, CR 13, 1041.

${ }^{507}$ PK Ps 49, CR 13, 1105. „At econtra pii etsi nunc sunt in magnis aerumnis, tamen in ipsa morte liberabuntur, et a Deo ornabuntur aeternis bonis, vita, sapientia, iusticia, laeticia, in illa aeterna consuetudine Ecclesiae.“

${ }^{508}$ PK Ps 51z, CR 13, 1230. „Nomen laeticiae perspicuum est, et liberatio ex inferis et morte, est talis vita, quae sentit laeticiam in Deo.“

${ }^{509}$ PK Ps 112, CR 13, 1177. „Deus erit memor ipsius, exaudiet, sustentabit, iuvabit et liberabit eum, sicut exaudivit Ioseph, Davidem, Ieremiam, et alios.“

${ }^{510}$ PK Ps 18, CR 13, 1043. „Deinde recitat gloriosas liberationes, et fatetur eas Dei beneficia esse.“

${ }^{511}$ Vgl. PK Ps 24, CR 13, 1053. „liberationem a peccato et morte, donabitur Spiritu sancto et vita aeterna.“

${ }^{512}$ Vgl. PK Ps 25, CR 13, 1056. „Significat igitur restare vitam aeternam, in qua Ecclesia liberata ab omnibus malis, acquiescet in Deo.“
} 
die Kirche um die Freiheit bitten, damit Gott geehrt wird. ${ }^{513}$ Die Kirche hat mit der Freiheit die Sündenvergebung und den Heiligen Geist, ${ }^{514}$ lobt und dankt Gott. ${ }^{515}$

Im PK meint die Freiheit zuerst die gegenwärtige Freiheit und dann die ewige Freiheit. Und Melanchthon lehrt, dass man, obwohl man in diesem Leben nicht frei ist, mit dem festen Glaube und der Hoffnung das ewige Leben und die Freiheit erwarten solle. ${ }^{516}$ Die Ausnahme der gegenwärtigen Freiheit findet sich doch in diesem Leben, aber die ewige Freiheit gewiss.

\subsubsection{Die Bekehrung}

Für Melanchthon ist die Bekehrung notwendig für die Erlösung. Vor allem ist die Bekehrung die Handlung der Kirche und die Richtung der Bekehrung ist hin zu Gott. Das Wissen des Zornes Gottes gegen die Sünde und die Furcht vor dem Gericht Gottes führen die Mitglieder der Kirche zur Bekehrung. ${ }^{517}$ Die Folge der Bekehrung sind die Anrufung Gottes und die Annahme des Evangeliums. ${ }^{518}$ So genießen die Bekehrten das Leben ${ }^{519}$ und die Abwesenheit des Zornes Gottes in den Bekehrenden. ${ }^{520}$

Bei der Bekehrung spielt das Amt der Kirche eine bedeutende Rolle, weil die Bekehrung durch die Predigt des Wortes Gottes geschieht. ${ }^{521}$ Das Amt wirkt mit dem Predigtamt und der Spendung der Sakramente. Durch die Predigt des Evangeliums erkennt man den Zorn Gottes gegen die Sünde und die Furcht vor dem Gericht. Dann geschieht die Bekehrung.

Es sind zwar alle Menschen der Sünde angeklagt, doch ist dabei zwischen zwei Gruppen zu unterscheiden. Einige bekehren sich zu Gott, erkennen und beklagen ihre Unreinheit, und

\footnotetext{
${ }^{513}$ Vgl. PK Ps 30, CR 13, 1063 . „quare sit petenda liberatio, scilicet ut Deus glorificetur“

${ }^{514}$ PK Ps 24, CR 13, 1053. „habens remissionem peccatorum et Spiritum sanctum“

${ }^{515}$ PK Ps 8, CR 13, 1032. „sed ipsa in perpetua laetitia celebrabit Deum. Pro hac liberatione, inquit ultimus versus, agimus tibi Deus Iehova gratias,“

${ }^{516}$ PK Ps 112, CR 13, 1177. „Hic Psalmus comprehendit et praesentes liberationes et aeternam, Deus est memor Abel etiam hac praesenti vita amissa, Docet ergo Psalmus restare aliud iudicium, nec deficiendum esse a Deo, etiamsi in hac vita non liberamur, sed certa fide et spe expectandam esse liberationem in vita aeterna,

${ }^{517}$ Vgl. PK Ps 32, CR 13, 1066. „His exemplis et coërcet Deus impios, et commonefacit omnes homines, ut agnoscant Deum vere irasci peccatis, et aliqui ad Deum convertantur." und vgl. PK Ps 52, CR 13, 1120. „Nam brevis calamitas in hac vita non est aequalis poena pro tantis sceleribus, sed est commonefactio de iudicio Dei, qua Deus ostendit se non esse oblitum delicti, ut alii metuant futurum iudicium, nec se talibus sceleribus contaminent, et ut convertantur.“

${ }^{518}$ Vgl. PK Ps 10, CR 13, 1035. ,et omnes agnoscant hunc vere Deum esse, quem Ecclesia Christi invocat, et ad eum convertantur et Evangelium amplectantur."

${ }^{519}$ Vgl. PK Ps 110, CR 13, 1155. „sed ut convertatur et vivat.“

${ }^{520}$ Vgl. PK Ps 31z, CR 13, 1235. „et remissio culpae significat Deum iam non irasci converso”

${ }^{521}$ Vgl. PK Ps 132, CR 13, 1218. „omnes conversi per ministerium celebrent te in omni aeternitate“
} 
sie beginnen, Gott zu gehorchen. Diese sind die Kirche, die Gott um des Sohnes Gottes willen erfreut. Im Gegensatz dazu verachtet die große Mehrheit der anderen Gott, erhöht ihre Sünde und versucht, das Licht der wahren Lehre zu vernichten. ${ }^{522}$

Melanchthon bezeichnet die Bekehrung als eine Handlung der kirchlichen Mitglieder. ${ }^{523}$ Aber in anderen Orten bezeichnet er sie als die Handlung Gottes, der die Kirche bekehrt. ${ }^{524}$ Beides macht bei Melanchthon keinen Widerspruch. Er unterscheidet die Bekehrung als die freiwillige Handlung der kirchlichen Mitglieder nicht von der als der Handlung Gottes gegenüber der Kirche. ${ }^{525}$ Das ist die Auffassung Melanchthons über die Handlungen in der Bekehrung von der Kirche und durch Gott. Gott bekehrt die Kirche, und die Kirche bekehrt sich aktiv. Eine Teilung und den Widerspruch zwischen beiden Handlungen gibt es nicht bei Melanchthon. So wirkt Gott im menschlichen Willen, und der Mensch handelt aktiv. Das ist bei Melanchthon die Wirklichkeit, in der die Bekehrung erscheint, und kein theoretisches Ding, sondern das aktuell praktische. ${ }^{56}$ Deshalb erklärt Melanchthon, dass man ohne Zweifel weiß, dass die zu Gott Bekehrten die Erben des ewigen Lebens sind. ${ }^{527}$ Bei Melanchthon zeigt die Bekehrung die Erlösung.

\footnotetext{
${ }^{522}$ Vgl. PK Ps 53, CR 13, 1123. „Haec concio vere universalis est, accusans peccatum in omnibus, sed postea discrimen est, Pauci aliqui convertuntur ad Deum, et agnoscunt ac deplorant suam immunditiem, et incipiunt Deo obedire, hi sunt Ecclesia Deo placens propter Filium. Ac reliqua ingens multitudo contemnit Deum, et plurimi manifestis furoribus cumulant peccata, polluuntur libidinibus, exercent saevitiam in gubernatione, conantur delere verae doctrinae lucem, et laxant frenos aliis malis cupiditatibus."

${ }^{523}$ Vgl. PK Ps 55, CR 13, 1130. „Deinde in personis discrimen est, sanabiles optat converti, sed blasphemos optat deleri ...“ und vgl. PK Ps 119, CR 13, 1195. „Septimus est precatio pro Ecclesia, Convertantur ad me.“

${ }^{524}$ Vgl. PK Ps 119, CR 13, 1188. „quod hac voce Deus convertat et vivificet credentes.“ und vgl. PK Ps 51z, CR 13, 1227. ,postquam convertisti me egi poenitentiam.“

${ }^{525}$ Vgl. PK Ps $31 z$, CR 13, 1238. „Iam discernit non conversos a conversis, ...“

${ }^{526}$ In diesem Punkt entstanden viele Streite über die Willensfreiheit schon seit $16 \mathrm{Jh}$. (vgl. Kobler 2014; Wengert 1999) Die Verdächtigung des Synergismus wird von vielen lutherischen Theologen Melanchthon zugeschrieben.(Meinhold 1960; Seeberg 1960) Insofern meint Melanchthon hier keinen Synergismus, als Melanchthon die aktive Bekehrung der Kirche durch die Wirkung Gottes als eine aktuelle Erfahrung der Kirche erklärt. Peters 1979 Dazu ist bei Melanchthon vorausgesetzt, dass der menschliche Wille durch das Wort Gottes gebildet und von dem Heiligen Geist geholfen werden soll. Wagner

${ }^{527}$ PK Ps 31z, CR 13, 1239. ,et sciamus sine ulla dubitatione conversos ad Deum fore haeredes vitae aeternae.“
} 
Auf der Seite der Kirche werden die Gerechten als die, die sich zu Gott bekehren, bezeichnet. ${ }^{528}$ Sie glauben, dass in der wahren Buße sie um des Sohnes Gottes willen von Gott frei angenommen werden. So meint die Bekehrung zu Gott, mit dem Glauben die Verheißung Gottes über die Erlösung zu teilen. ${ }^{529}$ Auf der Seite Gottes bedeutet die Bekehrung das Sammeln der Kirche. ${ }^{530}$ Außerdem hat die Bekehrung eine bestimmte Frist, vor dem Tod soll man sich bekehren. ${ }^{531}$

Bei Melanchthon steht die Bekehrung in der Anfangsphase der Erlösung, ${ }^{532}$ nämlich vor der Buße. ${ }^{533}$ Aber Melanchthon erklärt die Bekehrung nicht nur als eine Anfangsphase der Erlösung, sondern als die ganze Phase der Erlösung, in der die Bekehrten sich in diesem Leben ständig zu Gott bekehren. Deshalb erklärt Melanchthon als den besten Dienst die Bekehrung zu Gott und den Glauben an den Vermittler. ${ }^{534}$ Darüber hinaus erfreuen die Bekehrung und das in der Buße trauernde Herz Gott. ${ }^{535}$ So beziehen sich die Erklärung der Bekehrung und die der Buße bei Melanchthon aufeinander. Bei Melanchthon ist die Bekehrung eine bewegende Handlung, und die Buße ist der Ort, auf den die Bewegung der Bekehrung sich richtet. Deshalb kann man sagen, dass die Buße eine Folge der Bekehrung ist.

\subsubsection{Die Buße}

Die erste Reaktion der Kirche, der durch das Evangelium die ewige Freiheit verheißen ist, ist die Buße. Die Buße beginnt mit der Erkenntnis der Sünde. Das ist die wichtige Funktion des Gesetzes. Wie die Propheten Angst davor haben, dass sie unter der Erkenntnis der Sünde

\footnotetext{
${ }^{528}$ PK Ps 55, CR 13, 1130. „iustos dici omnes conversos ad Deum ...“ und vgl. PK Ps31z, CR 13, 1239. „quod nominat iustos conversos ad Deum ...“

${ }^{529}$ PK Ps 34z, CR 13, 1243. „,sed oportet vos converti ad Deum, et fide amplecti promissionem“

${ }^{530}$ PK Ps 22, CR 13, 1050. „Et de collectione Ecclesiae: Convertentur ad Dominum omnes fines terrae.“ Und vgl. PK Ps 113, CR 13, 1179. „sciamus vere colligi Ecelesiam, vere recipi eos qui convertuntur ad Deum fiducia Mediatoris"

${ }^{531}$ Vgl. PK Ps 34z, CR 13, 1244. „docet etiam hic locus oportere in hac vita ante mortem fieri conversionem ad Deum"

${ }^{532}$ Vgl. PK Ps 130, CR 13, 1214. „Hae promissiones non tantum ad initium conversionis pertinent, sed ad exercitium fidei in tota vita."

${ }^{533}$ Vgl. PK Ps 51z, CR 13, 1227. „postquam convertisti me egi poenitentiam.“

${ }^{534} \mathrm{Vgl}$. PK Ps 51z, CR 13, 1232. „Sunt autem cultus primi praecepti conversio ad Deum, et fides agnoscens Mediatorem“

${ }^{535}$ Vgl. PK Ps 51z, CR 13, 1232. „Sacrificium Deo, id est, placet Deo cor vere dolens in conversione seu potentia ..." und vgl. PK Ps 28, CR 13, 1233. „Hos veros cultus inquit David placere Deo, dolores in conversione, fidem, invocationem, spem etc."
} 
verurteilt werden, erfahren die Frommen die Konfusion der großen Furcht. ${ }^{536}$ Wenn man die Sintflut, den Turmbau zu Babel, das Massaker, den Götterdienst und die Bestrafung der Städte usw., nämlich die traurigen Beispiele der Welt, sieht, muss man den Zorn Gottes erkennen und sich zur Buße bekehren. ${ }^{537}$

Bei der Erkenntnis des Zornes Gottes ist die Gerechtigkeit Gottes der Grund für den Zorn. So halten die die Sünde Erkennenden ihre Strafe und den ewigen Tod für richtig. Wie das Bekenntnis Daniels, dass zu Gott die Gerechtigkeit gehört, zum Menschen jedoch die Konfusion, wollen die Frommen die gerechte Strafe annehmen und damit die Gerechtigkeit Gottes loben. ${ }^{538}$ Deshalb bezeichnet Melanchthon die Buße als die andere Erkenntnis vom Ungehorsam und dem Zorn Gottes. ${ }^{539}$

Diese Buße richtet sich auf die verheißene Barmherzigkeit Gottes. Die Büßenden gehen auf Gott nicht mit ihrer eigenen Gerechtigkeit zu, weil sie um ihre Sünde genau wissen. Aber sie glauben, in der wahren Buße um des Sohnes Gottes willen umsonst angenommen zu werden. ${ }^{540}$ Deswegen wird in den Psalmen bekannt, dass der Gerechte auf den Herrn vertraut. Melanchthon lehrt nämlich im PK, dass die Psalmen die Buße lehren, die auf die Verheißung Gottes angewiesen ist. ${ }^{541} \mathrm{Im}$ PK zu Psalm 51 kann man ein Beispiel dieser Auffassung Melanchthons sehen. ${ }^{542}$

\footnotetext{
${ }^{536}$ Vgl. PK Ps 28, CR 13, 1059. „Huius ingentis et horrendae consternationis gustum in sensu poenitentiae pii experiuntur.“"

${ }^{537}$ Vgl. PK Ps 110, CR 13, 1157. „Haec tristia exempla intuentes cogitemus iram Dei, et flectamur ad poenitentiam“"

${ }^{538}$ PK Ps 28, CR 13, 1059. „ut clamitat Daniel cap. 9. Tibi Domine iusticia, nobis autem confusio faciei: metuunt igitur se prorsus abiici cum damnatis in aeternum exitium."

${ }^{539}$ Vgl. PK Ps 51, CR 13, 1114. „Haec pars poenitentiae necessaria est, quae quidem est aliqua agnitio inobedientiae nostrae et irae Dei.“

${ }^{540}$ Vgl. PK Ps 55, CR 13, 1230. „qui in vera poenitentia credunt se propter filium Dei gratis recipi“

${ }^{541}$ Vgl. PK Ps 112, CR 13, 1177. „,... Hic iustus confidit Domino. ... Loquitur ergo Psalmus de iusto, sicut in Evangelio traditur doctrina de poenitentia, et de fide, ac fiducia quae erigit corda, et primum accipit remissionem peccatorum, et expectat liberationem aeternam propter Filium Dei gratis, iuxta iusiurandum"

${ }^{542}$ PK Ps 51, CR 13, 1113-1114. „Agnosco et fateor me vere esse reum et dignum ira. Iaceo prostratus coram te sentiens iram tuam iustissimam adversus peccata, meque ingenti mole peccatorum oneratum esse. Et haec plane fateor, ut tu iustificeris, id est, tribuam tibi laudem iusticiae, cum accusas et punis, quam non tribuunt hypocritae. Saul et similes clamitant se iniuste tantis calamitatibus obrui, cum sint bene meriti. Ego vero fateor me iustissime puniri. Cerno vitia cordis quae assidue circumfero, rapui alterius coniugem, struxi insidias vitae viri, praebui occasionem ingentibus scandalis in Ecclesia Dei, meumque eo gravius est delictum, quod ingentibus donis et victoriis a te ornatus fui prae caeteris Prophetis et ducibus in tuo populo. Tibi igitur iusticiam tribuo, meque volens aliquo modo poenis
} 
Alle sind zur Buße aufgerufen. ${ }^{543}$ Nur durch die Buße kann man auf Gott zugehen und die Erlösung erhalten. Und das Herz, das in der Buße den Schmerz erfährt, erfreut Gott. Die dieses Herz Besitzenden erkennen den Zorn Gottes und fliehen zum Vermittler, obwohl ihre Vernunft und das Gesetz sie verurteilen, hören sie der Stimme des Evangeliums zu. ${ }^{544}$ So nimmt Gott die an, die das Evangelium mit dem Glauben annehmen. Gott nimmt die Leidenden durch das zu Gott Fliehen an, erhört sie und hilft ihnen. Um durch den Schmerz nicht umzukommen, soll man sich zur Buße bekehren. ${ }^{545}$ Dagegen werden diejenigen, die sich nicht zur Buße bekehren, angeklagt. ${ }^{546}$ Ohne Buße ein Gegner Gottes zu bleiben und als Verworfener von Gott zu leben, bezeichnet Melanchthon deshalb als das schlimmste Elend. ${ }^{547}$

Bei der Erklärung Melanchthons über die Buße soll man aber berücksichtigen, dass Melanchthon die Buße in Hinsicht auf die aktuelle Erfahrung der Gläubigen darstellt. Er behauptet dabei nicht, dass die Bekehrung und die Buße als eine menschliche Handlung ohne die Wirkung Gottes möglich seien und dass eine Zusammenwirkung von Gott und Menschen nötig sei. Dazu erfahren die Gläubigen in diesem Leben die tägliche Buße.

\subsubsection{Die Gerechtigkeit der Kirche}

Die Lehre der Buße setzt voraus, dass die Mitglieder der Kirche, obwohl sie die Gerechtigkeit durch den Glauben besitzen, in diesem Leben immer unter der Sünde und in der Schwachheit leben. Deshalb können ihre gerechten Handlungen vor Gott nicht als gerecht anerkannt werden. ${ }^{548}$ Aber was ist dann das gerechte Leben der Gläubigen in diesem Leben

subiicio, sed ut eas mitiges oro. Te iustum praedico non me, nec adfero ad te fiduciam ullam meae dignitatis, sed ad misericordiam promissam confugio, propter hanc me recipi oro. Sic addit hanc antithesin: Ut tu iustificeris, ad discernendos hypocritas qui fremunt adversus iudicium Dei, ab iis qui vere agunt poenitentiam, et se Deo subiiciunt.“

${ }^{543}$ Vgl. PK Ps 31z, CR 13, 1238. ,vult multos ad poenitentiam revocari.“

${ }^{544}$ Vgl. PK Ps 51z, CR 13, 1232. „Nam ratio et lex dicunt, homines miseros et oppressos doloribus reiectos esse a Deo. Vox Evangelii affirmat hos esse templa Dei, et afflictiones eorum, qui ad Deum conversi sunt esse sacrificia“"

${ }^{545}$ Vgl. PK Ps 119, CR 13, 1194. „Cumque sciamus quare velit Deus Ecclesiam subiectam esse cruci, obediamus ei patienter in his miseriis, et petamus mitigationem, et expectemus liberationem.“

${ }^{546}$ Vgl. PK Ps 53, CR 13, 1123. „quarum altera accusat omnes homines non agentes poenitentiam“

${ }^{547}$ Vgl. PK Ps 110, CR 13, 1166. „, summa enim et extrema miseria est sine poenitentia tanquam hostem Dei et abiectum a Deo vivere."

${ }^{548} \mathrm{Vgl}$. Haikola sagt, nach Melanchthon ist der ,freier Wille“ des Rechtfertigten ,zumindest teilweise widerhergestellt.“ (Haikola 1961, S.97) Er denkt, die Auffassung Melanchthons über das Gesetz und die Bekehrung mündet in Synergismus. Aber er setzt den freien Willen des Menschen gleichrangig mit der Wirkung Gottes. Deswegen erklärt er die Aktivität des Menschen bei der Bekehrung als eine Zusammenwirkung von Gott und Menschen. Aber ein solcher Gedanke ist im PK nicht zu finden. Me- 
und welche Bedeutung hat ein solches Leben für die Gläubigen? Da Melanchthon aber das gerechte Leben der Gläubigen in diesem Leben betont, ist seine Antwort auf die vorangegangene Frage zu betrachten.

Nach Melanchthon besteht die Gerechtigkeit aus zwei Arten. Erstens die Gerechtigkeit der Person (Iusticia personae), zweitens die des guten Gewissens (Iusticia bonae conscientiae). ${ }^{549}$ Die Gerechtigkeit der Person ist die Gerechtigkeit, die allein der Messias macht, und sie wird durch den Glauben an den Vermittler von der Kirche erhalten. Diese Gerechtigkeit kann man selbst nicht gewinnen oder erhalten. ${ }^{550}$ Durch diese Gerechtigkeit werden die Gläubigen die Erben des ewigen Lebens nicht wegen ihres Wertes selbst, sondern wegen der Barmherzigkeit durch den Vermittler. ${ }^{551}$ Sie stehen nicht unter der Sünde, sondern unter der Gnade. Diese gnädige Verheißung ist gültig nicht nur am Anfang der Bekehrung, sondern auch in der aktuellen Praxis des Glaubens. ${ }^{552}$ Deswegen gibt es keine Möglichkeit des Abbrechens der Gnade. So werden die Gläubigen gerechtfertigt, allerdings bedeutet diese Rechtfertigung keine vollständige Heiligung der Gläubigen, weil sie in diesem Leben noch sündig sind. Die Sünde und die Strafe der Gläubigen werden vergeben, allerdings haben sie noch Sünde. Wenn sie wegen ihrer Sünde gestraft werden, ist die Strafe keine gerechte Strafe für ihre Sünde. Die Strafe dafür hat einen anderen Zweck. Die Sünde wird ihnen nicht zugerechnet. ${ }^{553}$

Vor diesem Hintergrund stellt sich die Frage nach dem Leben der gerechtfertigten Gläubigen. Die Antwort Melanchthons dazu findet sich in der zweiten Art der Gerechtigkeit. Diese

lanchthon hat mindestens im PK kein Interesse daran, eine Möglichkeit des Menschen, ohne die Wirkung Gottes gute Werke zu tun, zu behaupten.

${ }^{549}$ Vgl. PK Ps 7, CR 13, 1028. ,Alia est iusticia personae, qua persona tota coram Deo gratis reputatur iusta. Haec imputatio tantum fide accipitur, nec opponuntur nostrae virtutes aut beneficia. Cum autem hac iusticia personae donati simus, necesse est adesse et alteram iusticiam bonae conscientiae, seu operum: non indulgeamus ulli cupiditati contra conscientiam.“

${ }^{550}$ Vgl. PK Ps 119, CR 13, 1195. ,non loquitur de iusticia personae, et universaliter verum est, primum oportere statuere personam iustam esse, propter Mediatorem fide gratis, per misericordiam, iuxta illud, Non iustificabitur in conspectu tuo omnis vivens, sed iustificati fide pacem habemus, quae dicta loquuntur de iusticia personae.“ Und vgl. PK Ps 112, CR 13, 1175. „Deus est memor omni tempore et iusticiae personae, seu iusticiae fidei, et causae iustae, et eleemosynarum iusti, et tandem ostendit se curare iustos, et eorum causas et eorum eleemosynas ..."

${ }^{551}$ Vgl. PK Ps 130, CR 13, 1214. „qua propter Filium Dei et per eum donamur remissione peccatorum, iustificamur et sanctificamur Spiritu sancto, et efficimur haeredes vitae aeternae, non pendet ex conditione nostrae dignitatis.“

552 Vgl. PK Ps 130, CR 13, 1215. „Quanquam enim verum est in conversione haec fieri, Filius Dei vivificat eos qui convertuntur, et liberat ex aeterna morte, et sanctificat eos Spiritu suo sancto, et vere in eis divinitas habitat"

${ }^{553}$ PK Ps 31z, CR 13, 1235. ,non imputare peccatum“ 
ist die Gerechtigkeit des guten Gewissens. Die Gläubigen werden vor Gott um des Vermittlers willen durch die Barmherzigkeit Gottes angenommen. Und in der Berufung erfreut der Gehorsam des guten Gewissens Gott, und die Gläubigen rufen Gott an. ${ }^{554}$ Melanchthon verbindet den Glauben mit dem guten Gewissen. Der Glaube und das gute Gewissen bewahren die reine Lehre. ${ }^{555}$ Die Gläubigen arbeiten mit dem Glauben und dem guten Gewissen als die guten Soldaten. ${ }^{556}$ Wenn so das reine Wort im Glauben und dem guten Gewissen gehalten wird, wird das zur Freude für Gott. ${ }^{557}$ Das Wort Gottes zu halten, bedeutet mit dem Glauben und dem guten Gewissen die unbefleckte Lehre zu halten. ${ }^{558}$ Gott befiehlt, im Glauben und dem guten Gewissen zu leben. ${ }^{559}$ Wer so im Glauben und dem guten Gewissen das göttliche Wort bewahrt, ist ein wahres Mitglied der Kirche. ${ }^{560}$ Und wer den Herrn fürchtet, wird durch den Glauben gerechtfertigt und hat das gute Gewissen. ${ }^{561}$ Deshalb, wenn man von Gott geliebt werden möchte, soll man die Lehre bewahren und im Glauben und mit dem guten Gewissen leben. ${ }^{562}$ Melanchthon erwähnt David hierfür als Beispiel, der mit dem Glauben sein Amt machte. ${ }^{563}$

So bezieht sich das gerechte Leben der Gläubigen auf die Gerechtigkeit des guten Gewissens, nicht auf die keine Gerechtigkeit der Person. Damit der durch den Glauben Erlöste in diesem Leben Gott froh machen kann, hat er die Gerechtigkeit des guten Gewissens. Der Er-

\footnotetext{
${ }^{554}$ Vgl. PK Ps 59, CR 13, 1143. „Postea sciamus Deo etiam placere obedientiam in bonae causae defensione iuxta vocationem, et ibi ut possis invocare Deum et petere auxilium ad defendendam causam“"

${ }^{555}$ Vgl. PK Ps 119, CR 13, 1189. „sed hoc loco et saepe alias loquitur vox divina evangelice de professione incorruptae doctrinae, quae tamen fit fide et bona conscientia“"

${ }^{556}$ Vgl. PK Ps 128, CR 13, 1210. ,in qua servatur haec vitae regula, Milita bonam militiam, habens fidem et bonam conscientiam."

${ }^{557}$ PK Ps 119, CR 13, 1190. „Primus versus est recitatio mandati de custodienda puritate doctrinae, Sic via erit munda, id est, Deo placens, si custodies verbum Dei incorruptum, id est, si retinebis doctrinam incorruptam fide et bona conscientia"

${ }^{558}$ PK Ps 119, CR 13, 1192. „custodire mandata tua, id est, retinere doctrinam incorruptam fide et bona conscientia, iuxta illud, Si quis diligit me, sermonem meum servabit, etc.“

${ }^{559}$ PK Ps 119, CR 13, 1189. „Ambula coram me, et esto integer, id est, custos incorruptae doctrinae in fide et bona conscientia.“

${ }^{560}$ Vgl. PK Ps 119, CR 13, 1190. „Ita hic octonarius praecipue est doctrina docens, quae et ubi sit vera Ecclesia Dei“"

${ }^{561}$ PK Ps 112, CR 13, 1173. „sit iustus fide, et habeat bonam conscientiam“

${ }^{562}$ PK Ps 112, CR 13, 1174. „Custos meae doctrinae fide et bona conscientia, diligitur a patre, et est domicilium Dei.“

${ }^{563}$ Vgl. PK Ps 59, CR 13, 1142. „Ita et David habebat iusticiam bonae conscientiae, omnia faciebat fidelis ministri officia, ...
} 
halt der Gerechtigkeit der Person durch den Glauben hat eine enge Beziehung zur Handlung des guten Gewissens. Melanchthon bezeichnet den Glauben und das gute Gewissen als ein Paar. Beide können nicht getrennt bestehen. Wer die Gerechtigkeit durch den Glauben, nämlich die Gerechtigkeit der Person von Christus nicht erhält, bezieht sich nicht auf die Gerechtigkeit des guten Gewissens. Und wer die Gerechtigkeit durch den Glauben besitzt, hat unbedingt die Gerechtigkeit des guten Gewissens. Das ist notwendig, weil er ein Mitglied der Kirche ist. Wer deshalb die Gerechtigkeit des guten Gewissens verweigert, verweigert auch den Glauben. Obwohl die Gläubigen in diesem Leben wegen der noch bleibenden Sünde schwach sind, ist es nach Melanchthon nicht möglich, mit dem Glauben die Gerechtigkeit des guten Gewissens zu verweigern. Deshalb ist der Glaube mit dem Leben der Gläubigen nicht getrennt.

Die Gerechtigkeit der Person soll in der Beziehung zur Rechtfertigungslehre betrachtet werden. Die Gerechten erfreuen Gott mit dem guten Gewissen. Und für sie gibt es das Gute von der Ewigkeit und der Gegenwart. ${ }^{564}$ Die Gläubigen werden durch den Glauben an die gnädige Verheißung Gottes im ewigen Leben rechtfertigt und sie leben auch in diesem Leben unter der gleichen Regel durch den Glauben an die gnädige Verheißung Gottes.

\subsubsection{Der Zusammenhang zwischen der Kirche und dem politischen Reich}

Das alltägliche Leben der erlösten Gläubigen kann man vom politischen Hintergrund nicht trennen. So finden auch die Vorlesungen Melanchthons über die Psalmen in einer sehr dynamischen Zeit statt. Deswegen ist die Auffassung Melanchthons über den Zusammenhang zwischen der Kirche und dem politischen Reich im PK zu betrachten.

Gott gibt der Kirche jeweils andere Orte und andere politischen Verfassungen in jeder Zeit. Zuerst gibt er in der Zeit Moses einen bestimmten Ort, danach zerstreuen sich die zehn Stämme, dann rettet Gott den Stamm Juda aus Babylon. Endlich gibt er nach der Zerstörung Jerusalems die Kirche, in der die Stimme des Evangeliums klingt. Aber obwohl die Kirche kein weltliches Reich mehr ist, ${ }^{565}$ gilt das allgemeine Regierungsprinzip Gottes in der Politik noch. ${ }^{566}$ Deshalb bezeichnet Melanchthon Gott als den Bewahrer des Reiches. Das ist der

\footnotetext{
${ }^{564}$ PK Ps 112, CR 13, 1174. „Sciamus igitur hic in descriptione personae intelligi hominem iustum, et intueamur totam doctrinam de iustificatione, postea huic iusto attribuit promissiones. Hic iustus inquit est beatus, placet Deo, et habet bona aeterna et praesentia."

${ }^{565}$ Vgl. PK Ps 110, CR 13, 1153. „Hic affirmat regnum Messiae non fore mundanam politiam“

${ }^{566}$ Vgl. PK Ps 112, CR 13, 1176. „Hanc aeternam iusticiam etiam hic complectitur Psalmus, Quia quanquam in politico regimine etiam servat Deus regulam, ut atrocia scelera puniat atrocibus poenis in hac vita, et tandem vincant, qui antea iniuste oppressi fuerunt, sicut Angustus vincit Antonium:“
} 
Grund für die Bitte für das Reich. ${ }^{567}$ Die Unterhaltung des Reiches, die Wohlfahrt der Regierung und die Siege sind die Werke, die Geschenke und die Hilfe Gottes für die Führer, die Gott fürchten. ${ }^{568}$

Das Ziel Gottes für die Politik ist nach Melanchthon, den Willen Gottes zu lehren und den Menschen das Evangelium zu verkündigen. Gott hat einen bestimmten religiösen Zweck für die weltlichen Führer. Deshalb ist die Gottlosigkeit der Führer und Politiker verdammenswert. ${ }^{569}$ Die Führer sollen als die Bewahrer des Volkes fungieren, nicht als dessen Tyrannen, ${ }^{570}$ und sie sollen die ewige Ehre durch die Erfahrung mit Gott und Christus haben und ihr Reich und ihre Weisheit unter Gott legen. ${ }^{571}$ Sie können das Reich besser dadurch regieren, die Lehre zu hören, zu bilden und zu lehren. ${ }^{572}$ Aus diesem Grund weist Melanchthon darauf hin, dass die Stimme der Psalmen die Führer rühren wird. ${ }^{573}$

Gott fordert von den Führern, Gott anzurufen, um von ihm Hilfe zu bekommen. Hier treffen sich die Leistung der Berufung und der Gott anrufende Glaube. ${ }^{574}$ Melanchthon erwähnt den Gegensatz zwischen David und Ahab. David handelt gemäß der allgemeinen Leistung des Reiches, aber er empfindet die Hilfe und die Hand Gottes. Im Gegensatz dazu handelt Ahab zwar vergleichbar mit David, aber Ahab bittet nicht und erwartet keine Gegenwart Gottes. ${ }^{575}$

${ }^{567}$ PK Ps 21, CR 13, 1049. „Hunc versiculum non solum principes, sed nos quoque orantes pro politiis infigamus animis, credamus Deum custodem esse politiarum, et tunc incolumes mansuras esse, cum a Deo petemus defensionem.“

${ }^{568}$ Vgl. PK Ps 20, CR 13, 1047. „Dulcissima precatio est, pro rege, seu pro regno ac politico statu, quae docet et testatur, successus in imperiis, felicia consilia, salutarem gubernationem, et victorias, Dei opera et beneficia esse, et vere iuvari a Deo principes invocantes ipsum.“

${ }^{569}$ Vgl. PK Ps 24, CR 13, 1054. „,sed multo magis custodem disciplinae, prohibentem omnia externa scelera contra primam et secundam tabulam: ac primum sciat se debere gloriam Dei ornare, qui propterea coniunxit homines politica societate, ut alii alios de voluntate Dei doceant, et propagari Evangelium inter homines possit.“

${ }^{570}$ PK Ps 47, CR 13, 1100. „vult Principes protectores esse populorum, non tyrannos et vastatores terrae.“

${ }^{571}$ PK Ps 47, CR 13, 1100. „Principes se et sua imperia et suam sapientiam subiiciunt Deo, et ipsius doctrina reguntur, non propriis opinionibus.“

${ }^{572}$ Vgl. PK Ps 47, CR 13, 1100. „disciplina honestius et severius regi potest, cum congruunt piae voluntates et sententiae gubernantium Ecclesiam et politias“"

${ }^{573}$ PK Ps 47, CR 13, 1100. „Haec igitur vox Psalmi principibus inculcanda erat, ut excitarentur ad pietatem, cum audirent ipsorum obedientia gloriam Dei multipliciter augeri.“

${ }^{574}$ PK Ps 20, CR 13, 1047. „Concurrant haec, officium vocationis, et fides invocans Deum.“

${ }^{575}$ PK Ps 20, CR 13, 1047. „David facit officium vocationis, contrahit exercitum mediocrem, laborat, praeliatur: interim vero sentit consilia et dextras iuvari a Deo. At impius rex Achab aut similis contrahit exercitum quantum potest, et laborat, et hoc suo adparatu confidit, nec audet petere aut 
Deswegen weist Melanchthon darauf hin, dass die Psalmen außergewöhnlich deutlich und süß sind, wenn man die Gefahren aller frommen Führer hört. ${ }^{576}$ Die Bitte ist, dass die politischen Führer Gefälligkeit und Aufrichtigkeit gegenüber der Kirche und der Wissenschaft zeigen und dass sie den Diebstahl und die Zerstörung der Bildung verhindern. ${ }^{577}$

Allerdings hasst der Teufel Gott und regt die gottlosen Führer an, damit sie sich gegenüber der Kirche austoben. ${ }^{578}$ Dem zu Folge sind die frommen Führer vom Standpunkt Melanchthons aus wegen des Bekenntnisses zum Evangelium in Gefahr. ${ }^{579}$ Aber die Lehre muss bewahrt werden. Wenn die Staatgewalt die Lehre verweigert, soll man beten und die Pläne Gottes und die Bewahrung erwarten. Dabei muss man überlegen, welche menschliche Hilfe recht ist oder vermieden werden soll, und dann muss man die Methode anwenden, die mit der wahren Lehre übereinstimmt. ${ }^{580}$ Melanchthon erwartet, dass die Kirche und die Verfassung bewahrt und beschützt werden, wenn die Führer weise und fleißig sind. ${ }^{581}$ Gott richtet die Verfassung auf und bewahrt die Lehre, und er gibt die Kraft im Kampf. ${ }^{582}$

\subsubsection{Zusammenfassung}

Melanchthon behandelt den Unterschied zwischen dem AT und dem NT nicht als einen inhaltlichen, sondern als einen zeitlichen. Die Erlösung im AT und die im NT sind gleich durch den Glauben an den Messias. Die Einheit zwischen dem AT und dem NT ist ein wich-

expectare Dei praesentiam. Hoc discrimen considerandum est, ut et nostras actiones intelligere et fidem exercere discamus."

${ }^{576}$ PK Ps 20, CR 13, 1047. „quod Deus certo sit exauditurus invocantes, hac promissione confirmati fidem et invocationem accendamus. Erit autem hic Psalmus nobis et magis perspicuus et magis dulcis, si saepe recitabimus, precantes pro politia, et cogitantes de magnis periculis omnium piorum gubernatorum.,

${ }^{577}$ PK Ps 20, CR 13, 1048. „Ac meminerimus mandatum Dei, ut ex animo petamus, ut regat et iuvet omnes qui praesunt, et det politias tranquillas, quae sint honesta hospitia Ecclesiarum et litterarum, et prohibeat latrocinia, vastationes, et disciplinae dissolutionem.“

${ }^{578}$ PK Ps 44, CR 13, 1090. „sed quia diabolus odit Deum, irritat impios principes, ut saeviant in Ecclesiam.“

${ }^{579}$ Vgl. PK Ps 46, CR 13, 1094. „ut hoc tempore principes harum regionum propter Evangelii confessionem sunt in periculo.“

580 Vgl. PK Ps 46, CR 13, 1094. „Utantur mediocribus copiis hominum de vera doctrina consentientium"

${ }^{581}$ Vgl. PK Ps 60 , CR 13, 1147. „et concedi ei hospitia a Deo, nec regum aut gubernatorum sapientiam et diligentiam sufficere ad Ecclesiam vel politiam servandas aut defendendas.“

${ }^{582} \mathrm{Vgl}$. PK Ps 60, CR 13, 1149. „hoc est, ago gratias Deo quod Ecclesiam condidit, quod edidit promissionem gratiae, et hanc inter nos sonat, et nos ad aeternam societatem vocat: ago gratias etiam pro hoc singulari beneficio, quod hanc politiam et constituit et servat, ut sit hospitium doctrinae, et nobis opem fert in bellis, ne haec politia deleatur.“ 
tiger Punkt für den Anschluss zwischen dem AT und dem NT. Diese Einheit versichert die Anwendung der Psalmen an die in der Zeit des NTs.

Die Kirche genießt die Freiheit nach der Erlösung von der Sünde, dem Tod und der Tyrannei des Teufels. Bei der Freiheit ist Gott das gebende Subjekt und die Kirche das gegebene Objekt. Dazwischen vermittelt der Sohn Gottes als der Vermittler. Dazu ist der Zweck der Freiheit für die Kirche die Ehre Gottes. Melanchthon lobt Gott bei der Erlösung der Kirche. Gott wirkt nicht durch die Würde der Kirche, sondern um seiner eigenen Würde willen.

Wenn die Kirche die Freiheit Gottes genießt, bekehrt sie sich von ihrer Sünde zu Gott. Dabei spielt die Predigt des Wortes Gottes eine Rolle, damit die Mitglieder der Kirche die Sünde erkennen können. Die Bekehrten klagen über ihre Sünde und beginnt den Gehorsam gegenüber Gott. Die Bekehrung ist eine aktive Handlung der Kirche und eine göttliche Handlung für die Kirche. Dabei gibt es keine Konfusion nach Melanchthon. Außerdem sieht Melanchthon die Bekehrung als eine wiederholbare Handlung der Kirche in diesem Leben. Dabei verknüpft sich die Bekehrung mit der Buße. Die Buße bemerkt die Sünde in der Kirche und richtet sich auf die Barmherzigkeit Gottes. Dadurch kann man auf Gott zugehen.

Die Erlösung meint, dass die Kirche eine neue Gerechtigkeit erhält, die vom Werk des Sohnes Gottes gewonnen wird. Dabei bedeutet diese Gerechtigkeit die der Person. Nach der Erlösung meint die Gerechtigkeit der Kirche in diesem Leben die Gerechtigkeit des guten Gewissens. Über diese Gerechtigkeit freut sich Gott. In der Unterscheidung der beiden Arten der Gerechtigkeit kann man die Bedeutung der Gerechtigkeit in diesem Leben bemerken. Dazu verbindet sich die Aussage Melanchthons mit der schweren Situation seiner Zeit, dass das gerechte Leben ist, die wahre Lehre zu bewahren.

Die Kirche wohnt in diesem Leben unter einer weltlichen Regierung und ist selbst keine weltliche Regierung mehr. Aber Gott regiert noch die Welt, deshalb kann man Gott um eine weltliche Regierung bitten. Die weltlichen Führer sollen die Kirche fördern und Gott ehren. Diese Pflicht der Führer wird zum Nutzen für das Reich und auch für die Kirche. 


\subsection{Die anrufende Kirche}

\subsubsection{Die Passion des Messias und das Leiden der Kirche}

Melanchthon sieht in den Psalmen die Ehre der Kirche, die die Verheißung Gottes durch den Glauben annimmt. Dann aber konzentriert er sich im PK auf die Wirklichkeit seiner Kirche. In diesem Leben ist die Kirche Leiden unterworfen, obwohl sie bereits von Gott die Gerechtigkeit um des Sohnes Gottes willen erhalten hat. Melanchthon entdeckt solche Situationen der Kirche auch in den Psalmen, und damit verbindet er die schwierige Situation seiner Kirche. Seine Kirche leidet sehr stark und er sucht die Bedeutung Gottes in den Psalmen.

Bei der Betrachtung der Wirklichkeit der Kirche im PK, die das Evangelium annimmt, ist die Beziehung des Leidens der Kirche zur Passion des Messias von Bedeutung. Beide zeigen äußere Ähnlichkeiten, aber es zeigen sich aber auch gewisse Unterschiede. Melanchthon hält dennoch diese Beziehung für wichtig, weil sie eine Lösung Gottes für die schwierige Situation seiner Kirche erkennen lassen kann.

Melanchthon weist auf die enge Beziehung von beiden Leiden hin. Das Leiden der kirchlichen Mitglieder - wie es aus den Psalmen hervorgeht - hat eine enge Beziehung zur Passion des Messias. Ihr Leiden ist ein Bild der Passion des Messias. ${ }^{583}$ Das Leiden von David, Abel, Isaak und Joseph hat eine gleiche Bedeutung. ${ }^{584}$ Aber die Passion des Messias ist außergewöhnlicher. Melanchthon verwendet exklusiv das Wort „Passion (passio)“, um das Leiden des Messias zu bezeichnen. ${ }^{585}$ Melanchthon verleiht damit der Passion des Messias eine besondere Bedeutung und unterscheidet sie vom Leiden der kirchlichen Mitglieder. Wenn auch in den Psalmen das Leiden der Mitglieder der Kirche dargestellt wird, so soll man doch in vielen Fällen dieses Leiden als die Passion Christi verstehen. ${ }^{586}$ So verweisen das Leiden und der Sieg Davids in den Psalmen auf die Passion und den Sieg Christi. Der Messias gehorcht im Schmerz und vollendet sein Werk. Melanchthon betont, dass die Passion Christi sich nicht

\footnotetext{
${ }^{583}$ Vgl. PK Ps 117/118, CR 13, 1183. „Quanquam autem aliqui disputare volent Davidem hic loqui, tamen fatendum est typo principaliter significari Messiae passiones et victorias“"

${ }^{584} \mathrm{Vgl}$. PK Ps 59, CR 13, 1141. ,et typus ac vaticinium de futura Messiae passione, et poena Iudaeorum, quia Abel, Isaac, Ioseph et similium afflictiones, fuerunt typi passionis Filii Dei, et hi intelligebant Deum velle Ecclesiam subiectam esse cruci“

${ }^{585}$ Z.B. vgl. PK Ps 18, CR 13, 1043. „tamen ut aerumnae et victoriae Davidis sunt typus passionis et victoriae Christi““

586 Z.B. PK Ps 16, CR 13, 1040. „videlicet narratio de resurrectione Messiae, ac principaliter intelligatur loqui ipse Christus, etsi propterea, quod et Ecclesiam pati, et propter Christum ac per Christum resuscitari oportet, postea ad membra accommodari potest, quae accommodatio tamen prudenter fiat, ut Filio Dei suus honos proprius tribuatur, de quo et hic Psalmus loquitur, videlicet de merito passionis."
} 
nur in den Psalmen findet, sondern auch im Gesetz und bei den Propheten, also im ganzen AT. ${ }^{587}$

Nach der Auffassung Melanchthons liegt die Passion des Messias dem Leiden der Vorfahren voraus, ${ }^{588}$ weil die Passion des Messias das Urbild des Leidens der Vorfahren ist. Der Messias wird durch den unveränderbaren Befehl Gottes verheißen und gehorcht in der Passion. ${ }^{589}$ Er erträgt den Zorn Gottes und den Tod für das Menschengeschlecht. ${ }^{590}$ Seine Passion erhält einen Wert, ${ }^{591}$ mit dem die Kirche erlöst wird. Eigentlich ist so das Evangelium gemeint. Dazu ist die Passion Christi nicht vergeblich, sondern sie gebärt die Erlösung für die Kirche, die das Evangelium annimmt. ${ }^{592}$ Die ewige, ehrenhafte Kirche freut sich über diese Passion ${ }^{593}$ und lobt diese Passion. Durch den Gehorsam des Messias in der Passion versöhnt sich der Zorn Gottes. ${ }^{594}$ In der Folge werden bei der Kirche das ewige Leben, die Freude und die Ehre immer bleiben. ${ }^{595}$ So versteht Melanchthon die Passion Christi als den Inhalt des Evangeliums.

Außerdem ist nach Melanchthon die Passion des Messias als Methode der Überlieferung der Gerechtigkeit von dem Messias zu den Mitgliedern der Kirche zu bezeichnen. Nämlich ist die Passion Christi das Lösungsmittel für die Erlösung der Kirche. ${ }^{596}$ Wer an dieses Lösungsmittel glaubt, empfängt die Sündenvergebung und wird für gerecht gehalten ${ }^{597}$ Dafür

${ }^{587}$ PK Ps 40, CR 13, 1082. „Ecce venio, offero, et praesto obedientiam, quae in lege et Prophetis de me scripta est."

${ }^{588}$ PK Ps 22, CR 13, 1049. „Congruit igitur Psalmi recitatio Davidi ut typo significanti venturum Christum, at Christo, ut praecipuo membro Ecclesiae, imo illi cuius passio vere vincit omnium Patrum miserias, et cuius victoria restituit vitam aeternam."

${ }^{589}$ PK Ps 40, CR 13, 1082. „Ego Messias adsum promissus decreto immutabili Dei et obediam in passione ..."

${ }^{590}$ Vgl. PK Ps 110, CR 13, 1166. „sustinebit horrendam iram Dei, et mortem pro genere humano ...“

${ }^{591}$ Vgl. PK Ps 16, CR 13, 1040. „videlicet de merito passionis.“

${ }^{592} \mathrm{Vgl}$. PK Ps 16, CR 13, 1041. „Imo mea passio non fit frustra, ... sed mea passio profutura est et salutem pariet iis, qui me agnoscent et amplectentur meum Evangelium, et merebitur ut sit aeterna et gloriosa Ecclesia Deum celebrans.“

${ }^{593}$ PK Ps 16, CR 13, 1042. „Non frustra patior, sed fructus passionis meae erit aeterna et gloriosa Ecclesia, in qua et ego et tota Ecclesia coram Deo laetabimur, et Deum celebrabimus.“

${ }^{594}$ Vgl. PK Ps 40, CR 13, 1082. „mihi Messiae mandatum dedisti, ut mea obedientia fiat placata ira tua, et tollantur peccatum et mors."

${ }^{595}$ Vgl. PK Ps 16, CR 13, 1042. „verae non interiturae vitae, et uberrimam laeticiam, quam ex conspectu tuo capiemus, et aeternum gaudium."

${ }^{596}$ PK Ps 31z, CR 13, 1238. „Christi passio est Iu, tron.“

${ }^{597}$ Vgl. PK Ps 117/118, CR 13, 1184. „propter hoc lu, troncredentes accipiunt remissionem peccatorum, et reputantur iusti“ ${ }^{\text {“ }}$ 
erfährt der Sohn Gottes, der Messias, das Leiden und die Freiheit. ${ }^{598}$ Die Passion Christi bringt die Freiheit, lässt das Evangelium verkündigen, leitet die Kirche zum Sieg und gibt das ewige Leben, und damit sammelt er die Kirche. ${ }^{599}$ Melanchthon hält die Passion Christi für notwendig, ohne die es keine Erlösung der Kirche gibt.

Darüber hinaus weist Melanchthon auf den Nutzen für die Kirche durch die Passion Christi hin. Gott lehrt die Kirche durch die Passion des Messias, dass die Kirche Gott gehorchen soll und dass die Mitglieder der Kirche durch die Furcht oder die Schmerzen nicht entmutigt werden und erkennen sollen, dass Gott mit ihnen ist und die ewige Rettung gibt. ${ }^{600}$ So sieht Melanchthon im Leiden der Kirche die Passion des Messias und dazu den Nutzen für die Kirche durch die Passion des Messias. Deshalb soll die Kirche das Leiden erdulden und den Nutzen des Leidens sehen.

\subsubsection{Die unter das Kreuz geworfene Kirche}

Melanchthon vergleicht die Schwierigkeiten der Kirche seiner Zeit mit der Passion Christi. Der Messias leidet für die gnädige Sündenvergebung, dadurch werden das ewige Leben und die Seligkeit der Kirche verheißen. Aber in diesem Leben ist die Kirche noch im Leiden, und das Leiden ist schwer. Dazu erwähnt Melanchthon die Äußerungen der Gottlosen, die das Leiden der Kirche erhöhen wollen. Die Gottlosen behaupten wegen dieser schwierigen Situation der Kirche, dass Gott sich nicht um die Kirche kümmere, ${ }^{601}$ und dass die Kirche mit dem Unheil und Kreuz für verworfen gehalten werde, weil die Kirche elend und unglücklich wäre. ${ }^{602}$ Sie glauben, dass die Kirche in Hinsicht auf die Größe des Leidens von Gott verworfen wäre. ${ }^{603}$

Für Melanchthon ist klar, dass das Evangelium wirkt, dass die Verheißung Gottes verwirklicht wird, weil Gott die Verheißung der Kirche gibt, der allmächtig und treu an seiner

\footnotetext{
${ }^{598}$ Vgl. PK Ps 117/118, CR 13, 1185. „Recitantur et in hoc versu passio et liberatio, ...“

${ }^{599}$ Vgl. PK Ps 22, CR 13, 1049. „Et hunc Psalmum recitat David, significans venturum Christum similia passurum esse, et postea liberatum ac triumphantem propagaturum esse Evangelium, daturum vitam aeternam, et collecturum Ecclesiam inter gentes etc.“

${ }^{600}$ PK Ps 117/118, CR 13, 1184. „Praecipit ut obediamus Deo, et non faciamus contra eum fracti metu, aut doloribus, sed certo statuamus ipsum nobis adesse, et daturum aeternam salutem,“

${ }^{601}$ PK Ps 4, CR 13, 1023. „qui offensi specie crucis, existimant Deo non esse curae Ecclesiam invocantem ipsum:“"

${ }^{602}$ PK Ps 4, CR 13, 1023. „quia videmus Ecclesiam aut calamitosiorem esse caeteris gentibus, aut certe nihilo tranquilliorem."

${ }^{603}$ Vgl. PK Ps 38, CR 13, 1078. „Cum enim et caetera membra Ecclesiae vident in tantis miseriis esse, sciant se quoque non abiectos esse a Deo propter calamitatum magnitudinem." Und vgl. PK Ps51, CR 13, 1118. „Ratio, cum in calamitatibus sumus, iudicat nos negligi et proiici a Deo.“
} 
Verheißung festhält. Allerdings leben die Mitglieder der Kirche noch in Schwierigkeiten, und die Kirche liegt in diesem Leben unter dem Kreuz. Die Wirkung und die Ehre des Evangeliums erscheinen noch nicht deutlich. ${ }^{604}$ Weil die Schwierigkeiten der Kirche in der Welt so schwer sind, rühmen sich die Gegner der Kirche in den Bedrängnissen der Kirche ${ }^{605}$ und freuen sich an dem Unglück der Frommen, ${ }^{606}$ wie der Räuber am Kreuz in seinem Unheil über Christus spottet. ${ }^{607}$ Die Kirche erfährt im ständigen Schmerz das Leiden. ${ }^{608}$

Bei der Erklärung dieser Situation geht Melanchthon von der Unfähigkeit der menschlichen Vernunft aus. Die menschliche Vernunft kann in solcher Wirklichkeit nicht erkennen und erklären, warum die Kirche unter das Kreuz und das Leiden geworfen wird. ${ }^{609}$ In den großen Bedrängnissen gibt es die Klagen und die Disputationen der Weisen, aber sie erkennen das Evangelium nicht, das die Ursache des Unheils und den wahren Trost zeigt, ${ }^{610}$ wie Saul und viele in solchen Leiden von Gott entmutigt versuchten, andere Hilfen zu finden. ${ }^{611}$ Das Elend ist im Guten und Bösen allgemein, aber bei den Gerechten gibt es ab und zu wegen der Gerechtigkeit das größere Elend. Ist es dann töricht, gerecht zu handeln, wie die Epikureer die Gerechten als töricht sehen und süß den Sieg sagen, wenn die Gerechten wegen des wahrhaften Lehrens die Gefahr bringen. ${ }^{612}$ Sie erkennen nicht die Ursache des Unheils mit ihrer Ver-

${ }^{604}$ Vgl. PK Ps 29, CR 13, 1061. „,non dubitemus Deum efficacem esse etiam promulgato Evangelio: quanquam horribiliter onerati sumus cruce in hac vita, ac nondum efficacia illa et gloria cernitur.“

${ }^{605}$ Vgl. PK Ps 6, CR 13, 1028. „Vos, inquit, hostes Ecclesiae Dei gloriabamini in mea calamitate, et insultabatis nobis, ac laeti vociferabamini nos a Deo reiectos esse, ..."

${ }^{606}$ PK Ps 23, CR 13, 1050. „qui in calamitatibus piorum clamitant ...“ und Vgl. PK Ps 56, CR 13, 1131. „qui laetantur calamitate exulis, ...“

${ }^{607}$ Vgl. PK Ps 31z, CR 13, 1238. „Et sicut in cruce pendens impius latro, ridet in sua calamitate, et ridet Christum.“

${ }^{608}$ Vgl. PK Ps 119, CR 13, 1199. „Si enim nulla esset eius vocis efficacia, frustra testaretur David, se dies noctesque lectione et cogitatione doctrinae consumere."

${ }^{609}$ PK Ps 37, CR 13, 1074. ,de quo humana ratio ignorans cur Ecclesia subiecta sit cruci et aerumnis, non recte indicat.“ Und vgl. PK Ps 49, CR 13, 1103. „maxima pars generis humani ignara cur Deus subiecerit Ecclesiam cruci, ...“

${ }^{610} \mathrm{PK}$ Ps 28, CR 13, 1059. „Tales sunt in magnis aerumnis querelae et disputationes omnium sapientum, qui ignorant Evangelium, quod monstrat causas calamitatum et veras consolationes.“

${ }^{611}$ Vgl. PK Ps 4, CR 13, 1023. ,sicut multi victi dolore et deficiunt a Deo, et quaerunt inconcessa praesidia, ut Saul, Achas et Graeci imperatores, qui attraxerunt Turcas." Und vgl. PK Ps 112, CR 13, 1172. „Quia enim multi aerumnis Ecclesiae franguntur, et deficiunt a Deo, ...“

${ }^{612}$ Vgl. PK Ps 37, CR 13, 1074. „Epicureo stulti videntur Ieremias, Baptista, Christus, Paulus, et similes, cum sibi accersunt pericula recte docendo. Diceret enim eos suavius victuros esse, si tacerent, et potius foverent eum statum, quo delectabantur principes, ut faciebat Solon non opponens se Pisistrato, aut Hortensius, Lucullus et alii, non adversantes Syllae, quanquam satis crudeliter dominanti.“ Und vgl. PK Ps 10, CR 13, 1033. „Interim Epicurei illi, inimici verae Ecclesiae, iactant se 
nunft, deswegen finden sie eine falsche Ursache und ein vergebliches Heilmittel. ${ }^{613}$ Melanchthon erkennt in diesen Versuchen Zweifel an der Vorsehung Gottes. ${ }^{614}$

Melanchthon bekennt, dass am Ende der Welt die Gefahr und die Klage größer sind als früher. ${ }^{615}$ Wahrscheinlich sieht er mit dieser Aussage die Gefahr seiner Kirche. Wenn er die Gefahr der Kirche in den Psalmen liest, sieht er darin die Gefahr seiner Kirche. Er betrachtet die Schwierigkeit der Kirche in seiner Zeit und die Klagen der Frommen. ${ }^{616}$ So betrachtet er die große Gefahr aller frommen Führer. ${ }^{617}$ Insbesondere geht es um den Krieg. Viele unterstützen die Brutalität des Papstes. ${ }^{618}$ Das Reich, die Türken, das Papsttum und die großen Völker wollen die Kirche mit Hass vernichten. ${ }^{619}$ Einige wollen einen Bund schließen, um diese Gefahr zu überwinden, ${ }^{620}$ wie in seiner Zeit die Führer seiner Region unter der schwierigen Gefahr durch das Bekenntnis des Evangeliums sind. ${ }^{621}$ Ihre Bedrängnisse, Kämpfe und Bitten sind gleich in Christus und den anderen Mitglieder der Kirche Gottes, obwohl sie in Christus übertroffen werden. ${ }^{622}$

\subsubsection{Die Ursache des Leidens der Kirche}

Nach der Auffassung Melanchthons über die Sünde ist es verständlich, dass die Menschen die mühseligen Geschöpfe sind, die in der Sünde leben und dem Tod Unterworfenen

paci publicae consulere, et rident stoliditatem recte docentium, quod pericula sibi accersunt. Tales multi sunt in aulis regum et pontificum, ut in Anglia Wintoniensis, in Gallia Constabilis, et alibi alii, quorum aliquos si intueamur planior erit hic Psalmus."

${ }^{613}$ PK Ps 39, CR 13, 1080. „Hanc sententiam opponit humanis iudiciis, quae fontes calamitatum humanarum ignorant, et quaerunt falsas causas et inania remedia.“

${ }^{614}$ Vgl. PK Ps 49, CR 13, 1103. „Si nulla est providentia, stulte sibi accersit Ecclesia labores, et pericula."

${ }^{615}$ PK Ps 110, CR 13, 1165. „quia moles periculorum et calamitatum maior erit, quam fuit antea.“

${ }^{616}$ PK Ps 13, CR 13, 1036. „Si nos ipsos intuebimur, et nostra pericula considerabimus, agnoscemus similes esse gemitus omnium piorum et similia vota.“

${ }^{617}$ PK Ps 20, CR 13, 1047. „Erit autem hic Psalmus nobis et magis perspicuus et magis dulcis, si saepe recitabimus, precantes pro politia, et cogitantes de magnis periculis omnium piorum gubernatorum.“

${ }^{618}$ PK Ps 41, CR 13, 1084. „ut nunc plurimi adiuvant pontificum saevitiam.“

${ }^{619}$ Vgl. PK Ps 110, CR 13, 1165. „etiamsi pariter diaboli, et imperia, Turcicum, Pontificium, Regia, magnarum gentium odia, haereticorum et sectarum furores, delere Ecclesiam conantur,“

${ }^{620}$ Vgl. PK Ps 46, CR 13, 1094. ,ita cogitat ratio iustum esse, quam plurimos et firmissimos socios ad pericula propulsanda devinctos habere,“

${ }^{621} \mathrm{Vgl}$. PK Ps 46, CR 13, 1094. „ut hoc tempore principes harum regionum propter Evangelii confessionem sunt in periculo."

${ }^{622}$ Vgl. PK Ps 3, CR 13, 1027. „Similes sunt, in Christo et caeteris membris Ecclesiae Dei afflictiones, agones et precationes, etsi in Christo antecellunt.“ 
sind. ${ }^{623}$ Melanchthon sagt, dass die Ursache des Unheils der Menschen die Sünde in der menschlichen Natur ist. ${ }^{624}$ Aus diesem Grund werden die Frommen und die Gottlosen, also alle, dem Tod unterworfen und durch die furchtbare Konfusion belästigt. ${ }^{625}$

Allerdings findet Melanchthon einen Unterschied zwischen den Gottlosen und der Kirche bei dem Leiden. Für Gottlosen ist ihr Leiden einzig eine Strafe, aber für die Kirche liegt der Fall anders. Gott wünscht, durch die Sendung seines Sohnes den Sieg des Sohnes am Kreuz und in der Auferstehung zu zeigen. ${ }^{626}$ So offenbart Gott im Evangelium seinen versteckten Willen über die gnädigen Sündenvergebung und den wahren Trost im Kreuz. ${ }^{627}$ Die Kirche nimmt das Evangelium an, und Gott gibt der Kirche die ewige und gegenwärtige Güte mit der Verheißung. Allerdings gibt es bei der gegenwärtigen Güte die Ausnahmen des Kreuzes und der Bestrafung. ${ }^{628}$ So spricht Christus, dass, wer ihm folgen wolle, das Kreuz auf sich nehmen müsse, und dass, wer in Christus Jesus fromm leben wolle, verfolgt werde. ${ }^{629}$ Deshalb ist das Leiden der Kirche anders als das der Gottlosen.

Nach Melanchthon findet sich die Ursache des Leidens der Kirche in diesem Leben trotz der Sündenvergebung vor allem im göttlichen Plan. ${ }^{630}$ Gott wünscht den Gläubigen, die Sünde und das Verderbnis des ganzen Menschengeschlechtes zu erkennen. Deshalb wirft Gott die Gläubigen in das Leiden wie Abel und Jeremiah. ${ }^{631}$ Die Frommen erinnern sich in der schwierigen Gefahr an den Zorn Gottes und das furchtbare Gericht. ${ }^{632}$ Sie erkennen ihre Unwürdig-

${ }^{623}$ PK Ps 8, CR 13, 1031. „cum homo sit creatura aerumnosa, peccato et morti obnoxia,“

${ }^{624}$ Vgl. PK Ps 32, CR 13, 1066. „Principalis causa calamitatum humanarum est, non, ut philosophi putant, materia, sed peccatum in natura hominum.,

${ }^{625}$ Vgl. PK Ps 32, CR 13, 1066. „Utrique pii et impii morte onerati sunt, et horrendis calamitatibus excruciantur."

${ }^{626} \mathrm{PK}$ Ps 132, CR 13, 1219. „mittam Filium meum redemtorem, hunc volo ibi nasci et ostendere ibi suas victorias in cruce et resurrectione."

${ }^{627}$ PK Ps 32, CR 13, 1065. „Est enim vox Evangelii, in quo patefit arcana voluntas de gratuita remissione peccatorum, et de vera consolatione in cruce.“

${ }^{628}$ PK Ps 112, CR 13, 1173. „sed addita est promissionibus bonorum praesentium exceptio crucis et castigationis."

${ }^{629}$ PK Ps 112, CR 13, 1172. „omnes qui pie vivere volent in Christo Iesu, persecutionem patientur.“

${ }^{630}$ PK Ps 49, CR 13, 1104. „Interea in hac mortali vita cur sustinendae sint aerumnae, certa causa est consilii divini,“”

${ }^{631}$ PK Ps 49, CR 13, 1104. „Sed cur in hac vita calamitosi sint Abel et Ieremias, certe causae sunt consilii divini. Primum in his quoque haeret peccatum. Vult autem Deus praesertim in Ecclesia, agnosci peccatum et horrendam totius generis humani corruptionem. Ideo tota Ecclesia subiecta est aerumnis."

${ }^{632}$ PK Ps 115, CR 13, 1181. „qua phrasi dolores maximi significantur, sensus irae Dei et horrendi iudicii,“" 
keit und werfen das Vertrauen auf eine eigene Weisheit und Leidenschaft weg. Aber sie sind dadurch nicht entmutigt, sondern sie fliehen zu Gott, der der Kirche die Verheißung der Sündenvergebung gegeben hat. Das Leiden der Kirche verweist darauf, dass die Mitglieder der Kirche in diesem Leben kein Vertrauen auf sich selbst haben, sondern allein auf Gott vertrauen sollen. So sieht Melanchthon, dass das Leiden die Mitglieder der Kirche zu Gott führt.

Melanchthon sagt deshalb, dass allein das Evangelium die Ursache des Leidens der Frommen und den wahren Trost zeigt ${ }^{633}$ und dass in der Kirche die göttliche Stimme die Ursache des Leidens lehrt, um die Menschen wieder zur Buße zu rufen oder zu stärken oder ihnen die Zeugnisse der Lehre zu geben. ${ }^{634}$ So sieht Melanchthon im Leiden der Mitglieder der Kirche einen guten Plan Gottes für die Kirche. Das Leiden der Kirche ist nicht nur eine Strafe für die Sünden der Kirche, sondern ist auch von Nutzen für die Kirche, indem das Leiden zur Buße, der Anrufung Gottes und zur Stärkung des Glaubens führt.

Melanchthon stellt fest, dass die menschliche Vernunft die Ursache des Leidens nicht erklären kann. Allein Gott spricht von der Ursache des Leidens und dem Gericht nach diesem Leben. ${ }^{635}$ Auch für die Gottlosen gilt das Gericht Gottes nach diesem Leben. Das ist die Antwort Melanchthons auf die Auffassung der Gottlosen gegenüber dem Leiden der Kirche. Die Gottlosen irren, denn Gott hat einen bestimmten Plan für die Kirche im Leiden. Und alles wird am letzten Tag enthüllt. Nach Melanchthon soll man das ewige Leben immer mit dem künftigen Gericht verbinden. ${ }^{636}$ Gott nimmt die Frommen an und wirft die Gottlosen in den ewigen Tod. Gewiss ist, dass Gott das letzte Gericht vorbereitet, deshalb muss die Kirche keinen Zweifel daran haben, wenn auch die Kirche in sehr großen Schwierigkeiten ist. ${ }^{637}$

Daher ist für Melanchthon zu Bedeutung, dass das Leiden, das die Mitglieder der Kirche in diesem Leben erfahren, keine rechtwürdige Strafe für ihre Sünde ist, sondern das Leiden spielt eine Rolle für das Bekenntnis und die Erkenntnis der verheißenen Barmherzigkeit. ${ }^{638}$ Das Leiden könnte als die Strafe Gottes gegen die Sünde der Kirche angesehen werden. Allerdings kann das kurze Leiden in diesem Leben keine rechtwürdige Strafe bei einem so gro-

\footnotetext{
${ }^{633}$ PK Ps 28, CR 13, 1059. „quod monstrat causas calamitatum et veras consolationes.“

${ }^{634} \mathrm{PK}$ Ps $51, \mathrm{CR} 13,1118$. „Sed vox divina in Ecclesia docet, afflictionumalias esse causas, videlicet ut revocemur adpoenitentiam, aut confirmemur, aut sint testimoniadoctrinae."

${ }^{635}$ PK Ps 49, CR 13, 1105. „et dicit post hanc vitam restare aliud iudicium.“

${ }^{636}$ PK Ps 49, CR 13, 1105. „Continet igitur hic Psalmus articulum de Vita aeterna et futuro Iudicio.“

${ }^{637}$ Vgl. PK Ps 39, CR 13, 1079. „Ne deficias a Deo, ne dubites de providentia etiamsi florent impii, et Ecclesia magnis aerumnis premitur.“

${ }^{638}$ PK Ps 51, CR 13, 1114. „Sed ad hos dolores, et ad hanc confessionem necesse est accedere agnitionem promissae misericordiae."
} 
Ben Verbrechen sein. ${ }^{639}$ Wenn jemand durch das Leiden seine Strafe auf sich nehmen und dadurch die Sündenvergebung gewinnen will, dann irrt sicher. Denn solche rechtwürdige Strafe lädt allein Christus auf sich. Allein in diesem Leben wird jeder Fromme durch das Leiden geübt, wenn auch die Gottlosen prosperieren, die keinen göttlichen Plan erkennen. ${ }^{640}$

Melanchthon betrachtet das Leiden der Kirche nicht als eine Strafe wegen ihrer Sünde, sondern als eine Leistung Gottes, die Kirche zu Gott zu leiten. Insofern spielt das Leiden für die Kirche eine positive Rolle, um die Kirche auf ihrem Weg zu führen.

\subsubsection{Das Ziel des Leidens der Kirche}

Melanchthon weist darauf hin, dass das Leiden der Gerechten durch ihr rechtliches Verbrechen nicht verursacht wird. Er verbindet das Gesetz mit der Ursache des Leidens in der Lehre des Evangeliums über das künftige Leben. ${ }^{641}$ Die Gerechten werden in den Schmerz als die Elenden und die Unterdrückten geworfen, aber sie sind der Tempel Gottes, die Schmerzen der Bekehrten sind die Opfer. ${ }^{642}$ Nach Melanchthon dürfen die Gerechten diesen Sachverhalt nicht vergessen.

Aber die Wirklichkeit des Leidens der Kirche ist auch für Melanchthon noch schwer. Deutlich ist das Leiden für die Gerechten ein großer Schmerz, und im großen Schmerz und Leiden werden ihre Geister durch die Verschiebung der Hilfe Gottes entmutigt. ${ }^{643}$ Allerdings bemerkt Melanchthon, dass das Leiden besteht, nicht um sie zu töten, sondern um sie zur Buße zu bekehren ${ }^{644}$ und um sie noch heftiger bitten zu lassen. ${ }^{645}$ So erinnert die Kirche sich im Leiden an Gott und wendet sich zu Gott hin. Gott wünscht, dass die Kirche unter dem Kreuz ist, dass die Sünde gezeigt wird, dass die Anrufung Gottes erscheint, und dass die Gegenwart

\footnotetext{
${ }^{639} \mathrm{Vgl}$. PK Ps 52, CR 13, 1108. „Nam brevis calamitas in hac vita non est aequalis poena pro tantis sceleribus, sed est commonefactio de iudicio Dei, qua Deus ostendit se non esse oblitum delicti, ut alii metuant futurum iudicium, nec se talibus sceleribus contaminent, et ut convertantur."

${ }^{640}$ Vgl. PK Ps 49, CR 13, 1103. „Deinde disputat de iusticia Dei, quia causam consilii divini ignorat, et sic ratiocinatur."

${ }^{641}$ Vgl. PK Ps 49, CR 13, 1105. „et norunt legem et suarum aerumnarum causas, cognita doctrina Evangelii de futura vita recte conciliare.“

${ }^{642}$ Vgl. PK Ps 51z, CR 13, 1232. „Vox Evangelii affirmat hos esse templa Dei, et afflictiones eorum, qui ad Deum conversi sunt esse sacrificia,“

${ }^{643}$ PK Ps 13, CR 13, 1036. „Sicut omnes experimur in magno dolore et veris aerumnis, languefieri animos mora, cum non statim opitulatur Deus.“

${ }^{644}$ PK Ps 119, CR 13, 1194. ,et hoc testimonium ad causam finalem referatur, quod affligimur non ut pereamus, sed ut retrahamur ad poenitentiam,“

${ }^{645}$ PK Ps 43, CR 13, 1088. „Exponitur dolor, ut petitio sit ardentior.“
} 
Gottes in der Kirche betrachtet wird, um die Kirche zu bewahren. ${ }^{646}$ Und es ist für Melanchthon klar, dass das Leiden und der Trost Davids in den Psalmen für die Kirche geschrieben worden ist, um vom Leiden nicht überwältigt zu werden. ${ }^{647}$ So gibt Gott das Leiden der Kirche zu ihrem Nutzen und freut sich darüber, dass sich die Kirche durch das Leiden nicht auf sich selbst vertraut, sondern allein auf Gott. Deshalb ist das Leiden der Kirche ein Opfer, nämlich ein Gottesdienst.

Melanchthon versteht aber das Leiden nicht als Verdienst zur Erlösung. Wenn auch das Leiden der Kirche zum Opfer um Christus willen durch den Glauben wird, spielt das Leiden keine Rolle für die Sündenvergebung. ${ }^{648}$ Allein die Passion Christi wirkt die Sündenvergebung. Deshalb unterscheidet Melanchthon die Passion Christi deutlich vom Leiden der Kirche. Die Passion Christi ist das Lösungsmittel für die Erlösung der Kirche, aber das Leiden der Kirche zeigt die Hilfe, die Prüfung und die Zeugnisse. ${ }^{649}$ Das Leiden der Kirche bezieht sich nämlich in diesem Leben nicht auf die Erlösung, sondern es hat einen Nutzen für die bereits erlösten Mitglieder der Kirche.

Deshalb fordert Melanchthon die Geduld der Kirche im Leiden ${ }^{650}$ und die Erwartung im Bekenntnis auf die ewige Freiheit. ${ }^{651}$ Die Kirche soll durch das Kreuz nicht entmutigt werden, sondern die wahre Kirche gehorcht dem Kreuz in diesem Leben. ${ }^{652}$ Diesen Gehorsam der Kirche wünscht sich Gott. So aber wird uns ein deutlicher Unterschied zwischen den Frommen und den Gottlosen vor Augen geführt. ${ }^{653} \mathrm{Im}$ Gericht nach diesem Leben erkennt Melanchthon den Grund für die Geduld im Leiden.

\footnotetext{
${ }^{646}$ PK Ps 34z, CR 13, 1241. „Utrunque enim vult Deus, et esse Ecclesiam sub cruce, ut peccatum agnoscatur, et ut fiat invocatio, et Ecclesiam servari, ac praesentiam suam in Ecclesia conspici.“

${ }^{647}$ PK Ps 42, CR 13, 1087. „Hactenus utcunque ostendimus quales dolores ipse David sustineat, et quomodo se consoletur, sed haec non propter ipsum, sed propter nos scripta sunt.“

${ }^{648}$ PK Ps 16, CR 13, 1040. „Nostrae afflictiones etsi fiunt sacrificia propter Christum fide, id est, cultus grati Deo, tamen non merentur aliis remissionem peccatorum.“

${ }^{649}$ PK Ps 31z, CR 13, 1238. „Item de differentiis, quod aliae afflictiones sint timwri, ai, aliae dokimasi, ai, aliae martu, ria. Christi passio est lu, tron. “

${ }^{650}$ PK Ps 110, CR 13, 1151. „tolerantia in afflictionibus“

${ }^{651}$ PK Ps 115, CR 13, 1181. „toleremus crucem in confessione, et alias aerumnas Ecclesiae, et aeternam liberationem expectemus.“

${ }^{652}$ PK Ps 17, CR 13, 1043. „Econtra vera Ecclesia est subiecta cruci in hac vita.“

${ }^{653}$ PK Ps 52, CR 13, 1120. „quia certo consilio vult Deus Ecclesiam cruci subiectam esse,sed tamen postea cum fiet aeternum discrimen piorum et impiorum, universaliter omnes pii fruentur aeternis bonis, et impii erunt in poenis aeternis."
} 
Aber Melanchthon richtet seinen Blick auch auf dieses Leben. Er sagt, dass die VerheiBung der Guten in diesem Leben nicht vergeblich ist. ${ }^{654}$ Gott mildert die Strafe des Kreuzes mit der außergewöhnlichen Barmherzigkeit für die Anrufenden ${ }^{655}$ und bewahrt die Kirche. Somit erduldet die Kirche das Kreuz in diesem Leben, und der ewige Trost für die Kirche geht auch nicht verloren. Diese gegenwärtige Verheißung wird von Gott der Kirche gegeben und ist eine feste Grundlage für die Forderung der Bewahrung der Kirche im Leiden. So ist zu sehen, dass Melanchthon die Wirklichkeit seiner Zeit in dieser Auslegung der Psalmen berücksichtigt.

\subsubsection{Der Glaube der leidenden Kirche}

Für Melanchthon ist der Glaube das instrumentale Mittel, das die Verheißung Gottes annimmt. Man braucht den Glauben für die Erlösung und auch für das Leben der Erlösten. Nach Melanchthon soll die Kirche, die bereits um des Sohnes Gottes willen durch den Glauben erlöst wird, in diesem Leben noch den Glauben üben. Damit ist nicht gemeint, dass der Glaube unzureichend für die Erlösung ist oder dass bei dem Glauben ein Grad erreicht werden müsse, der für die endliche Erlösung in diesem Leben entwickelt werden soll. Melanchthon sieht im Glauben niemals ein menschliches Verdienst für die Erlösung. Der Glaube sieht allein die Verheißung Gottes und lehnt sich an die Verheißung an. Deshalb braucht man den Glauben von Anfang an in diesem Leben bis zum ewigen Leben. Für Melanchthon ist der Glaube eins in diesem Leben und auch im ewigen Leben. Immer lebt die Kirche bei Gott im Glauben.

Insbesondere spielt der Glaube eine Rolle für die Annahme der Verheißung Gottes. Im PK sieht Melanchthon die gegenwärtigen Verheißungen Gottes für die Kirche in diesem Leben. Sie helfen der Kirche im Leiden. Melanchthon fordert auf, dass die Kirche das Leiden in diesem Leben im Glauben an die Verheißung Gottes erdulden soll.

Außerdem erachtet Melanchthon das Bekenntnis des Glaubens und die Hoffnung der Anrufung als nötig, um das Leiden zu erdulden. Gott wünscht, dass die Mitglieder der Kirche wie die Autoren der Psalmen in den Gefahren die Hilfe Gottes erbitten, erwarten und Gott mit dem Glauben und der Hoffnung dienen, ${ }^{656}$ dass der Glaube und die Hoffnung in der Gefahr

\footnotetext{
${ }^{654}$ Vgl. PK Ps 112, CR 13, 1173. „tamen promissiones bonorum corporalium non sunt irritae, semper enim universo coetui praestantur, ...“

${ }^{655}$ PK Ps 112, CR 13, 1175. „Et tamen interea crucem et poenas immensa misericordia invocantibus mitigat, ..."

${ }^{656}$ PK: Ps 59, CR 13, 1145. „ut multi confirmati hoc exemplo in similibus periculis petant et expectent auxilium, et discant Deum velle hac fide et spe coli.“
} 
des Bekenntnisses sich nicht ändern. ${ }^{657}$ Hiermit verbindet sich bei Melanchthon der Glaube mit der Hoffnung. Wer glaubt, hofft auf die Verwirklichung der Verheißung. Dazu weist Melanchthon darauf hin, dass die Frommen, wenn sie das Bekenntnis des Glaubens und die Anrufung nicht erkennen, sie das Leiden nicht erdulden können. ${ }^{658}$ Deshalb soll die Kirche in der Gefahr und der Bedrängnis das wahre Vertrauen haben. ${ }^{659}$ Melanchthon betont die Rolle des Glaubens im Leiden. Denn der Kampf ist heftig, der Glaube und die Hoffnung kämpfen gegen die Verzweiflung. ${ }^{660}$

Der Glaube nährt sich von der Verheißung, mit der die Kirche in den ständigen Gefahren durch den Trost standhalten kann. Deshalb fordert Melanchthon auf, dass in der täglichen Gefahr die Kirche den Glauben, die Anrufung und die Hoffnung üben, die Hilfe und die Bewahrung von dem Sohn Gottes erbitten und erwarten soll. ${ }^{661}$ Die leidende Kirche soll den wahren Glauben an die Bewahrung und die Betreuung durch Gott haben. Dieser Glaube erstrahlt vor der Bitte um die Hilfe. ${ }^{662}$ Melanchthon ist von der Verwirklichung der Verheißung Gottes überzeugt. Wenn der Glaube in der Bedrängnis die Verheißung über die Bewahrung der Kirche sieht, erhält die Kirche die Milderung des Schmerzes. ${ }^{663}$ Die Kirche soll deshalb daran glauben, in der wahren Bedrängnis um des Vermittlers willen angenommen zu werden und gerecht zu sein. ${ }^{664}$ Die Kirche soll sich an den Glauben erinnern, um in der großen Schwierigkeit die Verheißungen Gottes festzustellen und zu erkennen, dass Gott der Kirche

\footnotetext{
${ }^{657}$ Vgl. PK Ps 60, CR 13, 1149. ,et hac fide et spe confirmata, vult nos in ferendis laboribus docendi, et omnibus periculis confessionis constantiores esse."

${ }^{658}$ Vgl. PK Ps 44, CR 13, 1089. „Haec omnia scire Ecclesiam necesse est, quid sit, qualis coetus sit, ad quod munus vocata sit, quae sit habitura pericula, quae auxilia, quos exitus. Nam pii non possent perferre aerumnas, si haec nescirent. Ideo historica commemoratio proponitur, quae quidem et causas petitionis continet.“

${ }^{659}$ Vgl. PK Ps 57, CR 13, 1134. „dicat quisque in suis periculis et aerumnis vera fiducia,“

${ }^{660}$ Vgl. PK Ps 42, CR 13, 1085. „Precatio est, in qua describitur agon et acerrimum certamen fidei seu spei, luctantis cum desperatione, ..."

${ }^{661}$ PK Ps 110, CR 13, 1165. „Discamus autem in his quotidianis periculis exercere fidem, invocationem et spem, petamus et expectemus auxilium et defensionem a Filio Dei, ...“

${ }^{662}$ PK Ps 55, CR 13, 1131. ,et haec fides praeluceat petitioni auxilii, ...“

${ }^{663}$ PK Ps 128, CR 13, 1211. „Has promissiones cum intuetur fides impetratur aerumnarum mitigatio, et leniuntur dolores.“

${ }^{664}$ PK Ps 31z, CR 13, 1234. „ut in veris doloribus credamus vere nos recipi propter Mediatorem, et nos esse iustos,“
} 
hilft, das Leiden mildert und sie befreit. ${ }^{665}$ Gott gibt den Gläubigen die Sündenvergebung und heiligt sie mit seinem Heiligen Geist. Er erhört, regiert und bewahrt die Gläubigen in verschiedenen Gefahren. ${ }^{666}$ Melanchthon hat dabei keine menschliche Handlung im Sinn, z.B. ein Bündnis in der Gefahr, sondern die göttliche Verteidigung für die Kirche. ${ }^{667}$ Gott wünscht der Kirche, dass im Herzen das feste Vertrauen entzündet werde, um die Milderung des Leidens zu erwarten, um sich an die bestimmten Zeugnisse der Kirche zu erinnern und um den Glauben zu stärken und fest zu machen. ${ }^{668}$ Damit macht der Glaube die Mühe und das Leiden der Kirche zum Gottesdienst. ${ }^{669}$ So ändert der Glaube etwas Schlechtes zu einem Guten. So findet sich der Wille Gottes im Leiden.

\subsubsection{Die Hoffnung und die Anrufung}

Melanchthon lehrt im PK, dass es der Wille Gottes ist, dass die Kirche in diesem Leben unter dem Leiden ist. Gott wünscht, dass die Kirche dem Kreuz gehorcht. Die Kirche soll mit Geduld in diesem Elend gehorsam sein, die Milderung des Leidens erbitten und die Freiheit erwarten. ${ }^{670}$ Obwohl die Verheißung Gottes über die Erlösung der Kirche gewiss ist, soll die Kirche dennoch die Verwirklichung der Verheißung Gottes erbitten und erwarten und Gott anrufen. In diesem Leben lebt die Kirche so mit der Hoffnung und der Anrufung als eine Übung des ewigen Lebens.

Zugleich erkennt Melanchthon, dass das Leiden, das die Kirche in diesem Leben erfährt, sehr groß und schwierig ist. Ein Psalm sagt, dass ich mich fast durch das Leiden erschöpfe,

\footnotetext{
${ }^{665}$ Vgl. PK Ps 27, CR 13, 1059. „Tenenda est promissio, et sciendum quod vere sit mandatum Dei, ut etiamsi sumus in aerumnis ingentibus, tamen iuxta verbum statuamus nobis adesse Deum opitulatorem, et mitigaturum esse calamitates, nosque tandem liberaturum esse."

${ }^{666}$ PK Ps 117/118, CR 13, 1186. „Secundo Messias est fundamentum non modo propter doctrinam, sed etiam propter redemtionem et efficaciam. Quia propter eum caetera eius membra electa sunt, propter ipsius deprecationem et passionem, et ipse est efficax in eis, remittit peccata credentibus sanctificat eos Spiritu suo sancto, exaudit eos, regit et protegit eos in variis periculis, depellit ab eis diabolos, dat eis vitam aeternam.“

${ }^{667}$ Vgl. PK Ps 46, CR 13, 1094. „Hae trepidationes oriuntur a diffidentia animorum, qui, quia non cernunt Dei praesentiam, quaerunt humana praesidia, seu concessa seu inconcessa. Etsi autem homines non ignari ${ }^{667}$ doctrinae fidei, iudicant hanc diligentiam magnam sapientiam esse:“

${ }^{668}$ PK. Prol CR 13, 1018. „meminerit insignia testimonia dogmatum Ecclesiae, ad alendam et confirmandam fidem“"

${ }^{669}$ PK Ps 9, CR 13, 1033. „His promissionibus et exemplis accendantur fides et invocatio. Hi sunt, ut saepe dicitur, praecipui cultus Dei.“

${ }^{670}$ PK Ps 119, CR 13, 1194. „Cumque sciamus quare velit Deus Ecclesiam subiectam esse cruci, obediamus ei patienter in his miseriis, et petamus mitigationem, et expectemus liberationem.“
} 
und dass ich die Barmherzigkeit, die Wiederherstellung und die Hilfe suche. ${ }^{671}$ Die Propheten gehorchen der Strafe Gottes für die Kirche und bitten Gott um die Milderung der Strafe, aber der Schmerz des Leidens ist groß. ${ }^{672}$ Deswegen sagt Melanchthon, dass sie um den Trost bitten, um nicht unter dem Gewicht des Schmerzes erdrückt und entmutigt oder getötet zu werden. ${ }^{673}$ So führt das Leiden der Kirche zum schweren Schmerz und führt zugleich dazu, Gott um die Milderung des Leidens und die Freiheit zu bitten.

Melanchthon merkt an, dass die Gegner der Kirche sich darüber freuen, dass die Kirche solches Leiden hat, und ausrufen, dass die Kirche von Gott abgelehnt würde. ${ }^{674}$ Aber Melanchthon weist diese Meinung der Gegner der Kirche zurück und erklärt im PK, dass die Psalmen den Zerfall der Gegner der Kirche zeigen, ${ }^{675}$ und dass die Kirche durch die Beispiele der gnädigen Handlungen Gottes für die Kirche aufgerichtet und nicht entmutigt wird. Die Kirche gehorcht Gott und erbittet und erwartet die Freiheit nach dem Plan Gottes. ${ }^{676}$

Darin - im Gehorsam der Kirche und der Erwartung der Freiheit - findet Melanchthon den Grund dafür, dass die Kirche durch das Leiden nicht entmutigt wird. Der Zerfall der Gegner ist ein Beispiel, um Gott um die Freiheit der Kirche zu bitten, und um sie zu erwarten. Der Messias bittet auch im schwersten Leiden darum. ${ }^{677}$ So lassen die Beispiele der gnädigen Handlungen Gottes die Kirche um die Freiheit bitten. Die Bewahrung der Juden in Babylon ist ein bedeutendstes Beispiel dafür. ${ }^{678}$ Diese Beispiele gelten auch für die ganze Kirche, deswegen kann die Kirche um die Milderung des Leidens bitten.

Aus diesem Grund fordert Melanchthon dazu auf, dass die Kirche im Leiden Gott anrufen soll. Für Melanchthon ist die Anrufung Gottes für die Kirche in ihrem Leiden selbstverständ-

\footnotetext{
${ }^{671} \mathrm{PK}$ Ps 42, CR 13, 1087. „sic ego pene consumtus dolore, quaero misericordiam, reconciliationem et auxilium.“

${ }^{672}$ PK Ps 6, CR 13, 1026. „haec repetitio, utcunque magnitudinem doloris significat.“

${ }^{673}$ PK Ps 51, CR 13, 1114. „Consolatio petitur, ne magnitudine dolorum oppressi extinguamur aut deficiamus a Deo,“

${ }^{674}$ PK Ps 6, CR 13, 1027. „Vos, inquit, hostes Ecclesiae Dei gloriabamini in mea calamitate, et insultabatis nobis, ac laeti vociferabamini nos a Deo reiectos esse,“

${ }^{675}$ Z.B. PK Ps 9, CR 13, 1033. "Generalis gratiarum actio est pro deletis hostibus, et adplicatio exempli ad reliquam Ecclesiam“"

${ }^{676}$ PK Ps 52, CR 13, 1022. „ut hoc exemplo confirmati non frangantur in aerumnis, sed obediant Deo, et petant ac expectent liberationem iuxta Dei consilium.“"

${ }^{677}$ Vgl. PK Ps 40, CR 13, 1081. „Ait Messias se tristissimis doloribus oppressum fuisse, sed tamen expectasse a Deo auxilium, atque ita praedicat se liberatum esse, non casu, non humanis consiliis et viribus, sed mirandis Dei operibus.“

${ }^{678}$ Vgl. PK Ps 60, CR 13, 1148. „saepe etiam Ecclesia poenas propter insignia peccata sustinet, ut cum abducta est in exilium Babylonicum.“
} 
lich. Zuerst bittet der Messias im größten Schmerz um die Hilfe Gottes. Seine Bitte ist zu vergleichen mit der Bitte der Väter um die Freiheit im Tod. ${ }^{679}$ Danach bitten die Vorfahren, wie Josua, in der großen Bedrohung um die Freiheit. ${ }^{680}$ Melanchthon fordert auch der Kirche auf, wie die Autoren der Psalmen, um den Trost und die Freiheit zu bitten. ${ }^{681}$ Die Kirche soll in der Gefahr den Schutz und die Bewahrung von Gott erbitten. ${ }^{682}$ Und sie soll die Hilfe in der Bitte und dem Leiden erwarten. Melanchthon weist darauf hin, dass das Bekenntnis der Psalmen für die Kirche weiterhin besteht. ${ }^{683}$ Die Kirche erhofft im Leiden die Milderung des Leidens und die Freiheit. ${ }^{684}$ Dann erhört Gott die Bitte der Kirche und mildert das Leiden. ${ }^{685}$ Deshalb soll die Kirche Gott in der Gefahr anrufen, aber sie darf keine verbotene Hilfe finden. ${ }^{686}$ Denn Gott hat die Kirche in der Bedrohung bewahrt, wie das Beispiel des Exils in Babylon zeigt. In solcher Bedrohung klagt die Kirche, aber zugleich erbittet und lobt sie die Freiheit. ${ }^{687}$ Durch die traurigen Beispiele soll die Kirche den Zorn Gottes erkennen, sich zur Buße wenden, die Bedrängnisse der Kirche erdulden und die Milderung erbitten. ${ }^{688}$ Dazu muss man die Freiheit erwarten und erbitten. ${ }^{689}$ Auch soll die Kirche um den Trost bitten. ${ }^{690}$ Die Bitte impliziert die Milderung der öffentlichen und persönlichen Strafen. ${ }^{691}$

\footnotetext{
${ }^{679} \mathrm{Vgl}$. PK Ps 22, CR 13, 1049. „Precatio est petentis liberationem in maximis aerumnis, et in morte, et habet tristia $\mathrm{pa}, \mathrm{qh}$, quibus confert suas afflictiones cum patrum aerumnis, et queritur suas esse maiores."

${ }^{680}$ PK Ps 6, CR 13, 1026. „Sicut precatur Iosue in summo periculo: Quid facies magno nomini tuo.“ ${ }^{681}$ Vgl. PK Ps 16, CR 13, 1047. „Ergo cum sis Deus meus, et velis tibi servare haereditatem tuam, et mea membra, non sinas me succumbere in his tristibus aerumnis, sed consolare et libera me."

${ }^{682}$ Vgl. PK Ps 23, CR 13, 1052. „Turci nunc denunciant bellum et vastationem toti Europae et universae Christi Ecclesiae, adversus haec tanta pericula tegi et defendi nos a Deo petamus, ne ipsius noticia deleatur."

${ }^{683}$ PK Ps 35, CR 13, 1071. „Nam liberationes Davidis hic propositae, sunt exempla promissionis, ut saepe dictum est, quae scripta sunt, ut nos quoque petamus et expectemus auxilium in nostris afflictionibus. Non propter unum Davidem, nec de uno Davide haec scripta sunt, sed de omnibus membris Ecclesiae Dei.“

${ }^{684}$ PK Ps 42, CR 13, 1087. ,sed sustentabo me promissione ipsius, et sperabo mitigationem calamitatis et liberationem."

${ }^{685}$ PK Ps 41, CR 13, 1085. „ita certo nos quoque precantes exaudit Deus, et mitigat nobis calamitates.“ ${ }^{686}$ Vgl. PK Ps 46, CR 13, 1098. „cum estis in periculis, non trepidate, non quaerite inconcessa praesidia, quasi nihil sit Deus, aut non curet vos.“

${ }^{687}$ PK Ps 60, CR 13, 1146. „Has aerumnas hic deplorat, et simul petit ac celebrat liberationes.“

${ }^{688}$ PK Ps 110, CR 13, 1157. „Haec tristia exempla intuentes cogitemus iram Dei, et flectamur ad poenitentiam, et modeste toleremus miserias nostras, et petamus mitigationem, “

${ }^{689}$ PK Ps 115, CR 13, 1181. ,et significat ut nos quoque fide propter Mediatorem petamus et expectemus liberationem, et deinde agamus gratias, toleremus crucem in confessione, et alias aerumnas Ecclesiae, et aeternam liberationem expectemus.“
} 
Melanchthon weist auch auf die unfreiwillige Natur der Menschen für den Gehorsam mit dem Beispiel von Laurentius ${ }^{692}$ hin. ${ }^{693}$ Das Leiden funktioniert dabei wie ein Hebel, um dem Willen Gottes zu gehorchen. Melanchthon erwähnt auch die Wirkung der Anrufung dafür. Man braucht die Anrufung, damit das Leiden für die Kirche eine Übung wird. ${ }^{694}$ Das Leiden selbst kann kein Nutzen für die Kirche sein, sondern die Hilfe Gottes und die Anrufung im Leiden bewirken den Nutzen für die Kirche.

So denkt Melanchthon, dass Gott der Kirche den Nutzen durch das Leiden gibt. Das Leiden braucht man nach Melanchthon, damit die Bitte der Kirche dringlicher wird. ${ }^{695}$ Die Kirche übt die Lehre im Leiden, um nicht in die Konfusion hineinzugeraten, Gott zu erwarten und sich an Gott anzulehnen. ${ }^{696}$ Deshalb ist das Leiden der Kirche in diesem Leben eine Übung und Schulung für das zukünftige Leben.

Darüber hinaus bezieht Melanchthon das Leiden auf den Dienst. Der Dienst, über den sich Gott freut, hat in der Bekehrung den Schmerz, den Glauben, die Anrufung und die Hoffnung zur Folge. ${ }^{697}$ So entdeckt Melanchthon in der Wirklichkeit der leidenden Kirche den Gottesdienst. Allerdings kann das Leiden ohne den Glauben und die Anrufung kein Gottesdienst sein. Die Verheißungen und die Beispiele sollen den Glauben und die Anrufung anzün-

\footnotetext{
${ }^{690}$ PK Ps 51z, CR 13, 1230. „Petit proprie consolationem in quibuscunque doloribus,“

${ }^{691}$ PK Ps 31z, CR 13, 1239. „His et similibus dictis commonefacti petamus et speremus mitigationem publicarum et privatarum calamitatum,“"

${ }^{692}$ Laurentius(?-257) ist Märtyrer in der Zeit des Kaisers Valentian. Er war tot auf dem Feuerrost.(Sauser, S.1252f.)

${ }^{693} \mathrm{Vgl}$. PK Ps 51, CR 13, 1116. „Et spiritu spontaneo sustenta me. Id est, sponte et placide obtemperante in afflictionibus, non fremente adversus te, sicut alacri animo perfert supplicium Laurentius. “

${ }^{694}$ PK Ps 60, CR 13, 1150. „In fine repetuntur querela et precatio, sicut subinde in novis aerumnis exercetur Ecclesia, et assidua invocatione opus est,“

${ }^{695}$ PK Ps 43, CR 13, 1089. „Exponitur dolor, ut petitio sit ardentior.“

${ }^{696}$ PK Ps 131, CR 13, 1217. „Ad has sententias et hic Psalmus accommodandus est, in quo Propheta eandem doctrinam in suo exemplo, imo universae Ecclesiae exemplo proponit, et in nostris doloribus hanc doctrinam exercere discamus, nec turbemus Ecclesiam incitati ambitione, curiositate, cupiditate vindictae, et similibus motibus, simus ablactati tales,“

${ }^{697}$ PK Ps 51z, CR 13, 1233. "Hos veros cultus inquit David placere Deo, dolores in conversione, fidem, invocationem, spem etc.“ PK Ps 51z, CR 13, 1233. „Hi sunt cultus quos nominat Paulus logikh, $n$ latrei,an, id est, in qua mens cogitat Deum, et in corde sentit eius praesentiam, terrores, et laeticiam in Deo.“
} 
den, denn diese sind ein Dienst Gottes. ${ }^{698}$ Für Melanchthon ist es Dienst, dass die Kirche in diesem Leben sich an Gott anlehnt und im Leiden Gott anruft.

\subsubsection{Zusammenfassung}

Das Kapitel handelte von der Wirklichkeit der leidenden Kirche in diesem Leben. Melanchthon sieht das Leiden des Messias in den Psalmen und auch das seiner Kirche. Die Passion des Messias ist außergewöhnlich, weil durch die Passion die Erlösung entsteht, denn die Passion ist der Inhalt des Evangeliums. So ist die Passion eine Methode der Zueignung der Gerechtigkeit für die Kirche.

Die menschliche Vernunft kann die Situation der leidenden Kirche nicht verstehen. Allein Gott teilt die Ursache und das Ziel des Leidens der Kirche mit. Das Leiden in diesem Leben ist dem ganzen Menschengeschlecht gemeinsam, aber Gott hat einen besonderen Plan für die Kirche im Leiden, durch das Gott sie nicht straft, sondern das Leid hat den Nutzen für die Kirche, die Kirche zu Gott zu führen und zur Buße zu bekehren. Deshalb wendet die Kirche sich im Leiden zu Gott hin.

In diesem Leben soll die Kirche die Verheißung Gottes mit dem Glauben festhalten. Deswegen wird die Geduld des Glaubens der Kirche im Leiden erprobt. Dabei üben die Gläubigen den Glauben, die Anrufung und die Hoffnung nach dem Willen Gottes. Die Kirche erbittet und erhofft mit der Geduld die Milderung des Leidens und die Freiheit in diesem Leben als eine Übung des ewigen Lebens. Dann erhört Gott die Bitte der Kirche und mildert das Leiden. Das ist die Verheißung Gottes für die Kirche. So gibt Gott dem Leiden der Kirche einen Nutzen, und die Kirche übt die Lehre im Leiden. In diesem Punkt wird das Leiden mit dem Gottesdienst verbunden.

\footnotetext{
${ }^{698}$ PK Ps 9, CR 13, 1033. „His promissionibus et exemplis accendantur fides et invocatio. Hi sunt, ut saepe dicitur, praecipui cultus Dei.“
} 


\subsection{Der erhörende Gott ${ }^{699}$}

\subsubsection{Die Verheißung der Erhörung}

Melanchthon sagt, dass die Verheißung der Gnade Gottes universal ist, dass der Befehl Gottes ewig ist und dass man diese Verheißung annehmen soll. ${ }^{700}$ Die Verheißung gilt allein für die Gläubigen, die mit dem Glauben die Verheißung annehmen. Dazu erwähnt Melanchthon die Bedingung des Gehorsams bei der gegenwärtigen Verheißung. ${ }^{701}$ Damit ist nach Melanchthon gemeint, dass die Sünde der Mitglieder der Kirche in diesem Leben von Gott gestraft wird, wie das Beispiel der Zerstörung Jerusalems verdeutlicht. Allerdings ist die Strafe für die Kirche keine ewige Strafe, sondern sie führt die Kirche zu Gott. Melanchthon bezeichnet die Funktion der Strafe als die Ausnahmen vom Leiden und dem Kreuz. ${ }^{702}$ Die Erlösung für die Kirche steht bereits fest und ist unveränderbar, aber die Kirche erfährt das Leiden als eine Übung des Glaubens. In dieser Lage wünscht Gott, dass die Kirche Gott anruft, und Gott gibt der Kirche die Verheißung der Erhörung.

Melanchthon hält das Leiden der Kirche für den Willen Gottes. Gott wünscht von der Kirche die Anrufung Gottes und will die Anrufung erhören. ${ }^{703}$ Er verheißt, die Kirche anzunehmen, zu erhören und ihr die gegenwärtigen und zukünftigen guten Dinge zu schenken. ${ }^{704}$ Die Kirche soll diese Verheißung Gottes mit dem festen Glauben annehmen. ${ }^{705}$ Das ist die Formel Melanchthons im PK. Gott gibt die Verheißung, die Kirche nimmt sie mit dem Glauben an. ${ }^{706}$

Melanchthon wendet diese Formel insbesondere auf dieses Leben der Mitglieder der Kirche an, nämlich auf die Heiligung. Melanchthon bezeichnet Gott als den Tröster und stellt die

\footnotetext{
${ }^{699}$ Über die Erfahrungen Melanchthon von den Gebetserhörungen siehe Jung 1998, S.200-202.

${ }^{700}$ PK Ps 57, CR 13, 1134. „Hic sit infixa animis verissima doctrina, promissionem gratiae universalem esse, et mandatum Dei aeternum esse, ut assentiamur promissioni,“

${ }^{701}$ PK Ps 132, CR 13, 1219. ,additur promissioni conditio obedientiae, quia promissiones corporales habent conditionem obedientiae."

${ }^{702}$ PK Ps 132, CR 13, 1219. „Et tamen hic etiam in vera Ecclesia sciendum est, promissiones corporales habere exceptiones castigationis et crucis“"

${ }^{703}$ PK Ps 132, CR 13, 1218. „,de quo erat traditum mandatum, Deum ibi velle invocari, et Deum ibi exauditurum esse.“

${ }^{704}$ PK Ps 33, CR 13, 1068. ,et promissionem nobis illustribus testimoniis tradidit, qua adfirmat se nos recipere, exaudire, et donare praesentibus et aeternis bonis propter promissum semen." und Vgl. PK Ps 48, CR 13, 1101.

${ }^{705}$ PK Ps 45, CR 13, 1091. „Haec omnia firma fide statuenda sunt.“

${ }^{706}$ PK Ps 3, CR 13, 1022. „intuetur personam, Deum videlicet, et eius praecepta, promissiones et exempla. Ideo te invoco unum, quia tu es scutum meum, id est, tu praecepisti te invocari, et dedisti promissiones, vis exaudire et iuvare, et toties iam declarasti ipsis factis, servasti me invocantem.“
} 
Dienste des Trösters vor. Erstens, Gott befreit die Kirche von der Sünde und dem Tod. Zweitens, Gott stellt die Gerechtigkeit und das ewige Leben für die Kirche wieder her. Beides handelt von der Rettung, in anderen Worten, von der Folge der Sündenvergebung, nämlich der Rechtfertigung. Drittens, Gott erhört die Kirche und hilft ihr. ${ }^{707}$ Das gehört zum Leben der Mitglieder der Kirche, nämlich zur Heiligung durch den Heiligen Geist. Die Heiligung impliziert die Erhörung, die Regierung und die Bewahrung Gottes. ${ }^{708}$ Deshalb wirkt Gott bei der Heiligung sehr aktiv. Außerdem ist die Verheißung der Sündenvergebung durch die Barmherzigkeit um des Vermittlers willen der Grund für die Verheißung von der Annahme und der Erhörung der Kirche. ${ }^{709}$ Die Erhörung ist die besondere Verheißung für die Mitglieder der Kirche, die durch den Glauben an Christus erlöst werden. Durch diese Verheißung unterscheiden sich die Frommen von den Gottlosen in diesem Leben. So behandelt Melanchthon im PK die Anrufung Gottes in der Kirche und die Erhörung durch Gott, die die Mitglieder der Kirche in diesem Leben erfahren.

Die Erhörung durch Gott zeigt die außergewöhnliche Beziehung zwischen Gott und der Kirche. Melanchthon erklärt die Bedeutung damit, dass Gott mein Gott ist, damit, dass Gott mich erhört. ${ }^{710}$ Gott gibt der Kirche und den Mitgliedern der Kirche zum Trost der Kirche die Verheißung, dass Gott ihre Bitte erhört. ${ }^{711}$ Melanchthon bezeichnet die Erhörung Gottes als eine Eigenschaft Gottes. ${ }^{712}$ Bei Melanchthon ist Gott wahrhaft der Erhörende von der Klage und dem Wunsch der Leidenden. ${ }^{713}$ So ist die Verheißung der Erhörung Gottes sehr fest und bestimmt.

Bei der Verheißung der Erhörung betont Melanchthon die Rolle des Glaubens, der die Verheißung annimmt. Gott gibt die Verheißung, dass Gott die Anrufung erhört, und Gott for-

\footnotetext{
${ }^{707}$ PK Ps $117 / 118$, CR 13, 1187. ,consolator liberans nos a peccato et a morte, restituens iusticiam et vitam aeternam exaudiens et iuvans nos.“

${ }^{708}$ PK Ps 117/118, CR 13, 1186. „remittit peccata credentibus sanctificat eos Spiritu suo sancto, exaudit eos, regit et protegit eos in variis periculis, depellit ab eis diabolos, dat eis vitam aeternam.“

${ }^{709} \mathrm{Vgl}$. PK Ps 50, CR 13, 1108. ,scit datam esse promissionem remissionis peccatorum Gratis dandae propter Mediatorem. Et scit mandatum Dei esse immotum, ut iuxta hanc promissionem credamus nos recipi et exaudiri:““

${ }^{710}$ PK Ps 56, CR 13, 1132. „Quandocunque clamo ad te, ecce cognosco quod Deus meus tu sis. Non est, inquit, irrita invocatio, vere exaudis et iuvas invocantes te.“

${ }^{711}$ PK Ps 6, CR 13, 1027. „Ideo enim recitatur consolatio, ut sciamus Deum vere exaudire preces Ecclesiae et membrorum Ecclesiae.“ Und vgl. PK Ps 36, CR 13, 1073, PK Ps 33, CR 13, 1067, PK Ps 111, CR 13, 1170 und PK Ps 20, CR 13, 1047. etc.

${ }^{712}$ PK Ps 9, CR 13, 1033. „,non sit alligatus causis secundis, sed vere nos respiciat, nos exaudiat, adsit, opituletur, etiam cum destituimur a causis secundis.“

${ }^{713}$ PK Ps 10, CR 13, 1035. „Tu vere exaudis gemitus et desideria adflictorum in Ecclesia tua.“
} 
dert, dass die Kirche Gott anruft. ${ }^{714}$ Allerdings ist die Sache allein nicht genug, dass Gott die Anrufung erhört. Man muss die Verheißung der Erhörung auf sich anwenden. ${ }^{715}$ In anderen Worten: die Kirche glaubt, dass sie von Gott erhört wird. ${ }^{716}$ Die Mitglieder der Kirche sollen auch im schwierigen Leiden auf die Erhörung durch Gott vertrauen. Deshalb bezeichnet Melanchthon den Glauben als die Gott sehende Erkenntnis. ${ }^{717}$ Eigentlich ist das Vertrauen auf die Erhörung durch Gott nicht leicht, weil Gott nach seiner gerechten Eigenschaft die gerechte Strafe ausspricht. ${ }^{718}$ Deshalb bezweifeln die Gottlosen die Verheißung der Erhörung. ${ }^{719}$ Sie haben Zweifel an der Vorsehung und dem Willen Gottes und glauben nicht an die Erhörung der Anrufung in der Kirche. ${ }^{720}$ Allein die Kirche Gottes überzeugt sich von der Annahme und der Erhörung. ${ }^{721}$ Sie erkennt, dass in der Strafe Gott sie nicht verwirft, deshalb geduldet sie sich im Leiden und bittet Gott um Vergebung. Und sie erkennt, dass Gott sie erhört, ihr hilft und die Freiheit für sie plant. ${ }^{722}$ Nach Melanchthon sind durch diese Handlungen die Unterschiede zwischen den Mitgliedern der Kirche und den Gottlosen zu erkennen.

Melanchthon stellt die Erhörung durch Gott an Beispielen aus den Psalmen fest. David ist das bedeutendste Beispiel. Wie Gott David erhört und schützt, will er die Kirche schützen. ${ }^{723}$ Die Beispiele aus den heiligen Schriften werden gegeben, damit die Frommen die Fürsorge Gottes, die Erhörung und die Strafe gegen die Gottlosen erkennen. ${ }^{724}$ Melanchthon erklärt die verschiedenen Handlungen der Barmherzigkeit Gottes als die Erhörung durch Gott und Zeug-

\footnotetext{
${ }^{714}$ PK Ps 3, CR 13, 1022. „tu praecepisti te invocari, et dedisti promissiones, vis exaudire et iuvare,“

${ }^{715}$ PK Ps 13, CR 13, 1037. „sed oportet nos fide amplecti promissiones, et eas ad nos accommodare.“

${ }^{716}$ PK Ps 30, CR 13, 1063. „ut nos quoque credamus similiter exaudiri.“

${ }^{717}$ PK Ps 11, CR 13, 1035. „Nam haec fides est agnitio intuens Deum,“

${ }^{718}$ PK Ps 57, CR 13, 1134. „Do iustas poenas meorum delictorum, ideo non est petenda liberatio, sum peccator, sum indignus, ideo non exaudior".

${ }^{719}$ PK Ps 33, CR 13, 1037. ,et semper dubitant, an exaudiantur hominum preces.,, und vgl. PK Ps 51, CR 13, 1113.

${ }^{720}$ PK Ps 53, CR 13, 1123. „tamen haerent dubitationes perpetuae de providentia, et de voluntate Dei an recipiat, et an exaudiat ipsos vel alios."

${ }^{721}$ PK Ps 56, CR 13, 1133. „Sed Ecclesia Dei affirmat se recipi et exaudiri,“

${ }^{722}$ PK Ps 32, CR 13, 1066. „Econtra vero petentes remissionem peccatorum, sciunt se propter peccatum subiectos esse morti et aliis miseriis, sed tamen non abiici a Deo propter has poenas."

${ }^{723}$ PK Ps 54, CR 13, 1127. „Et ut adest Davidi, et eum exaudit et protegit: ita non dubitemus eum adesse caeteris Ecclesiae membris, et exaudire, et multis modis servare innocentes." Und vgl. PK Ps6, CR 13, 1027, PK Ps 41, CR 13, 1085.

${ }^{724}$ PK Ps 58, CR 13, 1140. ,item ut pii confirmati his liberationibus, agnoscant se Deo curae esse, se exaudiri et puniri impios,“
} 
nisse der Hilfe. ${ }^{725}$ Durch diese Beispiele aus den Psalmen überzeugen sich die Mitglieder der Kirche davon, dass die wahrhaft Anrufenden von Gott erhört werden.

Einen weiteren Grund erwähnt Melanchthon dafür, dafür, dass die Anrufung in der Kirche nicht vergeblich ist, nämlich den Vermittler. Die Kirche wird um des Vermittlers willen von Gott erhört. ${ }^{726}$ In anderen Worten, die Kirche wird durch den Glauben, der den Vermittler erkennt, von Gott angenommen und erhört. ${ }^{727}$ Der Grund für die von Gott gegebene VerheiBung ist aber der Vermittler, der Messias. Obwohl die Mitglieder der Kirche in diesem Leben noch sündig sind, haben sie keinen Zweifel an ihrer Erlösung wegen des Werkes des Messias für die Erlösung. Zugleich hilft Gott wahrhaft der Kirche und erhört die Kirche durch den Vermittler. ${ }^{728}$ Dies kann die Welt zwar nicht verstehen. ${ }^{729}$ Aber nach Melanchthon werden die Annahme und die Erhörung wegen des Messias so gedeutet, dass er der Eckstein der Kirche ist. ${ }^{730}$ Deswegen ist die Anrufung in der Kirche nicht vergeblich, weil Gott wegen des Messias die Anrufung erhört.

Den Grund dafür, dass Gott der Kirche die Verheißung von der Erhörung und der Bewahrung mit Beispielen in den Psalmen gibt, findet Melanchthon vor allem im Nutzen für die Kirche. Gott erhört die Klage und das Gelübde der Mitglieder der Kirche, damit die anderen zum Glauben, der Hoffnung und der Anrufung eingeladen werden. ${ }^{731}$ Die Erhörung durch Gott ist ein Zeugnis der Kirche für seine Anwesenheit in der Kirche und seine Sammlung der Kirche. Damit kann die Kirche im Leiden sich vertrauensvoll an Gott anlehnen. Darüber hinaus nennt Melanchthon noch wichtigen Grund, die Ehre Gottes. Gott erhört die Kirche um der

\footnotetext{
${ }^{725}$ PK Ps 30, CR 13, 1062. „Itaque gratiarum actio in hoc Psalmo, ut alibi, testatur nos exaudiri, et iubet exemplo ut petamus auxilium, et accepto beneficio gratias agamus, et alios nostra fide et confessione ad invocationem invitemus." Vgl. PK Ps 31, CR 13, 1064.

${ }^{726}$ PK Ps 31z, CR 13, 1235. „Non in iusticia nostra, sed in misericordia tua exaudi nos propter Dominum.“

${ }^{727}$ PK Ps 51z, CR 13, 1232. „Sunt autem cultus primi praecepti conversio ad Deum, et fides agnoscens Mediatorem, qua habemus accessum ad Deum, et credimus nos recipi et exaudiri.“

${ }^{728}$ PK Ps 111, CR 13, 1169. „sed vere iuvans et exaudiens nos propter mediatorem,“

${ }^{729}$ Vgl. PK Ps 114/115, CR 13, 1180. „Vero Deo tribuit, quod sit verax et misericors, quod dederit promissiones, constituerit Mediatorem, exaudiat et salvet iuxta promissionem, tribuit etiam quod agat liberrime, Omnia quaecunque voluit fecit, id dictum opponendum est stoicis imaginationibus, quae fingunt Deum alligatum esse causis secundis.“

${ }^{730}$ PK Ps 117/118, CR 13, 1184. „et quidem exaudiri nos propter hunc ipsum Messiam, qui hic profitetur se constitutum esse, ut sit caput anguli, id est, ut habeat Ecclesiam, quam non sinat interire." ${ }^{731}$ PK Ps 52, CR 13, 1122. „et testatur se exaudire gemitus et vota nostra, ut invitentur alii ad fidem, spem et invocationem,“
} 
Ehre Gottes willen. ${ }^{732}$ Gott erhört die anrufende Kirche, damit die Gottlosen nicht sagen können, wo denn Gott ist ${ }^{733}$ und damit der Name Gottes nicht beleidigt wird. ${ }^{734}$ So ist die Ehre Gottes der wichtigste Grund dafür, dass Gott die Anrufung in der Kirche erhört. ${ }^{735}$

Nach Melanchthon wird die Verheißung, dass Gott die anrufende Kirche erhört, als eine feste Verheißung wie eine Eigenschaft Gottes gegeben, die Kirche soll die Verheißung mit dem Glauben festhalten, die um des Vermittlers willen für die Ehre Gottes gegeben wird. Wenn Melanchthon die Verheißung der Erhörung durch Gott im Leiden der Kirche sieht, richtet er den Blick nicht auf etwas Eigenes der Kirche, sondern auf die Verheißung Gottes und den Vermittler, wie viele Beispiele in den Psalmen zeigen. Der Blick richtet sich also stets auf das Wesen Gottes, darauf, dass Gott sich auf die Kirche bezieht.

\subsubsection{Das Verhältnis Gottes gegen die Gottlosen}

Melanchthon lehrt im PK die bestimmte Strafe gegen die Gegner des Evangeliums, wie die bestimmte Erhörung der Bitten der Kirche, die im Leiden ist, durch Gott. Dies ist zuerst in diesem Leben gewiss, weil die Menschen durch ihre sündige Natur leiden. ${ }^{736}$ Darin besteht kein Unterschied zwischen den Frommen und den Gottlosen. Aber im Leiden wird ein wichtiger Unterschied erkennbar. Die Kirche flieht im Leiden zu Gott, aber im Gegensatz fliehen die Gottlosen von Gott. ${ }^{737}$ Die Gottlosen erkennen, dass Gott der gerechte Richter ist, und sie deshalb vor Gott nicht als Gerechte treten können. Aus diesem Grund fliehen sie wegen ihrer Sünden nicht zu Gott, sondern von Gott, wenn sie ihre Sünde finden.

Die Gottlosen erkennen - so Melanchthon - nicht an, dass ein besonderer Plan und die Vorsehung Gottes für die Kirche vorhanden sind. Vielmehr halten sie den Glauben und die Anrufung Gottes durch die Kirche für töricht. Wenn sie das allgemeine Leiden der Kirche

\footnotetext{
732 PK Ps 23, CR 13, 1051. „propter gloriam tuam Deus exaudias et iuves nos,“

${ }^{733}$ PK Ps 42, CR 13, 1088. „Causa finalis etiam consideretur, cur petat exaudiri et liberari, videlicet: Ne blasphemiae dicantur adversus Deum, ubi est Deus tuus?"“

${ }^{734}$ PK Ps 39, CR 13, 1080. „,ne tandem nomen tuum contumelia adficiatur, sed ut conspici possit doctrinam"

${ }^{735}$ PK Ps 38, CR 13, 1077. „Utrumque autem promisit, et exauditurum se invocantes, et asserturum se esse gloriam suam. Hanc fidem discamus nos quoque ad Deum in precando adferre. Has causas, quae toties in Psalmis repetuntur, proponamus Deo: quod si faciemus, experiemur certo, non esse irritos gemitus nostros, et petitiones.“

${ }^{736}$ PK Ps 32, CR 13, 1066. „Principalis causa calamitatum humanarum est, non, ut philosophi putant, materia, sed peccatum in natura hominum.“

${ }^{737}$ PK Ps 113, CR 13, 1179. „Etsi enim Ethnici norunt dicta de providentia, tamen in aerumnis fugiunt Deum, quia agnoscunt se reos et indignos esse, sed Ecclesia opponit promissionem de Mediatore, imo etiamsi es reus, tamen Deus edidit promissionem, et vult te recipere propter Mediatorem,"“
} 
betrachten, rufen sie glücklich aus, dass die Kirche von Gott abgelehnt würde, ${ }^{738}$ wie Epikureer das Unheil der Frommen bejubeln. ${ }^{739}$ Sie unterdrücken die Kirche ${ }^{740}$ und denken, dass sie über die Kirche siegen, wenn die Kirche durch die wahrhaften Lehren leidet. ${ }^{741}$ In diesem Leben ist es ein Argument für die Gottlosen, dass einige Gottlosen prosperieren. Aber sie wissen nichts über den Plan Gottes. ${ }^{72}$ Melanchthon erkennt die Anwesenheit der Verkehrtheit an, aber er hält die Meinung der Gottlosen nicht für wahr, weil der Gehorsam der Kirche im Leiden der Wille Gottes ist. ${ }^{743}$ Melanchthon ist überzeugt von der bestimmten Strafe gegen die Gottlosen.

Melanchthon weist in der Auslegung zu Psalm 5 darauf hin, dass das Gebet des Psalms voll ist vom Schmerz und dem Unheil der Gottlosen. ${ }^{744}$ Gott, der die Anrufung der Frommen erhört, tadelt und bedroht aber im Gegenzug die Gegner des Evangeliums. ${ }^{745}$ Die Gottlosen können die Kirche nicht zerstören. ${ }^{746}$ Die Vernichtung der Gegner der Kirche - wie es die Psalmen zeigen - belegt die Richtigkeit der Haltung der Kirche. ${ }^{747}$ Gott offenbart sich der im Leiden anrufenden Kirche und greift das Urteil der Gottlosen an. ${ }^{748}$

${ }^{738}$ PK Ps 6, CR 13, 1027. „Vos, inquit, hostes Ecclesiae Dei gloriabamini in mea calamitate, et insultabatis nobis, ac laeti vociferabamini nos a Deo reiectos esse,“

${ }^{739}$ PK Ps 23, CR 13, 1050. „,ne tuum nomen apud Epicureos contumeliaadficiatur, qui in calamitatibus piorum clamitant" und vgl. PK Ps56, CR 13, 1131. „qui laetantur calamitate exulis,“

${ }^{740}$ PK Ps 41, CR 13, 1083. „videlicet Ecclesiam oppressam ab impiis fovendam et tuendam esse.“

${ }^{741}$ PK Ps 37, CR 13, 1074. „Epicureo stulti videntur Ieremias, Baptista, Christus, Paulus, et similes, cum sibi accersunt pericula recte docendo. Diceret enim eos suavius victuros esse, si tacerent, et potius foverent eum statum, quo delectabantur principes, “

${ }^{742}$ Vgl. PK Ps 49, CR 13, 1103. „Deinde disputat de iusticia Dei, quia causam consilii divini ignorat, et sic ratiocinatur."

${ }^{743}$ Vgl. PK Ps 52, CR 13, 1120. „Primum de his quoque universaliter verum est, et in hac vita servari causam, et corpus Ecclesiae, etiamsi multi sunt in magnis aerumnis, et aliqui interficiuntur, quia certo consilio vult Deus Ecclesiam cruci subiectam esse,sed tamen postea cum fiet aeternum discrimen piorum et impiorum, universaliter omnes pii fruentur aeternis bonis, et impii erunt in poenis aeternis.“ ${ }^{744}$ PK Ps 5, CR 13, 1024. „Totus enim precatio est, plena doloris et indignationis adversus impios doctores"

${ }^{745}$ PK Ps 2, CR 13, 1020. „vehemens increpatio est hostium Evangelii et comminatio.“

${ }^{746}$ PK Ps 125, CR 13, 1207. „nec deleri eam posse furoribus impiorum, etiamsi magnae erunt persecutiones,"

${ }^{747}$ PK Ps 9, CR 13, 1032. „Generalis gratiarum actio est pro deletis hostibus, et adplicatio exempli ad reliquam Ecclesiam, cui hoc exemplum proponit,“

${ }^{748}$ PK Ps 57, CR 13, 1137. ,atque ita post afflictionem ostendit sese invocantibus, et impiorum iudicia refutat." 
Viele Weisen und Kräftigen leisten ihre Arbeit in der Welt. Aber Melanchthon weist auf die Kürze ihrer Kraft und Ehre hin. ${ }^{749}$ Deshalb werden die, die die menschliche Kraft, die Fähigkeit und den menschlichen Willen vor Gott stellen, in den ewigen Tod geraten. Und davon kann keine menschliche Hilfe sie retten. ${ }^{750}$ So werden die Gottlosen trotz des Prosperierens in diesem Leben sicherlich in den ewigen Tod geraten. ${ }^{751}$ Somit erfahren sie das schlimmste Elend, nämlich ohne Buße ein Gegner Gottes zu sein und von Gott verworfen zu werden. ${ }^{752}$ Indem Melanchthon den endlichen Untergang und das Verwerfen der Gottlosen erklärt, richtet er den Blick der Frommen nicht allein auf die Gegenwart, sondern auf das letzte Gericht Gottes.

\subsubsection{Die verheißene Milderung des Leidens}

Die Kirche, die in diesem Leben im Leiden ist, ruft Gott an, dann erhört Gott sie nach seiner Verheißung und wird ihr helfen. Melanchthon sieht die Erhörung und die Hilfe Gottes, die die Kirche in diesem Leben erfährt, in der Bewahrung und der Milderung des Leidens.

Melanchthon ist überzeugt von der Bewahrung der Kirche in diesem Leben. ${ }^{753}$ Obwohl die Ursache des Leidens der Zorn Gottes gegen die Sünde ist, werden die Mitglieder der Kirche im großen Schmerz und Leiden nicht verworfen. ${ }^{754}$ Melanchthon sagt, dass in den großen Bedrängnissen die Kirche in diesem Leben bewahrt wird, und dass Gott wünscht, dass die Kirche im Plan Gottes dem Kreuz gehorcht. ${ }^{755}$ Die Kirche klagt im Leiden, bittet Gott um die Freiheit und lobt Gott. ${ }^{756}$ Melanchthon entdeckt das Gebet für die Bewahrung im Leiden und der Verfolgung in den Psalmen. ${ }^{757}$

\footnotetext{
${ }^{749}$ PK Ps 47, CR 13, 1098. „sed quam brevis est horum potentia et gloria?“

${ }^{750}$ PK Ps 49, CR 13, 1105. „Etsi enim nunc florent, tamen post mortem ruent in exitium aeternum, unde nullis opibus, nullis humanis praesidiis eripi possunt."

${ }^{751}$ PK Ps 49, CR 13, 1106. „quia etiamsi nunc florent impii, tamen aliquanto post perituri sunt, et ruent in aeternum exitium, ex quo nec opibus suis nec ullis humanis viribus eripi poterunt:“

${ }^{752}$ PK Ps 110, CR 13, 1166. „summa enim et extrema miseria est sine poenitentia tanquam hostem Dei et abiectum a Deo vivere.“

${ }^{753}$ PK Ps 112, CR 13, 1173. „Quia scilicet semper in hac vita conservatur,“

${ }^{754}$ PK Ps 38, CR 13, 1079. „Cum enim et caetera membra Ecclesiae vident in tantis miseriis esse, sciant se quoque non abiectos esse a Deo propter calamitatum magnitudinem.“

${ }^{755}$ PK Ps 52, CR 13, 1120. „et sciamus haec membra recte consentire, Ecclesiam subiectam esse cruci, et tamen non deesse ei bona praesentia.“

${ }^{756}$ PK Ps 60, CR 13, 1148. „Has aerumnas hic deplorat, et simul petit ac celebrat liberationes.“

${ }^{757}$ Z.B. PK Ps 119, CR 13, 1190. „Primus versus est precatio, ut in calamitate et persecutione protegatur,"
} 
Die Kirche erkennt durch das Wort Gottes die Bewahrung und die Anwesenheit des Plans Gottes, obwohl die Gegner der Kirche glauben, die Kirche mit ihrer Weisheit zerstören zu können. So verheißt Gott die Bewahrung der Kirche um der Ehre Gottes und der Verbreitung der Lehre willen. ${ }^{758}$ Für die Bewahrung der Kirche verwendet Gott die wunderbare göttliche Methode, wie auch David in den großen Gefahren durch Gottes Hand bewahrt wurde. So tritt das Zeugnis der Gegenwart Gottes in der Gefahr der Kirche hervor. ${ }^{759}$

Allerdings bedeutet die Verheißung der Bewahrung Gottes keine Abwesenheit vom Leiden und dem Schmerz. Melanchthon verweist aber auf die Milderung des Leidens. So erhofft und erbittet die Kirche im Leiden die Milderung. ${ }^{760}$ Dann erhört Gott die Bitte und mildert das Leiden, ${ }^{761}$ und er will die Bedrängnisse der Kirche leichter machen. ${ }^{762}$ So wird die Kirche bewahrt, und ihr Leiden wird gemildert, ${ }^{763}$ wie es das Beispiel Davids zeigt. ${ }^{764}$ Obwohl Gott die Kirche bewahrt, besteht noch das Leiden in der Kirche. Aber die Kirche soll glauben, dass Gott im großen Leiden mit der Verheißung helfen, das Leiden mildern kann, und sie soll sich fest daran erinnern, dass das Leiden zum Nutzen für die Kirche ist.

Melanchthon verbindet dieses Leben mit dem ewigen Leben mit dem Gedanken von der Bewahrung der Kirche und der Milderung des Leidens. Die Kirche trägt für kurze Zeit eine Last, aber danach hat sie die ewige Freude. Die Gottlosen aber werden mit der ewigen Strafe verurteilt. Und die Frommen erfahren in diesem Leben die Sündenvergebung und erkennen die Fürsorge und die Hilfe Gottes, wenn auch keine menschliche Hilfe besteht. ${ }^{765}$ Die Gerechten haben viele Bedrängnisse in diesem Leben, aber nach diesem Leben werden sie die Frei-

\footnotetext{
${ }^{758}$ PK Ps 26, CR 13, 1057. „Et in tali periculo peculiariter promisisti defensionem propter tuam gloriam, et propter doctrinae propagationem.“

${ }^{759}$ PK Ps 57, CR 13, 1133. „David enim in extremo periculo divinitus, mirando modo custoditur, et hic eventus testimonium est praesentiae Dei in periculis Ecclesiae.“

${ }^{760}$ PK Ps 110, CR 13, 1164. „Haec spes quoque tibi dolores leniat, teque in doctrinae propagatione confirmet, quod certum est ad posteros quoque mansuram esse Ecclesiam, et aliqua Ecclesiae et doctrinae hospitia."

${ }^{761}$ PK Ps 41, CR 13, 1085. ,ita certo nos quoque precantes exaudit Deus, et mitigat nobis calamitates.“ ${ }^{762}$ PK Ps 57, CR 13, 1135. „Vera etiam spe mitigationem poenarum expectemus, tuos gemitus etiam vere respicit Deus, tibi vult mitigare calamitates“"

${ }^{763}$ PK Ps 128, CR 13, 1211. „De talibus periculis consolationes hic proponuntur, erit curae Deo, ut piis familiis diu servet patriam et Ecclesiam, et quanquam ruent regna, tamen hae protegentur, sicut multae familiae in exilio Babylonico conservatae sunt. Has promissiones cum intuetur fides impetratur aerumnarum mitigatio, et leniuntur dolores.“

${ }^{764}$ PK Ps 6, CR 13, 1027. „Et invocantes vero gemitu et hac fide, haud dubie sentient levationem,“

${ }^{765}$ PK Ps 39, CR 13, 1079. „Altera est, quod etiam in hac vita pii norunt remissionem peccatorum, et sciunt se Deo curae esse, et a Deo defendi, etiamsi non habent praesidia humana.“
} 
heit, das ewige Leben, die Gerechtigkeit und die ewige Freude genießen, und in diesem Leben wird ihr Leiden gemildert. So wird die Kirche vor den Gottlosen bewahrt, die die Kirche zerstören wollen. ${ }^{766}$ Nach Melanchthon zeigen die Erfahrungen der Kirche von der Bewahrung und der Milderung des Leidens in diesem Leben die Freude, die die Kirche ewig genießen wird.

Die Bewahrung der Kirche bezieht sich auf die konkreten geschichtlichen Kontexte. In der Zeit Melanchthons ist das besonders richtig. Die Zeit, in der Melanchthon seine Psalmenvorlesungen hält, ist eine sehr dynamische im Hinblick auf die Reformation. Die wahre Kirche, die durch die Reformation wahrhaft wiederhergestellt wird, ist in eine gefährliche Situation geraten, die Gegner der Kirche verfolgen die wahre Kirche mit all ihrer Macht. In solcher Gefahr liest Melanchthon die Psalmen und sieht in den Psalmen die Verheißung Gottes für die Bewahrung der Kirche und entdeckt in den frommen Führern die Beispiele herfür. David nämlich erbittet die Verteidigung, um im Haus Gottes zu dienen, die himmlische Lehre zu lernen und die Kirche mit der Verbreitung der Lehre der Rettung zu schmücken. Der Zweck ist für einen frommen Führer vorgegeben. ${ }^{767}$ Dazu erklärt Melanchthon, dass den weltlichen Führern, die die von den Gottlosen verfolgte Kirche schützen, eine Belohnung verheißen ist. ${ }^{768}$ Und Gott schützt die Kirche auf seine Weise. ${ }^{769}$ Deshalb muss man die Hilfe Gottes erwarten. ${ }^{770}$ Gott gibt die Verheißung in der Gefahr zur Ehre Gottes und zur Verbreitung der Lehre. ${ }^{771}$ Nach der Verheißung Gottes wird die Versammlung der Kirche bis zum ewigen Leben bleiben. ${ }^{772}$ Melanchthon verweist auf die Wirkung der gegenwärtigen Verheißung Gottes mit der Bewahrung der politischen Verfassung. ${ }^{773}$ Er stellt die Bewahrung der Kirche fest,

\footnotetext{
${ }^{766}$ Vgl. PK Ps 34z, CR 13, 1244. ,et corpus Ecclesiae servabitur etiam ruentibus imperiis.“

${ }^{767}$ PK Ps 23, CR 13, 1051. „Sed David petit defensionem, ut postea serviat in domo Domini, discat doctrinam coelestem, et ornet Ecclesiam propagatione salutaris doctrinae, assuefaciat iuventutem et populum ad agnitionem Dei. Hic finis pio gubernatori propositus est.“

${ }^{768}$ PK Ps 41, CR 13, 1084. „sed etiam eius defensoribus concionatur. Ac primum doctrina et promissio traditur, videlicet Ecclesiam oppressam ab impiis fovendam et tuendam esse. Et promittuntur praemia iis qui Ecclesiae in aerumnis benefaciunt,“

${ }^{769}$ PK Ps 43, CR 13, 1088. „Sed piae mentes intueantur hos Psalmos, qui ideo divinitus propositi sunt, ut nobis notae sint promissiones Dei, et extent exempla auxilii divini, ut petamus et expectemus a Deo auxilium, saepe ita cogites.“

${ }^{770}$ PK Ps 46, CR 13, 1097. „et ab eo auxilium petite et expectate iuxta promissiones.“

${ }^{771}$ PK Ps 26, CR 13, 1057. „Et in tali periculo peculiariter promisisti defensionem propter tuam gloriam, et propter doctrinae propagationem. “

772 PK Ps 122, CR 13, 1264. ,et collectionem Ecclesiae ad vitam aeternam,“

${ }^{773}$ PK Ps 132, CR 13, 1219. „,consolator et liberator Davidis et aliorum credentium, nam propter hunc servabo hanc politiam.“
} 
die der Teufel, das Reich, die Türken, das Papsttum, die Fürsten und der Hass der großen Heiden vernichten wollen. ${ }^{774}$ So vertraut Melanchthon auf die Fürsorge und die Regierung Gottes für die Kirche und die Regierung.

\subsubsection{Der verheißene Trost für die anrufende Kirche}

Melanchthon sieht in der Bewahrung der Kirche und der Milderung des Leidens den Trost für die Kirche in diesem Leben. Gott bewahrt die, die die wahre und reine Lehre der Kirche mit dem frommen Eifer annehmen. Das ist der süße Trost. ${ }^{775}$ Melanchthon sagt, dass Gott nicht wünscht, dass die Kirche unter dem Leiden in Trauer gerät, deswegen tröstet und befreit er die Kirche. ${ }^{776}$

Der Trost, den Melanchthon im PK erwähnt, ist wirkungsvoll in seiner geschichtlichen Wirklichkeit. Er steht über dem Elend des Krieges. ${ }^{777}$ In einer solch schmerzhaften Zeit gehorcht die wahre Kirche Gottes dem Kreuz. Melanchthon erklärt, dass dadurch der Trost zum ewigen Leben hinzugefügt wird. ${ }^{778}$ So verbindet er das jetzige Leiden mit dem ewigen Trost. Das Leiden ist kurz, aber der Trost ist ewig. Die Zeit des Leidens bringt die Ewigkeit der Ehre. $^{779}$

\footnotetext{
${ }^{774}$ PK Ps 110, CR 13, 1165. „etiamsi pariter diaboli, et imperia, Turcicum, Pontificium, Regia, magnarum gentium odia, haereticorum et sectarum furores, delere Ecclesiam conantur, tamen eam proteget et servabit Messias, et tandem omnibus his hostibus repressis, et imperiis mundi deletis, prorsus liberabit eam."

${ }^{775}$ PK Ps 41, CR 13, 1084. „Et nunc aliqui pii principes nolunt adiuvare furores pontificum et regum exercentium saevitiam in homines innocentes, veram et puram Evangelii doctrinam pio studio amplexos, et fovent Ecclesias et pia studia magno suo et suarum ditionum periculo. Talibus hic Psalmus dulcissimam consolationem proponit, ac adfirmat Deum defensurum esse hos ipsos, qui piorum aerumnis adficiuntur, et eis opem ferunt."

${ }^{776}$ PK Ps 16, CR 13, 1041. „,non sinas me succumbere in his tristibus aerumnis, sed consolare et libera me.“

777 Z.B. PK Ps 128, CR 13, 1211. „ut consoletur nos in tanta mole periculorum privatorum et publicorum. Magnum onus est per sese educatio sobolis, et in publicis miseriis, bellis et vastationibus multo plus mali accedit: Patres interficiuntur, matres et filii abducuntur in exilium. De talibus periculis consolationes hic proponuntur, erit curae Deo, ut piis familiis diu servet patriam et Ecclesiam, et quanquam ruent regna, tamen hae protegentur, sicut multae familiae in exilio Babylonico conservatae sunt."

${ }^{778}$ PK Ps 17, CR 13, 1043. „Econtra vera Ecclesia est subiecta cruci in hac vita. Sed consolatio hic additur de vita aeterna,“

${ }^{779}$ PK Ps 30, CR 13, 1063. „Significat breve esse tempus adflictionis, sed postea consolationem aeternam,“
} 
Zudem verbindet Melanchthon den Trost mit der Passion Christi. Ein Modell Christi, so erfährt David das Leiden und den Sieg wie Christus selbst. ${ }^{780}$ Die Kirche ist in diesem Leben unter dem Kreuz, aber sie wird siegen, gleich wie Christus gelitten und gesiegt hat. So liegt der Trost der Kirche wahrhaft in der Passion Christi, und solcher Trost zeigt die Lehre der gnädigen Sündenvergebung durch das Kreuz. Darin besteht der wahre Trost. ${ }^{781} \mathrm{Im}$ großen Schmerz beginnt, hält und erfährt die Kirche die Rettung, nämlich das Leben. So freut sie sich über den Trost des Kreuzes und die gnädige Vergebung. ${ }^{782}$

Die menschliche Vernunft kann nicht erklären, warum die Kirche unter das Kreuz und das Leiden geworfen ist. ${ }^{783}$ Deswegen sind die Aussagen Davids in den Psalmen von Bedeutung. Melanchthon wünscht, dass die Kirche die Psalmen daraufhin betrachtet, wie David das Leid erduldet und den Trost bekommt, um durch das Leiden nicht überwältigt zu werden. ${ }^{784}$ Die Kirche soll Gott um den Trost bitten, um unter dem Gewicht des Schmerzes nicht erdrückt oder getötet zu werden. ${ }^{785}$ Deshalb soll die Kirche den Trost in der täglichen Anrufung sehen, wie Jonah und die Israeliten es getan haben. ${ }^{786}$ Aber Melanchthon betont auch, dass der Kirche die Bewahrung und die Milderung des Leidens verheißen sind. ${ }^{787}$

\footnotetext{
${ }^{780}$ PK Ps 22, CR 13, 1049. „Et hunc Psalmum recitat David, significans venturum Christum similia passurum esse, et postea liberatum ac triumphantem propagaturum esse Evangelium, daturum vitam aeternam, et collecturum Ecclesiam inter gentes etc."

${ }^{781}$ Vgl. PK Ps 32, CR 13, 1065. „Etsque doctrina propria Ecclesiae de remissione peccatorum, de peccato manente in Sanctis in hac vita, de confessione peccati, de discrimine verae iusticiae arrogantiae hypocritarum, de causis calamitatum humanarum, de vera consolatione, quae in Ecclesia traditur in doctrina de cruce."

${ }^{782}$ Vgl. PK Ps 32, CR 13, 1066. „Has consolationes de gratuita remissione, et de auxilio in cruce qui tenent, experiuntur in magnis doloribus veram levationum, imo vitae aeternae gustum et incoationem." ${ }^{783}$ PK Ps 37, CR 13, 1074. „de quo humana ratio ignorans cur Ecclesia subiecta sit cruci et aerumnis, non recte indicat."

${ }^{784}$ Vgl. PK Ps 42, CR 13, 1087. „Omnes autem discamus voluntatem Dei esse, ut in talibus doloribus non succumbamus, sed erigamus nos fide et spe.“

${ }^{785}$ Vgl. PK Ps 51, CR 13, 1116. „Consolatio petitur, ne magnitudine dolorum oppressi extinguamur aut deficiamus a Deo,“

${ }^{786}$ PK Ps 110, CR 13, 1152. „Tales consolationes intueamur quotidie in invocatione, in nostris et communibus periculis, et sciamus vere nos servari ab hoc Domino, sicut Israëlitae servantur in mari rubro, aut Ionas in ventre ceti, et hac fide accendatur invocatio, et acquiescamus in Deo, ita sentiemus nos vere vivificari et iuvari.“

${ }^{787}$ PK Ps 112, CR 13, 1173. „et tamen non deesse ei bona praesentia. Quia scilicet semper in hac vita conservatur, et Deus mitigat aerumnas invocantibus,“
} 
Melanchthon zeigt so im PK entgegen des Ärgernisses des Kreuzes die Verheißung für die gegenwärtigen und zukünftigen Guten. ${ }^{788}$ Das Kreuz besteht für die Kirche, die Kirche verliert aber den ewigen Trost nicht. ${ }^{789}$ Deshalb sind die Mühen der Kirche nicht vergeblich. Mit dieser Hoffnung erdulden die Mitglieder der Kirche die Mühen und die Bedrängnisse. ${ }^{790}$ In diesem Sinn wird auf die Verheißung im PK verwiesen, um die Kirche in den Bedrängnissen des Leidens zu trösten. ${ }^{791}$

Nach Melanchthon ist der Trost in diesem Leben wichtig und ist für die Kirche verhießen. Aber eigentlich zeigt der Trost in diesem Leben den Trost, der im ewigen Leben genossen wird. In diesem Leben ist die Kirche unter dem Kreuz. Das ist der Wille Gottes, aber um nicht überwältigt zu werden, soll die Kirche Gott um den Trost bitten. Und Gott bereitet die Freiheit für die Kirche vor.

Melanchthon konzentriert sich auf den Nutzen für die Kirche in diesem Leben. Der Trost in diesem Leben ist wirklich und wirksam durch die Verwirklichung der Verheißung Gottes, nämlich durch die Bewahrung der Kirche und die Milderung des Leidens.

\subsubsection{Die verheißene Freiheit für die anrufende Kirche.}

Melanchthon verbindet das Elend und die Freiheit der Kirche in diesem Leben mit dem Beispiel Christi. Es wird vorhergesagt, dass Christus, der Kopf der Kirche, kurzzeitig die Ehre nicht hat, allerdings werden die verheißene Ewigkeit und die Seligkeit wiederhergestellt. So wird die Freiheit vorhergesagt und gelobt. ${ }^{792}$ Und die Erfahrung Christi verbindet sich mit der Kirche, wie die Beispiele Davids. ${ }^{793}$ Wenn auch die Kirche in den großen Bedrängnissen ist, von den Gott Nicht-Erkennenden verachtet wird und in der Welt am schlimmsten leidet, wird

\footnotetext{
${ }^{788}$ Z.B. Vgl. PK Ps 112, CR 13, 1172. „Hic Psalmus consolatio est Ecclesiae et piorum adversus scandalum crucis. Quia enim multi aerumnis Ecclesiae franguntur, et deficiunt a Deo, opponitur hic consolatio continens dulcissimas promissiones praesentium et aeternorum bonorum, sicut et Paulus inquit, Pietas promissiones habet praesentis vitae et futurae.“

${ }^{789}$ PK Ps 112, CR 13, 1176. „Deinde petamus et expectemus caetera necessaria, sed ita ut simul parati simus ad crucem, et tamen non amittamus aeternam consolationem,“

${ }^{790}$ PK Ps 126, CR 13, 1208. „Non erit labor vester inanis in Domino. Hac spe sustineamus labores et aerumnas in docendo, in discendo, et in confessione Evangelii, et expectemus auxilium et protectionem a Filio Dei.“

${ }^{791}$ PK Ps 128, CR 13, 1211. „et addit promissiones, ut consoletur nos in tanta mole periculorum privatorum et publicorum.“

792 PK Ps 8, CR 13, 1032. „et haec liberatio hic praedicitur ac celebratur.“

${ }^{793}$ Vgl. PK Ps 22, CR 13, 1049. „Nam etiam David de se quoque loquitur, et similia patitur, tamen scit suas afflictiones et liberationes imagines esse afflictionum et victoriarum Christi, quas secutura erat Evangelii propagatio et collectio Ecclesiae.“
} 
die Kirche ehrenhaft befreit, von Gott regiert. Wenn der Erlöser kommt, vollendet sich die Kirche in der allgemeinen Auferstehung. ${ }^{794}$ Nach Melanchthon ist die Freiheit der Kirche die Freiheit vom gegenwärtigen Leiden, der Verachtung der Gottlosen und den großen Bedrängnissen. Wenn auch die Gegner Gottes sich über das Leiden der Kirche freuen und behaupten, dass die Kirche von Gott abgelehnt werde, sind ihre Freude und ihr Urteil falsch. Im Gegenteil - die Kirche ruft in der Gefahr und dem Schmerz Gott an und sieht die Freiheit. ${ }^{795}$ Gott gibt der Kirche die Freiheit in den großen Bedrängnissen. ${ }^{796}$

Außerdem weist Melanchthon auf Beispiele der Vernichtung der Gegner hin, wie in den Psalmen geschrieben steht. Dadurch kann die Kirche auch im Leiden Gott um die Freiheit bitten und sie erwarten. ${ }^{797}$ Und die Beispiele von David und den Vorfahren lassen die Kirche die Verheißung Gottes zu ihrer Bewahrung und die Hilfe erkennen. Deshalb soll die Freiheit der Kirche erbeten werden. ${ }^{798}$ So ruft die Kirche in der Gefahr, dem Streit und dem Leiden Gott an, und Gott offenbart sich mit den bestimmten Zeugnissen und befreit die Kirche. Das ist die Gnade Gottes und das Geschenk. ${ }^{799}$ Durch diese Beispiele soll die Kirche stärker werden, das Leiden erdulden, mit der Erkenntnis über den Willen Gottes und die Gegenwart getröstet werden und auf die Freiheit hoffen. ${ }^{800}$

Melanchthon fordert auf, dass die Kirche sich daran erinnern soll, dass eine Ursache der Gefahr und des Leidens der Kirche die noch in der Kirche verbliebene Sünde ist. Gott erlaubt deswegen das Leiden der Kirche, und die Kirche erduldet das Leiden und erbittet die Verge-

\footnotetext{
${ }^{794}$ PK Ps 14, CR 13, 1038. „cum veniet Messias, et suum regnum incoabit, et gloria ornabit, quod coepit Christus facere in resurrectione sua, et perficiet in universali resurrectione."

${ }^{795}$ PK Ps 6, CR 13, 1027. „Ipsum autem exemplum liberationis Davidis testimonium est promissionis. Ideo in nostris periculis et aerumnis legamus haec exempla, et credamus nos quoque exaudiri et impetrare mitigationem poenarum et liberationem.“"

${ }^{796}$ PK Ps 13, CR 13, 1037. „exaudiat, iuvet, opem ferat, non deserat adflictos, sed pro calamitate retribuat liberationem.“

${ }^{797}$ PK Ps 9, CR 13, 1033. „Generalis gratiarum actio est pro deletis hostibus, et adplicatio exempli ad reliquam Ecclesiam, cui hoc exemplum proponit, ut nos ad eundem modum in nostris aerumnis petamus a Deo, et expectemus liberationem.“

${ }^{798}$ PK Ps 28, CR 13, 1060. „Sic igitur exempla liberationis Davidicae legamus, et ut nobis promitti auxilium statuamus, ac praecipi discamus, ut talibus commonefacti exemplis liberationem petamus et expectemus." Vgl. PK Ps22, CR 13, 1049.

${ }^{799}$ PK Ps 18, CR 13, 1043. „Deinde recitat gloriosas liberationes, et fatetur eas Dei beneficia esse.“

${ }^{800}$ PK Ps 52, CR 13, 1120. „,celebrare haec exempla coram Sanctis tuis, scilicet ut ipsi etiam fiant fortiores, perferant aerumnas in confessione, et se consolentur agnitione voluntatis, et praesentiae Dei, et sperent liberationem.“”
} 
bung, weil die Kirche erkennt, dass Gott sie erhört, ihr hilft und die Freiheit für sie plant, ${ }^{801}$ wie David und Josua im großen Leiden die Milderung und die Freiheit erbeten haben. ${ }^{802}$ So hofft Melanchthon, im Leiden der Kirche seiner Zeit die Milderung der Bedrohung und die Freiheit davon zu erfahren. ${ }^{803}$ Gott befreit so die dem Haus Gottes Dienenden, nämlich die Kirche. ${ }^{804}$ Er befreit den Anrufenden. Deshalb bezeichnet Melanchthon die Verheißung Gottes als die Bitte um Hilfe und als die Hoffnung. ${ }^{805}$

Melanchthon sagt, dass die von Gott verheißene Freiheit aber komplett umfassend erst im ewigen Leben erfahren wird. Die Kirche ist ewig und wird am Ende von der Sünde, dem Tod, der Tyrannei des Teufels und dem Leiden befreit. ${ }^{806}$ Aus diesem Grund ist es für Melanchthon irrig, die menschliche Fähigkeit, die Kraft und den Willen höher zu achten als Gott. Die menschliche Kraft kann die Menschen aus dem ewigen Tod nicht erretten. Aber die Frommen werden auch aus den großen Bedrängnissen gerettet und befreit. Dazu schmückt Gott die Kirche mit dem ewigen Guten, dem Leben, der Weisheit und der Freude in jenem Leben. ${ }^{807}$

In diesem Leben soll die Kirche allein die Verheißung Gottes von der Freiheit mit dem Glauben festhalten ${ }^{808}$ und die Freiheit nach dem Plan Gottes erbitten und erwarten. ${ }^{809}$ Melanchthon ist überzeugt davon, dass die Kirche zwar unter das Joch des Leidens gedrückt ist, schließlich aber davon befreit wird. ${ }^{810}$ Die Kirche klagt im Leiden, zugleich aber bittet und

${ }^{801}$ PK Ps 32, CR 13, 1066. „et sciunt se vere exaudiri a Deo, et iuvari, et tandem liberationem propositam esse.“

802 PK Ps 38, CR 13, 1077. „sunt precationes in quibus petit David mitigationem ingentium calamitatum et liberationum,“ PK Ps6, CR 13, 1026. „Itapropter gloriam Dei liberationem petimus. Sicut precatur Iosue in summo periculo“

${ }^{803}$ PK Ps 42, CR 13, 1087. „et sperabo mitigationem calamitatis et liberationem.“

${ }^{804}$ PK Ps 52, CR 13, 1119. „,in quibus Deus testatur, se liberaturum esse servientes in domo Dei, id est, Ecclesiae, invocantes ipsum, servientes sive in docendo, sive in aliis vocationibus necessariis."

${ }^{805}$ PK Ps 52, CR 13, 1120. „ut extent exempla promissionum, quae alios invitent ad petendum et sperandum et expectandum auxilium, ut hac vera et salutari consolatione sustententur,“

${ }^{806}$ PK Ps 47, CR 13, 1098. „,certo mitti Messiam, et per eum colligi Ecclesiam aeternam, liberandam a peccato, morte, tyrannide diaboli, et ab omnibus calamitatibus.“

${ }^{807}$ PK Ps 49, CR 13, 1106. „At econtra pii etsi nunc sunt in magnis aerumnis, tamen in ipsa morte liberabuntur, et a Deo ornabuntur aeternis bonis, vita, sapientia, iusticia, laeticia, in illa aeterna consuetudine Ecclesiae.“

${ }^{808}$ PK Ps 53, CR 13, 1124. „Deus tradidit promissiones, et adfirmat Messiam liberaturum esse Ecclesiam ipsum invocantem, haec consolatio et hic proponitur.“

${ }^{809}$ PK Ps 52, CR 13, 1122. ,et petant ac expectent liberationem iuxta Dei consilium.“

${ }^{810}$ PK Ps 53, CR 13, 1123. ,altera promittit oppressae Ecclesiae liberationem, ac significat interea Ecclesiam ingentibus aerumnis oneratam esse" 
lobt sie Gott um der erwarteten Freiheit willen. ${ }^{811}$ Die Kirche erduldet im Bekenntnis das Kreuz und erwartet das ewige Leben. ${ }^{812}$ Gott befreit die Kirche auf wunderbare Weise. ${ }^{813}$

Obwohl die Verheißung über die Freiheit sich erst im ewigen Leben vollendet, erfährt die Kirche die Freiheit auch bereits in diesem Leben. Melanchthon erklärt im PK, wie das Leiden der Kirche in den Zeiten besteht, wie die Kirche die Freiheit erbittet und erwartet und wie die Kirche durch die gnädigen Handlungen Gottes aus den großen Verfolgungen befreit wird. Dabei wird die Gegenwart Gottes gelobt. ${ }^{814}$ Melanchthon sieht in den Psalmen die gnädigen Handlungen für die Freiheit der Kirche. ${ }^{815}$ Wenn er auch die Vollendung sieht und erwartet, richtet er seinen Blick doch auf die gegenwärtige Situation der Kirche seiner Zeit im schweren Leiden. Dabei erwartet Melanchthon vor allem die Wundertaten Gottes für die Kirche.

\subsubsection{Die Übungen des Glaubens}

Damit die Kirche im Leiden die Bewahrung, den Trost und die Freiheit Gottes erfährt und sich ihrer versichert, braucht sie den Glauben. Dieser Glaube hält die Verheißung Gottes für die Kirche fest. Der Glaube ist eine menschliche Handlung auf der menschlichen Seite, aber zugleich wird dieser Glaube der von Gott erwählten Kirche erlaubt. Der Glaube wird nämlich von Gott gegeben, und aus diesem Grund soll die Kirche Gott um den Glauben bitten.

Nach der Auffassung Melanchthons sollen die Menschen sich nicht auf sich selbst verlassen, sondern allein Gott vertrauen. Aufgrund ihres Glaubens will Gott die Menschen vom Tod befreien. Das ist die Verheißung Gottes für die Kirche. ${ }^{816}$ Besonders betont Melanchthon dabei die Übungen des Glaubens. Die Kirche braucht die Übungen des Glaubens. Der Glaube soll sich in den Gläubigen entwickeln. Aber die Entwicklung bedeutet keine Änderung des Inhaltes, sondern dieser Inhalt, sich allein an Gott anzulehnen, wird nur stärker im Willen verankert. Der Glaube verlässt sich nicht auf die Menschen, sondern allein auf Gott. Bei Melanchthon wird der menschliche Wille betont, aber eigentlich bedeutet seine Betonung des menschlichen Willens, die Hilfe Gottes umso dringlicher zu erbitten und zu erwarten. Deshalb

\footnotetext{
${ }^{811}$ PK Ps 60, CR 13, 1148. „Has aerumnas hic deplorat, et simul petit ac celebrat liberationes.“

${ }^{812}$ PK Ps 115, CR 13, 1181. „toleremus crucem in confessione, et alias aerumnas Ecclesiae, et aeternam liberationem expectemus."

${ }^{813}$ PK Ps 126, CR 13, 1208. „sed Deus eam liberat ita mirandis modis,“

${ }^{814}$ Vgl. PK Ps 129, CR 13, 1213. „ut haec ipsa imago ostendat, quales sint aerumnae Ecclesiae omnium temporum, et quod fide et spe petenda et expectanda sit liberatio, et celebranda sit praesentia Dei, gratiarum actione, quoties eripimur, et agnoscenda voluntas Dei,“”

${ }^{815}$ Vgl. PK Ps 34z, CR 13, 1240. „Hic Psalmus est praecipue gratiarum actio, quod ex periculo quodcunque illud fuit liberatus est.“

${ }^{816}$ PK Ps 33, CR 13, 1068. „qui ex tanta morte nos liberavit, et rursus liberabit,““
} 
richtet Melanchthon den menschlichen Willen immer auf Gott aus. Für ihn ist der Mensch ohne Gott nicht möglich.

Melanchthon weist darauf hin, dass die Kirche im Leiden die Anrufung Gottes üben soll und dass die wahre Lehre des Glaubens gelehrt werden soll. ${ }^{817}$ In der täglichen Gefahr sollen die Übungen des Glaubens geleistet werden. In der Folge lernt die Kirche die Anlehnung an Gott. ${ }^{818}$ Der Fortgang der Übungen ist nicht leicht. Durch das ungeheure Leiden werden die Frommen geübt. Zwar prosperieren die Gottlosen, ${ }^{819}$ doch soll die Kirche in diesem Leben trotzdem an den Übungen des Glaubens festhalten. ${ }^{820}$

Diese Übungen des Glaubens sind nach Melanchthon kein abgeschiedener Monolog, weil Gott der Kirche die Verheißung über die Hilfe und die Bewahrung gegeben hat. ${ }^{821}$ Man kann diesen Glauben nicht herstellen. Die Gläubigen sollen üben, von dem Vater Jesus Christi, dem Schöpfer der Menschen und der Kirche, die Hilfe zu erbitten und zu erwarten. ${ }^{822}$ So wünscht Gott, dass die Kirche im neuen Leiden geübt wird. ${ }^{823}$ Durch diese Übungen lernt die Kirche mit der Bekehrung und der Anrufung diesen Glauben. ${ }^{824}$

Dieser Glaube zeigt auch das Vertrauen auf den Vermittler, den Messias. Die Kirche leistet die Übungen, indem sie erwartet, dass das Gebet um des Vermittlers willen erhört wird. ${ }^{825}$

${ }^{817}$ Vgl. PK Ps 2, CR 13, 1021. „Sed Prophetae inculcarunt veram de fide doctrinam, et postea Christus et Apostoli. Et haec discenda est in veris exercitiis invocationis.“

${ }^{818}$ PK Ps 110, CR 13, 1165. „Discamus autem in his quotidianis periculis exercere fidem, invocationem et spem, petamus et expectemus auxilium et defensionem a Filio Dei, et doctrinam pie sonemus,"

${ }^{819}$ PK Ps 49, CR 13, 1103. ,et interea impii floreant potentia, opibus et imperiis, et fruantur voluptatibus, maxima pars generis humani ignara cur Deus subiecerit Ecclesiam cruci, appetit haec commoda praesentis vitae, potentiam, opes, voluptates, et fugit aerumnas."

${ }^{820}$ PK Ps 130, CR 13, 1214. „Hae promissiones non tantum ad initium conversionis pertinent, sed ad exercitium fidei in tota vita."

${ }^{821}$ Vgl. PK Ps 37, CR 13, 1077. „Timor obediat, et fides intuens Deum statuat nos iuvari et tegi a Deo, ac petat et expectet bonos eventus. Ac in talibus exercitiis lux fidei in omni vita crescere debet.“

${ }^{822}$ PK Ps 54, CR 13, 1127. „Talibus sententiis et exemplis nos quoque in his calamitatibus fidem confirmemus, et petere et expectare auxilium a Deo aeterno patre Domini nostri Iesu Christi conditore generis humani et Ecclesiae discamus, in talibus exercitiis et Psalmi nobis fient perspicui, et quid sint fides, spes et invocatio, melius discemus.“

${ }^{823}$ PK Ps 60, CR 13, 1150. ,sicut subinde in novis aerumnis exercetur Ecclesia“

${ }^{824}$ PK Ps 110, CR 13, 1166. „Haec saepe cogitanda sunt, ut nos ad exercitia poenitentiae, fidei et invocationis exuscitemus."

${ }^{825}$ PK Ps 44, CR 13, 1091. „Ita placebit Deo precatio et erit efficax, cum vere credimus nostros gemitus et nostra vota exaudiri propter Mediatorem nobis donatum, propter quem misericordia promissa est. Et haec fides in invocatione exercenda est expectatione auxilii.“ 
Sie lehnt sich nicht an den Menschen im Leiden. Durch solche Übungen soll der Glaube angezündet werden. ${ }^{826}$ So verbindet das Leiden die Anrufung mit den Übungen des Glaubens.

\subsubsection{Das Leben als der Grottesdienst}

In diesem Leben rufen die Mitglieder der Kirche im Leiden Gott an und leisten die Übungen des Glaubens. So entwickeln sich die Mitglieder der Kirche dazu, wahrhaft Gott zu dienen. Aus diesem Grund erklärt Melanchthon, dass der Glaube die Gott sehende Erkenntnis ist und dass das Streben und der Schmerz der Kirche zum Dienst Gottes werden. ${ }^{827}$

Ohne die Furcht Gottes und den wahren Glauben ist - nach Melanchthon - der Dienst eine bloße Zeremonie. ${ }^{828}$ Der Dienst, den Gott fordert, hat die Anrufung, den Glauben, die Hoffnung, die gnädigen Handlungen und das Lob zur Grundlage und lädt andere zum Glauben, der Hoffnung und dem wahren Dienst ein. ${ }^{829}$ So wird der wahre Dienst gefordert. ${ }^{830}$ Dieser Dienst muss gelehrt werden. ${ }^{831}$

Die Gottlosen selbst machen ihren Dienst weitab von dem Wort Gottes. Beispiele solcher Art bei Mahomet, dem Papst und Mönchen. ${ }^{832} \mathrm{Zu}$ dieser Gruppe gehören auch Priester und Canonisten. Und der Streit mit ihnen wird durch die Lehre der Unterscheidung zwischen dem wahren Dienst und dem irrigen verursacht. ${ }^{833}$ Nach Melanchthon handelt die Reformation vom wahren Dienst nach dem Wort Gottes gegen den irrigen Dienst weitab von dem Wort Gottes. Deshalb sollen der Glaube, die Hoffnung, die Anrufung und die gnädigen Handlungen in den Gläubigen erweckt werden. Sie sollen die Hilfe Gottes erbitten und erwarten. Dieser Dienst macht den Unterschied zwischen der Kirche Gottes und den Heiden aus. ${ }^{834}$ Melan-

\footnotetext{
${ }^{826}$ PK Ps 33, CR 13, 1067. „Accendi igitur et crescere fidem huius invocationis exercitio oportet.“

${ }^{827}$ PK Ps 11, CR 13, 1036. „Nam haec fides est agnitio intuens Deum, et facit ut nostri labores et aerumnae fiant cultus Dei,“"

${ }^{828}$ PK Ps 51, CR 13, 1118. „Ceremoniae non sunt cultus Dei, sine vero timore et vera fide,“

${ }^{829}$ PK Ps 56, CR 13, 1131. „et hos cultus tu praecipue postulas, invocationem, fidem, spem, gratiarum actionem, celebrationem, ut alii quoque ad agnitionem, fidem, spem et ad veros cultus invitentur."

${ }^{830}$ PK Ps 47, CR 13, 1098.

${ }^{831}$ PK Ps 47, CR 13, 1099. „quidem monet qui cultus sit praecipuus cum ait, Psallite sapienter. “

${ }^{832}$ PK Ps 119, CR 13, 1189. ,fingentes sua dogmata et suos cultus, ut Mahomet, Papa, monachi operantur iniquitatem, id est, displicentia Deo, damnata,“

${ }^{833}$ PK Ps 50, CR 13, 1112. „ut nunc Pontifices, Canonici et Monachi ceremonias suas magna crudelitate defendunt. ... Semper doctrina de discrimine veri et falsi cultus magna certamina excitavit, ut ostendunt Prophetarum, Christi et Apostolorum contentiones.“

${ }^{834}$ PK Ps 57, CR 13, 1134. ,et Deum sic velle coli, ut fides, spes, invocatio, gratiarum actio in nobis excitentur, et hos cultus sciamus discrimen efficere inter veram Dei Ecclesiam, et inter Ethnicos, imo inter vere invocantes et hypocritas:“
} 
chthon hält die Anlehnung an Gott, den Gehorsam gegenüber den Befehlen Gottes maßgeblich dafür, ob man Gott wahrhaft dient.

Nach Melanchthon ist der gerecht Handelnde keiner, der bloß seinen Dienst verrichtet. Die Gerechten leisten den von Gott überlieferten Dienst. ${ }^{835}$ Dieser Dienst ist außergewöhnlich und für die menschliche Vernunft nicht zu erfassen. Deshalb soll der Glaube durch die Übungen der Anrufung angezündet und entwickelt werden. ${ }^{836}$ Melanchthon erklärt, dass die Frommen nicht ihren eigenen Dienst machen. ${ }^{837}$ Weil sie den Befehl Gottes respektieren, ist ihr Dienst Ausdruck der Furcht Gottes. ${ }^{838}$ Gott wünscht kein Opfer aus den vollzogenen sakramentalen Handlungen. ${ }^{839}$ Das Leiden der Kirche in diesem Leben ist ein Dankdienst. ${ }^{840}$ Der Gottesdienst, der nach dem Wort Gottes durch die Anlehnung an dem Vermittler geleistet wird und der durch die Stimme des Evangeliums gelehrt wird, ist der reine Dienst. Dieser Dienst erfreut Gott und ist ewig. ${ }^{841}$ Aus diesem Grund weist Melanchthon darauf hin, dass der äußere Dienst ohne den inneren Dienst nichts ist. ${ }^{842}$

Die Kirche erfreut Gott in diesem Leben im Leiden mit der Darbringung der Lippe, mit der Anrufung, dem Bekenntnis, der Verbreitung und dem Studium der Lehre und bringt die Dienste Gott dar. ${ }^{843}$ Melanchthon erklärt, dass die Anrufung in der Kirche ein besonderer Dienst Gottes ist. ${ }^{844}$ Deshalb behauptet er, dass der beste Dienst Gottes in der Kirche ist. ${ }^{845}$ Es ist der darbringende und Gott erfreuende Dienst, dass die Kirche im Leiden Gott anruft und

\footnotetext{
${ }^{835}$ PK Ps 15, CR 13, 1040.

${ }^{836}$ PK Ps 33, CR 13, 1067. „Hos cultus monet esse praecipuos et ignotos humanae rationi. Accendi igitur et crescere fidem huius invocationis exercitio oportet."

${ }^{837}$ PK Ps 131, CR 13, 1216. ,non instituam cultus“

${ }^{838}$ PK Ps 128, CR 13, 1211. „Timor Dei significat cultum non simulatum,“

${ }^{839}$ PK Ps 51z, CR 13, 1232. „Deus non vult haec sacrificia cum opinione, quod sint cultus ex opere operato, aut quod mereantur remissionem peccatorum.“

${ }^{840}$ PK Ps 16, CR 13, 1040. „Nostrae afflictiones etsi fiunt sacrificia propter Christum fide, id est, cultus grati Deo, tamen non merentur aliis remissionem peccatorum."

${ }^{841}$ PK Ps 19, CR 13, 1046. „hic cultus Dei, quem docet vox Evangelii, est mundus, Deo placens et aeternus."

${ }^{842}$ PK Ps 51z, CR 13, 1232. „quia externi cultus nihil sunt sine interiore cultu.“

${ }^{843}$ PK Ps 119, CR 13, 1197. „oblationes oris mei, invocatio, confessio, propagatio et studia doctrinae placeant tibi. Hos cultus offert Deo, et significat veros cultus esse, non mactationes pecudum,“

${ }^{844}$ Vgl. PK Ps 111, CR 13, 1169. „David cum expellitur in exilium erigit se fide, et statuit se habere remissionem peccatorum propter Mediatorem. Deinde petit et expectat reductionem, et tamen paratus est ad poenam, nec amittit interea aeternam consolationem, scit Deo se debere hunc honorem et hunc cultum, credam promissioni gratiae, scit Messiam non esse contumelia afficiendum, sed potentiorem esse regno peccati et mortis,“

${ }^{845}$ PK Ps 117/118, CR 13, 1186. „vult etiam sciri hos esse summos cultus Dei in Ecclesia,“
} 
die Übungen des Glaubens leistet. Melanchthon bekennt hier die Wirklichkeit seiner Kirche. Deshalb ist die Geduld, wenn die leidende Kirche zu Gott flieht, Gott sie annimmt, erhört und ihr hilft, eigentlich der Dienst Gottes. ${ }^{846}$ Die Kirche steht fest auf der festen Verheißung Gottes, aber die Kirche ist in diesem Leben schwach, deshalb ist die Anlehnung an Gott noch schwierig für die Kirche, und die Kirche braucht die Übungen des Glaubens mit der Geduld. So ist bei Melanchthon die Wirklichkeit der leidenden Kirche ein Dienst der Geduld.

\subsubsection{Zusammenfassung}

Wenn die Kirche im Leiden Gott um Hilfe bittet, hat die Kirche keinen Zweifel an der Erhörung durch Gott, weil Gott der Kirche die Verheißung der Erhörung gegeben hat. Das Leiden der Kirche besteht im Willen Gottes, der die Anrufung in der Kirche wünscht. So wird die Verheißung der Erhörung in diesem Leben zum Nutzen der Kirche gegeben. Aber dagegen werden die Gottlosen, die keine Verheißung der Erhörung erhalten, das fürchterliche Elend erfahren.

Die Kirche ruft Gott nach seiner Verheißung im Leiden an, dann erhört Gott die Anrufung, mildert das Leiden und gibt der Kirche den Trost sowohl im ewigen Leben als auch in diesem Leben. Die Freiheit, die der Kirche gegeben wird, wird auch in diesem Leben verheißen, obwohl die Freiheit in diesem Leben nicht vollständig wäre. Deshalb soll die Kirche mit dem Glauben die Verheißung Gottes festhalten. Damit die Kirche die Bewahrung, den Trost und die Freiheit erfährt, braucht sie den Glauben in diesem Leben. Aus diesem Grund soll die Kirche den Glauben im Leiden üben. Durch diese Übungen des Glaubens entwickelt sich die Kirche dazu, Gott wahrhaft zu dienen. Dieser Dienst in diesem Leben erfreut Gott. So besteht der beste Gottesdienst in der leidenden Kirche.

Melanchthon findet in der schwierigen Wirklichkeit seiner Kirche einen schönen Dienst Gottes. Gott wünscht der leidenden Kirche einen wahren Dienst.

\footnotetext{
${ }^{846}$ PK Ps 51, CR 13, 1118. „Ideoque adfirmat adflictos confugientes ad Deum vere recipi, exaudiri et iuvari, et tolerantiam ipsam gratum Deum cultum esse.“
} 


\subsection{Zusammenfassung}

Im PK steht die Kirche immer in der Mitte. Die wahre Gotteserkenntnis, die Gotteseigenschaften kann man allein in der Beziehung zur Kirche erhalten, weil in der Kirche die Offenbarung Gottes besteht. Insbesondere zeigt sich bei der Kirche der Zusammenhang zwischen dem Gesetz und dem Evangelium. Im allgemeingültigen Prinzip Gottes steht die Kirche noch in der Mitte. Durch das Gesetz werden alle Menschen zum Tod verurteilt, aber Gott verheißt einen anderen Weg für die Erlösung der Kirche, nämlich die Gesetze, die sich auf das Evangelium beziehen und es vollenden. Die Lösung Gottes für die Erlösung gilt allein für die Kirche. So nimmt die Kirche das von Gott verheißene Evangelium durch den Glauben an, wird gerechtfertigt, bekehrt sich zu Gott, legt die Buße ab, wird befreit und lebt mit dem Glauben und dem guten Gewissen, um Gott zu erfreuen.

Melanchthon konzentriert sich auf das wirkliche Leben der Kirche, die in diesem Leben unter das Leiden gemäß des Willens Gottes geworfen ist. Aber das Leiden der Kirche besteht nicht als Strafe, sondern zum Nutzen für die Kirche. Aus diesem Grund soll die Kirche dem Willen Gottes gehorchen, das Leiden durch den Glauben erdulden und um die Milderung des Leidens und die Hilfe Gottes bitten. Dieses Anliegen Melanchthons zeigt sich im PK. Daher ist der PK keine allein wissenschaftlichen Auslegungen ohne die Beziehung zur Wirklichkeit der Kirche, sondern eine Auslegung, die das aktuelle Leben der Kirche spiegelt.

Das Anliegen Melanchthons im PK liegt so auf dem Leben der Kirche, nämlich auf der Heiligung der Kirche. Im Lauf der Heiligung gibt Gott der Kirche das Leiden, und die Kirche entwickelt sich durch das Leiden. Wahrhaftig ist die Verheißung Gottes die Freiheit und die Milderung des Leidens in diesem Leben. Dadurch wird der Glauben der Kirche geübt.

Bei Melanchthon sind die Rechtfertigung und die Heiligung unterschieden, aber beide bestehen aus einer gleichen Regel. Gott gibt der Kirche die Verheißung, und die Kirche nimmt die Verheißung durch den Glauben an. Insofern kann man eine Einheit von der Rechtfertigung und der Heiligung sehen. Bei Melanchthon sind die Rechtfertigung und die Heiligung nicht getrennt. Bei beiden wirkt Gott erst mit der Verheißung, und der Mensch handelt aktiv unter der Wirkung Gottes. Infolge dessen entstehen Bekehrungen, Buße, die Zuflucht zu Gott und das das Gesetz Gottes Einhalten mit dem Glauben und dem guten Gewissen anlehnend an Gott.

Nach Melanchthon sind Rechtfertigung und Heiligung Wirkungen Gottes. Der Mensch ist dabei aktiv, aber unter der Wirkung Gottes, die an denen menschlichen Handlungen vorausgesetzt wird. Wie erwähnt, kann die menschliche Vernunft die Wirkung Gottes nicht bemer- 
ken, allein ist die Wirkung Gottes durch die Äußerungen der heiligen Schriften zu verstehen. Daher versucht Melanchthon, die Äußerungen der heiligen Schriften mit den Erfahrungen der Gläubigen übereinstimmend zu erklären. Melanchthon findet in den Psalmen die Wirkung Gottes für die Kirche und will sie seiner Kirche sichtbar machen. So sieht Melanchthon die leidende Kirche und stellt so der Kirche den Trost und die Bewahrung gemäß der Verheißung Gottes vor.

Die Erklärung Melanchthons über die Lehre im PK geht immer von der Erfahrung der Gläubigen aus. Er erklärt den Glauben, die Bekehrung und die Buße als eine menschliche Handlung, aber dabei ist nicht gemeint, dass der Mensch selbst ohne die Wirkung Gottes ein gutes Werk tun könne, sondern dass der Mensch Gott allein durch die Wirkung Gottes im Mensch erfreuen kann. Diese Erklärung Melanchthon beruht nicht auf Spekulationen über die göttliche Lehre, sondern auf Erfahrungen der Gläubigen. Er erkennt die Wirkung Gottes in den Gläubigen an, aber wenn Gott in den Gläubigen wirkt, können die Gläubigen die Wirkung nicht bemerken, wie die menschliche Vernunft die Wirkung Gottes nicht bemerken kann. So wehrt Melanchthon eine Spekulation über die Wirkung Gottes und die des menschlichen Freiwillens ab und versucht nach der Betrachtung von den Äußerungen der heiligen Schrift und der Erfahrungen der Gläubigen eine logische Erklärung darzustellen.

Im PK will Melanchthon den Willen und den Trost Gottes für die Wirklichkeit seiner leidenden Kirche durch die Wirkung Gottes und die Erfahrungen der Kirche zeigen. 


\section{Vergleich und Einfluss}

Die Psalmen sind die am meisten geliebte Schrift unter den biblischen Schriften. ${ }^{847}$ In der Reformationszeit lieben und lesen insbesondere die Reformatoren die Psalmen. Bevor Melanchthon in der Mitte des 16. Jahrhunderts seine Psalmenvorlesung an der Wittenberger Universität hielt, hatten schon die wichtigen Reformatoren ihre Psalmenkommentare veröffentlicht. Darunter waren die Wittenberger Kollegen, Martin Luther ${ }^{848}$ und Johannes Bugenhagen, ${ }^{849}$ dazu der Straßburger Reformator Martin Bucer. ${ }^{850}$ Sie verfassten ihre Psalmenkommentare in den 1520-er Jahren. Der Genfer Reformator, Johannes Calvin, hielt seine Vorlesung zu den Psalmen in den 1550-er Jahren und veröffentlichte seinen Psalmenkommentar im Jahre 1557. ${ }^{851}$ Nicht allein in der evangelischen Kirche wurden die Psalmen viel beachtet, sondern auch in der katholischen Kirche. So erforschte Cajetan die Psalmen und veröffentlichte seinen Psalmenkommentar 1530. ${ }^{852}$ Ich werde im Folgenden die Exegese und die Theologie dieser Psalmenkommentare betrachten und sie mit der Auffassung Melanchthons vergleichen. Abschließend werden auch die Loci Melanchthons mit seinem Psalmenkommentar verglichen.

\subsection{Luther}

\subsubsection{Die PKe Luthers}

Nach Ebeling war die Methode der theologischen Arbeit Luthers die Exegese. ${ }^{853}$ So enthüllt sich die Theologie Luthers durch seine Exegese. Besonders die Psalmen sind für Luther von Bedeutung. Luther wertet die Psalmen als eine der tiefsten prophetischen biblischen Schriften. Die Auslegung der Psalmen sei ebenso wichtig wie die der Paulusbriefe. ${ }^{854}$ Mit den

\footnotetext{
847 Über die Psalmen in der alten Kirche und dem Mittelalter siehe Sæbø 1996 und Sæbø 2000.

${ }^{848}$ Luther hielt drei Psalmenvorlesungen(1513-1515, 1519-1521 und 1532-1535) an der Wittenberger Universität und legte sieben Bußpsalmen vor(1517). Über die ausführliche Information siehe Kapitel 5.1.1.

${ }^{849}$ Bugenhagen hielt die Psalmenvorelsung(1521-1522 oder 1523) an der Wittenberger Universität. Über die ausführliche Information siehe Kapitel 5.2.1.

${ }^{850}$ Bucer hielt die Psalmenvorlesung(1528-1529). Über die ausführliche Information siehe Kapitel 5.3.1.

${ }^{851}$ Calvin hielt die Psalmenvorlesung(1554) in der Genfer Schule. Über die ausführliche Information siehe Kapitel 5.4.1.

${ }^{852}$ Cajetan legte den Psalmenkommentar(1530) vor. Über die ausführliche Information siehe Kapitel 5.5.1.

${ }^{853}$ Ebeling 1951, S.174.

${ }^{854}$ Beintker 1986, S.8.
} 
Psalmen arbeitet und betet Luther in seinem ganzen Leben. ${ }^{855}$ Für ihn sind die Psalmen eine besondere Quelle der Frömmigkeit und der Theologie.

Im Oktober 1512 promoviert Luther in Wittenberg und wird dann in den Senat der theologischen Fakultät aufgenommen. Dann hält er die Psalmenvorlesung (Dictata super Psalterium $)^{856} 1513-1515$ wahrscheinlich als die erste, die die ganzen Psalmen umfasst. ${ }^{857}$ Danach beschäftigt er sich mit den paulinischen Schriften.

1518 kehrt Luther wieder zum Psalter zurück. Er wollte in der Vorlesung ursprünglich alle Psalmen behandeln, aber er muss bei der Auslegung von Ps 22 wegen des Aufenthaltes auf der Wartburg 1521 abbrechen. ${ }^{858}$ Das Ergebnis der zweiten Psalmenvorlesung ist Operationes in psalmos. ${ }^{859}$

Dazwischen, im Frühling 1517, veröffentlicht er die sieben Bußpsalmen. ${ }^{860}$ Schon vor den Ablassthesen 1517 kann man daraus die Auffassung Luthers über die Buße ersehen. Dann 1525 kam die Revision der sieben Bußpsalmen. ${ }^{861}$ Dabei waren die damaligen Umstände wirksam. Erstens die Auseinandersetzung über die Willensfreiheit mit Erasmus, zweitens der Streit mit den Radikalen, z.B. Karlstadt und Thomas Müntzer. ${ }^{862}$

1532-1535 hält Luther nochmals die Psalmenvorlesungen, behandelt aber nicht alle Psalmen, sondern nur einige ausgewählte (Ps 2, 51, 45, Stufenpsalmen (Ps 120-134) und 90). ${ }^{863}$ Vielleicht wegen seiner gesundheitlichen Probleme wollte er damals nicht versuchen, alle Psalmen in der Vorlesung zu behandeln. ${ }^{864}$

\subsubsection{Exegese}

Bei der Betrachtung von Luthers Exegese der Psalmen muss darauf geachtet werden, dass Luther eigentlich kein Interesse an dem formalen Problem der Hermeneutik hat. Vielmehr war das Problem der Erlösung wichtiger für Luther. Deshalb stimmt es nicht, dass Luther durch

\footnotetext{
${ }^{855}$ Aurelius 2000, S.195.

${ }^{856}$ WA 3(Ps 1-83), WA 4,1-462(Ps 84-150). Und WA 55,I(Neue Ausgebe der Glossenexegese) und WA 55,II(Neue Ausgabe der Scholien).

${ }^{857}$ Brecht 1983, S.127f.

${ }^{858}$ Mikoteit 2004, S.3.

${ }^{859}$ AWA 2.

${ }^{860}$ Erste Bearbeitung 1517. WA 1,154-220.

${ }^{861}$ Zweite Bearbeitung 1525. WA 18,467-530.

${ }^{862}$ Seiling 2006, S.30.

${ }^{863}$ Mikoteit 2004, S.3. Vgl. WA 40,II,185-610(Ps 2, 51 und 45), WA 40,III,1-475 (Stufenpsalmen) und WA 40,III,476-594 (Ps 90).

${ }^{864}$ Brecht 1987, S.157.
} 
die Prinzipien der neuen Hermeneutik eine neue exegetische Einsicht gewinnt. ${ }^{865}$ Umgekehrt ließ seine exegetische Mühe um die Erlösung ein neues hermeneutisches Ergebnis entdecken. Aus diesem Grund ist die theologische Einsicht bei Luther wichtiger als die exegetische. Aber nicht als eine vollständige Form der reformatorischen Exegese, sondern als eine zu entwickelnde gibt Luthers Exegese eine bedeutende Einsicht. Denn die reformatorische Tendenz bei der Exegese findet sich in der Abkehr von dem philosophischen Schriftverständnis und der Hinwendung zum christologischen Schriftverständnis, von abstrakter zu konkreter und von gesetzlicher zu evangelischer Auslegung. ${ }^{866}$ Aus den Psalmenauslegungen Luthers ist die Entwicklung seiner formalen und inhaltlichen Exegese zu ersehen.

Weil Luthers hebräische Sprachkenntnisse während seiner ersten Psalmenvorlesung noch gering waren, wendete er für seine Auslegung der Psalmen Hilfsmittel an, wovon einige von den zeitgenössischen Humanisten gefasst waren, z.B. Faber Stapulensis, Reuchlin, Lyra und Burgensis. ${ }^{867}$ Deswegen ist es klar, dass bei der Auslegung durch Luther eine humanistische Anregung besteht.

Aber in den Dictata finden sich noch die mittelalterlichen Methoden der Exegese in der Form und der Auslegung. Er wendet die Form von glossa und scholia an und behandelt nicht ganze Verse des Psalms. Z.B. konzentriert Luther sich bei der Scholia der Auslegung zu Ps 51 überhaupt nur auf die Verse 4-6. ${ }^{868}$ Das entspricht der mittelalterlichen Methode. Dazu wendet er noch die vierfache Auslegung (quadriga) als Auslegungsmethode an. Die vierfache Auslegung über den Berg Zion ist in dieser Hinsicht repräsentativ. ${ }^{869}$ So verwendet Luther traditionelle Ausdrücke, aber die Bedeutungen sind jeweils anders, z.B. für Christus selbst prophetisch, für die Kirche allegorisch und für die Christen tropologisch. ${ }^{870}$ Bei den Dictata Luthers finden sich also beide Charaktere der humanistischen und der mittelalterlichen Exegese.

Luther verwendete die vierfache Auslegung, aber nicht im mittelalterlichen Sinn. Nach der Auffassung Luthers richtet der Text der Psalmen sich auf Christus. ${ }^{871}$ Die Psalmen sind

\footnotetext{
${ }^{865}$ Ebeling 1991, S.276

${ }^{866}$ Ebeling 1991, S.275.

${ }^{867}$ Über die Hilfsmittel, die Luther bei der ersten Psalmenvorlesung anwendete, siehe Raeder 1961, S.3f. und Paul 2015, S.7.

${ }^{868}$ WA 3,287f.

${ }^{869}$ WA 3, 11,22-32.

${ }^{870}$ Wicks 2010, S.31.

${ }^{871}$ Vgl. Ebeling 1991, S.279.
} 
der prophetische Text, der von Christus spricht, und das meint den literarischen Sinn des Textes. Deshalb legt Luther die Psalmen christologisch nach dem literarischen Sinn aus, und das Alte Testament soll durch das Neue Testament ausgelegt werden. ${ }^{872}$ Für Luther ist der literarische Sinn wichtig, der sich auf Christus richtet und den anderen drei Sinnen den Grund für die Auslegung gibt. ${ }^{873}$ Deshalb ist der Bezug zu Christus für das Verständnis der Psalmen unentbehrlich. Anders gesagt, erschließt das Verständnis über Christus den schwierigen Text. $^{874}$

Bei den sieben Bußpsalmen bleibt noch die Form von glossa und scholia erhalten. Dazu bleiben noch die typologische und die allegorische Auslegung bei. ${ }^{875}$ Aber allmählich legt die exegetische Methode Luthers die mittelalterliche Farbe bei der Form und der Auslegung ab. Besonders bringen die sieben Bußpsalmen die evangelische Theologie über die Buße deutlich zum Ausdruck. Im Mittelalter wird z. B. die Sünde quantitativ verstanden, und die Kirche hat das Recht, die Strafe zu tragen. Aber nach der Auffassung und der Erfahrung Luthers ist dies nicht möglich. ${ }^{876}$

Bei den Operationes bricht Luther mit der mittelalterlichen Form, nämlich glossa und scholia. Und es tritt die allegorische Auslegung zurück und er weicht von der vierfachen Auslegung ab. ${ }^{877}$ Luther weiß um das Wesen der vierfachen Auslegung. Bei der vierfachen Auslegung besteht keine Autorität, sondern die Meinungen der Exegeten sind für die Auslegung allein wichtig. Bei den scholastischen Auseinandersetzungen sind die drei Begriffe (Allegorie, Anangogie und Tropologie) von besonderen Gewicht. ${ }^{878}$ Aber bei Luther ist die Rolle der Allegorie begrenzt. Die Allegorie dient nicht dem Beweis. ${ }^{879}$ Bei Luther ist die allegorische Auslegung „ein Mittel der applicatio und der Einübung in die Denkweise der Schrift.“ 880

Litera und Spiritualis sind entscheidende Begriffe in der Hermeneutik Luthers. Für Luther ist die Heilige Schrift als das Wort Gottes spiritualis, und litera ist die menschliche Aus-

\footnotetext{
872 Ebeling 1991, S.280.

${ }^{873}$ Paul 2015, S.7.

${ }^{874}$ Ebeling 1991, S.281.

${ }^{875}$ Black 1985, S.330.

876 Throntveit 1987, S.503.

${ }^{877}$ Ebeling 1991, S.285.

${ }^{878}$ Vgl. Ebeling 1991, S.286.

${ }^{879}$ Ebeling 1991, S.286.

${ }^{880}$ Ebeling 1991, S.287.
} 
legung. ${ }^{881}$ Luther versteht die Auslegung nicht als eine menschliche Handlung, sondern als eine Handlung der Schrift. Die Auslegung wird allein durch die Gnade in dem Glauben und als Geschenk Gottes erfüllt. ${ }^{882}$

Dazu nimmt die formal christologische Deutung der Psalmen mehr und mehr ab. ${ }^{883}$ Diese Tendenz ist für die Entwicklung der reformatorischen Exegese von Bedeutung. Luther entwickelt sich aus der mittelalterlichen Tradition, aber seine nachfolgenden Reformatoren entwickeln sich aufgrund seiner reformatorischen Exegesen. ${ }^{884}$

Bei der dritten Psalmenvorlesung Luthers bleibt noch die Spur der mittelalterlichen Form erhalten. Glossa scheidet sich noch nicht ganz von Scholia, aber grundsätzlich folgt die Vorlesung der Form der Scholia. ${ }^{885}$ Dazu bestehen weiterhin die allegorische und tropologische Auslegung. Luther wendet die mittelalterliche Methode weiter an, ${ }^{886}$ aber auf der Grundlage seiner evangelischen Theologie.

Die Auslegung Luthers zu den Psalmen beginnt in der mittelalterlichen Tradition. Aber Luther hatte von Anfang an einen anderen Standpunkt, denn er hatte kein Interesse an mittelalterlichen scholastischen Auseinandersetzungen, die theoretisch und spekulativ sind, sein Interesse war auf die praktische Erlösung gerichtet. Aus diesem Grund vermeidet er die Willkürlichkeit der vierfachen Auslegung und es tritt die Allegorie mehr und mehr in seiner Auslegung zurück. Stattdessen konzentriert er sich auf den literarischen Sinn des Textes, der sich auf Christus richtet.

Die Entwicklung Luthers aus der mittelalterlichen Tradition ist auf der Seite der exegetischen Methode nicht qualitativ, sondern quantitativ. Christus mit den Psalmen oder dem Alten Testamentes zu verbinden, ist zwar auch mittelalterliche Tradition, aber es ist entscheidend für Luther, dass er Christus nicht in dem allegorischen Sinn des Textes entdeckt, sondern in dem literarischen Sinn. Spiritualis meint nicht Allegorie für Luther. ${ }^{887}$ Allerdings wendet Lu-

\footnotetext{
${ }^{881}$ Vgl. Ebeling 1991, S.288. Nach Ebeling steht Luther im Verständnis über Litera und Spiritualis gegen das alexandrinische Verständnis (Origen, Hieronymus) aber bei Augustin.

${ }^{882}$ Ebeling 1991, S.288.

${ }^{883}$ Tetz 2012, S.53.

${ }^{884}$ Es muss weiter erforscht werden, wie die exegetische Entwicklung Luthers bei anderen Reformatoren wirksam ist. Aber nach der Exegese Luthers ist es nicht nötig für die evangelischen Exegeten, die Exegese aus den traditionellen exegetischen Methoden zu beginnen. Insofern wäre die Exegese Luthers ein Modellfall der beginnenden reformatorischen Exegese.

${ }^{885}$ Black 1985, S.334.

${ }^{886}$ Black 1985, S.335.

${ }^{887}$ Ebeling 1951, S.176.
} 
ther noch die allegorische Auslegung in der späten Psalmenvorlesung an. ${ }^{888}$ Es ist klar, dass bei der Auslegung durch Luther der allegorische Charakter immer mehr auch bei der christologischen Auslegung abnimmt. ${ }^{889}$

Luther setzt sich dafür ein, die Absicht des Verfassers der Heiligen Schrift, nämlich des Heiligen Geistes, zu enthüllen. Er wollte bei der Auslegung keine allegorische Methode ausklammern, sondern die willkürliche Absicht des menschlichen Exegeten. Dabei spielt Christus eine Rolle als der externe Maßstab, um die wahre Absicht des Textes zu erfassen. ${ }^{890}$ Wenn jedoch die Allegorie oder die Metapher die wahre Absicht des Textes enthüllt, wendet er gerne diese Methode an. ${ }^{891}$ So bezieht die exegetische Auslegungsmethode sich auf die Theologie.

\subsubsection{Theologie}

Ein theologisches Thema, das häufig von den Wissenschaftlern, mit dem sich die Wissenschaftler häufig in Luthers Psalmenauslegungen auseinander gesetzt haben, ist, wann der Umbruch der reformatorischen Theologie Luther stattgefunden hat. Ob schon in Dictata der reformatorische Gedanke vorliegt, ist umstritten. Aber es ist klar, dass der exegetische und theologische Umbruch von der mittelalterlichen Tradition schon in Dictata angefangen hat. ${ }^{892}$ In den sieben Bußpsalmen findet sich deutlich die evangelische Auffassung über die Buße. Luther versteht die Sünde nicht quantitativ, sondern qualitativ und moralisch. Die Sünde soll in der Beziehung zu Gott betrachtet werden. ${ }^{893}$ Bei Operationes finden sich auch deutlich die Gotteslehre und die Christologie Luthers. ${ }^{894}$

Sofern das erste Anliegen Luthers die Frage nach der Erlösung war, spielt die Auffassung Luthers über die Buße eine wichtige Rolle, um seine Theologie zu verstehen. Die Buße beginnt mit der Erkenntnis der Sünde. Wer die Sünde nicht erkennt, macht Gott zum Lügner,

\footnotetext{
${ }^{888}$ Park urteilt, dass Luther ein mittelalterliches Element hat, weil er Ps 8 und Ps 16 als die Prophezeiung Christi auslegt. Sie hielt diese Auslegungen für die Beispiele der Auslegungsmethode der Lutheraner.(Pak 2005, S.171) Ihr Urteil ist voreilig, weil die Entwicklung der Reformation bei der exegetischen Seite nicht qualitativ, sondern quantitativ ist.

${ }^{889}$ Vgl. Tetz 2012, S.53 und Wolff 2005, S.104.

${ }^{890}$ Vgl. Hendrix 1983, S.233.

${ }^{891}$ Z.B., in der Auslegung zu Ps 22 versteht Luther die Person als Christus.(WA 5,599,9-11)

${ }^{892}$ Vgl. Ebeling sagt, „Die Dictata super psalterium sind das erste und ungewöhnlich reiche Dokument der exegetischen Arbeit Luthers und stehen in engster zeitlicher Nähe zu der in Luthers Selbstzeugnis aus dem Jahre 1545 beschriebenen reformatorischen Grundentdeckung."(Ebeling 1951, S.180) ${ }^{893}$ Vgl. Throntveit 1987, S.503.

${ }^{894}$ Beintker 1986, S.7.
} 
wehrt die Herrlichkeit Gottes ab und macht Gott durch seine Verurteilung rechtfertig. ${ }^{895}$ Nach der Auffassung Luthers bezieht die Gerechtigkeit sich nicht auf das Tun, sondern auf das Sein. ${ }^{896}$ Die Sünde liegt also in der Beziehung zu Gott. Deshalb kommt die Erlösung nicht aus irgendeiner Tugend, die ein Mensch zeigt, sondern aus der Auflösung der Sünde, die sich auf Gott bezieht. Dabei ist die Sünde ein universales Problem aller Menschen, das aus der Erbsünde resultiert. Wir tun Sünde, weil wir Sünder sind. ${ }^{897}$ Aus diesem Grund ist die Sünde für die Gläubigen kein spekulatives Problem, sondern ein täglicher schwerer Krieg, den die Kirche bekämpfen muss.

Luther erklärt die Sünde mit der wahren Buße. In der wahren Buße zeigt sich zuerst die Furcht vor Gott durch die Sündenerkenntnis und zweitens die Gotterkenntnis. ${ }^{898}$ Das Gewissen ist nicht geeignet, um die Sünde aufzulösen, sondern allein die göttliche Gnade macht die Sündenvergebung möglich. Die Gerechtigkeit, die den Menschen gezeigt wird, ist eine äußerliche, denn die Gerechtigkeit der Menschen kann die Erlösung nicht verdienen, daher kann man mit dieser Gerechtigkeit auch nicht erlöst werden. Denn diese menschliche Gerechtigkeit ist nicht vollständig vor Gott. Für die Erlösung braucht man eine Gerechtigkeit aus Gott. Diese Gerechtigkeit zu gewinnen, ist die Rechtfertigung. Die Rechtfertigung besteht aus zwei Teilen. Der erste ist die durch Christus enthüllten Gnade, nämlich sich allein an die Barmherzigkeit Gottes anzulehnen und zu der absoluten Gerechtigkeit Gottes zu fliehen, und der zweite ist die Verleihung des Heiligen Geistes, der die Erinnerung an den reichen Verdienst Christi gibt. ${ }^{899}$

Bei den Psalmenauslegungen Luthers spielt Christus eine wichtige Rolle, weil Christus sich dafür entscheidet, ob eine Auslegung legitim ist oder nicht. ${ }^{900}$ Wolff erklärt die Rolle Christi in der Auslegung Luthers so: „die Christologie ist kein Teilbereich der Theologie, sondern alles, was sie geben und womit sie dienen kann.“901 Obwohl Luther die Psalmen für die Prophezeiung über Christus hält, fordert er allerdings den Bezug auf Christus nicht immer. ${ }^{902}$ Man kann die Psalmenauslegung Luthers als christozentrisch beurteilen, aber das

\footnotetext{
${ }^{895}$ WA 3,288. Vgl. Black 1985, S.328.

${ }^{896}$ Raeder 1977, S.122.

897 Throntveit 1987, S.504.

${ }^{898}$ Black 1985, S.336 und Throntveit 1987, S.505.

${ }^{899}$ Black 1985, S.337.

${ }^{900}$ Hendrix 1983, S.233.

${ }^{901}$ Wolff 2005, S.102.

${ }^{902}$ Hendrix 1983, S.233.
} 
meint nicht, dass Luther alle Psalmen einfach zu Christus passend allegorisch auslegen würde. In der Tat liebt Luther die allegorische Auslegung nicht. ${ }^{903}$

Eine andere theologische Bedeutung der christozentrischen Auslegung der Psalmen durch Luther ist der Zusammenhang zwischen dem AT und dem NT. Nach der Auffassung Luthers zeigen die Psalmen und die Schriften des ATs eigentlich Christus und sollen durch Christus verstanden werden. Somit können das AT und das NT nicht getrennt werden. Das AT ist der prophetische Text über Christus, und das NT ist das Zeugnis der Erfüllung des prophetischen Textes über Christus. Deshalb stehen für Luther das AT und das NT nicht nebeneinander, sondern sie sind ein einheitliches Buch, das eine Geschichte erzählt. Die Einheit der Heiligen Schrift ist ein grundlegendes Thema für das Verständnis der Heiligen Schrift und die Auslegung durch Luther.

Aus der christozentrischen Auslegung durch Luther folgt auch eine praktische Bedeutung. Luther wendet die tropologische Deutung an, um die Texte auf Christus und die Kirche zu beziehen. Somit werden die Psalmen über Christus auf die Kirche angewendet. Luther konzentriert sich nicht nur auf das wissenschaftliche Ziel, sondern auch auf das praktische. Selbstverständlich erwähnt und analysiert Luther die frühen Auslegungstraditionen und erklärt seine Stellung dazu, weil er die Auslegung als eine Vorlesung an der Wittenberger Universität hielt. Allerdings war sein eigentliches Interesse die Anwendung der Psalmen auf die Kirche. Für Luther war es von Bedeutung, wie die Psalmen für seine Kirche angewendet werden können. Er betrachtet den Text theologisch durch die grammatische historische Kritik und wendet die Ergebnisse auf seine Kirche an. ${ }^{904}$ Dieser praktische Charakter findet sich deutlich in seinem Vorwort zum Psalter. Das Hauptanliegen der Psalmen sind die Heiligen der Heiligen Schrift und die Kirche, und der Grund dafür ist, dass die Psalmen das Buch für ihr beispielhaftes Leben und ihr herzliches Gebet zu Gott sind. ${ }^{905}$

Die wichtige praktische Funktion der Psalmen ist für Luther zuerst das Gebet. Die Psalmen informieren und leiten die Kirche über das Gebet. In Bezug auf die Buße ist das Leben der Gläubigen ein Krieg. Wie David in seinem schwierigen Leben um die Bewahrung gebetet hat, sollen die Gläubigen zu Gott um die Bewahrung beten. Dazu ist das Gebet für Luther

\footnotetext{
${ }^{903}$ Vgl. Wolff 2005, S.104.

${ }^{904}$ Hendrix 1983, S.238.

${ }^{905}$ WA DB 10,I,98.
} 
nicht nur eine persönliche Handlung der Einzelnen, sondern er behauptet, dass das Gebet ein wichtiges Zeichen der Kirche ist und die Kommunion aller Gläubigen. ${ }^{906}$

Die andere praktische Funktion der Psalmen ist der Trost für die Kirche. Luther wollte mit den Psalmen seine Kirche trösten. Das bezieht sich eng auf das damalige historische Umfeld. Und in den Psalmenvorlesungen finden sich die Wirkungen des Umfeldes. ${ }^{907}$ Aber das meint nicht, dass das Umfeld die Auslegung durch Luther bestimmt. Luther hat in der Auslegung zu Ps 119 seinen Dank für das Geschenk der unermesslichen Güte Gottes aufgeschrieben, trotz der Schwierigkeiten in der Zeit um 1530, z.B. seine schwere Gesundheit und die Situation des Augsburger Reichstages. ${ }^{908}$ Luther konzentriert sich in seiner Psalmenauslegung auf das geistliche Reich Christi, das in der letzten Zeit erfüllt werden wird. Und die Kirche ist dieses Reich Christi, obwohl die Kirche noch nicht vollständig ist. ${ }^{909}$

Das Problem des Leidens der Kirche war für Luther faktisch gegeben. Das Leiden bezieht sich unmittelbar auf Christus und auch auf die heutige Kirche. Beintker erklärt über die Auslegung Luthers zu Ps 22, „der angefochtene Christus, der von Gott verlassene Mensch Jesus, der sterbende und doch siegende „Menschensohn“ (und also Gottessohn) in Luthers Theologie und Glaubenszeugnis geht unseren christlichen Glauben auch heute, erst recht heute an. "910 Außerdem ist das Leiden ein Ausdruck des wahren Evangeliums und die Gegner der Kirche behindern den Frieden der Kirche. ${ }^{911}$ Aber Gott bewahrt die Kirche.

So enthüllt die Psalmenauslegung Luthers seine seelsorgerliche Intention. In der Situation, in der das gegenwärtige Leben unterschieden von der geistlichen Realität ist, wollte Luther die Leidenden trösten. So wendet Luther die Heiligen Schrift auf diese Situation des Leidens der Kirche an. ${ }^{912}$ Für Luther sind der Trost und das Gebet die Hauptfunktionen der Psalmen. Das Anliegen Luthers in seinen Psalmenauslegungen liegt in Christus und der Kirche. ${ }^{913}$

\footnotetext{
${ }^{906}$ Aurelius 2000, S.204.

${ }^{907}$ Z.B. die Revision der sieben Bußpsalmen zeigt die Wirkungen.(Vgl. Seiling 2006)

${ }^{908}$ WA 31,I,68,17-74,33. Vgl. Parsons 2011.

${ }^{909}$ Parsons 2011, S.248f.

${ }^{910}$ Beintker 1986, S.6.

${ }^{911}$ Parsons 2011, S.245.

912 Parsons 2011, S.251.

${ }^{913}$ Vgl. Wicks 2010, S.32.
} 


\subsubsection{Vergleich mit dem PK Melanchthons}

Melanchthon bezieht sich eng auf Luther bei der Auslegung zu den Psalmen. Die Vorrede der Operationes von Melanchthon ist ein Zeugnis dafür. ${ }^{914}$ Melanchthon lernte die Theologie von Luther. Allerdings lief der Einfluss nicht einseitig. Melanchthon gab Luther eine starke Impression bei der biblischen Auslegung. Luther liebte seine biblischen Vorlesungen und veröffentlichte sogar seine Schriften ohne Erlaubnis. ${ }^{915}$ Aus diesem Grund ist es nicht verwundert, dass die allmähliche Entwicklung der Exegese Luthers mit der Methode Melanchthons übereinstimmt. Durch die Zusammenarbeit von beiden gestaltete sich die Methode der biblischen Exegese in Witteberg.

In der Theologie in den PKen stimmen die theologischen Gedanken von Melanchthon und Luther über die Sünde vor Gott, die Erbsünde und die Sündenvergebung allein durch die Gnade Gottes überein. Besonders interessierten sie sich für die praktische Sache, nämlich die Anschluss der Psalmen an die Kirche, die Gebete, den Trost und das Leiden der Kirche. Allerding sind die zeitlichen Hintergründe anders. Luther setzte sich mit den PKen dafür, die wahre Kirche aufzustellen, aber Melanchthon setzte sich mit seinem PK dafür, die aufgestellte wahre Kirche festzustellen und zu ermuntern.

\subsection{Bugenhagen}

\subsubsection{Der PK Bugenhagens}

Bieber-Wallmann stellt die Tätigkeit Johannes Bugenhagens in Wittenberg vor und sagt, dass er „die Rechtfertigung aus dem Glauben anhand der biblischen Schriften“ in Wittenberg neben Luther und Melanchthon gelehrt habe. ${ }^{916}$ Schon bevor Bugenhagen in Wittenberg angekommen ist, stand er unter dem Einfluss Luthers. Dieser Einfluss Luthers war sicherlich auch der Grund dafür, Theologie an der Wittenberger Universität zu studieren. Aber als Luther die zweite Psalmenvorlesung begann, war Bugenhagen wahrscheinlich noch nicht in Wittenberg, und als Bugenhagen in Wittenberg eintraf, war Luther auf der Wartburg. Als Luther im März 1522 nach Wittenberg zurückkam, lernte Bugenhagen Luther persönlich kennen. Nach Holfelder kann Bugenhagen durch die Begegnung mit Luther die neuen Deutung der Heiligen Schrift finden. ${ }^{917}$

\footnotetext{
${ }^{914}$ Melanchthon, Theologiae studiosis Philippus Melanchthon salutem, in AWA 2, S.17-22; MBW 47.

${ }^{915}$ Peters 2005, S.164.

${ }^{916}$ Bieber-Wallmann 2013, S.679.

${ }^{917}$ Holfelder 1974, S.8.
} 
Der enge Zusammenhang zwischen Bugenhagen und Melanchthon ist von Anfang an zu ersehen, auch bei seiner Psalmenvorlesung. Der Ort nämlich, wo Bugenhagen die Psalmenvorlesung begann, war das Zimmer Bugenhagens im Hause Melanchthons. ${ }^{918}$ Durch die Empfehlung Melanchthons konnte er an der Wittenberger Universität seine Psalmenvorlesung halten. Dazu verwendete er bei seiner Vorlesung die Psalmenübersetzung Melanchthons in das Lateinische. Darüber hinaus kann man die Spur der sprachlichen Beratung Melanchthons für die Psalmenauslegung Bugenhagens in der Auslegung zu Ps 4 erkennen. ${ }^{919}$ Bei seinem PK kann man so auch auf gemeinsame Beratungen mit Melanchthon schließen. ${ }^{920}$

Bugenhagen sieht die Psalmen ,,als eine Art Inbegriff und summa des göttlichen Wortes. “921 Besonders behandelt demnach Ps 1 das Ziel der Heiligen Schrift. ${ }^{922}$ Deshalb dient die Psalmenauslegung dem Verständnis der ganzen Heiligen Schrift. Daher ist es selbstverständlich für Bugenhagen, die Psalmenvorlesung als die erste seiner Vorlesungen in Wittenberg zu halten.

Als fast 36-Jähriger traf Bugenhagen im März 1521 in Wittenberg ein, um Theologie zu studieren. Ungefähr ein halbes Jahr später begann er seine Psalmenvorlesung für die in Wittenberg die Theologie studierenden Pommern in seinem Zimmer im Hauss Melanchthons. Nach dem Vorschlag Melanchthons begann Bugenhagen seine Psalmenvorlesung an der Wittenberger Universität am 3. November 1521 nochmals von Anfang an, obwohl er schon die Vorlesung bis zu Ps 16 gehalten hatte. ${ }^{923}$ Die Vorlesung fand etwa bis Ende 1522 oder Anfang 1523 statt.

Um die Vorlesung zu veröffentlichen, überarbeitete er sie, und am 30. Dezember 1523 datierte er den Widmungsbrief an den Kurfürsten, Friedrich von Sachsen. Dann wurde Bugenhagens „Interpretatio in librum psalmorum“ im März 1524 mit den lobenden Vorreden Luthers und Melanchthons in Basel veröffentlicht. ${ }^{924}$ Seine Psalmenvorlesung „bildet den Grund- und Eckstein für Bugenhagens öffentliches Wirken in Theologie und Praxis. ${ }^{6925}$ We-

\footnotetext{
${ }^{918}$ Vgl. Gummelt 1994, S.78.

${ }^{919}$ Vgl. Holfelder 1974, S.106.

${ }^{920}$ Holfelder 1974, S.107.

${ }^{921}$ Willi 2010, S.42f.

${ }_{922}$ Bieber-Wallmann 2013, S.681.

${ }^{923}$ Willi 2010, S.40.

${ }^{924}$ Geisenhof 1963, Nr 3. S.6.; VD 16 B 3187.

${ }^{925}$ Willi 2010, S.41.
} 
nig später, im Jahr 1526, wurde die Übersetzung ins Deutsche durch den Straßburger Reformator, Bucer, veröffentlicht. ${ }^{926}$

Im Oktober 1523 wurde Bugenhagen als Stadtpfarrer in Wittenberg eingesetzt, und seine Berufung „,bezeichnet ohne Frage eine Schlüsselposition in seiner Biographie und ist für weite Bereiche seines reformatorischen Wirkens von grundlegender Bedeutung gewesen. “927 Aber auf Grund der Arbeitsbelastung musste er seine Lehrtätigkeit begrenzen. Dies zeigen die Wiederholungen der Vorlesung zu den Psalmen und dem Galaterbrief. ${ }^{928}$

Bugenhagen erklärt in seinem Widmungsbrief, dass sein Psalmenkommentar wegen der Abwesenheit Luthers in Wittenberg Aufnahme finden könne und allein die Lücke der Operationes Luthers ausfülle. ${ }^{929}$ Trotzdem lehnte die Psalmenvorelsung Bugenhagens sich nicht an die Operationes Luthers an. Z.B. legte er Ps 19 nach der christologischen Auslegungstradition aus, anders als Luther. Sein PK trägt so seine eigene Handschrift. ${ }^{930}$

\subsubsection{Exegese}

In 1520-er Jahren entstanden die Beschäftigungen mit den biblischen Sprachen und die neue Betrachtungsmethode der Heiligen Schrift durch die evangelische Theologie. Der erste Psalmenkommentar, der diese Strömungen der Zeit aufgegriffen hat, war der PK Bugenhagens. ${ }^{931}$

Bugenhagen verwendete für seine Psalmenvorlesung die griechischen und hebräischen Texte und die Vg, dazu die Psalmenübersetzung von Melanchthon. ${ }^{932}$ Aber Bugenhagen hatte keine gründlichen Kenntnisse des Hebräischen. Aus diesem Grund verwendete er die Übersetzungen der Psalmen für seinen PK. Und gegenüber der Vg hatte er eine kritische Einstellung, deshalb ist seine Beschäftigung mit der Vulgatakritik häufig zu finden. ${ }^{933}$

Bugenhagens Psalmenkommentar zeigt folgten Aufbau: erstens Titel(titulus), zweitens Hauptgedanke(summa oder argumentum), drittens Übersetzung(translatio) und viertens Auslegung(interpretatio). Es ist auffällig, dass seine Auslegung(interpretatio) kein hermeneuti-

\footnotetext{
${ }^{926}$ Bucer, Psalter wol verteutscht auß der heyligen sprach, 1526 Basel.; Geisenhof 1963, Nr 13. S.30.; VD 16, B 3291; BiblBuc Nr. 12.

${ }^{927}$ Leder 2002, S. 183.

${ }^{928}$ Gummelt 1994, S.24.

${ }^{929}$ Vgl. Holfelder 1974, S.97.

${ }^{930}$ Holfelder 1974, S.98f.

${ }^{931}$ Hobbs 2009, S.479.

932 Bieber-Wallmann 2013, S.679.

${ }^{933}$ Holfelder 1974, S.8.
} 
sches Vorwort(prolog) hat, anders als die der Patristik und des Mittelalters. Deshalb kann man seinen hermeneutischen Hauptgedanken allein in seiner konkreten Auslegung finden. ${ }^{934}$

Nach der Auffassung Bugenhagens öffnet sich der Sinn der Heiligen Schrift „den Hörenden und Lesenden. “935 Deshalb ist die Interpretation der Heiligen Schrift keine menschliche Handlung, nämlich die Buchstaben des Textes zu verstehen, sondern ein göttliches Geschehen, nämlich dass der wirkende Gott eine Person trifft. Aus diesem Grund enthüllt sich bei der Auslegung nicht das Verständnis der Ausleger, sondern die Absicht Gottes. Darin ist eine negative Position Bugenhagens gegenüber der mittelalterlichen spekulativen Auslegungsmethode zu erkennen.

Die unmittelbare Überlieferung durch Gott ist notwendig, um die Heilige Schrift wahrhaft zu verstehen. In Bezug darauf befindet sich das Spiritus-Litera-Problem häufig in den Bußpsalmen. ${ }^{936}$ Den geistlich wahrhaften Sinn zu erfassen ist allein dann möglich, wenn man in der Buße Gott trifft. Daher ist nach der Auffassung Bugenhagens die Erfahrung der Anfechtung vor Gott unentbehrlich, um die Heilige Schrift zu verstehen. ${ }^{937}$ Das impliziert auch, dass „Bugenhagen einem früheren Stadium seiner Schrifttheologie, das durch den Einfluss der Heiligkeitstheologie des Erasmus bestimmt war, den endgültigen Abschied“" gibt. ${ }^{938}$ In seinem PK zeigt sich seine Stellung gegenüber der evangelischen Theologie deutlich.

Betrachtet man die Einstellung Bugenhagens über den geistlichen Sinn der Heiligen Schrift, so wird klar, dass Bugenhagen die spirituale Auslegung nicht als Allegorese verstand. Vielmehr lehnt er die vierfache Schriftauslegung des Mittelalters ab. In seinem PK gibt es keine Spur der vierfachen Auslegung. Die Allegorese war für Bugenhagen ein Randproblem. ${ }^{939}$

So war Bugenhagen kritisch gegenüber einer mystischen Sinnerfahrung. Damit ist seine kritische Stellung zur Allegorese als traditioneller Form geistlicher Schriftauslegung gegeben. ${ }^{940}$ Er kritisiert die Allegorese und betont die Geschichtlichkeit des Wortes Gottes. ${ }^{941}$ Und

\footnotetext{
${ }^{934}$ Holfelder 1974, S.6.

${ }^{935}$ Willi 2010, S.43.

${ }^{936}$ Holfelder 1974, S.145.

${ }^{937}$ Holfelder 1974, S.153.

${ }^{938}$ Holfelder 1974, S.8.

${ }^{939}$ Holfelder 1974, S.154.

${ }^{940}$ Holfelder 1974, S.9.

${ }^{941}$ Holfelder 1974, S.153.
} 
er erwähnt den Grund dafür, nämlich seine Betonung der Erfahrung der Anfechtung vor Gott und der Einheit von dem AT und dem NT.

\subsubsection{Theologie}

Bugenhagen betonte die Geschichtlichkeit Gottes, der mit seinem Volk zusammen ist. Geschichte wird im AT gezeugt, im NT bestätigt und bleibt immer noch. ${ }^{942}$ Bugenhagen dachte, dass die Auslegungen durch die Propheten, Christus und die Apostel als ausgezeichnet und angemessen gewürdigt werden sollen. ${ }^{943}$ Daher spielt die Zitierung der Psalmen im NT eine autoritative Rolle, um den wahren Sinn der Psalmen aufzufassen. ${ }^{944}$ Für Bugenhagen ist die Einheit von dem AT und dem NT ein wichtiger Schlüssel der Heiligen Schrift. Insofern stellt Bugenhagen die Widerspruchsfreiheit der Heiligen Schrift fest. ${ }^{945}$

\subsubsection{Vergleich mit dem PK Melanchthons}

Der PK Bugenhagens bezieht sich eng auf Melanchthon von Anfang an. Seine Vorlesung begann im Haus Melanchthons und fand an der Wittenberger Universität durch die Empfehlung Melanchthons statt. Dazu verwendete Bugenhagen bei seiner Psalmenvorlesung die Materialien und die Meinungen Melanchthons. Außerdem verfasste Melanchthon die Vorrede von dem PK Bugenhagens. Diese Indizien zeigen, dass Melanchthon einen Einfluss auf den PK Bugenhagens hatte. Die exegetische Methode und die Theologie in seinem PK sind Zeugnisse dafür. In seinem PK findet sich eine ähnliche exegetische Tendenz über die Allegorese mit der von Luther und Melanchthon. Bei seiner Behauptung der Einheit von dem AT und dem NT und der Widerspruchsfreiheit der Heiligen Schrift zeigt sich die Einheit der Wittenberger Theologie.

\subsection{Bucer}

\subsubsection{Der PK Bucers}

Der Straßburger Reformator, Martin Bucer, nahm Anteil an der Reformation schon seit 1518. Er übersetzte die wichtigen Schriften der Reformation, darunter den Psalmenkommentar Bugenhagens. ${ }^{946}$ Und er war zudem ein ausgezeichneter Hebräist im 16. Jh.

\footnotetext{
${ }^{942}$ Holfelder 1974, S.154.

${ }^{943}$ Vgl. Holfelder 1974, S.166.

${ }^{944}$ Holfelder 1974, S.166.

${ }^{945}$ Bieber-Wallmann 2013, S.682.

${ }^{946}$ Psalter wol verteutscht, Basel 1526. Geisenhof 1963, S.25f. Nr. 13 \& 14 und BiblBuc Nr. 12. Die Übesetzung Bucers ist nicht wörtlich. Damals gab es eine Auseinandersetzung über das Abendmahl
} 
Die Stadt Straßburg schaffte 1529 die lateinische Messe ab und machte den Protestantismus im Reichstag zu Speyer 1529 mit. Für diese Entwicklung der Reformation in Straßburg spielte das Vorlesungsprogramm der Heiligen Schrift für die Laien eine wichtige Rolle. ${ }^{947}$ Dazu gehört auch die Psalmenvorlesung Bucers Er unterrichtete die Psalmen 1528 bis 1529 und veröffentlichte seinen Psalmenkommentar 1529 unter dem Titel „Sacrorum Psalmorum libri quinque“. ${ }^{948} 1532$ legte Bucer die zweite Auflage des PKs vor, und dann 1547 und 1554 wurde der PK ohne große Revisionen erneut aufgelegt. ${ }^{949}$

Es ist klar, dass Bucer unter dem Einfluss von Erasmus, Luther und Bugenhagen stand. Allerdings kann er nicht einfach als deren Nachfolger bezeichnet werden. Bucer verfügte über eine besondere Sprachkenntnisse, anders als Luther und Bugenhagen, und Besonderheiten in seiner Theologie, anders als Erasmus. Nach der Auffassung von Hobbs ist der PK Bucers von Bedeutung als der erste Kommentar, der von einem fähigen evangelischen Hebräisten im 16. Jh. aus dem hebräischen Text verfasst wurde. ${ }^{950}$

\subsubsection{Exegese}

Die Grundlage des PKs Bucers ist also der hebräische Text. Bucer hob die Vg in seinem PK auf und erschloss seine Auslegung auf der Grundlage des Hebräischen. Bei der materialen Verwendung des PKs Bucers ist die Annehme der jüdischen Traditionen charakteristisch. Wegen seines Gewichtes in der literarischen und geschichtlichen Deutung folgte Bucer nicht LXX, sondern dem masoretischen Text, und lehnt sich an die jüdischen Ausleger an, aber kritisch. ${ }^{951}$ Denn die jüdischen Auslegungen werden meistens durch die talmudische Tradition geprägt und wenden sich gegen das Christentum. Die Verwendung der jüdischen Texte beruht auf der Überzeugung Bucers, dass das christliche Lesen des AT unbedingt auf dem richtigen Verständnis von der hebräischen Sprache beruhen soll. ${ }^{952}$ Die Beschäftigung der jüdischen Ausleger mit dem literarischen Sinn des Textes schätzte Bucer hoch und wandte dies auch auf seinen PK an. Bucer fand eine Auslegungsmöglichkeit der Heiligen Schrift in den jüdischen

\footnotetext{
und Bucer hatte andere Meinung darüber als Bugenhagen. Deshalb erwähnte Bucer in der Übersetzung zu Ps 111,5 das Abendmahl nicht. (Geisenhof 1963, S.28 und Spijker 1987, S.265.)

${ }^{947}$ Hobbs 2008, S.455.

${ }^{948}$ Bucer, „Sacrorum Psalmorum libri quinque ad Ebraicam veritatem versi et familari explanatione elucidati. Per Aretium Felinum Theologum", Straßburg, 1529.; VD 16 B 3145.; BiblBuc Nr. 25.

${ }_{949}$ BiblBuc Nr. 25b(1532), BiblBuc Nr. 25c;VD16 B 3186 (1547) und BiblBuc Nr 25d(1554).

${ }^{950}$ Hobbs 2009, S.480.

${ }^{951}$ Hobbs 2009, S.485.

${ }^{952}$ Hobbs 2008, S.471.
} 
Literaturen. ${ }^{953}$ Und bei der Auslegung zu Ps 2 ist der Einfluss der jüdischen Exegese deutlich. Aber seine Position gegenüber der jüdischen Tradition ist kritisch. So findet Bucer z.B. ein wichtiges Thema für die Christologie und die Trinität in Ps 2,7. Hierin wendet sich Bucer gegen die antichristliche Auslegung des Juden David Kimhi. ${ }^{954}$

Für die Darstellungsform des PKs Bucers ist ihre Ausführlichkeit charakteristisch. Er wollte die Leser möglichst über alles Nötige informieren. Dazu kann man in seinen rhetorischen Analysen den Einfluss von Erasmus finden. ${ }^{955}$

Sein PK zeigt folgenden Aufbau: die Behauptung des Psalms(Argumentum), eine kurze Erklärung zu den Themen und der Entwicklung des Psalms, seine neue Übersetzung, dann jeden einzelnen Vers und zuletzt gelegentlich ein theologischer Aufsatz über das Ziel des Psalms. ${ }^{956}$ Besonders in seiner Übersetzung ist der Zweck, die Leser die wahre Lehre und die Frömmigkeit der Heiligen Schrift erfahren zu lassen. ${ }^{957}$

Der Grundgedanke Bucers bei der Psalmenauslegung ist, dass der Text fasslich ist und dass die Zuverlässigkeit der Lehre auf der Knappheit des Textes und dem Wort Gottes beruhen soll. Die vierfache Auslesung erlaubt dagegen die Willkürlichkeit der Deutung. ${ }^{958}$ Die unliterarische Auslegung richtet sich darauf, die Autorität der Heiligen Schrift zu schwächen. Bucer betonte, dass die Apostel auch bei dem geschichtlichen Sinn blieben. Aus diesem Grund beurteilte Bucer die jüdische Tradition positiv, die auf die geschichtliche Deutung Gewicht legt. ${ }^{959}$

Bucer betonte den geschichtlichen Hintergrund des Textes, um die wahre Bedeutung des Textes aufzufassen. Dabei verwendet er die jüdische Kritik und lehnt die mittelalterliche Sophistik ab. ${ }^{960}$ So liegt Bucers Interesse bei seiner Auslegungsmethode auf dem Kontext des Textes und der reichen Erforschung der hebräischen Wörter. ${ }^{961}$

Obwohl Bucer in seinem PK auf den literarischen Sinn des Textes Gewicht legt, bleibt noch das Problem der Allegorese, weil einige Psalmen allegorisch verfasst wurden. So er-

\footnotetext{
${ }_{953}^{95}$ Dafür sind Ps 19 und 72 gute Beispiele. (Hobbs 2009, S.487.)

${ }^{954}$ Paul 2015, S.14.

${ }^{955}$ Hobbs 2009, S.485.

${ }^{956}$ Hobbs 2008, S.467.

${ }^{957}$ Hobbs 2008, S.469.

${ }^{958}$ Hobbs 2009, S.482.

${ }^{959}$ Hobbs 2009, S.483.

${ }^{960}$ Hobbs 2009, S.481.

${ }^{961}$ Hobbs 2009, S.491.
} 
kennt er in einzelnen Fällen die allegorische Deutung der Psalmen an. ${ }^{962}$ Aber er erlaubt keine Willkürlichkeit der Allegorese in dem mittelalterlichen Sinn und verbindet keine Allegorese mit der christologischen Auslegung.

Bucer findet die christologische Auslegung in der Typologie, die den doppelten Sinn für David und Christus bietet. ${ }^{963}$ Bucer unterscheidet die typologische Auslegung von der allegorischen. Dabei spielt das Auge des Glaubens eine wichtige Rolle, um alles unter dem Schatten des ewigen Sohnes Gottes zu schauen. Aber die Auslegung stellt sich er auf geschichtlichen Grund. ${ }^{964}$

Nach Pak beruht die geschichtliche Auslegung bei Bucer auf drei Arten. Erstens, er liest den Text christologisch durch die geschichtliche Typologie. Zweitens, wenn David Prophet ist, ist der Text die literarische Prophezeiung Christi. Drittens, der Text erfüllt sich in der Erfahrung der Kirche. Dabei bezieht David sich auf Christus. ${ }^{965}$ Bucer versteht die Psalmen als die literarisch durch David gezeigte Prophezeiung des Heiligen Geistes über Christus und die Kirche. ${ }^{966}$

\subsubsection{Theologie}

Im Vorwort zu Ps 18 fordert Bucer dazu auf, David zu erkennen, weil in David der Schlüssel besteht, um die Psalmen zu verstehen. ${ }^{967}$ Für Bucer ist David der inspirative Prophet und die Gestalt, die die Integrität und den Glauben hat. ${ }^{968}$ Vor allem beschäftigt sich David mit seiner Stellung und seinen Aufgaben. Er ist der von Gott gesegnete fromme Führer seines Volks und der Lehrer der Gerechtigkeit. Er erhört Gott und stärkt den Glauben seines Volkes zu. ${ }^{969}$ Außerdem ist er das ethische Vorbild für sein Volk. ${ }^{970}$ Bucer versteht David als ein Typ Christi und aller Christen. Damit meinte Bucer mit seinem PK den Trost der Frommen. ${ }^{971}$

\footnotetext{
962 Hobbs 2009, S.489.

${ }_{963}$ Paul 2015, S.14.

${ }^{964}$ Hobbs 2009, S.490.

${ }^{965}$ Pak 2010, S.59. Ein gutes Beispiel ist die Auslegung zu Ps 2.

966 Paul 2015, S.14. Paul sieht dabei den Unterschied über das Verständnis des literarischen Sinns der Heiligen Schriften zwischen Luther und Bucer.

967 Über die Einstellung Bucers über David sagt Hobbs so, „I think it is apparent that our reformer has, like others before him, also created a David after his own heart."(Hobbs 2003, S.128)

${ }^{968}$ Hobbs 2003, S.114.

${ }^{969}$ Hobbs 2003, S.119.

${ }^{970}$ Hobbs 2003, S.116

${ }^{971}$ Spijker 1987, 267.
} 
Darüber hinaus ist David der Verfasser der Psalmen. Er sieht die Zukunft prophetisch. ${ }^{972}$ Deshalb glaubt Bucer, dass die Zeugnisse Davids wahrhaft und gültig sind. Dazu war das AT dem Christus und den Aposteln bekannt und enthält die Erkenntnis für die Erlösung. ${ }^{973}$ Bucer glaubt, dass die Wahrheit des ATs mit der Wahrheit des NTs übereinstimmt. ${ }^{974}$

Aber nach der Auffassung Bucers ist die paulinische Anwendung nicht literarisch, trotzdem in der Gänze eine angemessene Erweiterung des ersten Sinnes. ${ }^{975}$ So war Bucer überzeugt, dass die Auslegung des hebräischen Textes und die Deutung des NTs über das AT übereinstimmen. ${ }^{976}$

\subsubsection{Vergleich mit dem PK Melanchthons}

Bucer und Melanchthon haben eine wichtige Gemeinsamkeit, dass sie den hebräischen Text als die Grundlage ihrer PKe verwenden. Bucer verwendete die jüdischen Materialien häufig, Melanchthon allerdings nicht häufig. Die Differenzierung beruht auf ihren Methoden; im PK Bucers ist die Ausführlichkeit bezeichnet, im PK Melanchthons dagegen die Knappheit.

Bei dem Problem der Allegorese erlaubt Bucer keine Willkürlichkeit, wie bei der Methode der Wittenberger. Seine Theologie im PK stimmt mit der Wittenberger Theologie außer der Abendmahlslehre überein. In der Einheit von dem AT und dem NT besteht eine Abweichung, dass nach der Auffassung Bucers die Zitate des NTs nicht immer den ersten Sinn des alttestamentlichen Text, allerdings den richtigen Sinn zeigt. In dem PK Melanchthons versucht Melanchthon, zu zeigen, dass seine Deutung mit der des NTs übereinstimmt. Deswegen kritisiert Melanchthon die Deutung des NTs nicht. Allerdings erkennen Melanchthon und Bucer die Einheit von dem AT und dem NT an.

\subsection{Calvin}

\subsubsection{Der PK Calvins}

Calvin unterrichtete die Psalmen 1554 in der Genfer Schule. Eine Veröffentlichung seiner Psalmenvorlesung plante er anfangs nicht. Allerdings wegen einer Möglichkeit der Veröffent-

\footnotetext{
${ }^{972}$ Obwohl die Psalmen keine Zeit Davids zeigt, schreibt Bucer die Psalmen David zu. Z.B. Ps 79 und 80. Hobbs stellt die Meinung Bucers so dar, „Now Bucer's David was certainly a seer, and might potentially have been supernaturally given such insights into the future." (Hobbs 2003, S.120.)

${ }^{973}$ Hobbs 2008, S.456.

${ }^{974}$ Spijker 1987, S.279.

${ }^{975}$ Vgl. Hobbs 2008, S.473.

${ }^{976}$ Hobbs 2009, S.489.
} 
lichung der unautorisierten Mitschriften legte er seinen PK 1557 vor. Sein Hauptanliegen war es allerdings, am Aufbau der Kirche mitzuwirken. ${ }^{977}$

Der PK Calvins wurde 1557 drei Jahre später nach seinem Unterricht zu den Psalmen veröffentlicht. Sein PK war sehr umfangreich, von fast doppelter Größe seiner Institutio 1559. Sein PK, librum Psalmorum commentarius, wurde von Robert Estienne in Genf publiziert. Die Übersetzung in Französisch wurde 1558 vorgelegt und die Revision des PKs folgte 1561. Der PK war der dritte alttestamentliche Kommentar nach dem Kommentar zur Jesaja(1551, 1559) und dem zur Genesis(1554). ${ }^{978}$

Die Psalmen spielten eine wichtige Rolle in der Liturgie und gestalteten das Wesen des Preisens der Versammlung. Insbesondere waren die Psalmen das einzig von Calvin im Sonntagsgottesdienst gepredigte alttestamentliche Buch. ${ }^{979}$

Für Calvin sind die Psalmen wichtig wie der Spiegel seiner Seele. Sie sind zuerst die Gebete und leiten uns zu Gott. Außerdem lehren die Psalmen, wie wir Gott loben sollen. Darüber hinaus führen sie uns dazu, das Kreuz zu legen, und um die Vorsehung und die Regierung Gottes anzunehmen. ${ }^{980}$

Sein PK zeigt die Frömmigkeit Calvins, die sich eng auf David bezieht. ${ }^{981}$ Durch David erkennt sich Calvin selbst in seinem Erleben, und darin findet er auch seine Kirche. Deshalb braucht man die aktive Anwendung der Psalmen und die Identifizierung mit seiner Kirche, um die Psalmen besser zu verstehen. ${ }^{982}$

\subsubsection{Exegese}

Calvin verwendete bei seinem PK den hebräischen Text von Luis Bude als Grundlage. Er schob LXX beiseite. ${ }^{983}$ Unter den Kommentaren der kontemporären Autoren verwendete Calvin die Operationes Luthers und den PK Bucers(1532 oder 1547), ${ }^{984}$ und er kannte auch den PK von Musculus. Weiterhin verwendete Calvin Werke der patristischen Autoren, z.B. Hie-

\footnotetext{
${ }^{977}$ Hasselhoff 2009, 116.

${ }^{978}$ Greef 2006, S.85-86.

979 Jong 1994, S.1.

980 Jong 1994, S.2.

${ }^{981}$ Jong 1994, S.14.

${ }^{982}$ Vgl. Selderhuis 2000, S.33f und Freudenberg sagt, „Um David und seine zuweilen klagende Rede $\mathrm{zu}$ Gott zu verstehen, reflektiert Calvin über sein eigenes Leben und nimmt identisches Erleben und analoges Erleiden wahr.“(Freudenberg 2008, S.85.)

983 Roussel 2007, S.12.

${ }^{984}$ Bei dem Fall Bucer hat Calvin eine persönliche Verbindung. während des Aufenthaltes in Strasbourg lernte Calvin Hebräisch weiter bei Bucer und Capito. (Opitz 2008, S.440.)
} 
ronymus, Eusebius und Augustin usw. ${ }^{985}$ Häufig zitierte er Augustin und erkannte die Autorität Augustins trotz der Kritik an. ${ }^{986}$

Die Psalmen wurden absichtlich als ein Buch verfasst, aber jeder Psalm ist eine selbstständige Einheit. Deshalb wird jeder Psalm einzeln behandelt. ${ }^{987}$

Calvin erklärt die Psalmen möglichst nach der Abfolge des hebräischen Textes. Der Titel des Psalms ist ein wichtiges Element, das sich auf den Inhalt des Psalms bezieht. ${ }^{988}$ Calvin behandelt den Titel ausführlich, wenn der Titel sich auf die Verfassung des Psalms bezieht. ${ }^{989}$

Der Charakter der Auslegung Calvins ist literarisch und geschichtlich. Bucer legte schon die Psalmen auf die gleiche Weise aus. ${ }^{990}$ Calvin erwähnt die rhetorische Figur, wenn er sie für wichtig hält. Er begrenzt allerdings die Vielfalt auf Metapher, Synekdoche und Hyperbel. ${ }^{991}$

Die Aufgabe der Auslegung ist es, den Sinn des biblischen Textes und die Absicht des Verfassers zu enthüllen. Dafür sollen die Gattung, der geschichtliche Hintergrund, der Kontext und der Verfasser des Textes betrachtet werden. Mit solchen geschichtlichen und sprachlichen Kontexten nähert Calvin sich dem Sinn des Textes an. ${ }^{992}$

Die Auslegung Calvins bezieht sich nicht durchgängig auf die geschichtlichen Sachverhalte, sondern auf eigene Erfahrung. ${ }^{993}$ Die Ähnlichkeit der Erfahrung Calvins mit der Davids bietet Calvin die Kompetenz für die Psalmenauslegung. ${ }^{994} \mathrm{Je}$ mehr er die Situation des Verfassers des Psalms mitfühlt, desto besser kann er den Psalm verstehen.

Aber bei der Auslegung der Heiligen Schrift ist die Rolle des Heiligen Geistes auch wichtig. Die Wirkung des Wortes Gottes bezieht sich eng auf den Geist Gottes. Allein wer in dem Heiligen Geist ist, kann die Kraft des Wortes erfahren. Die Erkenntnis über das Wort Gottes geht dem die Erfahrung der Gnade voran, und ohne das Wort gibt es keine Gnade. ${ }^{995}$

\footnotetext{
${ }^{985}$ Greef 2006, S.88.

${ }^{986}$ Greef 2006, S.89.

987 Greef 2006, S.90.

${ }_{988}$ Z.B. Ps 38,70 und 100.

${ }^{989}$ Greef 2006, S.92.

${ }^{990}$ Greef 2006, S.92.

${ }^{991}$ Greef 2006, S.86.

${ }^{992}$ Opitz 2008, S.441.

${ }^{993}$ Nach der Auffassung Selderhuis impliziert die humanistische Auslegung des Textes eine subjektive Beteiligung des Auslegers.(Selderhuis 2007, S.271)

${ }^{994}$ Opitz 2008, S.451.

${ }^{995}$ Selderhuis 2007, S.274.
} 
Gott besiegelt innerlich die Überzeugung, die vom Heiligen Geist durch das Wort gegeben wird. Der Heilige Geist verbindet Gott und das Wort. Dies Wort gibt uns die Hoffnung, und wir bekennen die Hoffnung mit unserem Wort. Aus diesem Grund lehnt Calvin die Schwärmer ab, die das äußerliche Wort ablehnen. ${ }^{996}$

Calvin hat kein Interesse an der vierfachen Auslegung und kritisiert die grundlose Allegorese. ${ }^{997}$ Für Calvin bezieht sich die Unterscheidung von litera-spiritura darauf, wovon das AT den Christen spricht. ${ }^{998}$ In seinem PK zielt Calvin den einfachen und natürlichen Sinn des Textes vor. ${ }^{999}$

Die Psalmen allein in Bezug auf die Christologie zu betrachten, ist nach Calvin überzogen. Eine solche Betrachtung vernichtet die Erfahrung der Verfasser der Psalmen in Bezug auf Gott. Aus diesem Grund richtet Calvin sich danach, woran die Verfasser glauben, was sie erfahren und worauf sie hoffen. ${ }^{1000}$ Das Interesse Calvins ist sehr praktisch ausgerichtet.

Calvin lehnt die traditionelle christozentrische Auslegung ab, die den Kontext des Textes verachtet. ${ }^{1001}$ Diese Ablehnung meint nicht, dass bei der Psalmenauslegung Calvins es keinen Christus gibt. Vielmehr deutet Calvin die Geschichte der Heiligen Schrift in Hinsicht auf das gegenwärtige Reich Christi. Aber man darf deshalb nicht behaupten, dass die Zeugnisse des ATs allein Christus zeigen. Die Geschichte der Kirche zeigt Christus und wird in Christus gleichzeitig gegründet. ${ }^{1002}$ So begrenzt Calvin das christologische Lesen und konzentriert sich auf den einfachen und natürlichen Sinn. Calvin versucht also nicht, die Psalmen einseitig christologisch auszulegen. Er warnt vielmehr davor, gegen den Kontext den Text unmittelbar mit Christus zu verbinden. ${ }^{1003}$.

Trotzdem behauptet Calvin, dass der alttestamentliche Text sich selbst auf Christus bezieht. Selderhuis zeigt den hermeneutischen Schlüssel Calvins für die christologische Auslegung der Psalmen auf. Was in der Zeit des ATs nicht erfüllt wird, muss sich auf Christus beziehen. ${ }^{1004}$ Wenn die Äußerung zur geschichtlichen Situation nicht passt, dann ist es die Pro-

\footnotetext{
${ }^{996}$ Selderhuis 2007, S.275.

997 Opitz 2008, S.441.

${ }^{998}$ Greef 2006, S.94.

${ }^{999}$ Greef 2006, S.95.

${ }^{1000}$ Greef 2006, S.89.

${ }^{1001}$ Vgl. Opitz 2008, S.448f.

1002 Opitz 2008, S.449.

${ }^{1003}$ Selderhuis 2007, S.275.

${ }^{1004}$ Ps 72,10 CO 31,669.
} 
phezeiung Christi. ${ }^{1005}$ Mit diesem Schlüssel öffnet Calvin die Tür der christologischen Auslegung. Diese Methode Calvins ist nicht anders als die christologische Auslegung Luthers. ${ }^{1006}$

\subsubsection{Theologie}

Calvin behauptet nicht, anders als die patristischen und jüdischen Ausleger, dass alle Psalmen David zuzusprechen sind. ${ }^{1007}$ Aber Calvin erkennt an, dass die meisten Psalmen zu David gehören. Dann, wenn der Kontext des Psalms sich auf David beziehe, sei auch die Zuordnung sicher. ${ }^{1008}$ David wird von Calvin für den Typ des kommenden Christus gehalten. David zeige Christus mit seiner Rede, seinem Wesen, dem von Gott gegebenen Gesetz und seinem Leiden. ${ }^{1009}$

Christus ist das Ziel und die Vervollkommnung des Reiches Davids. ${ }^{1010}$ Die Psalmen verweisen auch prophetisch auf das Leiden Christi, aber nicht allein auf David, sondern auch auf Christus. Z.B. In den Ps 22 und 60 sowie 109 sieht Calvin zwar Erfahrungen Davids nachgezeichnet, aber gleichzeitig seien die Psalmen eine Prophezeiung über Christus. ${ }^{1011}$

Nach der Auffassung Calvins ist der Verfasser von Ps 60 David, aber er nennt keinen Namen im Psalm, weil David als eine Person der Kirche den Psalm verfasste. So verbindet Calvin häufig David mit Christus und der Kirche. Diese Verbindung leitet sich vom PK Augustins her, der behauptet hat, dass die Psalmen von Christus und der Kirche handeln. ${ }^{1012}$ Aber der Unterschied zwischen Calvin und Augustin ist, dass Calvin den Text nicht allein auf Christus anwendet. ${ }^{1013}$ David ist für Calvin nicht nur der Typ des kommenden Christus, sondern auch der König und das Haupt seiner Gesellschaft. David zeigt Christus und ist gleich-

\footnotetext{
${ }^{1005}$ Ps 149,7 CO $32,439$.

${ }^{1006}$ Selderhuis 2007, S.276. Vgl. Pak stellt drei Prinzipien Calvins vor, die Calvin verwendet, wenn der Psalm sich auf Christus anwendet. Erstens, Wenn der Text durch Christus mehr erfüllt wird oder besser dem Christus entspricht, nämlich das typologische Lesen. Zweitens, wenn Christus selbst in der Beziehung zu sich den Text der Psalmen erwähnt. Allerding wird der erste Lesen des Textes auf dem Leben Davids gelegt.(z.B. Ps 22,1 und Ps 110,1) Drittens, wenn das christologische Lesen den einfachen und natürlichen Sinn zeigt, die Absicht des Verfassers hält und durch den menschlichen Verfasser und den Heiligen Geist abgezeichnet wird.(Pak 2010, S.80.)

${ }^{1007}$ Greef 2006, S.91.

${ }^{1008}$ Selderhuis 2007, S.271f.

${ }^{1009}$ Opitz 2008, S.450.

${ }^{1010}$ Ps 72, 2, 45, 89 und 110 .

1011 Greef 2006, S.101.

1012 Vgl. Fiedrowicz 1997, S.234f. und Greef 2006, S.101.

${ }^{1013}$ Greef 2006, S.102. Diesen Charakter kann man auch bei anderen Reformatoren z.B. Melanchthon finden.
} 
zeitig ein Körper der Kirche. ${ }^{1014}$ Diese Tendenz Calvins ist nicht allein für ihn charakteristisch, sondern auch bei anderen Reformatoren, z.B. Melanchthon, Bucer usw. zu finden.

Die neutestamentlichen Autoren zitierten die Psalmen(z.B Ps 8, 16, 22 und 118) als die Prophezeiung Christi. Calvin erkennt den prophetischen Charakter der Psalmen an, wie im NT deutlich wird. ${ }^{1015}$ Aber Calvin versteht Ps 8 nicht als Prophezeiung über die Inkarnation, das Leiden und die Wiedererstehung Christi, sondern er erklärt damit die Vorsehung Gottes und die unermessliche Güte Gottes für die Menschen. ${ }^{1016}$ Ähnlich ist Ps 16 für Calvin kein Gebet Christi in seinem Leiden und kein Beispiel der Wiedererstehung Christi, sondern das Gebet Davids, bei dem David als ein Christ die Bewahrung Gottes erbittet und Gott für die Güte dankt. ${ }^{1017}$ Bei Ps 22 und 118 erkennt Calvin die christologische Anwendung, allerdings legt er die Psalmen vor allem als die Erfahrung und das Leiden Davids aus. ${ }^{1018}$ Calvin und Bucer lesen die Verse von Ps 8 und 16 nicht in der Beziehung zu Christus, sondern sie sehen David als ein Beispiel der Gläubigen. ${ }^{1019}$

Der Zusammenhang der Auslegung der Psalmen mit der persönlichen Erfahrung Calvins hat auch einen weiteren Zweck, nämlich den Nutzen der Kirche durch die Lektüre der Psalmen. Der Nutzen der Kirche ist ein großes Interesse Calvins in seinem PK. ${ }^{1020}$ Der Nutzen wird auch durch den Begriff von der accommodatio erklärt. Gott adaptiert sich für das Wort, um sein Volk verstehen zu lassen. Gott spricht, um das Wort auf die Menschen anzuwenden. ${ }^{1021}$ Gott adaptiert sich für die einfachen und ungelernten. ${ }^{1022}$ Damit kann die Kirche durch die Heilige Schrift Nutzen erfahren. Anders gesagt, zeigt der PK Calvins das seelsorgerlich-praktische Anliegen für die Kirche. ${ }^{1023}$

Insofern ist das Gebet, das die Handlung der Kirche für Gott ist, für Calvin von Bedeutung. Denn ohne das Gebet „würde der Glaube werklos und leblos werden.“ „Indem die Be-

\footnotetext{
1014 Opitz 2008, S.450.

1015 Greef 2006, S.91.

1016 Pak 2011, S.12.

1017 Pak 2011, S.13.

${ }^{1018}$ Pak 2011, S.13.

1019 Pak 2005, S.173.

${ }^{1020}$ Opitz sagt, „Auch Calvin geht es letztlich um den »Nutzen«, den die heutige Kirche aus der Lektüre des hebräischen Psalters ziehen kann.“(Opitz, CStA 6, S.10.)

${ }^{1021}$ Selderhuis 2007, S.276.

1022 Selderhuis 2007, S.277.

${ }^{1023}$ Freudenberg 2008, S.89.
} 
tenden ihre Hoffnung nicht auf Menschen oder Dinge, sondern auf Gott allein setzen, geben sie ihm die Ehre.“1024

Nach der Auffassung Calvins ist das AT vor allem Zeugnis der Geschichte, dass das von Gott erwählte Volk erzogen wird. ${ }^{1025}$ Und Christus ist das Ziel des Gesetzes. Das Gesetz Gottes enthält alles, was zu dem Gesetz gehört, und die ganze Heilige Schrift ist die Auslegung des Gesetzes. ${ }^{1026}$ Alle Verheißungen des ATs sprechen von Gott und dem Gnadenbund, und die Opfergesetze, die die Erlösung zeigen, besitzen das feste Fundament in Christus. ${ }^{1027}$

In seinem PK erwähnt Calvin häufig die ecclesia. Nach der Auffassung Greefs bedeutet ecclesia keine Kirche des NTs, sondern Israel, das Volk Gottes. Greef urteilt, dass Calvin Israel für das besondere Volk Gottes hält. ${ }^{1028}$ Aber das Urteil ist zu subjektiv. ${ }^{1029}$ Wenn Calvin das Volk Israel mit der Kirche des NTs nicht verbinden würde, würde der Nutzen der Kirche, den Calvin in seinem PK anstrebt, vermindert werden.

Die Zitierungen der Psalmen im NT harmonisieren nach der Auffassung Calvins nicht immer mit den Kontexten der Psalmen, aber die Harmonie von beiden ist auch nicht notwendig. Dabei unterscheidet Calvin die Zitierung als Analogie von der Zitierung als Zeugnis. ${ }^{1030}$ Wenn die Zitierung als Zeugnis verwendet wird, findet sie sich in dem einfach natürlichen Sinn. Obwohl Calvin sich auf den geschichtlichen Kontext der Psalmen konzentriert, erinnert er gleichzeitig daran, dass die Psalmen von Gott Israels und von unserer Erlösung handeln. ${ }^{1031}$

Pak behauptet, dass die Einheit von dem AT und dem NT bei Luther und Calvin anders gezeigt werde. Die Einheit wird bei Luther durch sein christologisches Lesen hergestellt. Dagegen geht Calvin von dem geschichtlichen Kontext des ATs und dem überlieferten Wert für die christliche Bildung und Erbauung aus. ${ }^{1032}$ Aber der Unterschied der christologischen Auslegung Calvins von der Luthers ist nicht so groß, sondern eher ein quantitatives Problem. Man

\footnotetext{
${ }^{1024}$ Freudenberg 2008, S.94.

1025 Opitz 2008, S.442.

${ }^{1026}$ Greef 2006, S.90.

1027 Opitz 2008, S.448.

1028 Greef 2006, S.95.

${ }^{1029}$ Selderhuis weist auf die Einheit des Bundes bei Calvin hin.(Selderhuis 2000, S.231) Vgl. Bei der Erklärung Calvins über die Sündenvergebung wird sein Gedanke über die Kirche ersehen, dass die Kirche(ecclesia) von der Zeit des ATs bis zur Zeit des NTs immer gleich ist. Instutio IV.1.24. „ut ab ipsis pene incunabulis Ecclesiae ordiamur ..."

${ }^{1030}$ Greef 2006, S.98.

${ }^{1031}$ Greef 2006, S.105.

1032 Pak 2011, S. 15.
} 
kann sagen, dass im Verständnis der Einheit von dem AT und dem NT sich von Luther zu Calvin eine Entwicklung zeigt.

Für Calvin stimmt das Wort mit der Verheißung Gottes überein, und Gott zeigt seine Güte in seinem Wort. ${ }^{1033}$ Im Wort kann man den Trost in allem Trauern finden, und da besteht die fromme Lehre, die die Schatzkammer der Erlösung ist. ${ }^{1034}$ Calvin erkennt keine Unklarheit in der Heiligen Schrift. Dies ist zugleich seine Kritik an der katholischen Kirche. Die Reformation ist das Ergebnis des Wortes Gottes. Calvin sieht in dem Heiligen Geist den Urheber der Heiligen Schrift. Er inspiriert die Zunge Davids. ${ }^{1035}$

Calvin betont die Einheit von dem AT und dem NT. Nach der Auffassung Calvins ist das Kommen Christi nicht der Anfang der Kirche, sondern der Anfang der neuen Ära in der Kirche. ${ }^{1036}$ Dabei verwendet Calvin die Begriffe von Schatten und Substanz, Kind und Erwachsenem und weniger und mehr. ${ }^{1037}$ Bei Calvin ist die Einheit von der Kirche des ATs und der des NTs klar - wie bei Melanchthon.

\subsubsection{Vergleich mit dem PK Melanchthons}

Die Verfassungszeit des PKs Calvins ist ähnlich wie die des PKs Melanchthons. Dazu gibt es viele Gemeinsamkeiten von beiden. Ihre Grundlage ist der hebräische Text, sie halten die Meinungen der Kirchenväter für wichtig, darunter ist Augustin am wichtigsten. Ihr Hauptanliegen liegt auf der Kirche, die unter dem Kreuz und dem Leiden ist. Bei der Auslegung zu den Psalmen verwendet Calvin wie Bucer die literarische und geschichtliche Methode, die damals bei den Reformatoren eine allgemeine Tendenz der Exegese war. Melanchthon verwendet auch die gleiche Methode. In dem Einzelfall betrachten beide Reformatoren besonders den Titel des Psalms. Ihre Einstellungen über die Allegorese und die christozentrische Auslegung stimmen überein. Darüber hinaus haben sie gemeinsam den praktischen Charakter, sich mit dem Anschluss der Psalmen an die Kirche zu beschäftigen. Sie verbinden David mit Christus und der Kirche und konzentrieren sich auf den Nutzen der Kirche. Bei den Zitaten des NTs steht Calvin in der Linie Bucers.

\footnotetext{
${ }^{1033}$ Selderhuis 2007, S.272.

${ }^{1034}$ Ps 147,19 CO 32, 235. ,pietatis doctrina, quae aeternae salutis thesaurus est, ... “

${ }^{1035}$ Selderhuis 2007, S.273.

${ }^{1036}$ Ps 96,7 CR 32,39.

${ }^{1037}$ Selderhuis 2007, S.277.
} 
Durch diese Gemeinsamkeiten zwischen dem PK Calvins und dem Melanchthons könnte man einen Einfluss von beiden gegeneinander betrachten, allerdings zeigen die Gemeinsamkeiten vor allem die Identifizierung zwischen der Theologie in Wittenberg und der in Genf.

\subsection{Cajetan}

\subsubsection{Cajetan und der PK(1530)}

Cajetan, Kadinal Tommaso de Vio(1469-1534) ist ein dominikanischer Theologe. Er ist bekannt geworden durch das Verhör Luthers im Jahre 1518. Er verfasste den Kommentar zur Summa Theologica von Thomas von Aquin(1508-1522), war zweimal als Legat des Papstes tätig(1518-1519 in Deutschland, 1523-1524 in Ungarn) und konzentrierte sich danach (15241534) bis zu seinem Tod auf das biblische Studium aufgrund eines Auftrags des Papstes, Clement VII. ${ }^{1038}$

Cajetan spielte eine Hauptrolle in der Wiederherstellung des Thomismus in 16. Jh. ${ }^{1039}$ Weiterhin ist er eine Hauptgestalt in der Geschichte der katholischen Ekklesiologie ${ }^{1040}$ und spielte eine Rolle als Prüfer der Lehre Luthers auf dem Augsburger Reichstag 1518. Dann veröffentlichte Cajetan neun Streitwerke gegen die frühe Reformation. ${ }^{1041}$

Cajetan beschäftigte sich mit der biblischen Auslegung, aber nicht wegen der Anregung durch die evangelische Kirche. Nach O'Connor ist das Hauptproblem Luthers nicht seine Lehre, sondern seine Liturgie. ${ }^{1042}$ In Bezug auf die Lehre glaubte Cajetan, dass der Kern des Problems Luthers die Disziplin und die Einheit der Kirche sei. ${ }^{1043}$ Im Grunde verfasste Cajetan seinen PK und die biblischen Werke nicht für die Gegenreformation. ${ }^{1044}$

Sein PK wurde 1530 in Venedig vorgelegt. ${ }^{1045}$ Cajetan erklärt in der Widmung seines PKs die Wichtigkeit der Psalmen im kirchlichen Leben. Cajetan verfasst seinen PK, um den Priestern und den Frommen bei ihren Gebeten zu helfen. ${ }^{1046}$ So ist das Ziel seines PK, die Unklarheiten und die Dunkelheiten der Heiligen Schrift für die zu erklären, die beten, die Heilige Schrift erforschen und predigen, und eine ethische Leitung der Frommen unter dem Licht der Heiligen Schrift zu geben. Eigentlich hatte Cajetan in seinem PK kein Interesse an der

\footnotetext{
${ }^{1038}$ Wicks 2008, S.618.

${ }^{1039}$ Wicks 1977, S.9.

${ }^{1040}$ Wicks 1977, S.10.

${ }^{1041}$ Wicks 1977, S.11.

1042 O'Connor 2001, S.74.

1043 O'Connor 2001, S.75.

1044 O'Connor 2001, S.78.

${ }^{1045}$ Cajetan, „Liber Psalmorum ad verbum ex Hebraeo versorum“.

${ }^{1046}$ O'Connor 2001, S.79.
} 
Häresie, nämlich die evangelische Kirche, ${ }^{1047}$ obwohl er betonte, dass das NT die Lehre der katholischen Kirche bezeuge. ${ }^{1048}$

\subsubsection{Exegese}

Cajetan verwendet für seinen PK den hebräischen Text. Er erkennt die Kritik der damaligen Humanisten an der Vg an. Im Vorwort seines PKs zeigt sich seine Begründung der Verwendung des hebräischen Textes deutlich. Und er konzentriert sich auf den literarischen Sinn des Textes. ${ }^{1049}$

Cajetan konnte kein Hebräisch lesen, stattdessen hatte er zwei Mitarbeiter für das Hebräische. Er ist kein Übersetzer, aber trotzdem ein sehr besonnener Ausleger. Er vergleicht möglichst alle Zeugnisse des Textes in den verschiedenen Traditionen, z.B. LXX, Biblia Parisiensis, Hexapla Origens, den hebräischen Text Hieronymus, Psalterium juxta hebraicam veritatem von Hieronymus und den masoretischen Text, usw. ${ }^{1050}$ Aber es ist auffällig, dass Cajetan fast kein patristisches Material verwendet. ${ }^{1051}$

Der PK Cajetans zeigt folgenden Aufbau: erstens Titel, zweitens Zusammenfassung, drittens Inhalt und viertens Anwendung. Er konzentrierte sich auf den literarischen Sinn und legte keinen Schwerpunkt auf die Auslegung der patristischen und mittelalterlichen Verfasser. Dazu erkannte er, dass die Auslegung des literarischen Sinnes damals innovativ war. ${ }^{1052}$

Klarheit, Knappheit und Kürze charakterisieren seinen PK. Anders als die Scholastik, legt er den Schwerpunkt auf den literarischen Sinn. Cajetan folgt bei seinen biblischen Arbeiten dem Prinzip, dass die Auslegung der Heiligen Schrift nach dem literarischen Sinn betrachtet werden soll. ${ }^{1053}$ Wahrscheinlich zitierte Cajetan aus diesem Grund keine patristischen und mittelalterlichen Auslegungen. Er glaubte, er sei der Erste, der die Psalmen durch den literarischen Sinn auslegt.

Er erkannte an, dass es in der Heiligen Schrift den literarischen Sinn und den spiritualen Sinn gibt, und dass ein Sinn verschwinden kann, wenn ein anderer Sinn zu stark betont

\footnotetext{
${ }^{1047}$ O'Connor 2001, S.80.

${ }^{1048}$ O'Connor 2001, S.71.

${ }^{1049}$ Collins 1955, S.364.

${ }^{1050}$ Collins 1955, S.365.

${ }^{1051}$ Collins 1955, S.371.

1052 Wicks 2008, S.619.

${ }^{1053}$ Collins 1955, S.366.
} 
wird. ${ }^{1054}$ Aber Cajetan vergaß nicht den spiritualen Sinn der Heiligen Schrift. Allerdings legte er sein Interesse der Auslegung hauptsächlich auf den literarischen Sinn. ${ }^{1055}$

Cajetan glaubte, dass ein neuer literarischen Sinn noch bestehe, den die Kirchenväter in ihren Werken nicht zum Ausdruck brachten. Allerdings soll die neue Deutung dem Kontext entsprechen und dazu mit der Lehre der Kirche harmonisiert werden. ${ }^{1056}$

\subsubsection{Theologie}

Nach der Auffassung Cajetans sind alle Psalmen David zuzuschreiben, und andere Autoren der Psalmen sind bei der Psalmenauslegung kleine Sache. ${ }^{1057}$ Jedenfalls erkennt Cajetan durchaus eine gewisse inhaltliche Insuffizienz der Schrift an. Zu den Gegenständen, die nur durch die kirchliche Autorität festgelegt sind, rechnet er vor allem die Bestimmung des biblischen Kanons. ${ }^{1058}$ Bei der Auseinandersetzung mit Luther geht es um die Suffizienz der Heiligen Schrift. Cajetan stellt die Heilige Schrift der kirchlichen Tradition voran, aber er betont die Insuffizienz der Heiligen Schrift. ${ }^{1059}$

Seine biblischen Kommentare in der 1520-er Jahren stellen Christus als das Haupt der Kirche und die einzige Quelle des Lebens, die wirksam in der Kirche gefunden wird, vor. Cajetan behauptete die Notwendigkeit der kirchlichen Reform und die Einigung mit der evangelischen Kirche Luthers 1531. ${ }^{1060}$

In ihrem Kern entspricht die theologische Einstellung Cajetans nicht der Lehre der katholischen Kirche im 16. Jh. Es ist hochwahrscheinlich, dass er durch das Verhör Luthers in seinem theologischen Denken beeinflusst wurde. Jenkens urteilt, dass die Theologie Cajetans näher zur englischen Kirche als zur katholischen Kirche steht. ${ }^{1061}$

Die Erkenntnisweise Cajetans ist ähnlich wie die Erkenntnisweise der frühen Reformation. Außerdem betont er die eingerichteten Traditionen, z.B. die Scheidung, die Wiederheirat und die liturgischen Tradition des lateinischen Dienstes usw. ${ }^{1062}$

Die Auffassung Cajetans über die Erbsünde und die Notwendigkeit der aktiven Erneuerung durch die Gnade stimmt nicht mit der evangelischen Auffassung darüber überein. Nach

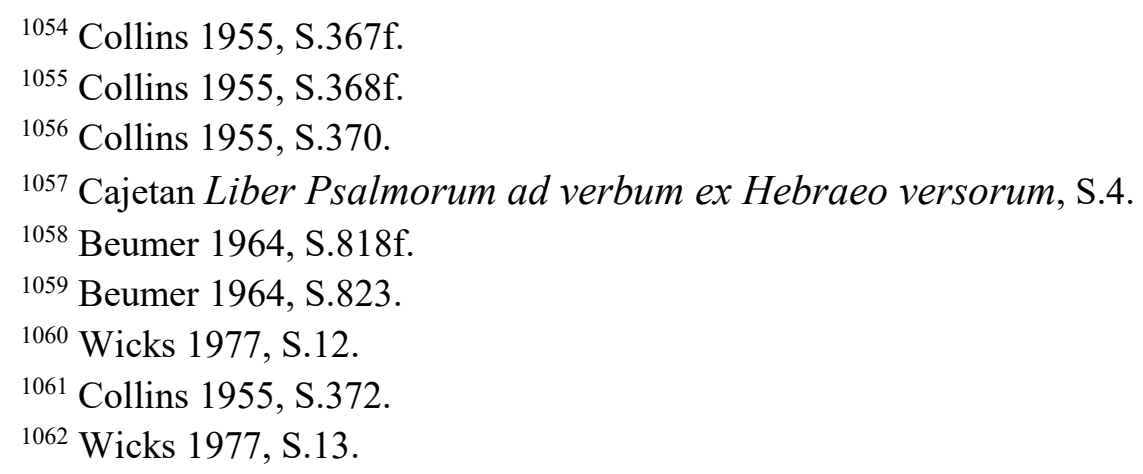


Cajetan führt das verkündigte Wort den Menschen zur Erkenntnis um den Wert seiner selbst. Der Mensch hat die Möglichkeit seiner Erlösung durch das Wort und die Gnade. Cajetan behauptet, dass die von Gott gegebene Gnade wirksam sei. Dagegen behauptet die evangelische Theologie, z.B. Luther, dass das Wort den Menschen zur Bekenntnis seiner Sünde führe. Cajetan verbleibt noch in der Theologie der katholischen Kirche, besonders hinsichtlich der Lehre über die Sünde und die Gnade.

\subsubsection{Vergleich mit dem PK Melanchthons}

Bei der exegetischen Methode steht Cajetan in der Linie der evangelischen Reformatoren. Seine Betonung über Klarheit, Knappheit und Kürze stimmt mit der Auffassung Melanchthons überein. Allerdings bleibt er in der Theologie auf der katholischen Seite. Er hält die kirchliche Tradition für wichtig, wie die Heilige Schrift. Dabei zeigt sich seine Abweichung von der Auffassung der Reformatoren.

\subsection{Zusammenfassung}

\subsubsection{Geschichte und die PKe}

In der Betrachtung der PKe der Theologen im 16. Jh. ist es notwendig, den geschichtlichen Hintergrund zu berücksichtigen. In der Zeit der ersten Hälfte des 16. Jh.s begann die Reformation, sie wurde entwickelt, angewendet und stabilisierte sich. Viele geschichtlichen Ereignisse und Entwicklungen in dieser Zeit standen in Zusammenhang mit der Reformation. Ohne das Verständnis dieser Geschichte ist es eigentlich unmöglich, die Theologie und die Entwicklung der Auslegungsmethode sachgerecht zu beurteilen.

Luther begann und entwickelte die Reformation mit den Psalmenvorlesungen in Wittenberg in den 1510er bis 1530er Jahren. Bugenhagen hielt seine Psalmenvorlesung in Wittenberg in den 1520er Jahren während des Festsetzens der Reformation. Der PK Bucers wurde in Straßburg in der Mitte der 1520er Jahre verfasst, um die Reformation in Straßburg einzuführen. Drei Psalmenkommentare sind in der Anfangszeit der Reformation verfasst worden und reflektierten die Strömung der damaligen Zeit. Sie kritisierten die Auffassungen der katholischen Kirche, konzentrierten sich auf die Aufrichtung der wahren Kirche und die Abtrennung von der frühen Tradition.

Die Psalmenkommentare von Melanchthon und Calvin zeigten dagegen andere Strömung Ende der 1540er und Anfang der 1550er Jahre verfasste Melanchthon seinen PK. Die Zeit war problematisch für die evangelische Kirche nach der Niederlage im Schmalkaldischen Krieg. In seinem PK stand die aufgerichtete wahre Kirche in einer schwierigen Situation. Für seine 
Kirche waren die Überzeugung von der Bewahrung und der Trost Gottes nötig. Calvin verfasste seinen PK Anfang der 1550er Jahre. Er beschäftigte sich damit, die Reformationstheologie auf die Kirche von Genf anzuwenden. Und er berücksichtigte immer die französische Kirche, die damals unter dem Leiden stand. Sie verteidigten die wahre Lehre der evangelischen Kirche und tadelten abweichende Lehren, die in der Reformation aufkamen. Bei der Einstellung über das Leiden wollten sie lieber die Kirche in dem Leiden trösten, weil die Kirche damals wirklich unter das Leiden geworfen war. Melanchthon und Calvin reflektierten in ihren PKen solche Stimmungen.

In dem PK Cajetans hingegen zeigen sich wenige Spuren der Stimmungen der damaligen Zeit, weil er sich aufgrund seiner Stellung im Katholizismus von der schwierigen Situation distanzierte. Aber er reflektierte sicher die Strömung des Humanimus und der Reformation in den 1530er Jahren, verteidigte die Stellung der katholischen Kirche gegen die neuen Gedanken und überzeugte sich davon, dass seine Einstellung durch die Heilige Schrift unterstützt wird.

\subsubsection{Exegetische Methode.}

Die Entwicklung der exegetischen Methode in der Psalmenauslegung der Reformationszeit wird von einer wachsenden Konzentration auf denTendenz literarischen und geschichtlichen Sinn gekennzeichnet. Diese Entwicklung zum literarischen und geschichtlichen Sinn geht von dem Humanismus aus. Allerdings waren es die evangelischen Theologen, die diese Methode auf die Auslegung der Heiligen Schrift im 16. Jh. anwendeten. Eine Ausnahme war der katholische Theologe, Cajetan.

Walter urteilt über die Methode der Psalmenauslegung durch Erasmus so, ,auch wenn er stets um die Aufhellung philologischer und historischer Details bemüht blieb, war die Zielrichtung seiner Psalmen-Auslegung eine geistliche.“ Erasmus hielt ,,an der christo- und ekklesiologischen Deutung der Psalmen in Form der Allegorese fest. “1063 Aus diesem Grund dachte Cajetan wahrscheinlich, dass er der erste Theologe sei, der die Heilige Schrift im literarischen Sinn auslegte. Aber diese Tendenz war allgemein verbreitet bei den evangelischen Theologen.

Bei den Psalmenkommentaren der evangelischen Theologen ist diese Tendenz als eine progressive Entwicklung zu beobachten. In der Anfangszeit der Reformation zeigte sich diese Tendenz der exegetischen Methode noch nicht deutlich. Luther und Bugenhagen hatten noch eine Nähe zur mittelalterlichen Tradition, allerdings ist eine neue Entwicklung bei Bucer fest-

${ }^{1063}$ Walter Peter 2008, S.754. 
zustellen. Bei Melanchthon und Calvin ist eine vertiefte Konzentrierung auf den literarischen Sinn zu erkennen. Mit der Zeit wird diese Tendenz noch verstärkt. Sie glauben, dass wenn man sich mit dem literarischen geschichtlichen Sinn abweichend von der mittelalterlichen Tradition beschäftige, er eine wahre Lehre der Heiligen Schrift erhalte. Die Tendenz der evangelischen Theologen zum literarischen Sinn in ihren PKen entspricht der literarischen geschichtlichen Auslegungsmethode, die von der mittelalterlichen traditionellen Auslegung abweicht.

Die äußeren Erscheinungsformen dieser Tendenz bei den evangelischen Theologen sind verschieden. $\mathrm{Zu}$ jedem Psalm können verschiedene Deutungen auch bei den evangelischen Theologen bestehen. Dazu unterscheiden sie sich darin voneinander, welche Psalmen zu den messianischen Psalmen gerechnet werden.

Die Unterschiede sind aber nicht qualitativ, sondern quantitativ. Alle evangelischen Theologen legten die Psalmen aufgrund ihrer eigenen Standpunkte aus. Aber in ihren Auslegungen existiert die Gemeinsamkeit der Auslegungsmethode als eine Tendenz zu dem literarischen und geschichtlichen Sinn. Aus diesem Grund muss man vorsichtig sein, mit eigenen Deutungen zu früh die Auslegungsmethode eines Theologen zu beurteilen oder zu generalisieren. Bei der Betrachtung ihrer PKe soll man sich nicht auf die kleinen Unterschiede konzentrieren, sondern auf die große Gemeinsamkeit, um ihre Auslegungen zu den Psalmen in ihrem Zusammenhang richtig zu verstehen.

Die Entwicklung der Auslegungsmethode zu den Psalmen im 16. Jh. richtet sich auf den literarischen und geschichtlichen Sinn statt auf die christozentrische Auslegung gemäß der mittelalterlichen Tradition. Allerdings trifft es nicht zu, dass Luther, Bugenhagen, Bucer, Calvin, Cajetan und Melanchthon kein Interesse an der Beziehung der Psalmen zu Christus hatten. Sie stimmen vielmehr zu, dass die Psalmen als eine Prophezeiung über Christus zu verstehen sind. Die Unterschiede unter den Auslegern kommen aus deren Erklärungen darüber, wie die Prophezeiungen der Psalmen über Christus mit dem literarischen und geschichtlichen Kontext der Psalmen zusammenhängen.

In der mittelalterlichen Deutung, nämlich die Psalmen unmittelbar auf Christus anzuwenden, konnte David häufig an den Rand gedrängt werden, obwohl die Psalmen deutlich doch über David sprachen. Durch die Berufung auf den literarischen Sinn ist dies allerdings nicht länger der Fall. Auf David soll nun der erste Sinn gelegt werden. Das ist der große Unterschied zwischen der mittelalterlichen Deutung und der reformatorischen Deutung der Psalmen. 
Die späten Auslegungen Luthers zu den Psalmen zeigen eine zurückhaltendere Einstellung gegenüber einer direkten Anwendung der Psalmen auf Christus. Bei den PKen von Bugenhagen, Bucer und Calvin kann man noch mehr eine Besonnenheit bei den Anwendungen der Psalmen direkt auf Christus beobachten. Sie verweigerten es, die Psalmen unmittelbar und allein auf Christus anzuwenden.

Melanchthon legte unter dem gleichen Prinzip die Psalmen aus. Wie andere Ausleger im 16. Jh., lässt er David in der Deutung der Psalmen durch die christozentrische Auslegung nicht „verschwinden“. Gleichzeitig vergisst er nicht die Tatsache, dass die Psalmen sich auf Christus beziehen. Vielmehr weist Melanchthon darauf hin, dass die Psalmen sich auf die Kirche richten. David spielt so eine wichtige Rolle, um die Psalmen an die Kirche anzuschließen.

Die Unterschiede unter den Reformatoren bestehen darin, wie sie die Psalmen auf Christus beziehen. Luther verwendet dafür noch traditionell die Allegorese, und Bucer verbindet die Psalmen mit Christus durch die Typologie. Melanchthon stützt sich auf den Grundgedanken, dass David, Christus und die Kirche gleich sind. Calvin bezieht die Psalmen auf Christus, wenn die Psalmen namentlich oder bestimmt mit Christus zu verbinden sind.

Die evangelischen Theologen berufen sich übereinstimmend auf den Gedanken, dass die Psalmen eine prophetische Bedeutung haben. Daher sind die Psalmen die schon überlieferte Offenbarung Gottes für die Kirche über Christus. Die Psalmen stimmen genau mit Christus überein und gelten und nützen den ganzen Mitgliedern der Kirche. Dieser Gedankengang entspricht auch der Auffassung Melanchthons über die Psalmen. So zeigen sich die Gemeinsamkeiten in der Auffassung der Reformatoren über die Methode der Auslegung der Psalmen und das Verständnis der Heiligen Schrift.

\subsubsection{Entwicklung der reformatorischen Theologie}

Die Auslegungsmethode verbindet sich mit einer theologischen Prämisse. Für die evangelischen Theologen war die Prämisse die Autorität und die Einheit der Heiligen Schrift. Dazu hatte der katholische Theologe, Cajetan eine andere Einstellung darüber. Auch wenn Cajetan sich auf den literarischen Sinn der Psalmen konzentrierte, stimmte er der einzigen Autorität der Heiligen Schrift nicht zu, sondern er stellte die Tradition der Kirche neben die Heilige Schrift. Daher fand die Frage nach der die Einheit der Heiligen Schrift kein Interesse bei Cajetan, weil die Autorität der kirchlichen Tradition eine bestimmte Lösung für die Probleme geben konnte. Aus diesem Grund konzentrierte Cajetan sich bei seinem PK nicht auf die theologischen Anliegen der Kirche, sondern auf die persönliche Frömmigkeit und Ethik. 
Im Gegensatz dazu konzentrierten sich die evangelischen Theologen auf die theologischen und kirchlichen Anliegen. Luther beschäftigte sich mit der Autorität und der Einheit der Heiligen Schrift ausgehend von einer Theologie, die zwar nicht zu der Tradition passt, wohl aber sondern zu der Heiligen Schrift. Andere Reformatoren, die den gleichen Gedanken über die Heiligen Schrift hatten, sahen in den Psalmen die Richtigkeit ihres Gedankens und forderten von der Kirche die theologische Erneuerung. Aber die katholische Kirche verweigerte die Erneuerung, weil die Autorität der Heiligen Schrift für die katholische Kirche nicht völlig anerkannt werden kann und die Hilfe der Kirche notwendig ist, um das wahre Verständnis von der Heiligen Schrift zu erkennen.

Die Exegese der Heiligen Schrift bezieht sich insofern immer auf die theologische Einstellung zu der Heiligen Schrift, nämlich dass die Heilige Schrift eine prophetische Eigenschaft hat und auf die Kirche angewendet werden soll. Diese Einstellung betrifft die Auffassung über die Autorität und die Einheit der Heiligen Schrift, davon ausgehend über den Zusammenhang zwischen dem AT und dem NT und den Anschluss an die heutige Kirche. Mit diesen Anliegen beschäftigten sich die evangelischen Theologen bei ihren PKen.

Der Gedanke über die Autorität und die Einheit der Heiligen Schrift stimmt bei den evangelischen Theologen überein. Sie suchen die einzige Autorität in der Heiligen Schrift, und die Kirche soll dieser Autorität gehorchen. Sowohl die Liturgie und die Ornamente der Kirchengebäude als auch die aktuelle Gegenwart jedes Lebens sollen der Heiligen Schrift folgen, in der sich die Verheißung Gottes für die Kirche, nämlich das Evangelium findet. Einheitlich entdeckten diese Theologen die Verheißung Gottes in der Heiligen Schrift und glaubten, durch die in der Heiligen Schrift entdeckte Verheißung erlöst zu werden.

Aber wenn sie ihre theologische Auffassung in ihren PKen herausstellen, verfassen sie keine dogmatische Darstellung, sondern sie bleiben ihre Auslegungen der Gattung nach eine Auslegung der Heiligen Schrift. Sie unterscheiden die Auslegung der Heiligen Schrift von der dogmatischen Darstellung der späteren lutherischen und reformierten Orthodoxie. Zumindest bei den evangelischen Theologen im 16. Jh. geht die Theologie nicht von der dogmatischen Lehre, sondern von der Auslegung der Heiligen Schrift aus. Ihre PKe sind Beispiele dafür. 


\subsection{Heubtartikel Christlicher Lere(1558, verfasst 1553)}

\subsubsection{Geschichte und der Charakter der Heubtartikel}

Nun werden die Loci Melanchthons in Deutsch 1558(Heubtartikel Christlicher Lere) ${ }^{1064}$ mit seinem PK verglichen. Die Heubtartikel wurden in zeitlicher Nähe PKs verfasst. ${ }^{1065}$ Aus diesem Grund kann man einen Einfluss voneinander erwarten. Die Heubtartikel, eine bedeutende Dogmatik Melanchthons, zeigen seine reife Theologie. Durch den Vergleich von dem PK und den Heubtartikeln zeigen sich die Charakter des PKs als die biblische Auslegung. Somit kann die Theologie des PKs objektiv urteilt werden.

Die Heubtartikel wurde schon 1553 von Melanchthon selbst in Deutsch verfasst ${ }^{1066}$ und erschienen 1558 in Wittenberg im Druck. Schilling schätzt die Heubtartikel so, ,als spätester Druck einer von ihm selbst bearbeiteten Ausgabe der Heubtartikel ist er eine Summe seiner Theologie und sozusagen sein theologisches Vermächtnis.“ ${ }^{1067}$ Melanchthon selbst stellt auch die Heubtartikel so dar, dass die letzte deutsche Ausgabe besser sei, als das lateinisch geschriebene Buch. ${ }^{1068}$ Daher zeigen die Heubtartikel 1558 die vollendete Theologie Melanchthons, und im Zusammenhang mit seinem PK könnten sie wahrscheinlich von der direkt nach dem Schmalkaldischer Krieg stattgefundenen Psalmenvorlesung einen emotionalen und theologischen Einfluss empfangen haben. ${ }^{1069}$

Bei diesen Heubtartikeln ist die Sprache, nämlich das Deutsche am auffälligsten. Die Sprache impliziert den Zweck des Werkes. Latein war damals die wissenschaftliche Sprache für die begrenzte Zahl gelehrter Menschen, dagegen war das Deutsche die Umgangssprache für die weit überwiegende Zahl der Bewohner. Daher sind die Adressaten der Heubtartikel nicht die Gelehrten, sondern die einfachen Menschen. Insofern ist seine Widmung an Anna

\footnotetext{
${ }^{1064}$ Heubtartikel wurden 2002 von Ralf Jenett und Johannes Schilling mit der Grundlage der Manuskripte Melanchthons 1553 herausgegeben.

${ }^{1065}$ Die beiden Werke bleiben ähnlich mit den Manuskripten Melanchthons. Über die Manuskripte von den Heubtartikel siehe Heubtartikel, S.17-49 und über die Manuskripte des PKs siehe Kapitel 2. 1066 Über die Geschichte dieser Fassung siehe Schilling 1996, S.337-352, und Stupperich 1958, S.4758.

1067 Schilling 1996, S.337.

${ }^{1068}$ MBW 7, 364. Nr 7636. „Scriberem ad te prolixe et de multis rebus, si non properaret tabellarius. De editione Germanici schripti, in quo utcunque summam doctrinae Eccelesiasticae complxus sum, totam rem tuo iudicio permitto. Si existimas illam nostram lucubrationem profuturam esse Ecclessis, nequaquam prohibeo edi, seu dialecto vestrae viciniae, seu nostra. Et iudico recentem Germanicam editionem meliorem esse libro Latine scripto, cui titulus est, Loci Theologici.“(CR 8, 607.)

${ }^{1069}$ Um die Zusammenhang zwischen den Loci 1558 und dem PK genau zu urteilen, ist es nötig, die Entwicklung der Loci nach dem Schmalkaldischer Krieg zu erforschen.
} 
Camerarius, die Frau seines vertrautesten Freundes, Joachim Camerarius, ein gutes Zeugnis dafür. Anna ist keine gelehrte Frau, sondern eine Hausfrau, die sich mit dem Haushalt und der Kindererziehung beschäftigte.

Obwohl Melanchthon die lateinischen Loci als ein Lehrbuch verfasste, ist seine besondere Absicht bei den Heubtartikeln darin zu sehen, dass er die göttliche Wahrheit der Heiligen Schrift für die einfachen Menschen mit seiner Schrift erklären wollte. Die Reformation sollte nicht nur den gelehrten Wissenschaftlern und Pfarrern bekannt werden, sondern auch den einfachen Menschen, z.B. einer Hausfrau wie Anna. Diese Intention bestand bei Melanchthon schon in seiner frühen Zeit wurde aber nach dem Schmalkaldischer Krieg und dem Fürstenkrieg gestärkt, weil die Reformation, nämlich die evangelische Kirche, eine schwierige Zeit der Verfolgung erfuhr und doch überlebte. Wahrscheinlich sah er einen Bedarf nach beiden Kriegen, die Hauptlehre der Reformation an die einfachen Menschen weiterzugeben, um die evangelische Kirche weiter zu stabilisieren. Dabei spielt die Frau in ihrem Haus eine wichtige Rolle für die Erziehung, um die evangelische Lehre auf das Alltagsleben anzuwenden und um eine fromme nächste Generation zu stellen. Bei den Heubtartikeln legte er so Gewicht auf die allgemeine Anwendung der Lehre.

\subsubsection{Unterschiede von den Heubtartikel und dem PK}

Im Vergleich mit seinem PK zeigen die Heubtartikel einige Unterschiede. Erstens die Adressaten. Wie erwähnt, sind die Heubtartikel eine in Deutsch geschriebene Schrift über die christliche Lehre für die gewöhnlichen Menschen, dagegen war der PK eine in Latein gehaltene Vorlesung für die an der Universität Studierenden, die die Heiligen Schrift recht auslegen und dann die Lehre der Heiligen Schrift in der Gemeinde lehren wollen. ${ }^{1070}$ So sind mit der Sprache auch die Adressaten von beiden Schriften verschieden.

Bayer erwähnt zwei wichtige Themen aus den Loci 1559, die in Latein geschrieben sind, aber inhaltlich nicht anders sind als die Heubtartikel. Erstens die Kirchlichkeit und zweitens die Wissenschaftlichkeit. ${ }^{1071}$ Damit erklärt Melanchthon, dass Gott die Wahrheit der Kirche für die Erlösung gab und auch der Welt für die Ordnung. Die Wahrheit Gottes ist vor allem für die Kirche von Bedeutung, aber auch für die Welt, weil Gott der Schöpfer und der Herrscher der ganzen Welt ist.

\footnotetext{
${ }^{1070}$ Vgl. Kapitel 3.3.2.

${ }^{1071}$ Bayer 1994, S.146f.
} 
Die Heubtartikel richten sich vor allem auf die Kirche, aber auch auf die, die das Evangelium durch den Glauben noch nicht angenommen haben. Mit den Heubtartikeln hatte Melanchthon die Absicht, allen Menschen zu verkündigen, dass jeder Mensch von Gott geschaffen sei und nach dem Gesetz Gottes leben solle. Erstens versucht Melanchthon mit den Heubtartikeln, den Willen Gottes für die Kirche und die Wahrheit der Erlösung zu verteidigen, um der Kirche den Nutzen und den Trost zu geben. Zweitens versucht er damit, der Welt die gültige Wahrheit Gottes zu verkündigen und zu erklären. Die Heubtartikel richten sich auch an die Menschen, die nicht der Kirche angehören.

Im Gegensatz, dazu richtet der PK Melanchthon sich allein an die Kirche. Melanchthon sieht in den Psalmen den Willen Gottes für die Kirche, die Bedrängnisse der Kirche in diesem Leben und die Bewahrung und die Gnade Gottes, die die Kirche unter dem Leiden in diesem Leben erfährt, und er überliefert diese Mitteilung der Psalmen denen, die den gleichen Glauben wie Melanchthon besitzen.

Zweitens sind der PK und die Heubtartikel in ihrer Gattung unterschieden. Die Heubtartikel ordnen die Themen der Wahrheit der Heiligen Schrift für die Erlösung ein, erklären sie und kritisieren die abweichende Lehren. Dagegen entdeckt und erklärt der PK die konkreten Inhalte in der Heiligen Schrift verständlich im Kontext der Heiligen Schrift.

Ein solcher Unterschied in der Gattung bewirkt auch Unterschiede in der Erklärungsweise und deren Inhalt. Der PK erklärt den Inhalt nach der Abfolge des Textes in seinem Kontext. Dagegen werden die Heubtartikel nach der Logik der gesamten Lehre der Heiligen Schrift dargestellt. Die Heubtartikel behandeln die Themen der Heiligen Schrift für die Erlösung, aber der PK erklärt die nicht im Text behandelten Themen wenig oder gar nicht. Dieser Unterschied resultiert allein aus der Gattung, nicht aus der Theologie.

Als repräsentatives Beispiel dafür kann man die Erklärung der Verwendung des Gesetzes anführen. Im PK werden allein zwei Verwendungen des Gesetzes genannt, nämlich usus theolgicus legis und usus tertius legis, ${ }^{1072}$ aber bei den Heubtartikeln werden drei Verwendungen des Gesetzes erklärt. Die Quantität der Erklärung ist größer in den Heubtartikeln als in dem PK. ${ }^{1073}$

Dazu kann auch die Erklärung über die Verwerfung als ein Unterschied zwischen beiden erwähnt werden. Bei den Heubtartikeln ist die Erklärung der Verwerfung deutlich, ${ }^{1074}$ aber

\footnotetext{
${ }^{1072}$ Vgl. Kapitel 4.2.7.

${ }^{1073}$ Vgl. Heubtartikel, S.228-234.

${ }^{1074}$ Heubtartikel, S.302-306.
} 
bei dem PK relativ wenig ausgeprägt. Er konzentriert sich im PK vor allem auf die Erwählung. ${ }^{1075}$

Diese Unterschiede zwischen beiden Schriften kann man mit dem theologischen Grund und der jeweiligen Gattung erklären. Wie erwähnt, sind die Gattungen der Heubtartikel und des PKs verschiedene. Deswegen ist es selbstverständlich, dass beide Werke auf eine andere Weise geschrieben worden sind, die Heubtartikel mehr logisch, der PK mehr dem Text folgend.

Es ist aber auch ein theologischer Grund zu nennen. Während die Heubtartikel für die einfachen Menschen die Lehre der Heiligen Schrift vorstellen, behandelt der PK die Psalmen, nämlich die Lieder der Kirche. Wie betrachtet, gehören die Psalmen für Melanchthon zum Evangelium. ${ }^{1076}$ Aus diesem Grund ist es unnötig, beim PK Nichtchristen zu berücksichtigen, die die Psalmen nicht lesen. ${ }^{1077}$ Die Psalmen sind allein für die Erwählten, nämlich die Kirche, die eine ausführliche Erklärung über die Verwerfung nicht braucht. Stattdessen braucht die Kirche die Psalmen als Erklärungen dazu, wie sie in diesem Leben lebt und leidet, und wie Gott sie leitet, beschützt und tröstet. Diese Aspekte sind in dem PK die Hauptanliegen Melanchthons.

Schilling erwähnt vier Gegner der Heubtartikel, erstens Osiander, zweitens das Trienter Konzil, drittens Täufer und viertens Thomas Müntzer. ${ }^{1078}$ Allerdings erwähnt er nicht den geschichtlichen Kontext, nämlich den Sieg von Moritz von Sachsen im Fürstenkrieg. Somit waren die geschichtlichen Hintergründe von dem PK und den Heubtartikel ganz andere. ${ }^{1079}$

Die Vorlesung an der Universität konnte die Stimmung der Zeit relativ besser reflektieren, als die objektive Darstellung der Lehre. Wenn das geschichtliche Geschehen so stark ist, ist die Äußerung auch so. Der Niederlage der evangelischen Lagers im Schmalkaldischen Krieg

\footnotetext{
${ }^{1075}$ Vgl. Kapitel 4.3.6.

1076 Vgl. Kapitel 3.1.2.

1077 Melanchthon weist darauf hin, dass die Gottlosen die Psalmen nicht lesen. Vgl. PK Ps 59, CR 13, 1144. „Haec consolatio cum necessaria sit Ecclesiae, saepe repetitae sunt maledictiones, quae quidem scriptae sunt magis ad consolandos et confirmandos pios, quam ad sanandos impios, qui eas non legunt."

${ }^{1078}$ Schilling 1996, S.350.

1079 Über die damalige Geschichte vgl. Kaufmann 2009, S.676-698 und Scheible 2016, S.208-223, S.261-268 und Kapitel 2.1.
} 
war der Hintergrund für den PK Melanchthons. ${ }^{1080}$ Der Sieg von Moritz von Sachsen im Fürstenkrieg war der Hintergrund für die Heubtartikel. $\mathrm{Zu}$ seinem PK hatte Melanchthon einen emotionellen Anstoß, dass die evangelische Kirche sich von der Bewahrung und dem Schutz Gottes überzeugt. Aber bei den Heubtartikel konnte er die wahre Lehre für die schon von Gott bewahrte Kirche ruhig erklären, um die Kirche noch mehr zu stabilisieren.

In den Darstellungen über Laurentius kann man etwa eine Spur dafür finden. In dem PK wird die Todeserfahrung von Laurentius in der Auslegung von einigen Psalmen dargestellt, um die Kirche seiner Zeit im Leiden durch das Beispiel Märtyrers Laurentius zu ermuntern und zu trösten. ${ }^{1081}$ Dagegen wird Laurentius in den Heubtartikeln mit anderen Heiligen kurz im Kontext der leidenden Kirche erwähnt. ${ }^{1082}$

Außerdem sind ausführliche Darstellungen über das Leiden in dem PK Melanchthons häufig zu finden. David ist ein repräsentatives Beispiel dafür. Melanchthon stellt die Trübsale Davids im PK dar und führt sie zu der Freiheit Davids. ${ }^{1083}$ In den Heubtartikeln behandelt Melanchthon das Thema des Leidens der Kirche unter dem Titel „Von Trübsal und Creutz zu tragen. “ ${ }^{1084}$ Hierbei erklärt er das Leiden der Kirche, den Grund dafür und den Zweck mit den entsprechenden Belegen der Heiligen Schrift. Die Darstellung ist objektiv und ruhig im Gegensatz zu seinem PK.

In der zeitlichen Folge der beiden Schriften könnte man eine theologische Entwicklung vermuten. Aber nach der Betrachtung der Gattungen und der Stimmungen der Zeit verweisen die Unterschiede nicht auf eine theologische Entwicklung. Zeitlich liegen zwar beide Schriften nahe beieinander, aber der Kontext des jeweiligen geschichtlichen Geschehens war so bedeutend, dass sich in den Heubtartikel und im PK deren Einflüsse spiegeln. Der PK wurde unter dem Leiden verfasst, aber die Heubtartikel wurden nach dem Leiden verfasst. Aus diesem Grund ist die Stimmung der Heubtartikel selbstverständlich ruhiger und positiver als die Stimmung des PKs.

\footnotetext{
${ }^{1080}$ Hier muss man berücksichtigen, dass der PK aus drei Teilen besteht. Der erste Teil des PKs wurde direkt nach dem Schmalkaldischen Krieg verfasst und die letzten Teilen danach. Daher wird hier eigentlich der erste Teil behandelt. Vgl. Kapitel 2.2.

${ }^{1081}$ PK Ps 4, CR 13, 1023; PK Ps 38, CR 13, 1078; PK Ps 51, CR 13, 1117; PK Ps 56, CR 13, 1132.

${ }^{1082}$ Heubtartikel, S.300 und 311.

${ }^{1083}$ Z.B. PK Ps 6, CR 13, 1025; PK Ps 10, CR 13, 1034; PK Ps 28, CR 13, 1059f.; PK Ps 35, CR 13, 1071; PK Ps 37, CR 13, 1076; PK Ps 38, CR 13, 1077; PK Ps 42, CR 13, 1086.

${ }^{1084}$ Heubtartikel, S.406-417.
} 


\subsubsection{Gemeinsamkeiten und Einfluss von den Heubtartikel und dem PK}

Wenn diese Unterschiede von beiden Werken nicht entsprechend berücksichtigt werden, könnte ein unangemessenes Urteil die Folge sein, wie z.B. ein Widerspruch in der Theologie Melanchthons. Trotz dieser Unterschiede stehen die beiden Werke Melanchthons auf dem gleichen theologischen Grund. Dieser Grund ist der Gedanke der Einheit von dem AT und dem NT. In den beiden Werken kann man die Überzeugung Melanchthons erkennen, dass die biblischen Schriften einheitlich und der einzige Grund für die christliche Lehre sind. Dieser Gedanke findet sich vor allem bei der Verwendung der biblischen Belege. Bei dem PK legt Melanchthon einen Vers aus, dann fügt er andere biblische Verse als Belege hinzu, um die Richtigkeit seiner Auslegung zu bestätigen. Bei der Darstellung der biblischen Belege macht er keinen Unterschied zwischen dem AT und dem NT. ${ }^{1085}$ Vielmehr wenn er das Wort Christi zitiert, betont er, dass das Zitat zu Christus gehört. ${ }^{1086}$

Diese theologische Einheit von dem AT und dem NT zeigt sich auch bei den Heubtartikel - vor allem in der Darstellung der biblischen Belege. ${ }^{1087}$ Dazu erklärt Melanchthon den Zusammenhang von dem AT und dem NT in einem getrennten Kapitel. ${ }^{1088}$ Er hat keinen Zweifel an der Einheit von dem AT und dem NT. Aus diesem Grund konnte er die christliche Lehre von dem AT und dem NT ohne Widerspruch einordnen und logisch erklären. Die Heilige Schrift braucht keinen anderen Grund, anders als die Auffassung der katholischen Kirche, die außer der Heiligen Schrift eine kirchliche Tradition für die Autorität in Anspruch nimmt.

Melanchthon findet die Wahrheit Gottes in der Heiligen Schrift und erkennt die Wahrheit als nicht widersprüchlich und als übereinstimmend mit dem Ganzen der Heiligen Schrift. Aus diesem Grund stimmt die Wahrheit des ATs mit der NTs überein, der Gott des ATs mit dem Gott des NTs, die Erlösung des ATs mit der Erlösung des NTs und die Lebensweise des ATs mit der Lebensweise des NTs. Die Unterschiede zwischen beiden Testamenten sind äußerlich, aber innerlich und wesentlich besteht kein Unterschied zwischen beiden Testamenten. Der äußere Unterschied ist das Kommen Christi. Das AT zeigt Christus, der noch nicht in der Welt ist, und Werke, die Christus für die Kirche machen wird. Dagegen sieht das NT Christus, der schon in der Welt gekommen ist, und seine Werke, die Christus für die Kirche gemacht

\footnotetext{
${ }^{1085}$ Vgl. Kapitel 3.2.1.

${ }^{1086}$ Ein Beispiel. PK Ps 26, CR 13, 1057. „sicut ait Christus: Qui negaverit me coram hominibus, negabo eum coram patre coelesti.“

1087 Schilling 1996, S.349.

${ }^{1088}$ Heubtartikel, S.307-309. Dabei erklärt Melanchthon die Gemeinsamkeit von beiden Testamenten, dass das AT auch die Verheißung Gottes ist.
} 
hat. Trotzdem sind der Christus des ATs und der Christus des NTs gleich. Unter diesem Prinzip einigt und harmonisiert Melanchthon freilich das AT und das NT.

Der Zusammenhang zwischen dem AT und dem NT zeigt sich in den Heubtartikel in der Lehre über Gott und die Erlösung und in dem PK in dem Auslegungsprinzip der Gleichsetzung von David, Christus und der Kirche. ${ }^{1089}$ Das AT verliert nicht seine Gültigkeit und ist nicht unnütz, sondern das AT ist gültig als die Verheißung Gottes wie das NT und zeigt Gott und den Menschen. Dadurch genießt die Kirche den Nutzen und den Trost. Das ist der Gedanke Melanchthons über den Zusammenhang der beiden Testamente.

Wie betrachtet, beziehen sich die Heubtartikel auf die Kirche und die einfachen Menschen als deren Adressaten. Allerdings richten die Heubtartikel sich vor allem auf die Kirche, um die Wahrheit Gottes für die Erlösung der Kirche vorzustellen. Denn die Heubtartikel zielen darauf, die Mitglieder der Kirche es zu lehren, wie sie die Heiligen Schrift einheitlich und wahrhaft sehen sollen. Deswegen ist der Zweck der Heubtartikel der Nutzen der Kirche. Sie sind ein Lehrbuch, nach dem die Mitglieder der Kirche als das Volk Gottes ihr Leben führen sollen. Durch das Lehrbuch können sie ihr Leben betrachten und die wahre Erkenntnis darüber erhalten, was sie in diesem Leben erfahren werden. Ihr Leben steht immer unter dem Leiden, und das Leiden bleibt bei ihnen bis zum Ende des Lebens. Obwohl sie schon die Realität des Leidens in diesem Leben erkennen, sehen sie die Hilfe und die Bewahrung Gottes und erhalten den großen Trost.

Melanchthon entdeckt seine Kirche in den Psalmen. Die Kirche leidet unter dem Kreuz. Das ist die Realität der Kirche in der Zeit Melanchthons. Wenn die Mitglieder der Kirche die gleiche schwierige Situation der Kirche in der Zeit der Psalmen sehen, dann erwarten und erbitten sie auch die gleiche Bewahrung, die gleiche Hilfe und die gleiche Erlösung. Der PK Melanchthons zielt somit auf den Nutzen

und den Trost der Kirche.

Für Melanchthon ist das Hauptanliegen in den Heubtartikeln und dem PK immer die Kirche. Er verfolgt in den Heubtartikeln und dem PK die Absicht, dass die Kirche einen großen Nutzen durch die Erkenntnis über die Wirkung Gottes und das allgemeine Leben der Kirche in diesem Leben erhält und den großen Trost in ihrem Leiden und ihrer Bedrängnis durch die Überzeugung von der Hilfe und der Bewahrung Gottes erfährt. Die Anliegen Melanchthons für die Kirche kann man also sowohl in seinen Heubtartikeln als auch in seinem PK finden.

${ }^{1089}$ Vgl. Kapitel 3.2.4. 
Melanchthon konzentrierte sich in beiden Werken nicht auf die Frömmigkeit der Einzelnen und die Beruhigung der Gesellschaft, sondern eher auf die Sache der Kirche. Die Kirche wird auch unter dem schwierigen Leiden bewahrt und befreit. So sah er allein die Situation seiner Kirche und erwartete die Verwirklichung der Verheißung Gottes für die Kirche. In dem PK und den Heubtartikeln ist die Konzentration Melanchtons auf die Kirche deutlich zu ersehen. Somit sieht man den Zusammenhang von beiden Werken. Dazu wird auch der Einfluss von beiden Werken erklärt.

Der PK Melanchthons betont die Sukzession der Kirche und fordert die Kirche auf, für die Bewahrung, die Milderung des Leidens und die Freiheit zu beten. ${ }^{1090}$ Damals war die geschichtliche Situation für seine Kirche schlimm und für die Kirche war die Freiheit nötig. ${ }^{1091}$ Allerdings als er die Heubtartikel verfasste, änderte sich die Situation. Durch den Sieg von Moritz von Sachsen im Fürstenkrieg 1552 erhielt seine Kirche wieder die Freiheit. Wahrscheinlich aus diesem Grund wollte Melanchthon die Freiheit der Kirche in dieser Zeit betonen. Das wichtige Zeugnis dafür ist die Reihenänderung des Kapitels über die Freiheit der Kirche in den Heubtartikeln. In den Loci 1559 liegt dieser Kapitel am Ende. Aber in den Heubtartikeln liegt dieser Kapitel vor dem Kapitel über die Kirche. ${ }^{1092}$ Er wollte die Freiheit der Kirche früher als die Kirche erklären. So können die Leser der Heubtartikel sich an ihre damaligen Gebete und die gegenwärtige Freiheit der Kirche, die im PK gefordert wurden, erinnern. Man kann erschließen, dass das damalige Hauptanliegen Melanchthons die Freiheit der Kirche war. Im PK erwartete er die Freiheit und in den Heubtartikel sah er die Freiheit. So kann die Reihenänderung des Kapitels über die Freiheit der Kirche durch den Einfluss des PKs erklärt werden.

\footnotetext{
${ }^{1090}$ Vgl. Kapitel 4.5

${ }^{1091}$ Vgl. Kapitel 2.1

${ }^{1092}$ Vgl. Heubtartikel, S.310 und CR 21, XV.
} 


\section{Samenvatting}

Het 'Commentaar op de Psalmen' van Melanchthon is samengesteld uit colleges over de Psalmen, die Melanchthon van 1548-1553 aan de Wittenberger universiteit heeft gehouden. In zijn 'Commentaar op de Psalmen', maakt hij gebruik van de humanistische methode voor exegese. Het commentaar bestaat uit een deel met argumenten en uit een deel met structuur. Bij de exegese speelt de theologische basis een belangrijke rol. Ten eerste is de eenheid van Oude en Nieuwe Testament belangrijk, ten tweede de onderscheiding tussen Wet en Evangelie, ten derde de samenhang tussen Christus en de kerk en ten vierde de samenhang tussen David en de Kerk. Belangrijke kenmerken van Melanchthons 'Commentaar op de Psalmen' zijn duidelijkheid, pedagogiek en de toepassing op de kerk.

De theologie van zijn 'Commentaar op de Psalmen' is te beschouwen vanuit zes thema's. Het eerste thema is de openbaring van God aan de kerk. Het tweede thema is de Wet die de inhoud van de openbaring is, en het beginsel waarmee God de wereld regeert. Door de Wet wordt het oordeel van God over de mensen vastgesteld. Ten derde geeft God de kerk het Evangelie, als een tweede principe voor de verlossing. Ten vierde is de kerk het object van het Evangelie. Ten vijfde lijdt de kerk die het Evangelie aanneemt, in dit leven en daarom roept de kerk tot God. Ten zesde verhoort God de roep van de kerk. Deze overwegingen wijzen erop, dat in het centrum van Melanchthons 'Commentaar op de Psalmen' de relatie van God met de kerk staat, concreet de troost en de belofte van God voor de bewaring van de kerk.

In de zestiende eeuw legden veel theologen, waaronder Melanchthon, de Psalmen uit. Zo zijn Luther, Bugenhagen, Bucer en Calvin als reformatoren en Cajetan als katholiek te noemen. Door hun commentaren op de Psalmen te vergelijken, wordt de eenheid van de reformatorische theologie en het onderscheid met de katholieke uitleg zichtbaar, met name als het gaat om de vraag naar de autoriteit. Bovendien is de invloed van Melanchthons 'Commentaar op de Psalmen' op de Loci 1553 te zien, door de verandering van de artikelen die in de Loci gaan over de vrijheid van de kerk. 


\section{Quellen und Literatur}

Die Abkürzungen folgen dem Abkürzungsverzeichnis von Siegfried Schwertner, Internationales Abkürzungsverzeichnis für Theologie und Grenzgebiete, Berlin/Boston 2014 $\left(\mathrm{IATG}^{3}\right)$. Darüber hinaus gibt die folgende Liste die verwendeten Abkürzungen in dieser Arbeit.

PK $=$ Psalmenkommentar

Prol $=$ Prolegomena von dem PK Melanchthons in CR 13, 1017-1018.

Ps 51z, 34z und 31z = PK Ps 51, 34 und 31 in CR 13, 1224-1244.

\subsection{Quellen}

\section{Philipp Melanchthon}

CR 1-28 = Philippi Melanchthons opera quae supersunt omnia, hg. v. Carl Gottlieb Bretschneider und Heinrich Ernst Bindseil, 28 Bde. Halle und Braunschweig 1834-1869 (Corpus Reformatorum 1-28).

Rhetorices $=$ Elementa rhetorices. Mit den Briefen Senecas, Plinius' d.J. und den "Gegensätzlichen Briefen" Giovanni Picos della Mirandola und Franz Burchards = Grundbegriffe der Rhetorik, hg. von Volkhard Wels, Berlin: Weidler 2001(Bibliothek seltener Texte, 7).

Heubtartikel $=$ Heubtartikel christlicher Lere. Melanchthons deutsche Fassung seiner Loci theologici, nach dem Autograph und dem Originaldruck von 1553, hg. v. Ralf Jenett und Johannes Schilling. Leipzig: Evang. Verl.-Anst 2002.

MBW $=$ Melanchthons Briefwechsel. Kritische und kommentierte Gesamtausgabe, im Auftrag der Heidelberger Akademie der Wissenschaften hg. v. Heinz Scheible u.a., StuttgartBad Canstatt 1977-.

Melanchthon deutsch, hg v. Michael Beyer u.a., Bd. 2: Theologie und Kirchenpolitik, Leipzig 1997.

MelStA II/1 = Melanchthons Werke in Auswahl, II. Bd. 1. Teil, Loci communes von 1521, Loci praecipui theologici von 1559 (1. Teil), hg. v. Hans Engelland, Gütersloh 1952.

Opera 1-4 = Omnium operaum reverendi viri Philipp Melanthonis, hg. v. Caspar Peucer, 4 Bde. Wittenberg 1562-1564.

\section{Psalmenkommentar Melanchthons}

Cod.Pal.Lat. 1829. = Codices Palatini latini 1829, Philipp Melanchthon, Commentarius in Psalmos, Wittenberg um 1547-1548(das eigene Manuskript Melanchthons, von Prol bis die Überschrift zu PK Ps 56). 
Cod.Pal.Lat. 1830. = Codices Palatini latini 1830, Philipp Melanchthon, Commentarius in Psalmos, Wittenberg um 1547-1548(eine Abschrift des PKs, von Prol bis PK Ps 51).

Ms. 87, B1. 1-59 in der Ratsschulbibliothek Zwickau(eine Abschrift des PKs, von Prol bis PK Ps 44).

Argvmenta Psalmorvm Sexaginta Distributis ordine Versuum Sententijs, hg. v. Mathias Flacius, Frankfurt am Main 1550.; VD 16 F 1273.

Enarratio aliquot psalmorum, in psalm $C X$, Wittenberg, 8.11.1550, AFSt/H A 25: 5 in Frankesche Stiftungen zu Halle (eine Abschrift von PK Ps 110).

Psalterium Davidis integrum, in quo psalmi octoginta tres illustrati sunt argumentis \& enarratione viri Reverendi \& clarissimi D. Philippi Melanthonis, hg. v. Paul Krell, Wittenberg 1561.; VD 16 B 3208.

Opera 2, S.548-711.; VD 16 M 2333.

CR 13, 1017-1244.

\section{Martin Luther}

WA = Martin Luhter, Werke. Kritische Gesamtausgabe, 1. Abt. Schriften, hg. v. Joachim Karl Friedrich Knaake, Gustav Kawerau, Ernst Thiele u.a., 64 Bde. Weimar 1883-1990.

WA DB = Martin Luther, Werke. Kritische Gesamtausgabe, 4. Abt. Deutsche Bible, hg. v. Ernst Thiele u.a., 12 Bde, Weimar 1906-1961.

\section{Psalmenkommentare Luthers}

Dictata super Psalterium : WA 3(Ps 1-83), WA 4,1-462(Ps 84-150). Und WA 55,I(Neue Ausgebe der Glossenexegese) und WA 55,II(Neue Ausgabe der Scholien).

Operationes in psalmos: AWA 2 = Archiv zur Weimarer Ausgabe der Werke Martin Luthers. Texte und Untersuchungen, Bd. 2: Martin Luther: Operationes in Psalmos 1519-1521, hg. v. Heino Gaese, Hans U. Perels, Gerhard Hammer und Manfred Biersack, Köln: Böhlau 1981

Sieben Bußpsalmen: Erste Bearbeitung 1517. WA 1,154-220. Zweite Bearbeitung 1525. WA $18,467-530$.

Dritte Psalmenvorlesung: WA 40,II,185-610(Ps 2, 51 und 45), WA 40,III,1-475 (Stufenpsalmen) und WA 40,III,476-594 (Ps 90).

\section{Johannes Bugenhagen}

JBW I,1 = Johannes Bugenhagen. Reformatorische Schriften (1515/16-1524), hg. v. BieberWallmann, Anneliese, Göttingen [u.a.]:V\&R 2013(Johannes Bugenhagen Werke, Band $\mathrm{I}, 1)$. 


\section{Psalmenkommentar Bugenhagens}

Interpretatio in librum psalmorum, Basel 1524.; Geisenhof 1963, Nr 3. S.6.; VD 16 B 3187.

Deutschübersetzung: Psalter wol verteutscht auß der heyligen sprach, übers. v. Martin Bucer, 1526 Basel.; Geisenhof 1963, Nr 13. S.30; VD 16, B 3291; BiblBuc Nr. 12.

\section{Martin Bucer}

Psalter wol verteutscht, Basel 1526. Geisenhof 1963, S.25f. Nr. 13 \& 14 und BiblBuc Nr. 12. (Übersetzung des PKs Bugenhagens)

BiblBuc $=$ Bibliographia Bucerana, hg. von Robert Stupperich unter Mitwirkung von Erwin Steinborn, in: SVRG Nr. 169 58, Heft 2. 1952, S.37-96.

\section{Psalmenkommentar Bucers}

Sacrorum Psalmorum libri quinque ad Ebraicam veritatem versi et familari explanatione elucidati. Per Aretium Felinum Theologum, Straßburg 1529.; VD 16 B 3145.; BiblBuc Nr. 25.; Revision: BiblBuc Nr. 25b(1532), BiblBuc Nr. 25c;VD16 B 3186 (1547) und BiblBuc $\mathrm{Nr} 25 \mathrm{~d}(1554)$.

\section{Johannes Calvin}

CO 1-59 = Ioannis Calvini opera quae supersunt omnia, hg. v. Wilhelm Baum, Eduard Cunitz und Eduard Reuss, 59 Bde., Braunschweig und Berlin 1863-1897(Corpus Reformatorum 29-87).

CStA = Calvin-Studienausgabe, hg. von Eberhard Busch u.a., 8 Bde., Neukirchen-Vluyn: Neukirchener 1994-2011.

Institutio = Institutio Christianae Religionis, 1536, 1539-1554 und 1559. CO 1 und Institutio Christianae Religionis. CO 2.

\section{Psalmenkommentar Calvins}

librum Psalmorum commentarius, Genf 1557.; CO 31(Ps 1-90) und CO 32, 1-442(Ps 91-150).

\section{Kadinal Tommaso de Vio Cajetan}

Liber Psalmorum ad verbum ex Hebraeo versorum. In: Opera omnia quotquot in sacrae scripturae expositionem reperiuntur, ..., Tomus Tertius, Lyon 1639, S. 1-504.

\subsection{Literatur}

"Man weiss so wenig über ihn". Philipp Melanchthon: ein Mensch zwischen Angst und Zuversicht (1997). Wittenberg: Drei Kastanien Verlag.

Ahn, Myung Jun (1999): The Ideal of Brevitas et Facilitas. The Theological Hermeneutics of John Calvin. In: SK 20 (2), S. 270-281. 
Alexiou, Evangelos (2014): Die Rhetorik des Aristoteles. In: Bernhard Zimmerman und Antonios Rengakos (Hg.): HGL. Bd. 2: Die Literatur der klassischen und hellenistischen Zeit. München: Verlag C. H. Beck (HAW7, 2), S. 761-772.

Aurelius, Carl Axel (2000): Luther on the Psalter. In: LuthQ 14, S. 193-205.

Bayer, Oswald (1994): Theologie. Gütersloh: Gütersloher Verl.-Haus (HST, 1).

Beintker, Horst (1986): Christologische Gedanken Luthers zum Sterben Jesu. Bei Auslegung von Psalm 8 und Psalm 22 im Kommentar von 1519 bis 1521 und verwandten Texterklärungen. In: $A R G 77$, S. 5-30.

Beumer, Johannes (1964): Suffizienz und Insuffizienz der Heiligen Schrift nach Kardinal Thomas de Vio Cajetan. In: Gr. Greg 45, S. 816-824.

Beutel, Albrecht (2005): Theologie als Schirftauslegung. In: Albrecht Beutel (Hg.): Luther Handbuch. Tübingen: Mohr Siebeck, S. 444-450.

Bieber-Wallmann, Anneliese (2013): Aus Bugenhagens Psalmenkommentar. Einleitung. In: JBW I,1 S. 679-696.

Binder, Gerhard (Hg.) (1998): Philipp Melanchthon. Exemplarische Aspekte seines Humanismus. Trier: WVT Wissenschaftlicher Verlag (Bochumer Altertumswissenschaftliches Colloquium, 32).

Black, C. Clifton (1985): Unity and Diversity in Luther's Biblical Exegesis: Psalm 51 As a Test-Case. In: SJT 38 (3), S. 325-345.

Brecht, Martin (1983): Martin Luther. Sein Weg zur Reformation. 1483-1521. 2. Aufl. Bd. 1. Stuttgart: Calwer.

Brecht, Martin (1987): Martin Luther. Die Erhaltung der Kirche. 1532-1546. Bd. 3. Stuttgart: Calwer.

Brüls, Alfons (1975): Die Entwicklung der Gotteslehre beim jungen Melanchthon, 1518-1535. Bielefeld: Luther-Verlag (UKG, 10).

Collins, Thomas Aquinas (1955): Cardinal Cajetan's Fundamental Biblical Principles. In: $C B Q 17$ (3), S. 363-378.

Cornill, Karl Heinrich (1897): Melanchthon als Psalmenerklärer. Königsberg.

Ebeling, Gerhard (1951): Die Anfänge von Luthers Hermeneutik. In: ZThK 48 (2), S. $172-$ 230.

Ebeling, Gerhard (1991): Evangelische Evangelienauslegung. Eine Untersuchung zu Luthers Hermeneutik. 3. Aufl. Tübingen: J.C.B. Mohr (Paul Siebeck). 
Fiedrowicz, Michael (1997): Psalmus vox totius Christi. Studien zu Augustins "Enarrationes in Psalmos". Freiburg [im Breisgau]: Herder.

Frank, Günter (1995): Die theologische Philosophie Philipp Melanchthons (1497-1560). Leipzig: Benno (EThSt, 67).

Frank, Günter und Meerhof, Kees (Hg.) (2002): Melanchthon und Europa. 2. Teilband Westeuropa. Stuttgart: Thorbecke (Melanchthon-Schriften der Stadt Bretten, 6/2).

Frank, Günter und Treu, Martin (Hg.) (2001): Melanchthon und Europa. 1. Teilband Skandinavien und Mittelosteuropa. Stuttgart: Thorbecke (Melanchthon-Schriften der Stadt Bretten, $6 / 1)$.

Freudenberg, Matthias (2008): Von Gott reden. Johannes Calvins Gottesverständnis in seiner Psalmenauslegung. In: Thomas Wagner, Dieter Vieweger und Erlemann Kurt (Hg.): Kontexte. Biografische und forschungsgeschichtliche Schnittpunkte der alttestamentlichen Wissenschaft. Festschrift für Hans Jochen Boecker zu 80. Geburtstag. Neukirchen-Vluyn: Neukirchener Verlag, S. 81-98.

Geisenhof, Georg (1963): Bibliotheca Bugenhagiana. Bibliographie der Druckschriften des D. Joh. Bugenhagen. Nieuwkoop: B. De Graaf (unveränderte Wiedergabe von Leipzig 1908) (QDGR, 4).

Greef, Wulfert de (2006): Calvin as commentator on the Psalms. In: Donald K. McKim (Hg.): Calvin and the Bible. Cambridge, UK, New York: Cambridge University Press, S. 85-106.

Gummelt, Volker (1994): Lex et Evangelium. Untersuchungen zur Jesajavorlesung von Johannes Bugenhagen. Berlin, New York: W. de Gruyter (AKG, 62).

Haikola, Lauri (1961): Melanchthons und Luthers Lehre von der Rechtfertigung. In: Vilmos Vajta (Hg.): Luther und Melanchthon. Referate und Berichte des Zweiten Internationalen Kongresses für Lutherforschung Münster, 8-13. August 1960. Göttingen: V\&R, S. 89-103.

Hasse, Hans-Peter (1997): Paul Krell(1531-1579). Melanchthons "Enarratio Symboli Nicaeni"(1550) und der Sturz des Philippismus in Kursachsen im Jahre 1574. In: Heinz Scheible (Hg.): Melanchthon in seinen Schülern. [Vorträge, gehalten anlässlich eines Arbeitsgespräches vom 21. bis 23. Juni 1995 in der Herzog August Bibliothek Wolfenbüttel]. Wiesbaden: Harrassowitz (Wolfenbütteler Forschungen, 73), S. 427-464.

Hasselhoff, Görge K. (2009): Calvin, Psalm 110 und Melchisedek. Auslegung und Quellen von Hieronymus bis Bucer. In: Matthias Freudenberg und van Ravenswaay, J. Marius J. Lange (Hg.): Calvin und seine Wirkungen. Vorträge der 7. Emder Tagung zur Geschichte des Reformierten Protestantismus. Neukirchen-Vluyn: Neukirchener, S. 115-128. 
Hendrix, Scott H. (1983): Luther Against the Background of the History of Biblical Interpretation. In: Interp. 37 (3), S. 229-239.

Hendrix, Scott H.; Wengert, Timothy J. (Hg.) (1999): Philip Melanchthon. then and now(1497-1997). essays celebrating the 500th anniversary of the birth of Philip Melanchthon, theolgian, teacher and reformer. Columbia, S. C.: Lutheran Southern Seminary.

Hobbs, R. Gerald (2003): Bucher's Use of King David as Mirror of the Christian Prince. In: $R \& R R 5$ (1), S. 102-128.

Hobbs, R. Gerald (2008): Pluriformity of Early Reformation Scriptural Interpretation. In: Magne Sæbø (Hg.): HBOT. II. Unter Mitarbeit von Michael Fishbane und Jean Louis Ska. Göttingen: V\&R, S. 452-511.

Hobbs, R. Gerald (2009): How Firm a Foundation. Martin Bucher's Historical Exegesis of the Psalms. In: ChH 53 (4), S. 477-491.

Hoffmann, Manfred (1997): Rhetoric and Dialectic in Erasmus's and Melanchthon's Interpretation of John's Gospel. In: Timothy J. Wengert und M. Patrick Graham (Hg.): Philip Melanchthon (1497-1560) and the commentary. Sheffield: Sheffield Academic Press, S. 4878.

Holfelder, Hans Hermann (1974): Tentatio et consolatio;. Studien zu Bugenhagens Interpretatio in librum psalmorum. Berlin, New York: De Gruyter (AKG, 45).

Jong, James A. de (1994): "An Anatomy of All Parts of the Soul". Insights into Calvin's Spirituality from His Psalms Commentary. In: Wilhelm H. Neuser (Hg.): Calvinus Sacrae Scripturae professor. Calvin as confessor of Holy Scriptures : die Referate des Congrès international des recherches calviniennes, International Congress on Calvin Research, Internationalen Kongresses für Calvinforschung, vom 20. bis 23. August 1990 in Grand Rapids. Grand Rapids, Mich.: W.B. Eerdmans Pub. Co, S. 1-14.

Jung, Martin (2010): Philipp Melanchthon und seine Zeit. Göttingen: V\&R.

Jung, Martin H. (1998): Frömmigkeit und Theologie bei Philipp Melanchthon. Das Gebet im Leben und in der Lehre des Reformators. Tübingen: Mohr Siebeck (BHTh, 102).

Junghans, Helmar (2000): Das Melanchthonjübliäum 1997. In: LuJ 67, S. 95-162.

Junghans, Helmar (2003): Das Melanchthonjubiläum 1997 II. In: LuJ 70, S. 175-214.

Junghans, Helmar, Beyer, Michael, Wartenberg, Günther und Hasse, Hans-Peter (Hg.) (1996):

Humanismus und Wittenberger Reformation. Festgabe anlässlich des 500. Geburtstages des Praeceptor Germaniae Philipp Melanchthon am 16. Februar 1997 : Helmar Junghans gewidmet. Leipzig: Evangelische Verlagsanstalt. 
Kaufmann, Thomas (2009): Geschichte der Reformation. Frankfurt am Main: Verlag der Weltreligionen.

Kirchner, Hubert und Haendler, Gert (1987): Reformationsgeschichte von 1532 - 1555/1566. Festigung der Reformation, Calvin, katholische Reform und Konzil von Trient. 1. Aufl. Berlin: Evang. Verl.-Anst. ([Spätes Mittelalter, Reformation, konfessionelles Zeitalter], 6).

Klowski, Joachim: Kausalität. In: TRE 18, S. 81-82.

Kobler, Beate (2014): Die Entstehung des negativen Melanchthonbildes. Protestantische Melanchthonkritik bis 1560. Tübingen: Mohr Siebeck (BHTh, 171).

Kolb, Robert (2013): Dynamics of Party Conflict in the Saxon Late Reformation GensioLutheras vs. Philippists. In: H. J. Selderhuis, Martin Leiner und Volker Leppin (Hg.): Calvinismus in den Auseinandersetzungen des frühen konfessionellen Zeitalters. Göttingen: V\&R (RHT, 23), S. 151-168.

Kuropka, Nicole (2002): Philipp Melanchthon. Wissenschaft und Gesellschaft : ein Gelehrter im Dienst der Kirche (1526-1532). Tübingen: Mohr Siebeck (SuRNR, 21).

Kuropka, Nicole (2010): Melanchthon. Tübingen: Mohr Siebeck (UTB, 3417 : Profile).

Leder, Hans-Günter (2002): Die Berufung Johannes Bugenhagens in das Wittenberger Stadtpfarramt. In: Volker Gummelt (Hg.): Johannes Bugenhagen Pomeranus - vom Reformer zum Reformator. Studien zur Biographie. Frankfurt am Main, New York: Peter Lang (GTF, 4), S. 183-214.

Lee, Nam Kyu (2009): Die Prädestinationslehre der Heidelberger Theologen 1583-1622. Georg Sohn (1551-1589), Herman Rennecherus (1550-?), Jacob Kimedoncius (1554-1596), Daniel Tossanus (1541-1602). Göttingen: V\&R (RHT, 10).

Löhr, Winrich (2007): Sündenlehre. In: Volker Henning Drecoll (Hg.): Augustin Handbuch. Tübingen: Mohr Siebeck, S. 498-506.

Lohse, Bernhard (1995): Luthers Theologie in ihrer historischen Entwicklung und in ihrem systematischen Zusammenhang. Göttingen: V\&R.

Mahlmann, Theolor (2005): Melanchthon als Vorläufer des Wittenberger Kryptocalvinismus. In: Günter Frank und Herman J. Selderhuis (Hg.): Melanchthon und der Calvinismus. Unter Mitarbeit von Sebastian Lalla. Stuttgart-Bad Cannstatt: Frommann-Holzboog (Melanchthon-Schriften der Stadt Bretten, 9), S. 173-230.

Meinhold, Peter (1960): Philipp Melanchthon. Der Lehrer der Kirche. Berlin: Lutherisches Verlagshaus. 
Mikoteit, Matthias (2004): Theologie und Gebet bei Luther. Untersuchungen zur Psalmenvorlesung 1532-1535. Berlin, New York: De Gruyter (TBT, 124).

O'Connor, Michael (2001): A Neglected Facet of Cardinal Cajetan. Biblical Reform in High Renaissance Rome. In: Richard Griffiths (Hg.): The Bible in the Renaissance. Essays on Biblical Commentary and Translation in the Fifteenth and Sixteenth Centuries. Aldershot: Ashgate, S. 71-94.

Opitz, Peter: Calvin als Ausleger der Psalmen. In: CStA, Bd. 6, S. 1-16.

Opitz, Peter (2008): The Exegetical and Hermeneutical Work of John Oecolampadius, Huldrych Zwingli and John Calvin. In: Magne Sæbø (Hg.): HBOT. II. Unter Mitarbeit von Michael Fishbane und Jean Louis Ska. Göttingen: V\&R, S. 407-451.

Pak, G. Sujin (2005): Luther, Bucer, and Calvin on Psalms 8 and 16. Confessional Formation and the Question of Jewish Exegesis. In: $N A K G$ 85, S. 169-186.

Pak, G. Sujin (2010): The judaizing Calvin. Sixteenth-century debates over the Messianic Psalms. Oxford, New York: Oxford University Press (OSHT).

Pak, G. Sujin (2011): A Break with Anti-Judaic Exegesis. John Calvin and the Unity of the Testaments. In: CTJ 46, S. 7-28.

Parsons, Michael (2011): Luther, the Royal Psalms and the Suffering Church. In: ERT 35, S. $242-254$.

Paul, Robert (2015): Luther on Psalm 2. The Importance of Hebrew in Understanding the Old Testament. In: Logia 24, S. 7-14.

Peters, Albrecht (1979): Der Mensch. Gütersloh: Gütersloher Verlagshaus Gerd Mohn (HST, $8)$.

Peters, Albrecht (1981): Gesetz und Evangelium. Gütersloh: Gütersloher Verlagshaus Gerd Mohn (HST, 2).

Peters, Christian (2005): Luther und Melanchthon. In: Albrecht Beutel (Hg.): Luther Handbuch. Tübingen: Mohr Siebeck, S. 161-168.

Philipp Melanchthon und Zerbst. Qullensammlung und Aufsätze zum 500. Geburtstag des Reformators/ Arbeitsgruppe Melanchthon am Francisceum Zerbst zum Melanchthonjahr 1997 (1997). Zerbst: Offsetdruck Kraft.

Raeder, Siegfried (1961): Das Hebräische bei Luther. untersucht bis zum Ende der ersten Psalmenvorlesung. Tübingen: J.C.B. Mohr (Paul Siebeck) (BHTh, 31).

Raeder, Siegfried (1977): Grammatica theologica. Studien zu Luthers Operationes in Psalmos. Tübingen: Mohr (BHTh, 51). 
Richter, Matthias (1999): Melanchthons Verständnis vom Gesetz Gottes und Folgen im Streit um den tertius usus legis. In: Udo Sträter (Hg.): Melanchthonbild und Melanchthonrezeption in der Lutherischen Orthodoxie und im Pietismus. Referate des dritten Wittenberger Symposiums zur Erforschung der Lutherischen Orthodoxie (Wittenberg, 6.-8. Dezember 1996). Lutherstadt Wittenberg: Edition Hans Lufft (Themata Leucoreana), S. 25-37.

Roussel, Bernard (2007): John Calvin's Interpretation of Psalm 22. In: Mack P. Holt (Hg.): Adaptations of Calvinism in Reformation Europe. Essays in honour of Brian G. Armstrong. Aldershot: Ashgate (StASRH), S. 9-20.

Sæbø, Magne (Hg.) (1996): HBOT. I/1: Antiquity. Unter Mitarbeit von C. Brekelmans, Menahem Haran, Michael A. Fishbane, Jean Louis Ska und Peter Machinist. Göttingen: V\&R.

Sæbø, Magne (Hg.) (2000): HBOT. I/2: The Middle Ages. Unter Mitarbeit von C. Brekelmans und Menahem Haran. Göttingen: V\&R.

Sauser, Ekkart: Lauentius. In: BBKL, Bd. 4, S. 1252-1254.

Scheible, Heinz: Melanchthon. In: TRE, Bd. 22, S. 371-410.

Scheible, Heinz (1986): D 1.3 Philippmus Melahchton, eigenhändiges Manuskript einer Vorlesung über die Psalmen, 1547/1548. In: Elmar Mittler (Hg.): Bibliotheca Palatina. Katalog zur Ausstellung vom 8. Juli - 2. November 1986, Heiliggeistkirche Heidelberg ; Ausstellung d. Univ. Heidelberg ; 600 Jahre Univ. Heidelberg 1386 - 1986. Textband. Heidelberg: Edition Braus (Heidelberger Bibliotheksschriften, 24), S. 143-144.

Scheible, Heinz (1998): Melanchthon als theologischer Gespächspartner Luthers. In: Birgit Stolt (Hg.): Philipp Melanchthon und seine Rezeption in Skandinavien. Vorträge eines internationalen Symposions anlässlich seines 500. Jahrestages an der Königlichen Akademie der Literatur, Geschichte und Altertümer in Stockholm den 9.-10. Oktober 1997. Stockholm, Sweden: Kungl. Vitterhets, historie och antikvitets akademien; Distributed by Almqvist \& Wiksell International (Konferenser / Kungl. VHAAÅ, 43), S. 67-91.

Scheible, Heinz (2007): Melanchthons Verständnis des Danielbuchs. In: Katharina Bracht und Daniel S. Du Toit (Hg.): Die Geschichte der Daniel-Auslegung in Judentum, Christentum und Islam. Studien zur Kommentierung des Danielbuches in Literatur und Kunst. Berlin (BZAW, 371), S. 293-321.

Scheible, Heinz (2010): Die Bedeutung der Unterscheidung von Gesetz und Evangelium für theologische Ethik und Praktische Theologie am Beispiel Melanchthons. In: Heinz Scheible: Aufsätze zu Melanchthon. Tübingen: Mohr Siebeck (SMHR, 49), S. 241-252. 
Scheible, Heinz (2016): Melanchthon. Vermittler der Reformation: eine Biographie. Neuausgabe, umfassend bearbeitet und erweitert. München: C.H. Beck.

Schilling, Johannes (1996): Melanchthons Loci communes deutsch. In: Michael Beyer und Günther Wartenberg (Hg.): Humanismus und Wittenberger Reformation. Festgabe anlässlich des 500. Geburtstages des Praeceptor Germaniae Philipp Melanchthon am 16. Februar 1997. Helmar Junghans gewidmet. Unter Mitarbeit von Hans-Peter Hasse. Leipzig: Evangelische Verlagsanstalt, S. 337-352.

Schilling, Johannes (Hg.) (1998): Melanchthons bleibende Bedeutung. Ringvorlesung der Theologischen Fakultät der Christian-Albrechts-Universität zum Melanchthon-Jahr 1997. Kiel.

Schneider, John R. (1997): The Hermeneutics of Commentary. Origins of Melanchthon's Integration of Dialectic into Rhetoric. In: Timothy J. Wengert und M. Patrick Graham (Hg.): Philip Melanchthon (1497-1560) and the commentary. Sheffield: Sheffield Academic Press, S. $20-48$.

Seeberg, Reinhold (1960): Lehrbuch der Dogmengeschichte 4/II. Die Fortbildung der reformatorischen Lehre und die Gegenreformatorische Lehre. 5. Aufl. Leipzig.

Seiling, Jonathan R. (2006): The 'Radical' Revisions of the commentary on the seven Penitential Psalms: Luther and his 'Enemies' (1517-1525). In: $R \& R R \quad 8$ (1), S. $28-47$.

Selderhuis, H. J. (2000): God in het midden. Calvijns theologie van de Psalmen. Kampen: Kok. Deutschübersetzung: Gott in der Mitte. Calvins Theologie der Psalmen. Leipzig: Evang. Verl.-Anst. 2004.

Selderhuis, H. J. (2002): Melanchthon und die Niederlande im 16. und 17. Jahrhundert. In: Günter Frank und Kees Meerhof (Hg.): Melanchthon und Europa. 2. Teilband Westeuropa. Stuttgart: Thorbecke (Melanchthon-Schriften der Stadt Bretten, 6/2), S. 303-324.

Selderhuis, H. J. (2007): Calvins view of the Bible as the word. In: RW 57 (4), S. 270-285.

Selderhuis, H. J. (2015): Psalms 1-72. Downers Grove, Illinois: InterVarsity Press (Reformation commentary on Scripture. Old Testament, 7).

Sick, Hansjörg (1959): Melanchthon als Ausleger des Alten Testaments. Tübingen: J.C.B.Mohr (Paul Siebeck) (BGBH, 2).

Spijker, Willem van't von (1987): Bucers commentaar op de Psalmen. Hebraica Veritas cum Christi Philosophia Coniungenda. Enkele opmerkingen over Bucers uitleg van de Psalmen. In: ThRef 30, S. 264-280. 
Stolt, Birgit (Hg.) (1998): Philipp Melanchthon und seine Rezeption in Skandinavien. Vorträge eines internationalen Symposions anlässlich seines 500. Jahrestages an der Königlichen Akademie der Literatur, Geschichte und Altertümer in Stockholm den 9.-10. Oktober 1997. Stockholm, Sweden: Kungl. Vitterhets, historie och antikvitets akademien; Distributed by Almqvist \& Wiksell International (Konferenser / Kungl. VHAA ̊, 43).

Sträter, Udo (Hg.) (1999): Melanchthonbild und Melanchthonrezeption in der Lutherischen Orthodoxie und im Pietismus. Referate des dritten Wittenberger Symposiums zur Erforschung der Lutherischen Orthodoxie (Wittenberg, 6.-8. Dezember 1996). Lutherstadt Wittenberg: Edition Hans Lufft (Themata Leucoreana).

Strohm, Christoph (2009): Johannes Calvin. Leben und Werk des Reformators. Müchen: C.H.Beck (C.H.Beck Wissen in der Beck'schen Reihe).

Stupperich, Robert (1958): Melanchthons "Theologia germania". Ein Beitrag zur Geschichte seiner lange verschollenen eigenhändigen deutschen Bearbeitung der Loci theologici von 1553. In: KD 4, S. 47-58.

Stupperich, Robert (1961): Der Unbekannte Melanchthon. Wirken und Denken des Praeceptor Germaniae in neuer Sicht. Stuttgart: Kohlhammer.

Tetz, Martin (2012): Zum Psalterverständnis bei Athanasius und Luther. In: LuJ 79, S. 39-61.

Throntveit, Mark A. (1987): The Penitential Psalms and Lenten Discipline. In: LuthQ 1 (4), S. $495-512$.

Wagner, Falk: Bekehrung II. In: TRE, Bd. 5, S. 459-463.

Walter Peter (2008). In: Franz Josef Worstbrock (Hg.): Deutscher Humanismus 1480 - 1520. Verfasserlexikon. Band 1 A-K. 3 Bände. Berlin, New York: De Gruyter.

Wels, Volkhard (2001): Nachwort. In: Rhetorices S. 443-476.

Wengert, Timothy J. (1987): Philip Melanchthon's Annotationes in Johannem in Relation to its Predecessors and Contemporaries. Genève: Librairie Droz S.A. (THR, 220).

Wengert, Timothy J. (1999): Melanchthon and Luther / Luther and Melanchthon. In: LuJ 66, S. $55-88$.

Wengert, Timothy J. (2012): The Biblical Commentaries of Philip Melanchthon. In: Irene Dingel, Robert Kolb, Nicole Kuropka und Timothy J. Wengert (Hg.): Philip Melanchthon. Theologian in classroom, confession, and controversy. Göttingen, Bristol, CT: V\&R (Refo500 academic studies, 7), S. 43-76.

Wengert, Timothy J.; Graham, M. Patrick (Hg.) (1997): Philip Melanchthon (1497-1560) and the commentary. Sheffield: Sheffield Academic Press. 
Wicks, Jared (1977): Thomism Between Renaissance and Reformation. the Case of Cajetan. In: $A R G 68$, S. 9-32.

Wicks, Jared (2008): Catholic Old Testament Interpretation in the Reformation and Early Confessional Eras. In: Magne Sæbø (Hg.): HBOT. II. Unter Mitarbeit von Michael Fishbane und Jean Louis Ska. Göttingen: V\&R, S. 617-648.

Wicks, Jared (2010): The beginning of Luther's beginnings in the Psalms. In: LuthFor 44, S. $30-34$.

Willi, Thomas (2010): Die Harfe Gottes - Bugenhagens »In librum psalmorum interpretatio« und ihre Quellen. In: Heinrich Kröger und Irmfried Garbe (Hg.): Johannes Bugenhagen (1485-1558). Der Bischof der Reformation: Beiträge der Bugenhagen-Tagungen 2008 in Barth und Greifswald. Leipzig: Evangelische Verlagsanstalt, S. 38-55.

Wolff, Jens (2005): "Die größten Worte der gesamten Schrift". Der gottverlassene Christus laut Psalm 22 aus Luthers Sicht. In: Luther 76, S. 101-107. 


\section{Lebenslauf}

Seonmin Ryu ist in Chunum, Südkorea am 10, Dez. 1978 geboren. In Sunchun besuchte er die Sunchun-Hyochun Oberschule bis zum Abitur 1997. Dann studierte er Forstwissenschaft an der Seoul National Universität in Seoul, mit dem Abschluss Bachelor im Jahr 2002. Von 2006 an studierte er Theologie an der Hapdong Theological Seminary in Suwon, wo er im Jahr 2009 mit dem M. Div. abschloss. Im Jahr 2009 besuchte er einen Deutschkurs am ÖSW in Bochum, Deutschland, dann immatrikulierte er sich 2010 im Magisterstudiengang an der Kirchlichen Hochschule Wuppertal/Bethel in Wuppertal, wo er alte Sprachen (Hebräicum 2010, Gräecum 2011, Latinum 2011) und Vorlesungen besuchte. Von 2013 studierte er weiter Theologie in Master II. mit der Begleitung von Prof. H. J. Selderhuis an der Theologischen Universität Apeldoorn in den Niederlanden, wo er im Jahr 2014 den Abschluss Th.M. erhielt. Der Titel der Masterarbeit ist „Die gerettete Kirche. Die Exegese und die Theologie Melanchthons in seinen Kommentaren zu Haggai und Sacharja“. Anschließend studiert er weiter als Doktorand von Prof. H. J. Selderhuis und im Juni 2017 findet seine Dissertationsverteidigung statt. Sein Dissertationstitel ist „Dulcissimae Carmina Ecclesiae. Die Theologie und die Exegese des Psalmenkommentars Melanchthons“.

Er arbeitete 2006-2009 in der Sungga Gemeinde in Seoul als Vikar und von 2010-2017 in der Wuppertaler Koreanischen Missionsgemeinde als Vikar und nach der Ordination (2012) als Pastor mit dem Schwerpunkt Jugendarbeit. Er heiratete im Jahr 2006 seine Frau Eunhye Cha, mit der er inzwischen 4 Kinder (Seongga, Minseo, Hyeseo und Eunseo) hat. 